\title{
TÉCNICAS DE PROPAGAÇÃO DE ONDAS NA ESTIMATIVA DE PROPRIEDADES MECÂNICAS DE PAINÉIS OSB
}

\author{
ELEN APARECIDA MARTINES MORALES
}

Tese apresentada ao Programa de Pós-Graduação Interunidades Ciência e Engenharia de Materiais, da Universidade de São Paulo, para obtenção do título de Doutor em Ciência e Engenharia de Materiais.

Orientador: Francisco Antonio Rocco Lahr

São Carlos

2006 
Morales, Elen Aparecida Martines

"Técnicas de propagação de ondas na estimativa de propriedades mecânicas de painéis OSB"

Elen Aparecida Martines Morales - São Carlos, 2006.

Tese (Doutorado) - Interunidades Ciência e Engenharia de Materiais, da Universidade de São Paulo, 2007 - páginas: 94

Área: Desenvolvimento, Caracterização e aplicação de materiais Orientador: Prof. Dr. Francisco Antonio Rocco Lahr

1. OSB. 2. Ultra-som. 3. Stress Wave

I. Título 
"Deus tem concedido talentos aos homens: um intelecto para inventar, um coração para ser o lugar de Seu trono, afeições que extravasem em bênçãos para outros, uma consciência para convencer do pecado. Cada um tem recebido algo do Mestre, e devem todos fazer a sua parte em suprir as necessidades da obra de Deus. Deus deseja que Seus obreiros olhem para Ele como o Doador de tudo que possuem, que se lembrem de que tudo o que têm e são vem dAquele que é maravithoso em conselho e grande em obra." Administração Eficaz, E. G. White. 
Ao meu querido Vinicius, o grande companheiro que Deus me deu. 
A Deus, o Princípio, o Meio e o Fim;

Aos meus pais, Roseli e Joaquim, pelo amor que me têm e porque sem eles não teria a felicidade e a vida que tenho hoje;

Ao meu querido esposo Vinicius, pelo amor, apoio e companheirismo, em especial, durante a elaboração deste trabalho;

Ao professor e amigo Francisco Antonio Rocco Lahr, pois sem sua orientação não teria concluído mais esta etapa;

Aos professores Raquel, Adriano Ballarin, André Bartholomeu, Alex Trinca, Obede Farias, Rosane, Ivaldo e Silvio Govone, bem como seus respectivos técnicos, Flávia, Gisleiva, Japão, Isabella, Ailton e Israel, por sugestões, críticas, apoio e auxílio nos ensaios;

A amiga e companheira de sala Fati, por todo apoio, atenção e carinho;

Ao amigo Fabricio, por todos os momentos de lutas compartilhados;

Aos amigos Orlando, Karin, Simone, Lik, Eloísa, Alessandra, Wesley, Késia, Anelise e Madison, por toda amizade e orações a mim dispensadas;

Às amigas Lilian, Yurikg e Loreta, que mesmo a distância foram companheiras constantes;

Aos professores do LaMEM Dias e Calil, e funcionários Andréa, Arnaldo, Bragatto, Cido, Jaime, José Francisco, Samuel, Silvio, Roberto e Tânia, pois fazem parte deste trabalho;

A MASISA do Brasil, pela doação de painéis OSB;

A CAPES, pelo apoio financeiro a esta pesquisa;

A todos que contribuíram de forma direta ou indireta para a conclusão deste trabalho. 


\section{SUMÁRIO}

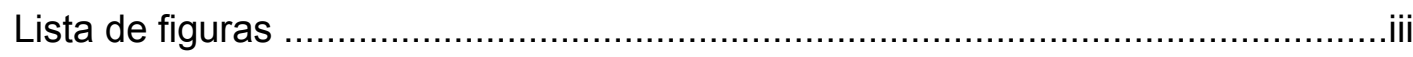

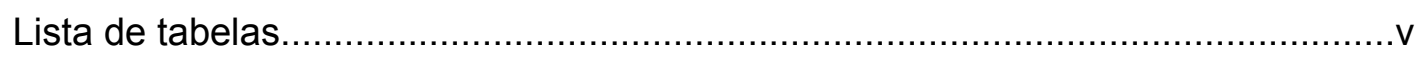

Lista de abreviaturas ou siglas................................................................viii

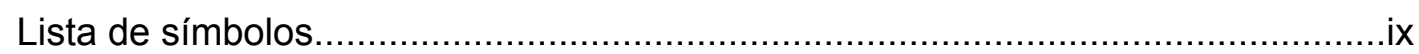

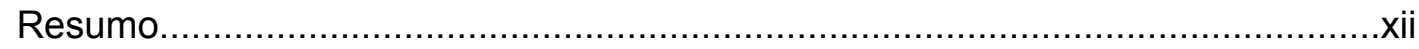

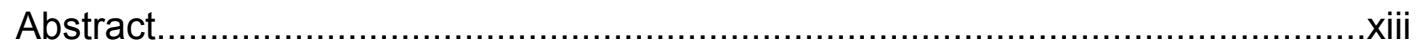

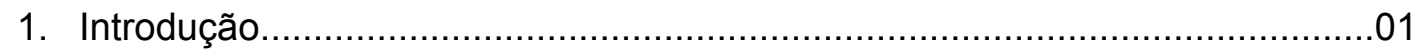

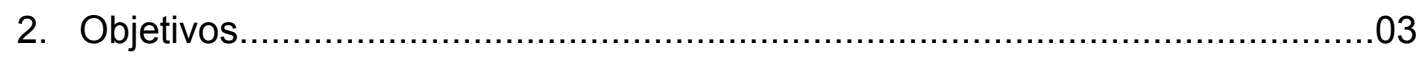

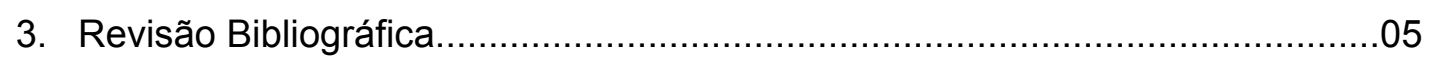

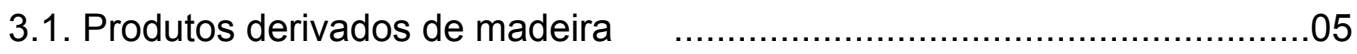

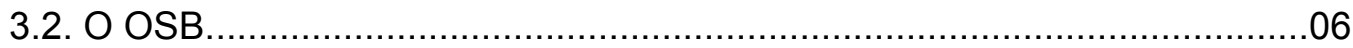

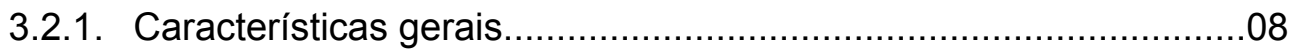

3.2.2. Propriedades mecânicas............................................................11

3.3. Avaliações não-destrutivas..........................................................13

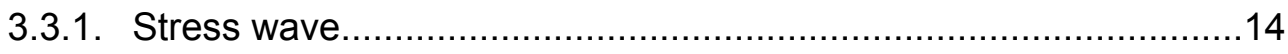

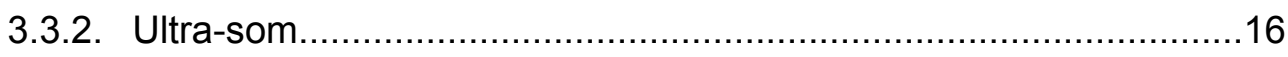

3.3.3. Atenuação..................................................................... 18

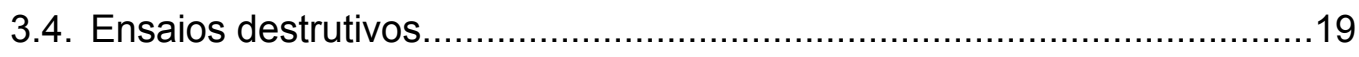

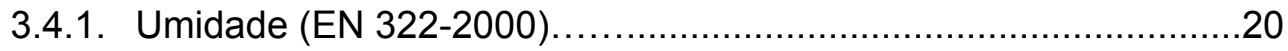

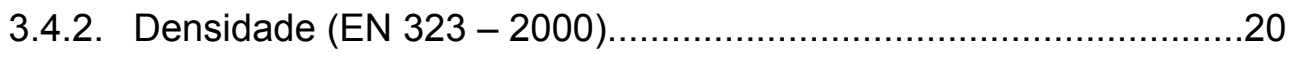

3.4.3. Inchamento em espessura e absorção de água (EN 317 - 1993)..21

3.4.4. Flexão Estática (EN 310 -2000) ...........................................22

3.4.5. Tração perpendicular às faces (EN 319 - 1993) .........................24

3.5. Amostragem dos painéis para controle de qualidade em fábrica (EN 326 -

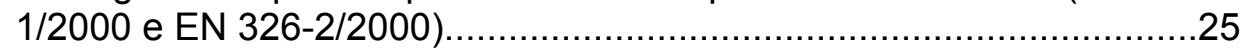

3.6. Ensaios não-destrutivos, stress wave e ultra-som em derivados de

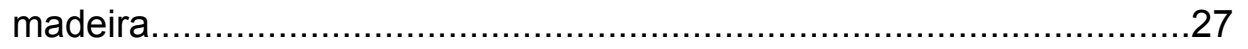


3.7. Comentários sobre a revisão bibliográfica apresentada .35

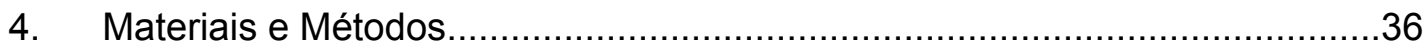

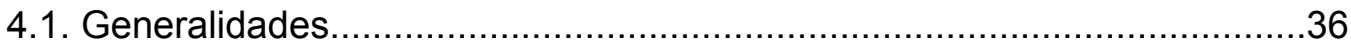

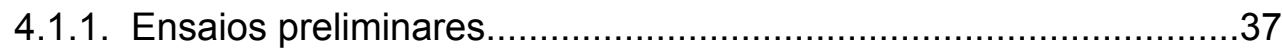

4.1.2. Ensaios principais - primeira etapa.......................................41

4.1.3. Ensaios principais - segunda etapa.........................................44

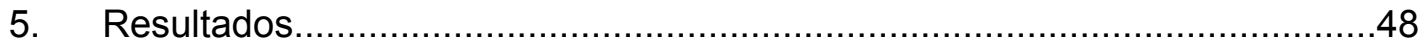

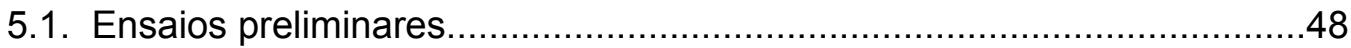

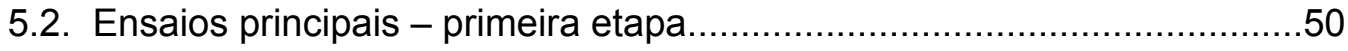

5.3. Ensaios principais - segunda etapa............................................54

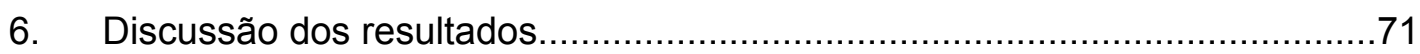

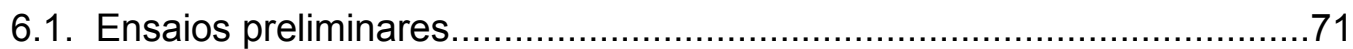

6.2. Ensaios principais - primeira etapa.................................................

6.3. Ensaios principais - segunda etapa.............................................77

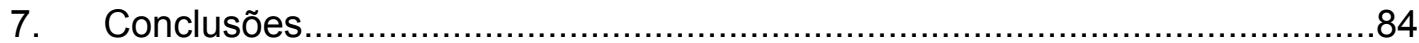

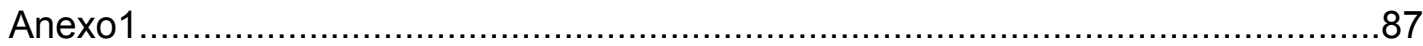

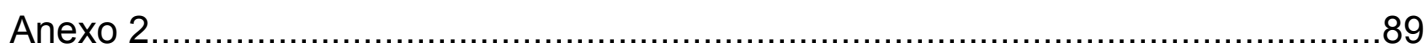

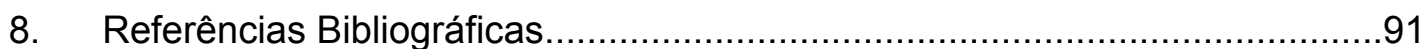




\section{LISTA DE FIGURAS}

Figura 1 - Exemplos de compósitos de madeira.................................... 5

Figura 2 - Localização das fábricas de painéis de madeiras no Brasil....... 6

Figura 3 - Painéis OSB................................................................. 8

Figura 4 - Exemplos de aplicações dos painéis OSB.............................. 9

Figura 5 - Processo de manufatura dos painéis OSB e aplicações estruturais.

Figura 6 - Disposição de aparelhos de ultra-som.............................................. 17

Figura 7 - Ponto de medição das espessuras para o ensaio de

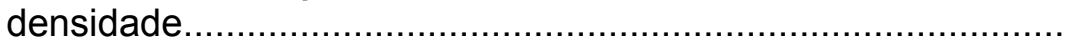

Figura 8 - Exemplo de plano de corte de corpos-de-prova segundo a EN 326-1/1994.

Figura 9 - Esquema da medição do tempo de propagação das ondas utilizando aparelho de ultra-som..

Figura 10 - Medições de tempo de propagação com o aparelho de ultra-som....

Figura 11 - Equipamento de ultra-som STEINKAMP, modelo BP-7........... 39

Figura 12 - Medições de tempo na espessura do painel........................... 40

Figura 13 - Exemplos de ensaios mecânicos nos painéis OSB................. 40

Figura 14 - Esquema de plano de corte para os painéis OSB................... 42

Figura 15 - Aparelho Stress Wave Timer, modelo 239 A - METRIGUARD e seu acessórios.

Figura 16 - Exemplo de posicionamento dos transdutores do aparelho stress wave para a medição do tempo no painel OSB e nos corpos-de-prova.

Figura 17 - Equipamento de ultra-som PANAMETRICS, modelo EPOCH4 e esquema para medição dedo tempo de propagação de onda através da espessura dos painéis

Figura 18 - Exemplo de posicionamento dos transdutores do aparelho stress wave para a medição do tempo nos painéis OSB nas direções longitudinal e transversal.

Figura 19 - Velocidade $x$ força máxima na flexão estática, na direção transversal, com medições realizadas pelo ultrasom.

Figura 20 - Velocidade $x$ força máxima na flexão estática, na direção transversal, com medições realizadas pelo stress wave painéis $15(2)$ e $25 \mathrm{~mm}$

Figura 21 - Velocidade $x$ resistência na flexão estática, na direção longitudinal, com medições realizadas pelo ultra-som valores médios

Figura 22 - Velocidade $\mathrm{x}$ resistência na flexão estática, na direção longitudinal, com medições realizadas pelo stress wave - 
valores médios.

Figura 23 - Valores de módulos de resistência $x$ velocidades para os três painéis.

Figura 24 - Normalidade dos valores das velocidades determinadas na direção transversal do painel de espessura 15(1) $\mathrm{mm}$.................

Figura 25 - Módulos de resistência x velocidades para os dois grupos de painéis. 


\section{LISTA DE TABELAS}

Tabela 1 - Painéis para usos gerais e para componentes para interiores (incluindo mobiliário) para utilização em ambiente seco Requisitos para as propriedades mecânicas e de inchamento

Tabela 2 - Painéis para fins estruturais utilizados em ambiente seco Requisitos para as propriedades mecânicas e de inchamento

Tabela 3 - Painéis para fins estruturais utilizados em ambiente úmido Requisitos para as propriedades mecânicas e de inchamento

Tabela 4 - Painéis para fins estruturais especiais utilizados em ambiente úmido - Requisito para as propriedades mecânicas e de inchamento

Tabela 5 - Número mínimo de corpos-de-prova m a serem ensaiados de cada painel.

Tabela 6 - Número mínimo de corpos-de-prova $m$ a serem ensaiados de cada painel e número de corpos-de-prova $\mathrm{m}_{\mathrm{u}}$ ensaiados em cada painel.

Tabela 7 - Propriedades físicas dos painéis OSB 1 e 2

Tabela 8 - Propriedades mecânicas dos painéis OSB 1 e 2 ...

Tabela 9 - Velocidades de propagação das ondas: espessura dos painéis.....

Tabela 10 - Constantes dinâmicas de propagação de ondas: espessura dos painéis.

Tabela 11 - Velocidades e constantes dinâmicas de propagação de ondas: direções longitudinal e transversal dos painéis.

Tabela 12 - Propriedades físicas dos painéis OSB.

Tabela 13 - Propriedades mecânicas dos painéis OSB.

Tabela 14 - Velocidades de propagação das ondas: espessura dos painéis.....

Tabela 15 - Constantes dinâmicas de propagação de ondas: espessura dos painéis

Tabela 16 - Velocidades e constantes dinâmicas de propagação de ondas: direções longitudinal e transversal dos painéis

Tabela 17 - Velocidades e constantes dinâmicas de propagação de ondas: direções longitudinal e transversal dos painéis - stress wave.

Tabela 18 - Velocidades e constantes dinâmicas de propagação de ondas: corpos-de-prova de flexão dos painéis - stress wave...

Tabela 19 - Equações, $R$ e $R^{2}$ entre os valores dos ensaios físicomecânicos e não-destrutivos pelo método de ultra-som.

Tabela 20 - Equações, $R$ e $R^{2}$ entre os valores dos ensaios físicomecânicos e não-destrutivos pelo método de stress wave painéis $15(1) \times 15(2) \mathrm{mm}$.

Tabela 21 - Equações, $R$ e $R^{2}$ entre os valores dos ensaios físicomecânicos e não-destrutivos pelo método de stress wave painéis $15(1) \times 25 \mathrm{~mm}$. 
Tabela 22 - Equações, $R$ e $R^{2}$ entre os valores dos ensaios físicomecânicos e não-destrutivos pelo método de stress wave painéis $15(2) \times 25 \mathrm{~mm}$.

Tabela 23 - Propriedades físicas dos painéis OSB dos grupos 1 e $2 \ldots \ldots \ldots . . . \quad 54$

Tabela 24 - Propriedades mecânicas das chapas OSB dos grupos 1 e $2 \ldots$.

Tabela 25 - Teor de umidade e densidade dos painéis OSB dos grupos 1 e 2 .......

Tabela 26 - Valores de inchamento e absorção de água (24h), e de resistência à tração perpendicular às faces, nos painéis OSB dos grupos 1 e 2 .

Tabela 27 - Valores de força de ruptura, de módulos de elasticidade e de resistência na flexão estática na direção longitudinal dos painéis OSB dos grupos 1 e 2

Tabela 28 - Valores de força de ruptura, de módulos de elasticidade e de resistência na flexão estática na direção transversal dos painéis OSB dos grupos 1 e 2 .

Tabela 29 - Velocidades de propagação de ondas: espessuras dos painéis OSB dos grupos 1 e 2 .

Tabela 30 - Constantes dinâmicas de propagação de ondas: espessura dos painéis OSB dos grupos 1 e 2 .

Tabela 31 - Atenuações de propagação de ondas: espessura dos painéis OSB dos grupos 1 e 2 .

Tabela 32 - Velocidades de propagação de ondas: direções longitudinal e transversal dos painéis OSB dos grupos 1 e 2 - ultra-som.......

Tabela 33 - Constantes dinâmicas de propagação de ondas: direções longitudinal e transversal dos painéis OSB dos grupos 1 e 2 ultra-som.

Tabela 34 - Velocidades de propagação de ondas: direções longitudinal e transversal dos painéis OSB dos grupos 1 e 2 - stress wave...

Tabela 35 - Constantes dinâmicas de propagação de ondas: direções longitudinal e transversal dos painéis OSB dos grupos 1 e 2 stress wave......

Tabela 36 - Equações, $R$ e $R^{2}$ entre os valores obtidos nos ensaios físicomecânicos e não-destrutivos pelo método de ultra-som...

Tabela 37 - Equações, $R$ e $R^{2}$ entre os valores obtidos nos ensaios físicomecânicos e não-destrutivos pelo método de stress wave todos os valores.

Tabela 38 - Equações, $R$ e $R^{2}$ entre os valores obtidos nos ensaios físicomecânicos e não-destrutivos pelo método de stress wave.......

Tabela 39 - Equações, $R$ e $R^{2}$ entre os métodos de ultra-som e stress wave (todos os valores)...

Tabela 40 - Equações, $R$ e $R^{2}$ entre os métodos de ultra-som e stress wave.

Tabela 41 - Equações, $R$ e $R^{2}$ entre os valores obtidos nos ensaios físicomecânicos e não-destrutivos pelo método de ultra-som - 
valores médios

Tabela 42 - Equações, $R$ e $R^{2}$ entre os valores obtidos nos ensaios físicomecânicos e não-destrutivos pelo método de stress wave valores médios.

Tabela 43 - Equações, $R$ e $R^{2}$ entre os métodos de ultra-som e stress wave - valores médios (todos os valores)

Tabela 44 - Equações, $R$ e $R^{2}$ entre os métodos de ultra-som e stress wave - valores médios.

Tabela 45 - Velocidade $\mathrm{x}$ resistência na flexão estática, na direção longitudinal, com medições realizadas pelo stress wave valores médios

Tabela 46 - Diferenças, em médias, entre valores de propriedades físicomecânicas dos painéis dos grupos 1 e 2: maiores valores para os painéis do grupo 2 


\title{
LISTA DE ABREVIATURAS OU SIGLAS
}

\author{
ASTM - American Society for Testing and Materials \\ EESC - Escola de Engenharia de São Carlos \\ EN - European Committee for Standardization \\ FEAGRI - Faculdade de Engenharia Agrícola \\ FEB - Faculdade de Engenharia de Bauru \\ HDF - High Density Fiberboard \\ LaMEM - Laboratório de Madeiras e de Estruturas de Madeira \\ $L V L$ - Laminated Venner Lumber \\ MDF - Medium Density Fiberboard \\ MUF - Melamine Fortified Urea Formaldheid \\ NDT - Nondestructive Testing \\ OSB - Oriented Strand Board \\ $P M D I$ - Isocianato \\ SBA - Structural Board Association \\ SET - Departamento Engenharia de Estruturas \\ TECO - Timber Company \\ UNESP - Universidade Estadual Paulista \\ UNICAMP - Universidade Estadual de Campinas \\ USP - Universidade de São Paulo
}




\section{LISTA DE SÍMBOLOS}

a - Comprimento do corpo-de-prova ( $\mathrm{mm}$ )

$a_{2}-a_{1}-$ Incremento da flecha correspondente a $F_{2}-F_{1}$

$A l$ - Tração perpendicular às faces ou adesão interna (MPa)

Atn - Atenuação de propagação de ondas $(\mathrm{d} \beta / \mathrm{cm})$

$A t n_{A \text { e I }}$ - Atenuação de propagação de onda no local correspondente ao corpo-deprova de absorção de água e de inchamento $(\mathrm{d} \beta / \mathrm{cm})$

$A t n_{A l}$ - Atenuação de propagação de onda no local correspondente ao corpo-deprova de adesão interna $(\mathrm{d} \beta / \mathrm{cm})$

$A t n_{d}$ - Atenuação de propagação de onda no local correspondente ao corpo-deprova de densidade $(\mathrm{d} \beta / \mathrm{cm})$

$A_{m}-$ Absorção de água, por imersão em água por 24h (\%)

$b$ - Largura do corpo-de-prova ( $\mathrm{mm})$

$b_{1}-$ Dimensão da borda $(\mathrm{mm})$

$b_{2}$ - Dimensão da borda $(\mathrm{mm})$

C - Constante Dinâmica (MPa)

$C_{A}$ - Constante dinâmica de propagação da onda no local correspondente ao corpo-de-prova de absorção de água (MPa)

$C_{A l}$ - Constante dinâmica de propagação da onda no local correspondente ao corpo-de-prova de adesão interna (MPa)

$C_{d}$ - Constante dinâmica de propagação da onda no local correspondente ao corpode-prova de densidade (MPa)

$C_{l}$ - Constante dinâmica de propagação da onda no local correspondente ao corpode-prova de inchamento (MPa)

$C_{\text {। e A }}$ - Constante dinâmica de propagação da onda no local correspondente ao corpo-de-prova de inchamento e absorção de água (MPa) 
$C V$ - Coeficiente de variação

$C_{\perp}-$ Constante dinâmica de propagação de ondas na direção transversal (MPa)

$C_{/ /}-$Constante dinâmica de propagação de ondas na direção longitudinal (MPa)

$d$ - Distância $(\mathrm{m})$

d.m.s. - Diferenças mínimas significativas

$E_{m}$ - Módulo de elasticidade na flexão estática (MPa)

$E_{m \perp}-$ Módulo de elasticidade na flexão estática na direção transversal (MPa)

$E_{m / /}-$ Módulo de elasticidade na flexão estática na direção longitudinal (MPa)

$f-$ Freqüência $(\mathrm{Hz})$

$f_{m}-$ Módulo de resistência na flexão estática (MPa)

$f_{m \perp}-$ Módulo de resistência na flexão estática na direção transversal (MPa)

$f_{m / /}-$ Módulo de resistência na flexão estática na direção longitudinal (MPa)

$F_{2}-F_{1}=$ incremento de força, em Newton, na seção retilínea da curva força-flecha,

onde $F_{1}$ deve ser cerca de $10 \%$ e $F_{2}$ cerca de $40 \%$ da força de ruptura

$F_{\text {max }}$ - Força de ruptura $(\mathrm{N})$

$F_{\text {max// }}$ - Força de ruptura na flexão estática, na direção longitudinal (N)

$F_{\max } \perp-F o r c ̧ a$ de ruptura na flexão estática, na direção transversal $(\mathrm{N})$

$F_{\max A l}$ - Força de ruptura na resistência à tração perpendicular às faces (N)

$G_{t}-$ Inchamento em espessura, por imersão em água por 24h (\%)

$H$ - Umidade (\%)

$I_{1}$ - Distância entre os centros dos apoios $(\mathrm{mm})$

$I_{2}$ - Comprimento $(\mathrm{mm})$

$m$ - Massa $(\mathrm{kg})$ e/ou número de corpos-de-prova

$m_{1}-$ Massa inicial (g)

$m_{2}-$ Massa final $(\mathrm{g})$

$p$ - Valor de probabilidade

$R$ - Coeficiente de variação 
$R^{2}$ - Coeficiente de determinação

$s$ - Desvio Padrão

$t$ - Tempo (s) e/ ou espessura (mm)

$t_{1}-$ Espessura inicial $(\mathrm{mm})$

$t_{2}-$ Espessura final $(\mathrm{mm})$

$\bar{x}$ - Média Aritmética

$V$ - Velocidade $(\mathrm{m} / \mathrm{s})$

$V_{A}$ - Velocidade de propagação da onda no local correspondente ao corpo-deprova de absorção de água $(\mathrm{m} / \mathrm{s})$

$V_{A l}$ - Velocidade de propagação da onda no local correspondente ao corpo-deprova de adesão interna $(\mathrm{m} / \mathrm{s})$

$V_{d}$ - Velocidade de propagação da onda no local correspondente ao corpo-de-prova de densidade $(\mathrm{m} / \mathrm{s})$

$V_{I}$ - Velocidade de propagação da onda no local correspondente ao corpo-de-prova de inchamento $(\mathrm{m} / \mathrm{s})$

$V_{\text {I e A }}$ - Velocidade de propagação da onda no local correspondente ao corpo-deprova de inchamento e absorção de água $(\mathrm{m} / \mathrm{s})$

$V_{\perp}-$ Velocidade de propagação de ondas na direção transversal $(\mathrm{m} / \mathrm{s})$

$V_{/ /}-$Velocidade de propagação de ondas na direção longitudinal (m/s)

$\alpha$-Nível de confiança

$\rho$-Densidade $\left(\mathrm{kg} / \mathrm{m}^{3}\right)$

$\lambda$ - Comprimento de Onda (m) 


\section{RESUMO}

Um dos painéis derivados de madeira que tem se destacado é o OSB (Oriented Strand Board). Cada vez mais se evidencia a necessidade de novas tecnologias relacionadas à avaliação das propriedades mecânicas desse tipo de derivado de madeira, atualmente realizada através de ensaios destrutivos, efetuados horas ou dias após a respectiva produção. A utilização de métodos não-destrutivos tem se mostrado eficiente na caracterização mecânica e na avaliação da qualidade da madeira, e promissora em relação aos derivados de madeira. O objetivo geral deste trabalho foi investigar a eficiência de técnicas não-destrutivas de ensaio, de ultrasom e de stress wave, na estimativa de parâmetros físicos e mecânicos de painéis OSB fabricados no país. Foram considerados dois grupos, com 10 painéis de espessuras nominais de $15 \mathrm{~mm}$ cada, que possuíam valores de resistência e de módulos de elasticidade na flexão estática, na direção longitudinal, distintos entre si. Primeiramente foram conduzidos os ensaios não-destrutivos, de ultra-som e de stress wave, nos painéis OSB e, em seguida, os ensaios destrutivos para a caracterização físico-mecânica e subseqüentes comparações. Os painéis estudados apresentaram valores de velocidades e constantes dinâmicas diferenciados na espessura e nas direções longitudinal e transversal. Os coeficientes de correlação obtidos entre os valores de velocidades e de constantes dinâmicas e os das propriedades físico-mecânicas, dos dois grupos de painéis, na espessura e direção transversal, não atingiram 0,70 e, na direção longitudinal superaram 0,90. Mostrou-se que é equivalente a estimativa de parâmetros mecânicos na flexão estática, ou até mesmo o estudo de painéis $O S B$, com a utilização dos métodos não-destrutivos de ultra-som e de stress wave. Com os resultados obtidos são gerados importantes subsídios para possibilitar a avaliação da produção de painéis $O S B$, viabilizando eventuais correções e ajustes até no decorrer do próprio processo produtivo.

Palavras-chave: derivados de madeira, ensaios não-destrutivos, OSB, stress wave, ultra-som. 


\begin{abstract}
Wood based materials production has grown in the national market, as it is the current international trend. Such products have been an interesting alternative to the sawn wood. Among them, OSB (Oriented Strand Board) has been of an outstanding importance. Its potential of production in the national context is expressive when supplying civil construction, furniture industry, and others. However, this fact also makes clear the need of innovative technologies for mechanical properties evaluation of this wood based material, since until the present day it has been conducted with destructive tests which are only made hours or days after production. Nondestructive methods utilization has been proven to be efficient for mechanical characterization and quality evaluation of sawn wood, and quite promising for wood based materials. The main goal of this research has been to investigate the efficiency of nondestructive testing (ultrasound and stress wave) when estimating physical and mechanical parameters of OSB panels made in Brazil. Two groups of ten $15 \mathrm{~mm}$ thick panels have been used, having each one of them strength and modulus of elasticity in static bending values distinct from each other in longitudinal direction. First the two types of nondestructive testing have been conducted on all OSB panels and then destructive tests have also been conducted for physical-mechanical characterization and following comparisons. Values of velocities and dynamic constants both in thickness and longitudinal and transversal directions have been different in the two groups of studied panels. Correlation coefficients between values of velocity and dynamic constants and values of physical-mechanical properties of the two groups of panels have not reached 0,70 in thickness and transversal direction, but they have exceeded 0,90 in longitudinal direction. It has been shown that ultrasound is analogous to stress wave either when estimating static bending mechanical parameters or studying OSB panels by nondestructive testing. Such results generate some important subsidies to the evaluation of OSB production, making feasible eventual corrections and adjustments even in the course of its process.
\end{abstract}

Keywords: wood based materials, nondestructive testing, OSB, stress wave, ultrasound. 


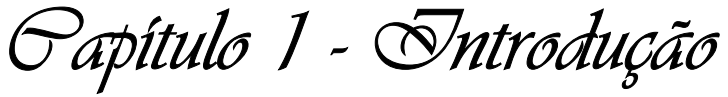

Uma das tendências mais evidentes na indústria madeireira é o crescimento da produção dos chamados painéis (ou chapas) à base de madeira. Estes têm se mostrado uma alternativa interessante em relação à madeira serrada pois, por exemplo, viabilizam a utilização de praticamente cem por cento de uma tora; não impõem restrições ao emprego de espécies de reflorestamento, de rápido crescimento e de densidade média; alguns deles podem ser fabricados com resíduos de madeireiras; propiciam diminuição da anisotropia e apresentam poucas limitações dimensionais.

Indústrias brasileiras têm fabricado e investido na produção de laminados como o compensado (1940), de compósitos de fibra de madeira como as chapas de fibra (1955) e o MDF (1998) bem como de compósitos de partículas de madeira como o aglomerado (1966) e o OSB (2002), o mais recente. Essa produção busca atender aos mercados interno e externo, nos setores da construção civil e moveleiro, entre outros.

Entre esses produtos, o que tem mostrado crescente aplicação mundialmente, em especial na construção civil, incluindo telhados, paredes, pisos, contrapisos e vigas de edificações com até três andares, é o OSB (Oriented Strand Board). No Brasil a sua utilização tem sido mais expressiva na área do design, móveis, decoração e embalagens. 
Um cuidado especial, que necessita urgentes investimentos de pesquisa, se refere ao desenvolvimento de tecnologia para permitir a avaliação mais expedita das propriedades mecânicas dos derivados de madeira.

Em indústrias nacionais de produtos derivados de madeira, até o presente momento, essa avaliação normalmente tem se baseado em procedimentos de amostragem estatística, nos quais partes desses produtos são testadas destrutivamente, em geral horas depois de sua produção.

Se a amostra apresentar valores de propriedades físico-mecânicas inferiores às requeridas do lote em fabricação, após mais algumas horas é realizada nova amostragem. Confirmado o primeiro resultado, a produção é paralisada, o problema no processo de produção é investigado, posteriormente corrigido e metros cúbicos de painéis produzidos são descartados.

Como descrito, tal procedimento demanda muito tempo. Além disto, caso sejam determinadas propriedades que não atendam aos requisitos de qualidade, somente haverá como introduzir modificações na linha de produção, de modo a corrigir o problema, após se consumarem grandes volumes de perdas.

Neste contexto fica plenamente evidenciada a importância de se investigar a adequação do uso de técnicas não-destrutivas de ensaio (NDT - Nondestructive Testing), como as do "stress wave" e do ultra-som, para a adequada estimativa de propriedades de painéis derivados da madeira. Essas técnicas são de fácil e rápida implementação, bem como de custo competitivo. 


\section{Papitulo 2 - Ebjetivos}

\subsection{Objetivo geral}

Constitui-se objetivo geral do presente trabalho investigar a eficiência de técnicas não-destrutivas de ensaio (stress wave e ultra-som) na estimativa de parâmetros físicos e mecânicos de painéis OSB fabricados no país.

\subsection{Objetivos específicos}

Como objetivos específicos, têm-se:

- Avaliar a existência de correlação entre os valores obtidos nos ensaios nãodestrutivos, de ultra-som e de stress wave, e nos ensaios físico-mecânicos destrutivos convencionais, conduzidos em painéis OSB de produção nacional;

- Avaliar a existência de diferenças entre valores de velocidades de propagação da onda, e correspondentes valores de constantes dinâmicas, na espessura e nas direções longitudinal e transversal de painéis OSB, de produção nacional, através da utilização dos métodos não-destrutivos de ultra-som e de stress wave;

- Avaliar a correlação entre valores de velocidades de propagação da onda, e correspondentes valores de constantes dinâmicas, obtidos nos métodos de ultra-som e stress wave, quando utilizados em painéis $\mathrm{OSB}$, de fabricação nacional; 
- Avaliar a existência de diferenças entre valores de velocidades de propagação da onda, e correspondentes valores de constantes dinâmicas, para painéis OSB, de fabricação nacional, pertencentes a lotes com propriedades mecânicas de valores distintos entre si, com a utilização dos métodos nãodestrutivos de ultra-som e de stress wave;

- Gerar subsídios para a disseminação do emprego de técnicas não-destrutivas de ensaio para a estimativa de propriedades de painéis derivados da madeira. 


\section{Papitulo 3 - Qevisã̃o ®ibliográfica}

Neste capítulo são apresentadas informações referentes ao OSB, a ensaios destrutivos e a avaliações não-destrutivas utilizadas com a madeira e seus derivados.

\subsection{Produtos derivados de madeira}

Os produtos derivados da madeira podem ser classificados de várias formas. Bodig (2001) propõe uma divisão em dois grandes grupos, os laminados e os compósitos de madeira.

Os compósitos de madeira são definidos, geralmente, como produtos nos quais a madeira é usada na forma de partículas ou fibras e estes componentes são aglomerados por adesivo, em processo que requer o controle de diversas variáveis.

Como exemplos podem ser citados os painéis aglomerados de madeira, 0 OSB (Oriented Strand Board), o MDF (Medium Density Fiberboard), o HDF (High Density Fiberboard). A Figura 1 mostra exemplos de compósitos de madeira.
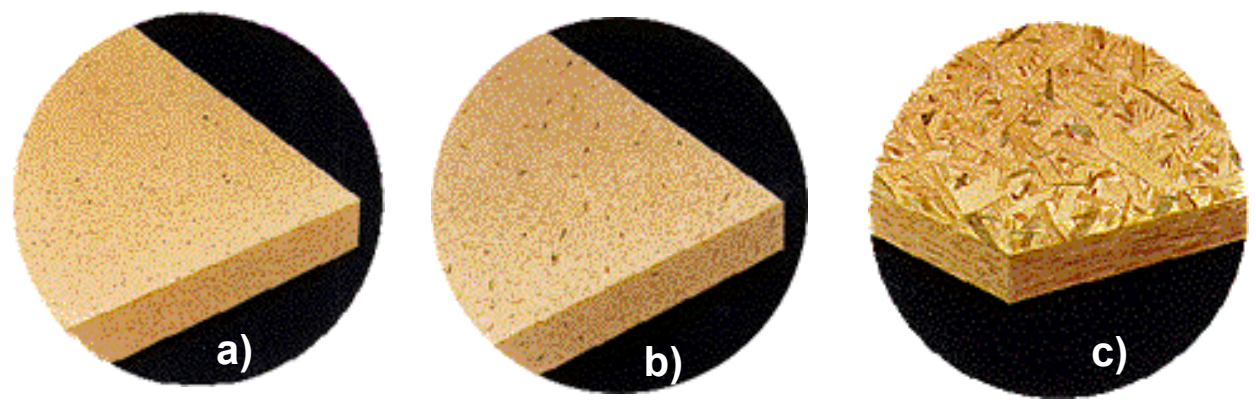

Figura 1 - Exemplos de compósitos de madeira: a) MDF, b) chapa de partículas e c) OSB. Fonte: http://www.wii.com/BLDGMATR.HTM 
No Brasil é expressiva a produção de painéis de partículas de madeira. A título de ilustração, a Figura 2 mostra onde estão localizadas as fábricas de painéis brasileiras, cuja concentração ocorre nas regiões sudeste e sul do país.

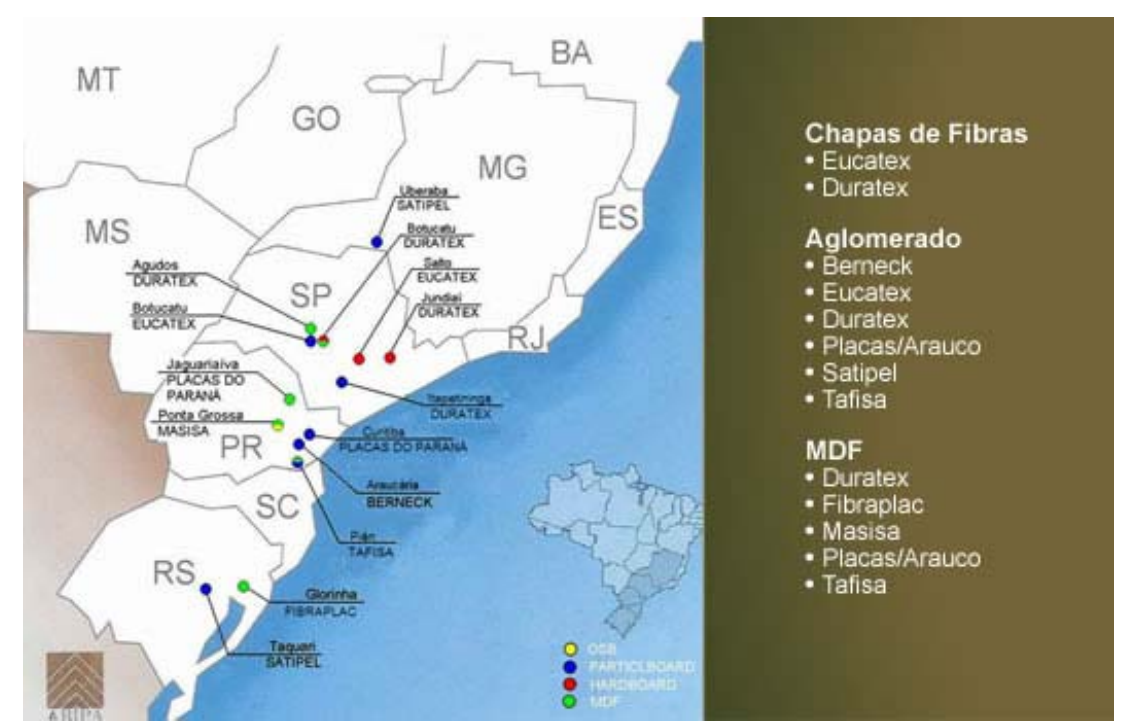

Figura 2 - Localização das fábricas de painéis de madeiras no Brasil. Fonte: ABIPA, 2006.

\subsection{O OSB}

O OSB é a segunda geração do Waferboard. Este produto foi desenvolvido por James Clarke, da US Potchland Corporation, em 1954, quando pesquisava novas utilizações para as espécies oriunda das florestas de Potchland, que não eram apropriadas para emprego como madeira serrada ou como polpa.

Clarke descobriu que o fatiamento de toras cortadas ao longo da grã em finos "wafers" e a união destes, por meio de resina fenólica, resultaria, após um período de prensagem, em um painel com características muito interessantes para diversas finalidades, quer na construção, quer na indústria do mobiliário (Janssens, 1998).

O desenvolvimento do Waferboard seguiu a ênfase colocada pelo Provincial Government of Saskatchewan (Canadá) para a utilização das suas florestas de Aspen (Populus tremuloides). Em 1955, o Waferboard foi fabricado comercialmente pela primeira vez, em pequena escala, pela Pack River Company, Sandpoint, Idaho, USA e, em larga escala, pela Wizewood Limited, Hudson Bay, 
Saskatchewan, Canadá, em 1962, com o nome comercial "Aspenite" (Cloutier, 1998).

Essa última indústria surgiu de um grupo de negociantes que compraram a patente de Clarke. Tal grupo teve sérios problemas financeiros em 1963 e a indústria foi incorporada pelo governo da província de Saskatchewan, sendo vendida à Macmillan Bloedel Ltd. O produto foi amplamente comercializado no setor da construção civil e teve sucesso no mercado, pelo seu desempenho e pelo seu preço competitivo.

A Associação Canadense de Waferboard (Canadian Waferboard Association - CWA) foi fundada em 1976 por quatro manufatores de Waferboard canadenses. Entre 1970 e 1980, muitos esforços foram feitos para caracterizar as propriedades e obter o reconhecimento do Waferboard nos códigos e normas de edificações dos EUA e Canadá.

Muita pesquisa foi realizada no antigo Eastern Forest Products Laboratory em Ottawa, Ontário, atual Forintek Canada Corp. (Québec), incluindo o estudo do impacto do alinhamento dos wafers sobre as propriedades do painel.

Em 1981 o termo "Oriented Strand Board" foi incluído à definição de Waferboard. O nome da CWA foi mudado para "Structural Board Association" (SBA) em 1990. No fim de 1996, a indústria de OSB já incluía 57 plantas na América do Norte (38 nos EUA e 19 no Canadá), responsáveis por uma produção de 13,3 milhões de $\mathrm{m}^{3}$ /ano. A SBA também inclui uma planta na Escócia, no Chile e na França (Cloutier, 1998).

O OSB tem sido rapidamente aceito desde o início de sua produção. De fato, muitas áreas da América do Norte têm substituído outros painéis derivados da madeira na construção residencial (SBA, 2002).

As principais diferenças entre o Waferboard e o OSB são: 
- Dimensões das partículas: os wafers apresentam dimensões $40 \mathrm{~mm}$ por 40mm, no Waferboard, sendo que os strands, no OSB, são mais longos, medindo aproximadamente $25 \mathrm{~mm}$ de largura por $80 \mathrm{~mm}$ a $150 \mathrm{~mm}$ de comprimento.

- Modo de formação do colchão: No Waferboard, as partículas são dispostas aleatoriamente no colchão, formando apenas uma camada, não-homogênea. $\mathrm{O}$ OSB é formado pelos strands dispostos em várias camadas (geralmente três), que são alinhadas perpendicularmente entre si (Janssens, 1998).

\subsubsection{Características gerais}

Segundo a EN 300/ 2002 (Norma Portuguesa), o OSB (aglomerado de partículas de madeira longas e orientadas) é composto por várias camadas constituídas por partículas de madeira longas, de determinado formato e espessura, aglutinadas por uma resina colante (adesivo). A Figura 3(a) mostra exemplos de painéis OSB.

As partículas longas de madeira das camadas exteriores encontram-se alinhadas e dispostas preferencialmente na direção paralela ao comprimento ou a largura do painel e as partículas da, ou das, camadas interiores podem encontrarse orientadas aleatoriamente ou alinhadas, geralmente, na direção perpendicular à das partículas de madeira longas das camadas exteriores. A Figura 3(b) mostra a orientação em camadas dos painéis OSB.

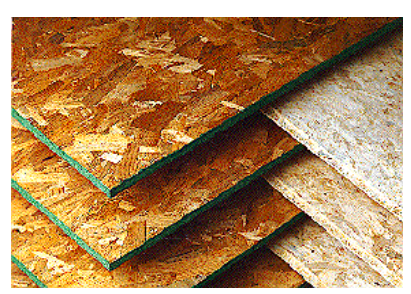

(a)

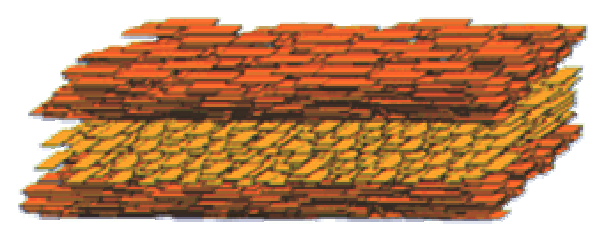

(b)

Figura 3: Painéis OSB. (a) Exemplos de painéis OSB e (b) Orientação das camadas dos painéis OSB. Fonte: http://www.osb-info.org/html/POset.html. 
Estas partículas de madeira longas ou "strands", são unidas umas às outras com resina à prova d'àgua, sob calor e pressão (FPL, 1999).

As dimensões das partículas são predeterminadas e têm uma espessura uniforme (SBA, 2002). Apresentam cerca de $25 \mathrm{~mm}$ de largura, 90 a $150 \mathrm{~mm}$ de comprimento por 0,50 a $0,75 \mathrm{~mm}$ de espessura (CLOUTIER, 1998). As dimensões dos painéis usualmente comercializados são $1220 \times 2440 \mathrm{~mm}$ e as suas espessuras comuns variam de 6 a $40 \mathrm{~mm}$.

As Figuras 4 (a), (b), (c), (d), (e) e (f) mostram exemplos das aplicações do OSB.

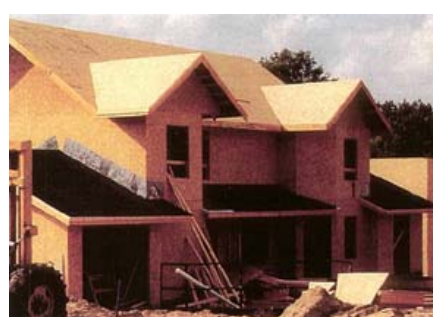

(a)

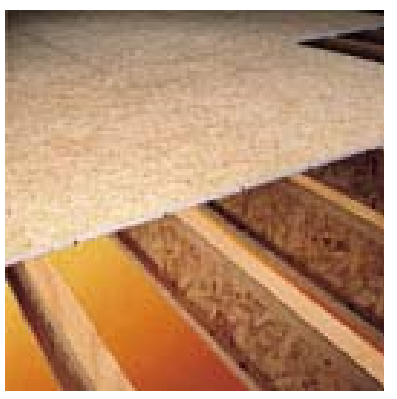

(d)

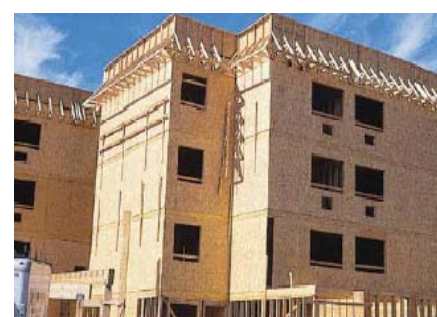

(b)

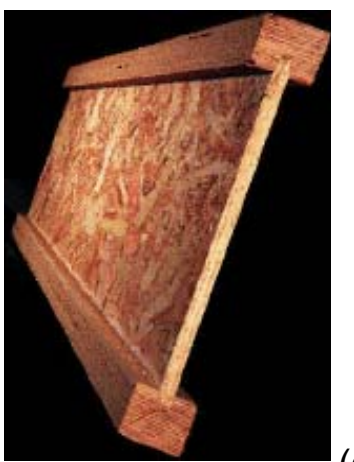

(e)

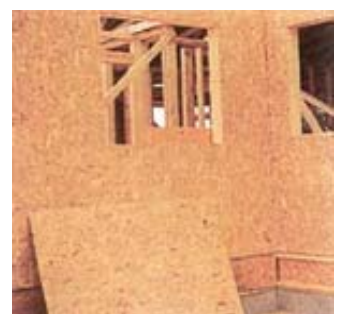

(c)

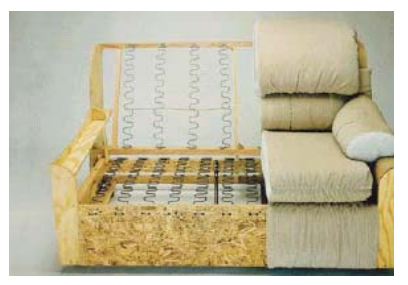

(f)

Figura 4: Exemplos de aplicações dos painéis OSB. (a) Construção residencial. Fonte: http://www.modular-homes-plans.com/roof sheathing.html, (b) Construção de edifício. Fonte: http://www.apawood.org/level b.cfm?content=prd osb main,

(c) Paredes projetadas com OSB. Fonte: http://www.modular-homesplans.com/roof sheathing.html, (d) Piso em OSB. Fonte:

http://www.ipcorp.com/productas/productsDetail.jsp?ProductGrouplD=14ProductlD=364b , (e) Exemplo de viga estrutural I. Fonte :http://www.wii.com/StrucjoistDG.pdf e (f) Móveis. Fonte: http://www.masisa.com.br.

Os adesivos habitualmente utilizados na fabricação dos painéis OSB são o fenol-formaldeído, a melamina-ureia-formadeido (Melamine Fortified Urea Formalheyde - MUF) e o isocianato (PMDI), sendo que todos estes são resistentes à umidade. Na Europa, é comum utilizar-se uma combinação de adesivos, sendo o PMDI normalmente utilizado na camada central e a MUF nas camadas exteriores, o 
que reduz os ciclos de prensagem e ao mesmo tempo confere um aspecto mais brilhante à superfície do painel (site http://www.osb-info.org, 2002).

As suas principais aplicações são: Produção de divisórias de ambientes; fechamento de paredes, contrapisos e forros de coberturas; produção de vigas I estruturais; fabricação de móveis (Einsfeld et al, 1998); tapumes e barracões de obras; corpos de motor-home; carrocerias de caminhões; pallets tipo container; embalagens; displays; decoração e design (site MASISA, 2002).

A Figura 5 mostra o processo de fabricação de painéis OSB, de uma forma simplificada, e suas aplicações estruturais.

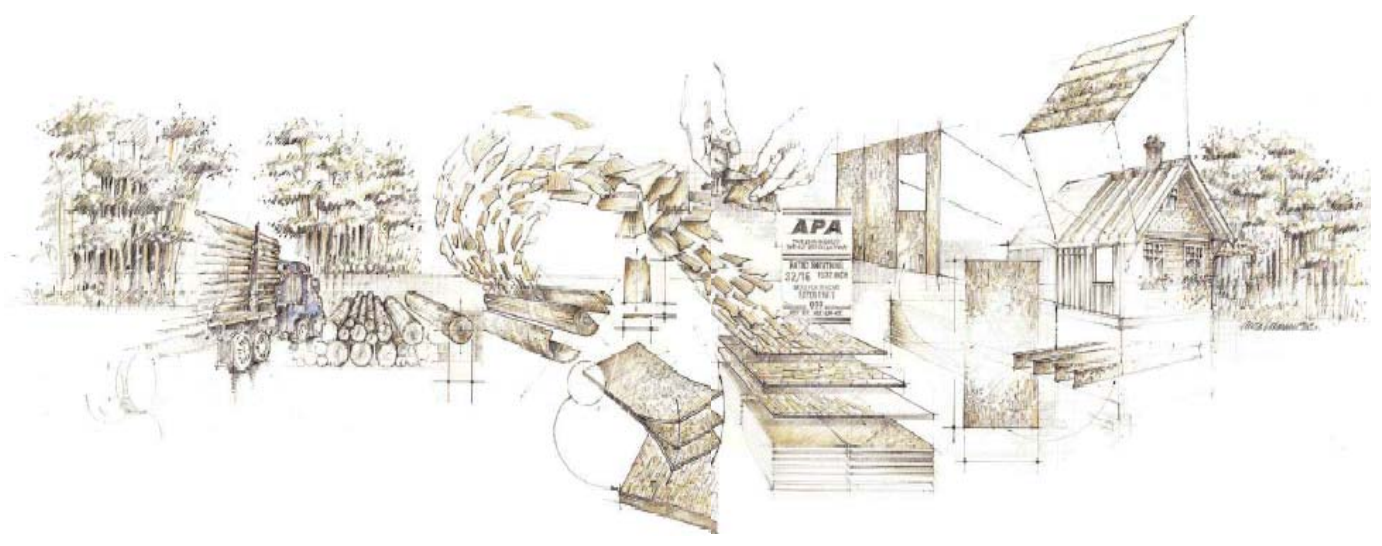

Figura 5 - Processo de manufatura dos painéis OSB e aplicações estruturais. Fonte: APA, 2000.

Segundo a EN 300 (2002) são especificados quatro tipos de painéis OSB:

a) OSB/1: Painéis para usos gerais e painéis para componentes interiores (incluindo mobiliário) utilizados em ambiente seco.

b) OSB/2: Painéis para fins estruturais utilizados em ambiente seco.

c) OSB/3: Painéis para fins estruturais utilizados em ambiente úmido.

d) OSB/4: Painéis para fins estruturais especiais utilizados em ambiente úmido.

Os painéis para fins estruturais são destinados ao projeto e constituição dos elementos estruturais para a construção, por exemplo, de paredes, de pavimentos, 
de telhados ou de vigas I (ENV 1995-1-1 e/ou Normas de desempenho) em utilização em ambiente seco ou úmido.

Considera-se como ambiente seco o definido para a classe de serviço 1 , de acordo com a ENV 1995-1-1, para painéis para fins estruturais, caracterizado por um teor de água dos materiais correspondentes a temperatura do ar de $20^{\circ} \mathrm{C}$ e umidade relativa do ar que apenas ultrapasse os $65 \%$ durante algumas semanas por ano.

Considera-se como ambiente úmido o definido para a classe de serviço 2, de acordo com a ENV 1995-1-1, caracterizado por uma umidade relativa do ar que apenas ultrapasse os $85 \%$ durante algumas semanas por ano.

Segundo a APA (2000), os painéis OSB são classificados quanto à sua resistência à exposição à umidade em dois grupos:

- Painéis Exteriores (Exterior): Produzidos com adesivos à prova d'água, são indicados para aplicações sujeitas à exposição permanente ao intemperismo.

- Painéis Exposição 1 (Exposure 1): Produzidos com adesivos à prova d'água, são indicados para aplicações onde podem ser esperados longos atrasos em construções e for programada uma proteção prévia. Aproximadamente $95 \%$ dos Painéis de Desempenho Classificado (Performance Rated Panels) são manufaturados com essa designação.

\subsubsection{Propriedades Mecânicas}

Os requisitos em termos de valores limites para as propriedades mecânicas dos 4 tipos de painéis OSB definidos no documento normativo EN 300 são apresentados nas Tabelas 1, 2, 3 e 4, onde $f_{m}, E_{m}$, Al e $G_{t}$ representam, respectivamente, os módulos de resistência e de elasticidade na flexão estática, resistência à tração perpendicular às faces e inchamento em espessura. Caracteriza-se por teor de umidade no material correspondente à umidade relativa de $65 \%$ e à temperatura de $20^{\circ} \mathrm{C}$. 
Tabela 1 - Painéis para usos gerais e para componentes de interiores (incluindo mobiliário) para utilização em ambiente seco - Requisitos para as propriedades mecânicas e de inchamento

\begin{tabular}{|c|c|c|c|c|c|}
\hline Painel tipo OSB/ 1 & \multirow{3}{*}{\multicolumn{2}{|c|}{$\begin{array}{c}\text { Método de Ensaio } \\
\text { Unidade }\end{array}$}} & \multirow{2}{*}{\multicolumn{3}{|c|}{$\begin{array}{c}\text { Requisitos } \\
\begin{array}{c}\text { Espessura do painel } \\
\text { (nominal, mm) }\end{array}\end{array}$}} \\
\hline \multirow[t]{2}{*}{ Propriedade } & & & & & \\
\hline & & & 6 a 10 & $>10 \mathrm{e}<18$ & 18 a 25 \\
\hline $\mathbf{f}_{m}-$ Direção longitudinal & EN 310 & $\mathrm{~N} / \mathrm{mm}^{2}$ & 20 & 18 & 16 \\
\hline$f_{m}-$ Direção transversal & EN 310 & $\mathrm{~N} / \mathrm{mm}^{2}$ & 10 & 9 & 8 \\
\hline $\mathrm{E}_{\mathrm{m}}$ - Direção longitudinal & EN 310 & $\mathrm{~N} / \mathrm{mm}^{2}$ & 2500 & 2500 & 2500 \\
\hline $\mathrm{E}_{\mathrm{m}}-$ Direção transversal & EN 310 & $\mathrm{~N} / \mathrm{mm}^{2}$ & 1200 & 1200 & 1200 \\
\hline Al & EN 319 & $\mathrm{~N} / \mathrm{mm}^{2}$ & 0,30 & 0,28 & 0,26 \\
\hline$G_{t}(24 h)$ & EN 317 & $\%$ & 25 & 25 & 25 \\
\hline
\end{tabular}

Fonte: EN 300, 2002.

Tabela 2 - Painéis para fins estruturais utilizados em ambiente seco - Requisitos para as propriedades mecânicas e de inchamento

\begin{tabular}{|c|c|c|c|c|c|}
\hline \multirow{3}{*}{ Propriedade } & \multirow{3}{*}{\multicolumn{2}{|c|}{$\begin{array}{c}\text { Método de Ensaio } \\
\text { Unidade }\end{array}$}} & \multirow{2}{*}{\multicolumn{3}{|c|}{$\begin{array}{c}\text { Requisitos } \\
\begin{array}{c}\text { Espessura do painel } \\
\text { (nominal, } \mathrm{mm} \text { ) }\end{array}\end{array}$}} \\
\hline & & & & & \\
\hline & & & 6 a 10 & $>10 \mathrm{e}<18$ & 18 a 25 \\
\hline$f_{m}-$ Direção longitudinal & EN 310 & $\mathrm{~N} / \mathrm{mm}^{2}$ & 22 & 20 & 18 \\
\hline$f_{m}-$ Direção transversal & EN 310 & $\mathrm{~N} / \mathrm{mm}^{2}$ & 11 & 10 & 9 \\
\hline$E_{m}-$ Direção longitudinal & EN 310 & $\mathrm{~N} / \mathrm{mm}^{2}$ & 3500 & 3500 & 3500 \\
\hline$E_{m}-$ Direção transversal & EN 310 & $\mathrm{~N} / \mathrm{mm}^{2}$ & 1400 & 1400 & 1400 \\
\hline $\mathbf{A l}$ & EN 319 & $\mathrm{~N} / \mathrm{mm}^{2}$ & 0,34 & 0,32 & 0,30 \\
\hline$G_{t}(24 h)$ & EN 317 & $\%$ & 20 & 20 & 20 \\
\hline
\end{tabular}

Fonte: EN 300, 2002.

Tabela 3 - Painéis para fins estruturais utilizados em ambiente úmido Requisitos para as propriedades mecânicas e de inchamento

\begin{tabular}{|c|c|c|c|c|c|}
\hline Painel tipo OSB/ 3 & \multirow{2}{*}{\multicolumn{2}{|c|}{$\begin{array}{c}\text { Método de Ensaio } \\
\text { Unidade }\end{array}$}} & & Requisitos & \\
\hline \multirow{2}{*}{ Propriedade } & & & \multicolumn{3}{|c|}{$\begin{array}{l}\text { Espessura do painel } \\
\text { (nominal, mm) }\end{array}$} \\
\hline & & & 6 a 10 & $>10 \mathrm{e}<18$ & 18 a 25 \\
\hline$f_{m}-$ Direção longitudinal & EN 310 & $\mathrm{~N} / \mathrm{mm}^{2}$ & 22 & 20 & 18 \\
\hline$f_{m}$ - Direção transversal & EN 310 & $\mathrm{~N} / \mathrm{mm}^{2}$ & 11 & 10 & 9 \\
\hline$E_{m}-$ Direção longitudinal & EN 310 & $\mathrm{~N} / \mathrm{mm}^{2}$ & 3500 & 3500 & 3500 \\
\hline $\mathrm{E}_{\mathrm{m}}-$ Direção transversal & EN 310 & $\mathrm{~N} / \mathrm{mm}^{2}$ & 1400 & 1400 & 1400 \\
\hline Al & EN 319 & $\mathrm{~N} / \mathrm{mm}^{2}$ & 0,34 & 0,32 & 0,30 \\
\hline$G_{t}(24 h)$ & EN 317 & $\%$ & 15 & 15 & 15 \\
\hline
\end{tabular}

Fonte: EN 300, 2002. 
Tabela 4 - Painéis para fins estruturais especiais utilizados em ambiente úmido - Requisito para as propriedades mecânicas e de inchamento

\begin{tabular}{|c|c|c|c|c|c|}
\hline Painel tipo OSB/ 4 & \multirow{3}{*}{\multicolumn{2}{|c|}{$\begin{array}{c}\text { Método de Ensaio } \\
\text { Unidade }\end{array}$}} & \multirow{2}{*}{\multicolumn{3}{|c|}{$\begin{array}{c}\text { Requisitos } \\
\text { Espessura do painel } \\
\text { (nominal, } \mathrm{mm} \text { ) }\end{array}$}} \\
\hline \multirow[t]{2}{*}{ Propriedade } & & & & & \\
\hline & & & 6 a 10 & $>10 \mathrm{e}<18$ & 18 a 25 \\
\hline$f_{m}-$ Direção longitudinal & EN 310 & $\mathrm{~N} / \mathrm{mm}^{2}$ & 30 & 28 & 26 \\
\hline$f_{m}-$ Direção transversal & EN 310 & $\mathrm{~N} / \mathrm{mm}^{2}$ & 16 & 15 & 14 \\
\hline $\mathrm{E}_{\mathrm{m}}-$ Direção longitudinal & EN 310 & $\mathrm{~N} / \mathrm{mm}^{2}$ & 4800 & 4800 & 4800 \\
\hline $\mathrm{E}_{\mathrm{m}}-$ Direção transversal & EN 310 & $\mathrm{~N} / \mathrm{mm}^{2}$ & 1900 & 1900 & 1900 \\
\hline Al & EN 319 & $\mathrm{~N} / \mathrm{mm}^{2}$ & 0,50 & 0,45 & 0,40 \\
\hline$G_{t}(24 h)$ & EN 317 & $\%$ & 12 & 12 & 12 \\
\hline
\end{tabular}

* Para os painéis OSB/2, OSB/3 e OSB/4 se o comprador notificar que os painéis são destinados a uma utilização específica em pavimento, parede ou telhado, a Norma de desempenho correspondente também tem que ser consultada. Este fato pode implicar a observância de requisitos adicionais.

Fonte: EN 300, 2002.

\subsection{Avaliações não-destrutivas}

A pesquisa sobre ensaios não-destrutivos em madeira e derivados de madeira foi incentivada nos EUA por um simpósio em Pullman, Washington, em 1980, organizado por Roy F. Pellerin (Washington State University) e Kent MacDonald (USDA Forest Service, Forest Products Laboratory). Incluem a medição de propriedades físicas e mecânicas, classificação de materiais, e monitoramento de defeitos em árvores, toras, madeira sólida, madeira serrada e tábua, derivados de madeira e produtos compósitos (Kawamoto e Williams, 2002).

A avaliação não-destrutiva de materiais (nondestructive evaluation - NDE) consiste na identificação de propriedades físico-mecânicas de parte do material sem alterar suas propriedades de utilização, com a finalidade de tomar decisões apropriadas a respeito de suas aplicações. Tais avaliações são feitas através de testes não-destrutivos (nondestructive testing - NDT) para prover informação a respeito das propriedades, desempenho ou condição do material em questão (Ross, 1998). 
Quase todos os tipos de ensaios não-destrutivos podem ser utilizados com a madeira e derivados de madeira, sendo que a escolha para a sua utilização depende da aplicação específica (Bodig, 2001).

Esses métodos apresentam muitas vantagens sendo uma das mais importantes a possibilidade de a madeira ser caracterizada eficazmente sem a extração de corpos-de-prova, uma vez que a avaliação é feita na própria peça ou estrutura (Oliveira, 2001). Proporcionam também maior rapidez para analisar uma grande população e versatilidade para se adequar a uma rotina padronizada numa linha de produção (Oliveira; Sales, 2000).

Dentre eles podem ser citados a classificação visual (que é um dos mais amplamente utilizados), testes químicos (para detectar defeitos biológicos), "stress wave", ultra-som, método de deflexão, teste de propriedades elétricas, radiações gama, penetração de radiação e método de raio-x. Destes, os mais usualmente utilizados para madeira e seus derivados são o "stress wave" e o ultra-som (Bodig, 2001).

\subsubsection{Stress wave}

Neste tipo de NDT são geradas ondas através de uma vibração produzida por impacto na peça em estudo. Mede-se a velocidade do som, cujo valor é utilizado na determinação da constante dinâmica (C) (Bodig, 2001).

As técnicas não-destrutivas de stress wave utilizam baixos movimentos moleculares de tensão para medir duas propriedades fundamentais dos materiais: a energia armazenada e a dissipação. A energia armazenada manifesta-se pela velocidade com a qual a onda percorre o material. Em contraste, a taxa sob a qual a onda é atenuada é uma indicação de dissipação de energia (Ross e Pellerin, 1988). 
Jayne (1958) apud Ross e Pellerin (1988) ${ }^{1}$ colocou como hipótese que estas propriedades são controladas pelos mesmos mecanismos que determinam o comportamento mecânico do material. Como uma conseqüência, seria possível estabelecer relações matemáticas entre as ondas de tensão e as propriedades mecânicas estáticas do material, através de técnicas de análise de regressão estatística.

A aplicação de ondas acústicas e, medição das mesmas, consiste no posicionamento de dois transdutores acelerômetros sobre o material a ser avaliado. Uma onda acústica é induzida ao material, ao tocar-se este com um martelo, um pêndulo ou outros meios.

Quando a onda acústica alcança o acelerômetro de partida, uma contagem de tempo, em microssegundos, é iniciada no instrumento. Quando esta onda atinge o acelerômetro de parada, a contagem de tempo cessa, o aparelho registra e mostra o tempo decorrido de trânsito da onda de tensão entre os acelerômetros através do material (METRIGUARD apud Matos, 1997)2.

Os tempos registrados são utilizados no cálculo da velocidade da propagação da onda (V), utilizando-se a Equação (1):

$$
V=\frac{d}{t}
$$

Onde:

$V=$ velocidade de propagação da onda $(\mathrm{m} / \mathrm{s})$

$d=$ distância entre os transdutores $(m)$

$\mathrm{t}=$ tempo de propagação da onda $(\mathrm{s})$

A partir do cálculo de $V$ este teste permite avaliar o valor da constante dinâmica (C), dada pela segunda lei de Newton (Equação 2):

\footnotetext{
1 JAYNE, B., A. Vibrational properties of wood as indices of quality. Forest Products Journal, v. 9 (11), p. $413-416,1959$.

2 METRIGUARD INC. Metriguard Model 239 A Stress Wave Timer. Manual care and instructions, theory and data reduction. Pullman, 1997.
} 


$$
C=\rho \cdot V^{2} \cdot 10^{-6}
$$

Onde:

$\mathrm{C}=$ constante dinâmica $(\mathrm{MPa})$

$\rho=$ densidade do material $\left(\mathrm{kg} / \mathrm{m}^{3}\right)$

$V=$ velocidade de propagação da onda $(\mathrm{m} / \mathrm{s})$.

\subsubsection{Ultra-som}

Este tipo de NDT utiliza freqüências mais altas e é similar ao "stress wave", com a diferença de que as ondas são induzidas por transdutores e não por impacto (Bodig, 2001).

Tem demonstrado ser um valioso instrumento para a estimativa das propriedades da madeira. O manuseio dos equipamentos de ultra-som é simples e seu custo não é alto, o que tem disseminado o seu uso em várias partes do mundo. Paralelamente a isso, cresce o interesse em torno de ensaios não-destrutivos para a determinação de propriedades físicas e mecânicas de toda sorte de materiais, o que se coaduna com a visão deste novo século, que deverá ser pautado pelos cuidados com a preservação ambiental (Bartholomeu, 2001).

A principal vantagem desta técnica é a flexibilidade em medir a velocidade e a atenuação de ondas ultra-sônicas. Esta última é caracterizada por três fatores: a geometria do campo de radiação, a dispersão e a radiação.

A disposição mais comum para aparelhos de ultra-som é composta por um gerador de ultra-som, transdutores piezoelétricos (emissor e receptor), um osciloscópio, um analisador espectral e um computador, como esquematizado na Figura 6. Os requisitos básicos de um transdutor de ultra-som são boa sensibilidadede e resolução (Bucur, 1999). 


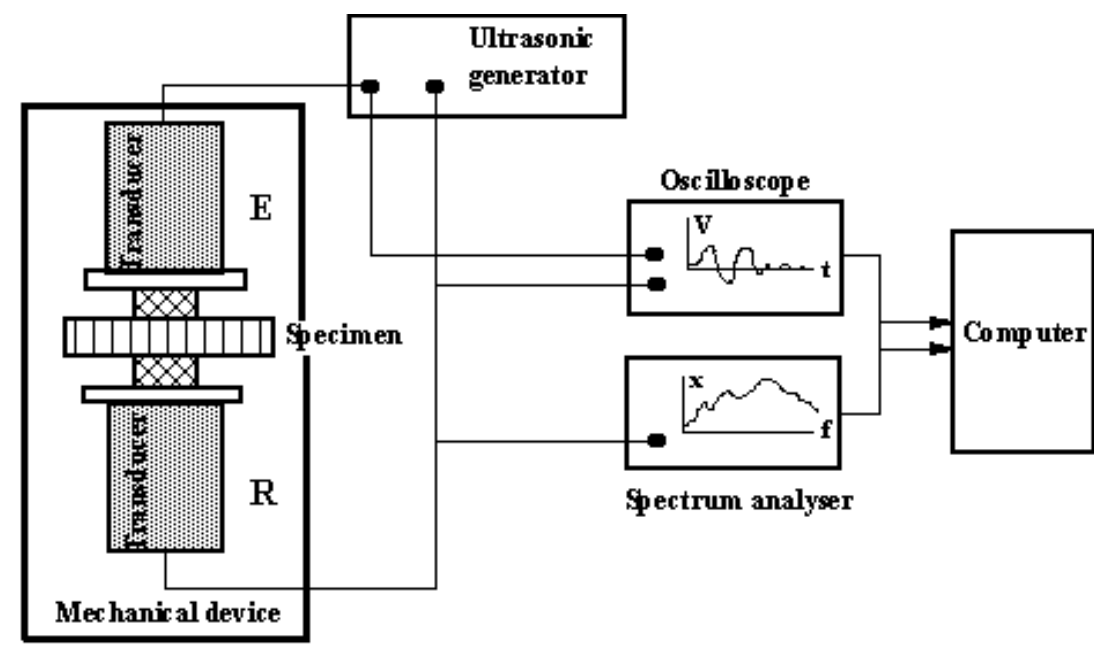

Figura 6 - Disposição de aparelhos de ultra-som: (a) gerador de ultra-som, (b) transdutores, (c) corpo-de-prova, (d) aparelho mecânico, (e) osciloscópio, (f) analisador de espectro e (g) computador. Fonte: http://www.ndt.net/article/v04n11/bucur/bucur.htm.

A aplicação e a medição pelo teste de ultra-som consistem no posicionamento de dois transdutores acelerômetros sobre o material a ser avaliado. A onda ultrasônica é introduzida por um dos transdutores e captada pelo outro, sendo a contagem do tempo, em microssegundos, efetuada pelo próprio equipamento de ultra-som. Os tempos registrados são empregados no cálculo de $\mathrm{V}$, utilizando-se a Equação (2), já mencionada anteriormente.

Calculado o valor $\mathrm{V}$, o teste de ultra-som permite avaliar o valor da constante dinâmica (C) segundo qualquer eixo, de acordo com o posicionamento dos transdutores, dada pela Segunda Lei de Newton, conforme a Equação (3), já mencionada anteriormente.

O cálculo de $V$ é afetado pela freqüência (f) e depende do comprimento da onda $(\lambda)$ de ultra-som, dada pela Equação (3):

$$
V=f \cdot \lambda
$$

Onde:

$V=$ velocidade de propagação da onda $(\mathrm{m} / \mathrm{s})$

$f=$ freqüência $(H z)$

$\lambda=$ comprimento da onda $(\mathrm{m})$. 
Os fatores que mais influenciam a propagação das ondas ultra-sônicas na madeira maciça são: teor de umidade, relação $d / \lambda$ (onde $d$ é a distância percorrida pela onda, que é equivalente ao comprimento da peça, e $\lambda$ é o comprimento de onda), freqüência e densidade aparente, quando esta última é considerada dentro de uma mesma estrutura anatômica.

\subsubsection{Atenuação}

A amplitude do pulso recebido é função da atenuação do pulso emitido. Além da divergência do sinal emitido pelo transdutor e da diminuição da amplitude do sinal durante a propagação da onda, o material testado também interfere na transmissão do sinal.

Essa influência ocorre em dois níveis. Um primeiro fator, a dispersão, resulta da não homogeneidade do material. Durante o percurso, a cada vez que a onda encontra um obstáculo não alinhado à sua propagação, a onda se dividirá em onda incidente e onda transmitida. Cada onda é então constantemente dividida em ondas parciais em complexos percursos.

A maior ou menor incidência desses fenômenos dependerá do tamanho do comprimento em relação à dimensão das descontinuidades do material. Para a madeira, se a relação entre a descontinuidade e o comprimento de onda $(\lambda)$ estiver entre $1 / 1000$ à $1 / 100$ esse efeito será desprezível. No entanto, caso essa relação seja inferior a $1 / 10$ a experimentação se torna impraticável (Krautkramer; Krautkramer, 1983).

A Absorção, o segundo fator da atenuação, consiste na conversão da energia sonora em calor e pode ser entendida como a redução da oscilação das partículas. A absorção aumenta com o aumento da freqüência do sinal, mas a uma taxa muito mais lenta do que a dispersão. 
Assim, o decréscimo da amplitude do sinal causado pela atenuação é dado pela relação:

$$
\mathrm{A}=\mathrm{A}_{0} \mathrm{e}^{-\alpha \mathrm{d}}
$$

Onde:

$A=$ amplitude final

$A_{0}=$ amplitude inicial

$\alpha=$ coeficiente de atenuação

$\mathrm{d}=$ comprimento da peça analisada.

Isolando-se $\alpha$ da Equação 4 e exprimindo em termos de decibéis por metro, se obtém a Equação 5:

$$
\alpha=\frac{20}{d} \log \frac{A}{A_{0}}
$$

No uso dessa expressão a amplitude é dada em unidades relativas que dependem do tipo de equipamento utilizado para a medição (Exemplo: volts).

A atenuação pode ser medida também em termos de $\mathrm{dB}$ perdidos, como é o caso do equipamento utilizado nessa pesquisa. Nesse caso verifica-se a diferença entre a amplitude inicial (em dB) e a amplitude final (em dB).

\subsection{Ensaios destrutivos}

A seguir são comentados os procedimentos adotados nos ensaios destrutivos realizados de umidade, densidade, inchamento e absorção de água, flexão estática e adesão interna. 


\subsubsection{Umidade (EN 322-2000)}

Para a determinação do teor de umidade dos painéis, devem ser deles retirados corpos-de-prova com peso mínimo de $20 \mathrm{~g}$, sendo que a sua forma e dimensões não são padronizados. Estes não devem conter partículas soltas.

Inicialmente os corpos-de-prova devem ser pesados e depois colocados em estufa a uma temperatura de $(103 \pm 2)^{\circ} \mathrm{C}$, até atingirem uma massa constante, ou seja, quando duas pesagens sucessivas, efetuadas com pelo menos 6 horas de intervalo, não diferem mais de $0,1 \%$ em relação a massa do corpo-de-prova.

Depois que os corpos-de-prova forem arrefecidos, aproximadamente à temperatura ambiente, eles devem ser pesados novamente. O teor de umidade $(H)$, dado em porcentagem, é calculado através da Equação (6):

$$
H=\frac{m_{H}-m_{0}}{m_{0}} .100
$$

Onde:

$\mathrm{m}_{\mathrm{H}}=$ massa inicial $(\mathrm{g})$

$\mathrm{m}_{0}=$ massa final $(\mathrm{g})$

\subsubsection{Densidade (EN 323-2000)}

Para a determinação da densidade dos painéis, devem ser deles retirados corpos-de-prova de formato quadrado, com os lados medindo $50 \mathrm{~mm}$ nominais.

Se necessário os corpos-de-prova devem ser condicionados até massa constante a uma umidade relativa de $(65 \pm 5) \%$ e a uma temperatura de $(20 \pm 2)^{\circ} \mathrm{C}$. Considera-se massa constante quando os resultados de duas pesagens sucessivas, efetuadas com pelo menos 24 horas de intervalo, não diferirem mais de $0,1 \%$ em relação à massa do corpo-de-prova.

Os corpos-de-prova devem ser inicialmente pesados e ter sua espessura $t$ medida no ponto de encontro de suas diagonais. Deve-se medir $b_{1}$ e $b_{2}$, em 2 
pontos, paralelamente às bordas do corpo-de-prova, ao longo das linhas que passam pelo centro das bordas opostas como mostra a Figura 7.

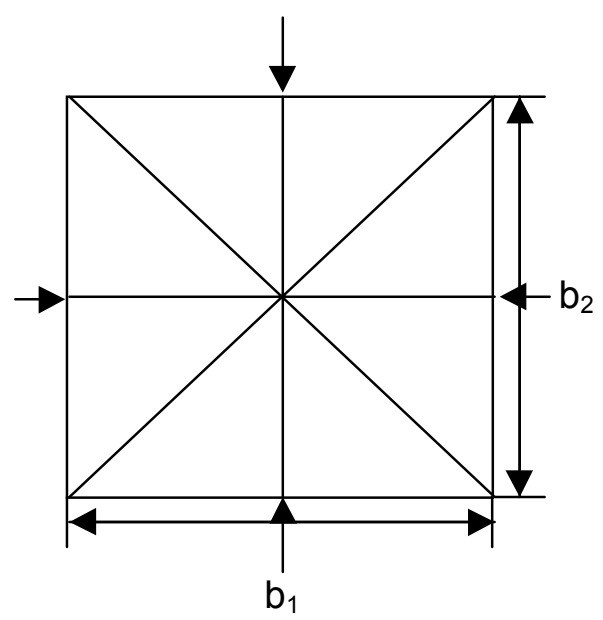

Figura 7: Ponto de medição das espessuras para o ensaio de densidade.

A densidade ( $\rho)$ é calculada através da Equação (7):

$$
\rho=\frac{m}{b_{1} \cdot b_{2} \cdot t} \cdot 10^{6}
$$

Onde:

$\mathrm{m}=\operatorname{massa}(\mathrm{g})$

$\mathrm{t}=\operatorname{espessura}(\mathrm{mm})$

$b_{1}$ e $b_{2}=$ dimensões das bordas $(\mathrm{mm})$

\subsubsection{Inchamento em espessura e absorção de água (EN 317-1993)}

Para a determinação de inchamento em espessura e absorção de água, após a imersão dos painéis em água destilada por $24 \mathrm{~h}$, devem ser retirados corpos-deprova das mesmas de formato quadrado, com $(50 \pm 1) \mathrm{mm}$ de aresta.

Devem ser medidas as espessuras dos corpos-de-prova na intersecção das diagonais antes e após a sua imersão em água limpa, com pH $7 \pm 1$ e temperatura de $20 \pm 1^{\circ} \mathrm{C}$ e estes devem permanecer cobertos por $25 \pm 5 \mathrm{~mm}$ de água durante 24h. O inchamento em espessura $\left(G_{t}\right)$, dado em percentagem, é calculado através da Equação (8): 


$$
G_{t}=\frac{t_{2}-t_{1}}{t_{1}} .100
$$

Onde:

$\mathrm{t}_{1}=$ espessura inicial $(\mathrm{mm})$

$\mathrm{t}_{2}=$ espessura final $(\mathrm{mm})$

No ensaio de absorção de água, deve ser medida a massa do corpo-deprova, antes e após a imersão. A absorção de água $\left(A_{m}\right)$, dada em porcentagem, é calculada através da Equação (9):

$$
A_{m}=\frac{m_{2}-m_{1}}{m_{1}} \cdot 100
$$

Onde:

$\mathrm{m}_{1}=$ massa inicial $(\mathrm{g})$

$\mathrm{m}_{2}=$ massa final $(\mathrm{g})$

\subsubsection{Flexão Estática (EN 310-2000)}

Para a determinação dos módulos de elasticidade $\left(E_{m}\right)$ e de resistência $\left(f_{m}\right)$ à flexão estática dos painéis, dados em MPa, devem ser deles retirados corpos-deprova de formato retangular, com a largura (b) igual a $(50 \pm 1) \mathrm{mm}$. O comprimento $\left(I_{2}\right)$ deve ser igual a 20 vezes a espessura nominal mais $50 \mathrm{~mm}$, com um comprimento máximo de $1050 \mathrm{~mm}$ e um mínimo de 150mm. A espessura deve ser medida no ponto de interseção das diagonais e a largura, na metade do comprimento.

A amostragem e corte dos corpos-de-prova devem ser efetuadas de acordo com as prescrições do documento normativo EN 326-1/1994, sendo necessárias séries de corpos-de-prova nas duas direções, longitudinal e transversal.

Os mesmos devem ser condicionados até a massa constante, sob umidade relativa de $(65 \pm 5) \%$ e uma temperatura de $(20 \pm 2)^{\circ} \mathrm{C}$, sendo que considera-se massa constante quando os resultados de duas pesagens sucessivas, efetuadas 
com pelo menos 24 horas de intervalo, não diferem mais de $0,1 \%$ em relação a massa inicial do corpo-de-prova.

Os corpos-de-prova devem ser biapoiados, a força deve ser aplicada pontualmente no centro do vão e o instrumento utilizado para medir a flecha deve ter precisão de $0,1 \mathrm{~mm}$.

A distância deve ser regulada entre os centros de apoios, de 20 vezes a espessura nominal do painel, sem que ela seja inferior a $100 \mathrm{~mm}$ e superior a 1000mm. A distância entre os centros de apoio, deve ser medida com a aproximação de $0,5 \mathrm{~mm}$.

Os corpos-de-prova devem ser colocados na horizontal, sobre os apoios, com o seu eixo longitudinal perpendicular aos eixos dos apoios com o ponto central sob a força. Aplica-se a força a velocidade constante e regula-se a velocidade do ensaio de modo que a força de ruptura seja atingida em $(60 \pm 30)$ s.

Mede-se a flecha no ponto médio do vão do corpo-de-prova em função das forças correspondentes. Se a flecha for determinada por leituras sucessivas, utilizar pelo menos 6 pares de leitura.

Os ensaios são efetuados sobre dois grupos de corpos-de-prova retirados segundo as duas direções do painel, isto é, segundo a direção longitudinal e a transversal. Em cada grupo, ensaia-se metade dos corpos-de-prova com a face superior para cima, e a outra com a face inferior para cima.

O módulo de elasticidade na flexão estática é calculado através da Equação (10). Para cada grupo de corpos-de-prova, tirados de um mesmo painel, consiste na média aritmética dos módulos de elasticidade na flexão dos corpos-de-prova considerados e deve ser expresso com três números significativos.

$\mathrm{E}_{\mathrm{m}}=\frac{\mathrm{l}_{1}^{3}\left(\mathrm{~F}_{2}-\mathrm{F}_{1}\right)}{4 \mathrm{bt}^{3}\left(\mathrm{a}_{2}-\mathrm{a}_{1}\right)}$

Onde, 
$l_{1}=$ distância entre os centros dos apoios (mm)

$\mathrm{b}=$ largura do corpo-de-prova $(\mathrm{mm})$

$\mathrm{t}=$ espessura do corpo-de-prova $(\mathrm{mm})$

$F_{2}-F_{1}=$ incremento de força, em Newton, na seção retilínea da curva força-flecha, onde $F_{1}$ deve ser cerca de $10 \%$ e $F_{2}$ cerca de $40 \%$ da força de ruptura $a_{2}-a_{1}=$ incremento da flecha correspondente a $F_{2}-F_{1}$

A resistência à flexão de cada corpo-de-prova é calculada pela Equação (11). Para cada grupo de corpos-de-prova retirados do mesmo painel, consiste na média aritmética das resistências à flexão dos corpos-de-prova considerados e é expressa com três algarismos significativos.

$\mathrm{f}_{\mathrm{m}}=\frac{3 \mathrm{~F}_{\max } 1_{1}}{2 \mathrm{bt}^{2}}$

Onde,

$\mathrm{F}_{\max }=$ força de ruptura $(\mathrm{N})$

$l_{1}=$ distância entre os centros dos apoios $(\mathrm{mm})$

$\mathrm{b}=$ largura do corpo-de-prova $(\mathrm{mm})$

$\mathrm{t}=$ espessura do corpo-de-prova $(\mathrm{mm})$

\subsubsection{Tração perpendicular às faces (EN 319-1993)}

Para a determinação da resistência à tração perpendicular às faces dos painéis, ou adesão interna ( $\mathrm{Al})$, devem ser deles retirados corpos-de-prova de formato quadrado, com $(50 \pm 1) \mathrm{mm}$ de aresta.

São colados suportes de metal nas duas faces dos corpos-de-prova, que posteriormente são tracionados em sentidos opostos, de forma que o mesmo se rompa.

A adesão interna é calculada através da Equação (12). 


$$
\mathrm{AI}=\frac{\mathrm{F}_{\max }}{\mathrm{ab}}
$$

Onde,

$\mathrm{F}_{\max }=$ força máxima $(\mathrm{N})$

$\mathrm{a}=$ comprimento do corpo-de-prova $(\mathrm{mm})$

$\mathrm{b}=$ largura do corpo-de-prova $(\mathrm{mm})$

\subsection{Amostragem dos painéis para controle de qualidade em fábrica segundo} os documentos normativos EN 326-1/2000 e EN 326-2/2002

Segundo as recomendações da EN 326-1/1994, o tamanho de uma amostra de painéis depende do propósito da determinação das propriedades dos mesmos e, devido à variedade no painel, e entre painéis, é necessário ensaiar um número de painéis, bem como um número certo de corpos-de-prova, apresentado na Tabela 5, cortados de um painel simples, para obter resultados confiáveis.

Tabela 5 - Número mínimo de corpos-de-prova m a serem ensaiados de cada

\begin{tabular}{ccc} 
& painel & m \\
\hline Propriedade do painel & Norma EN & 4 \\
\hline$H$ & EN 322 & 6 \\
$\rho$ & EN 323 & 6 \\
$E_{m}$ e f & EN 310 & 8 \\
$\mathrm{Al}$ & EN 319 & 8
\end{tabular}

Fonte: Adaptado da EN 326-1/1994.

* Para painéis com propriedades diferentes de acordo com a direção, devem ser utilizados 2 grupos de corpos-de-prova.

Para a retirada dos corpos-de-prova, devem ser seguidos os seguintes passos:

a) O corpo-de-prova poderá ser cortado de painéis individuais nas dimensões especificadas pelas normas dos métodos de ensaio, usando um planejamento de corte adequado para uma seleção não-parcial. No mínimo um corpo-de-prova de 
cada grupo será cortado da borda do painel aparado depois que qualquer perfil ou tratamento de proteção tenha sido removido;

b) Um exemplo de plano de corte para os corpos-de-prova é mostrado na Figura 8. A distância mínima entre dois corpos-de-prova para um mesmo tipo de ensaio deve ser de $100 \mathrm{~mm}$. Este requerimento pode ser omitido se for necessária uma troca de corpo-de-prova.

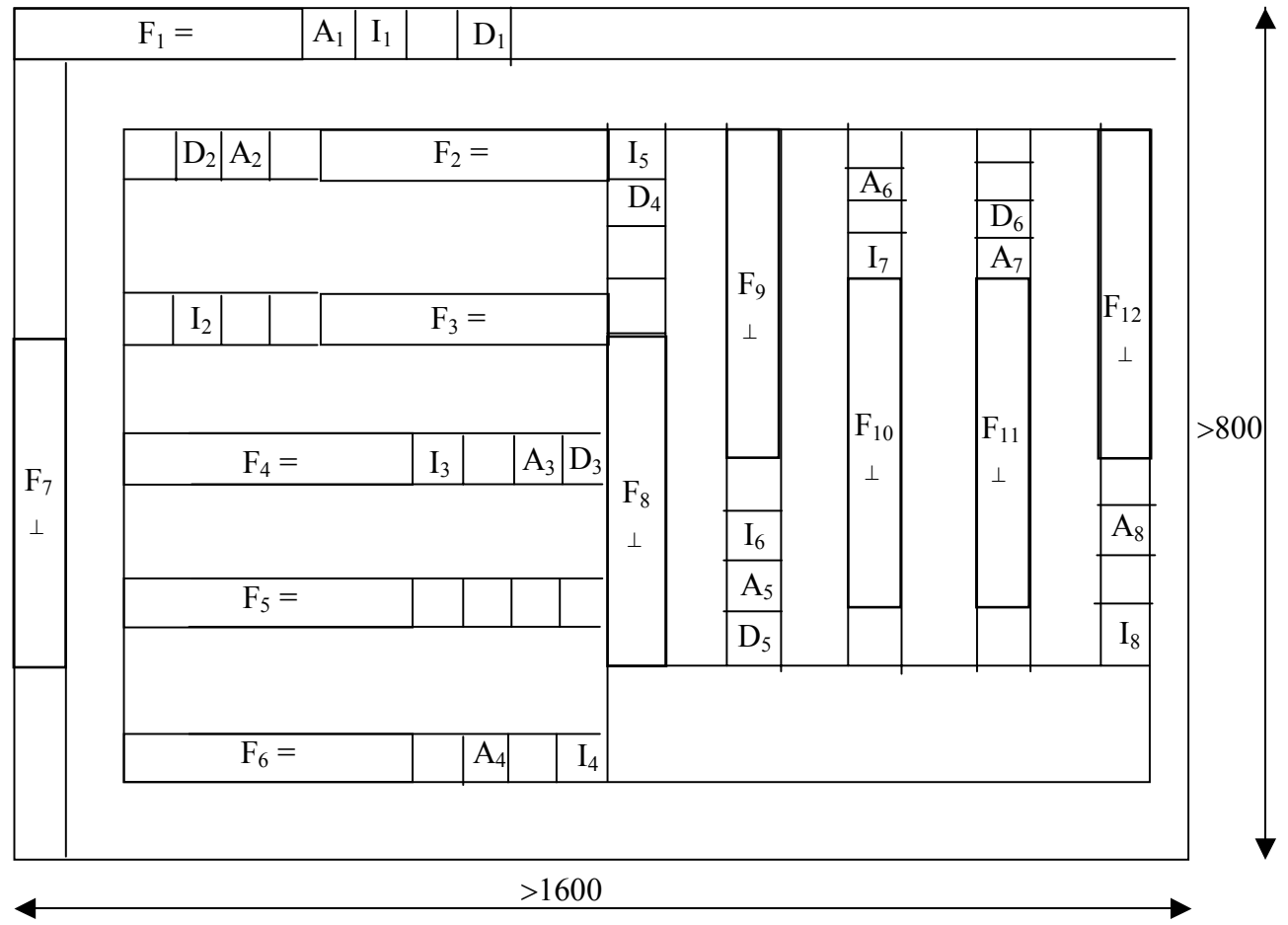

Figura 8: Exemplo de plano de corte de corpos-de-prova segundo a EN 326$1 / 1994$.

c) Para painéis assimétricos em relação ao centro de sua espessura como, por exemplo, o OSB que possui três camadas (camadas ímpares), já que o resultado do ensaio é influenciado pela superfície que é mais espessa quando ensaiada (isto, é na determinação da $f_{m}$ ), serão testados $\mathrm{m} / 2$ corpos-de-prova em cada superfície de orientação. Em todos os outros casos, quando a orientação da superfície do painel é de menor influência sobre a propriedade testada, a posição 
da superfície mais acima ou mais abaixo durante o ensaio deve ser escolhida aleatoriamente.

Quanto à determinação da correlação entre os resultados obtidos com um procedimento alternativo e os obtidos com o procedimento normalizado, deve-se realizar a amostragem aleatória de, pelo menos, 32 painéis do mesmo tipo de produto.

Se o valor calculado do coeficiente de correlação for superior ou igual a 0,70, que equivale a $R^{2}$ igual a 0,49 , a equação de regressão pode ser utilizada para ajustar os resultados do ensaio pelo procedimento alternativo aos obtidos pela aplicação do procedimento normalizado.

\subsection{Ensaios não-destrutivos, stress wave e ultra-som em derivados de madeira}

Tem se relatado o emprego de técnicas não-destrutivas na determinação de propriedades físicas e mecânicas, seja na madeira serrada, em produtos à base de madeira ou em árvores em pé (Bartholomeu, 2001 e Ballarin; Gonçalves, 2001).

Tais técnicas podem ser utilizadas na classificação de lâminas de madeira para painéis LVL, na localização de defeitos, como bolhas ou vazios, em painéis de partículas, MDF, OSB ou compensados (Ross, 1998).

Integrando o efeito do sistema, a eficiência industrial da avaliação com o ultrasom permite uma precisão de mais ou menos 95\%, que é extremamente significante nas técnicas das indústrias à base de madeira, e diretamente aplicável a ela. No eixo longitudinal do produto a ser testado, esse método se mostra uma ferramenta eficiente em qualquer passo do processo de transformação industrial da madeira. 
Estudos têm sido realizados com métodos não-destrutivos do tipo "stress wave" e ultra-som para a caracterização física e mecânica de derivados de madeira, incluindo o OSB. A seguir serão considerados alguns deles e que apresentam dados específicos para a presente pesquisa.

Ross e Pellerin (1988) revelaram em seu estudo que ensaios não-destrutivos com stress wave podem ser utilizados para estimar propriedades de tração, flexão e adesão interna de materiais compostos de madeira. Os resultados de ensaios preliminares indicaram que a velocidade da onda e a atenuação foram propriedades relatadas do material da mesma forma que as suas propriedades mecânicas.

Nesse estudo, os autores utilizaram uma amostra aleatória de 160 corpos-deprova de $0,60 \mathrm{~m} \times 2,40 \mathrm{~m}$ de compósitos de madeira com uma ampla variedade de propriedades mecânicas estáticas e de muitos produtores norte-americanos de painéis, que incluíam vários tipos de adesivos, formulações e níveis, espécies de madeiras e muitas geometrias de partículas.

O stress wave foi utilizado em cada corpo-de-prova, a $6 \%$ de umidade, e as dimensões eram de $15 \mathrm{~cm} \times 2,40 \mathrm{~m}$ para os ensaios de tração e flexão, e os ensaios destrutivos foram conduzidos de acordo com as recomendações da ASTM 1037-96.

Foram utilizadas regressões lineares em uma variável e multivariáveis para analisar a correlação entre os parâmetros não-destrutivos medidos, que incluíam densidade, velocidade de propagação da onda, módulo de elasticidade dinâmico e atenuação, e as propriedades de tração, flexão e adesão interna.

A equação de regressão utilizada nesta análise foi assumida na forma seguinte (Equação (13)):

$$
P=K N_{0}{ }^{x} N_{1}^{y} N_{2}^{z}
$$

Onde,

$\mathrm{P}=$ propriedade a ser estimada

$\mathrm{K}, \mathrm{x}, \mathrm{y}$ e $\mathrm{z}=$ constantes empíricas 
$\mathrm{N}_{0}, \mathrm{~N}_{1}$ e $\mathrm{N}_{2}=$ parâmetros não-destrutivos

Os parâmetros não-destrutivos incluídos foram a densidade, a velocidade de propagação da onda, a constante dinâmica e atenuação.

Foi utilizada análise de regressão linear dos dados que foram usados para determinar valores para $\mathrm{K}, \mathrm{x}, \mathrm{y}, \mathrm{z}$ e para o ajuste da regressão, linearizou-se a Equação (14) através da transformação In:

$\ln (\mathrm{P})=\ln (\mathrm{K})+\mathrm{x} \ln \left(\mathrm{N}_{0}\right)+y \ln \left(\mathrm{N}_{1}\right)+\mathrm{z} \ln \left(\mathrm{N}_{2}\right)$

Os valores obtidos na análise da regressão linear revelaram que a constante dinâmica foi melhor estimadora da resistência à tração perpendicular às faces e do módulo de ruptura na flexão estática do que a velocidade ao quadrado. Como a constante dinâmica é dada em função da densidade e da velocidade ao quadrado, mostraram que, apesar de a densidade ter sido uma estimadora pobre em comparação com as demais propriedades, ela teve efeito interativo que contribuiu significativamente quando utilizada em conjunto com a velocidade ao quadrado.

A velocidade de propagação da onda foi mais alta através dos corpos-deprova mais resistentes enquanto que a atenuação foi maior para os menos resistentes. Os valores de adesão interna foram menores nos corpos-de-prova menos resistentes e para essa propriedade mecânica foi melhor o modelo de análise multivariada, por que nesse se levou em conta os valores da atenuação além da constante dinâmica.

Os modelos de regressão desenvolvidos expressaram $94 \%$ do comportamento elástico observado e acima de $90 \%$ das resistências na tração e flexão. Foram encontradas também fortes correlações com propriedades de adesão interna, sendo que nas chapas onde a colagem era mais fraca, a atenuação se correlacionou mais efetivamente com essa propriedade mecânica. 
Vun et al (2000) estudaram painéis OSB, com 44 corpos-de-prova de camada simples $(609,6$ x 711,2 x 12,7)mm e 32 corpos-de-prova de camada tripla $(609,6$ x $609,6 \times 12,7) \mathrm{mm}$, com $0,5 \%$ de cera e ambas com $4 \%$ ou $6 \%$ de conteúdo de resina, através da espessura, com sistemas ultra-sônicos de contato direto e de não-contato.

Os aparelhos utilizados para estes sistemas foram, respectivamente, o Panametrics 5058 Pulser/Receiver, com a freqüência dos transdutores de $100 \mathrm{kHz}$ e o Second Wave Model NCA $1000-2 E$, com transdutores de freqüência $250 \mathrm{kHz}$ e com alta transmissão piezoelétrica sem contato, modelo NCT 102.

Encontraram nas chapas OSB de uma camada com densidade próxima a $600 \mathrm{~kg} / \mathrm{m}^{3}$, com o método de ultra-som (contato direto) valores de velocidades próximos a $700 \mathrm{~m} / \mathrm{s}$ e (sem contato) valores de atenuação próximos a $75 \mathrm{~d} \beta$. Correlacionaram os resultados de tais ensaios com valores dos módulos de elasticidade e resistência na flexão e também à adesão interna, obtidos através de ensaios destrutivos conduzidos de acordo com a ASTM D1037.

A velocidade de transmissão da onda ultra-sônica e os dados de atenuação foram ajustados através de um polinômio com termos linear (Equação (15)), quadrático e cúbico em relação à densidade, usando o SAS (Statistical Analysis System), cujo modelo tem a forma geral:

$$
Y=A+B \rho+C \rho^{2}+D \rho^{3}
$$

Onde $Y$ é a propriedade a ser investigada e A, B, C e D são as constantes de regressão.

Nesse estudo os autores chegaram às seguintes conclusões: a velocidade e a atenuação correlacionam-se não-linearmente com a densidade; os melhores modelos de propriedades de velocidade de onda ultrasônica foram para chapas com $4 \%$ de resina; devido ao nível de alinhamento das partículas, estas podem ser 
melhor caracterizadas através da atenuação do que da velocidade de propagação de ondas; os módulos de elasticidade e de resistência na flexão correlacionaram-se linearmente à velocidade de propagação das ondas; a correlação entre a densidade do painel e a velocidade de propagação de ondas provê um meio para determinar a variação da densidade do painel utilizando técnicas baseadas em ultra-som e ambos métodos, de contato direto e contato não-direto, mostraram-se técnicas promissoras para a caracterização interna do OSB.

Bektha, Niemz e Kucera (2000) utilizaram a freqüência de ressonância e velocidade da propagação de ondas, dois métodos de caracterização nãodestrutiva, em chapas de partículas, MDF e OSB de produção industrial, de 16, 17 e $18 \mathrm{~mm}$ de espessura, respectivamente, nas direções paralela e perpendicular à direção da produção da chapa, sendo que a velocidade do som foi medida também através da espessura da chapa.

Foram utilizados transdutores de freqüências 50,100 e $200 \mathrm{kHz}$ e os aparelhos Steinkamp/Bremen (Germany), system BP5 e Card PCUS 10 NF, de Fraunhofer Institute for Nondestructive Evaluations Methods, Saarbrücken (Germany) com sensores de Krautkrämer, tipo K0,1G (cilíndrico, diâmetro de $44,5 \mathrm{~mm})$.

Os resultados obtidos desses ensaios foram comparados às características elásticas e mecânicas obtidas nos ensaios estáticos destrutivos conduzidos de acordo com as recomendações dos documentos normativos DIN 52182, 52183 e 51286, para os cálculos respectivamente, de densidade, conteúdo de umidade e módulos de resistência e de elasticidade na flexão estática.

Nos painéis de partículas foram estudadas as variáveis: largura do corpo-deprova (20 a 200)mm, espessura do corpo-de-prova (16 a 96) $\mathrm{mm}$ e sete tipos de diferentes densidades e espessuras. 
Foram utilizados 50 corpos-de-prova nas dimensões 50 x 400mm, ambos nas direções paralela e perpendicular à direção de produção, já que as propriedades elásticas diferem nessas duas direções, 10 corpos-de-prova $(500 \times 50 \times 14) \mathrm{mm}$ a $8 \%$ de umidade a 6 temperaturas diferentes $(-30 \text { a }+70)^{\circ} \mathrm{C}$ e 10 corpos-de-prova (500x50x14)mm a $20^{\circ} \mathrm{C}$ a 5 níveis diferentes de umidade relativa (50 a 90\%).

Foi utilizada regressão linear para analisar relações entre a velocidade de propagação de ondas, freqüência e módulos de resistência e de elasticidade na flexão estática, bem como entre a constante dinâmica.

Encontraram as seguintes faixas de velocidades em relação à direção de propagação das ondas:

- Direção paralela: 2271 a 3294 m/s;

- Direção perpendicular: 2118 a $2991 \mathrm{~m} / \mathrm{s}$.

Os valores das velocidades de propagação das ondas foram menores ao longo da direção perpendicular do que os valores correspondentes na direção longitudinal para o MDF, OSB e chapas de partículas, indicando as propriedades anisotrópicas dos produtos. Para o MDF as diferenças foram menos significativas, indicando propriedades mais uniformes entre as duas direções principais.

Entre os produtos ensaiados, o OSB teve a velocidade das ondas mais alta a um dado nível de freqüência. A uma freqüência de $50 \mathrm{kHz}$, a velocidade média foi de cerca de $3294 \mathrm{~m} / \mathrm{s}$ (paralela) e de $2271 \mathrm{~m} / \mathrm{s}$ (perpendicular). Através da espessura, as velocidades do som não variaram.

Para o OSB, a melhor correlação foi encontrada na direção longitudinal, entre o módulo de elasticidade na flexão estática e a freqüência de ressonância $\left(R^{2}=\right.$ 0,53) bem como entre o módulo de elasticidade na flexão estática e constante dinâmica em relação a freqüência de ressonância $\left(R^{2}=0,64\right)$. A estimativa do módulo de resistência para as chapas de partículas e OSB tanto para a velocidade 
de propagação de ondas e para as freqüências de ressonância com regressão simples deram pouco significativos estatisticamente.

Concluíram que a velocidade de propagação de ondas, em geral, diminui com o aumento da espessura e da largura do corpo-de-prova; o aumento da umidade relativa do ar (50 a 90$) \%$ e temperatura $\left(-35^{\circ} \text { a }+70\right)^{\circ} \mathrm{C}$ ocasionam o decréscimo da velocidade de propagação de ondas e a medição em sete tipos diferentes de chapas de partículas (em densidade e espessura) mostrou diferenças de velocidade de propagação de ondas para todos os tipos de chapas.

Com o aumento da freqüência a velocidade do som também aumentou, mas para o OSB não foi possível mostrar uma diferença clara de maiores freqüências (100kHz e $200 \mathrm{kHz})$. Dentre as freqüências estudadas só a menor, de $50 \mathrm{kHz}$, foi capaz de penetrar o OSB. A espessura da chapa e a largura do corpo-de-prova não afetam a velocidade de propagação de onda abaixo de uma freqüência de $50 \mathrm{kHz}$.

No Brasil, o estudo da caracterização da madeira utilizando métodos nãodestrutivos do tipo "stress wave" e ultra-som tem sido expandido, mas com relação aos derivados de madeira ainda é recente.

Matos (1997) avaliou a viabilidade de utilização de lâminas de Pinus taeda para a produção de painéis estruturais de lâminas paralelas (LVL), através da classificação preliminar das lâminas em classes de resistência, utilizando método não-destrutivo de "stress wave", pela aplicação de ondas acústicas através do aparelho Timer METRIGUARD, modelo 239 A. Uma de suas conclusões foi de que a classificação proposta das lâminas em classes de qualidade, pela determinação do módulo de elasticidade dinâmico, baseada nesse método, mostrou-se altamente eficaz para as lâminas de Pinus taeda testadas.

Matos et al (2000) realizaram estudos de avaliação não-destrutiva de propriedades mecânicas de painéis compensados multilaminados, em diferentes espessuras, obtidos a partir de lâminas de Pinus spp, utilizando o método de "stress 
wave", através do aparelho Timer METRIGUARD, modelo 239 A, estabelecendo relação com as técnicas de avaliação convencionais destrutivas.

Concluíram que o uso desta técnica mostra-se viável e adequado para os compensados, tendo obtido bons índices de correlação entre o módulo de elasticidade na flexão estática obtido na técnica convencional destrutiva e a constante dinâmica, permitindo a classificação de painéis por sua qualidade ou a predição dos seus valores de resistência mecânica através de modelos matemáticos.

Mendes et al (2002) realizaram estudos de avaliação não-destrutiva de propriedades mecânicas de 39 painéis OSB produzidos com seis espécies de Pinus spp e mistura entre elas, com e sem parafina, através do método de "Stress Wave", utilizando o aparelho Timer METRIGUARD, modelo 239 A, onde estabeleceram relação entre os resultados obtidos nesses ensaios e os obtidos com as técnicas de avaliação convencionais.

Encontraram baixos coeficientes de correlação entre os valores do módulo de elasticidade na flexão estática obtidos nesses dois tipos de avaliação, mas encorajaram mais pesquisa neste tema com painéis OSB, visto que alguns trabalhos demonstraram que esta técnica é viável quando aplicada em outros tipos de painéis de madeira como, por exemplo, compensados convencionais e LVL.

Silva (2003) estudou chapas MDF produzidas com Pinus spp e Eucalipto spp no Laboratório Piloto da Empresa Duratex, sob seis condições experimentais, com variações de adesivo, pressão, temperatura, espessura, umidade e densidade das fibras de madeira e utilização de adesivo poliuretano à base de óleo de mamona.

Realizou a caracterização física e mecânica das mesmas também através do método não-destrutivo de ultra-som, utilizando o aparelho Steikamp, modelo BP-7, com transdutores exponenciais de $45 \mathrm{kHz}$, para a propagação de ondas de compressão, através do comprimento das chapas de $40 \times 40 \mathrm{~cm}$; com transdutores 
planos, para a aplicação de ondas de superfície e com transdutores planos posicionados na espessura das chapas, gerando ondas de compressão.

Obteve correlações significativas entre a velocidade e o módulo de elasticidade na flexão estática $\left(R^{2}=96,98\right.$ e $\left.95 \%\right)$ com os transdutores planos aplicando ondas de superfície e, assim, a indicação da possibilidade da utilização da velocidade de propagação de ondas de compressão para a estimativa do módulo de resistência na flexão estática de chapas MDF, o que ocorreu também com os transdutores exponenciais e com as correlações entre a constante dinâmica e o módulo de elasticidade estático com estes dois tipos de transdutores $\left(R^{2}\right.$ maiores do que 0,94$)$. Os dados obtidos foram processados através do MINITAB.

\subsection{Comentários sobre a revisão bibliográfica apresentada}

Nas referências bibliográficas até aqui consultadas, não se localizou qualquer trabalho que aborde, de modo conclusivo, a adequação do emprego de técnicas não-destrutivas, como a de ultra-som e de stress wave, para a estimativa de propriedades de produtos derivados da madeira, em particular do OSB, principalmente quando analisadas as medições em painéis comerciais e inteiros.

Em conformidade com o objetivo proposto de se investigar a eficiência de técnicas não-destrutivas de ensaio (stress wave e ultra-som) na estimativa de parâmetros físicos e mecânicos de painéis OSB comerciais, vê-se que a literatura reforça a originalidade do tema investigado no trabalho. 


\section{Papitulo 4 - Chateriais e CKétodos}

\subsection{Generalidades}

O desenvolvimento deste trabalho se deu em três etapas:

1) Ensaios preliminares: nesta fase foram realizados ensaios exploratórios, utilizando a técnica de ultra-som, para avaliação preliminar da propagação das ondas através de painéis OSB/3. Foram empregados dois painéis de espessura nominal $15 \mathrm{~mm}$. Buscou-se, com tal procedimento, verificar a possibilidade de serem correlacionados os valores de velocidades obtidos através deste método e os valores obtidos nos ensaios físico-mecânicos.

2) Ensaios principais - primeira etapa: como não se obtiveram correlações entre os resultados dos ensaios destrutivos e não-destrutivos na fase preliminar, na primeira etapa dos ensaios principais, buscou-se investigar a existência, ou não, dessa correlação ao se estudarem painéis $\mathrm{OSB} / 3$ de três espessuras diferentes (6, 15 e 25mm), utilizando-se medições realizadas pelas técnicas de ultra-som e "stress wave".

3) Ensaios principais - segunda etapa: nesta etapa o objetivo foi verificar a existência de correlações entre os resultados dos ensaios destrutivos e nãodestrutivos, pelos métodos de ultra-som e stress wave, entre dois grupos contendo dez painéis $\mathrm{OSB} / 3$ de espessura $15 \mathrm{~mm}$ e que apresentaram valores discrepantes em propriedades da flexão estática, não-equivalentes estatisticamente nessa propriedade, e respectivos valores de velocidade e constantes dinâmicas. 
A segunda etapa dos ensaios principais foi planejada por que, embora algumas correlações hajam sido obtidas nos ensaios principais (primeira etapa), para painéis de espessuras diferentes, os valores de propriedades físico-mecânicas apresentaram baixa variabilidade. Por outro lado, se detectou, com o método de stress wave, uma diferenciação entre valores de velocidades de propagação de ondas de painéis que apresentaram valores diferentes de módulos de elasticidade e de resistência na flexão estática, em uma dada direção dos painéis.

Para as três etapas do trabalho, primeiramente foram realizados os ensaios não-destrutivos nos painéis OSB.

Em seguida, em corpos-de-prova retirados dos mencionados painéis, foram realizados ensaios destrutivos para a determinação do inchamento, da absorção de água, do teor de umidade, da densidade, da resistência à tração perpendicular às faces e dos módulos de resistência e de elasticidade na flexão estática, conduzidos de acordo com as recomendações das EN 317, 322, 323, 319 e 310, respectivamente.

A adoção dos documentos normativos europeus se justifica pelo fato de não estarem, ainda, disponíveis os métodos brasileiros específicos para esta categoria de painel.

A partir dos ensaios destrutivos foram determinados os valores dos parâmetros físico-mecânicos, para subseqüentes comparações com os obtidos nos ensaios não-destrutivos.

A seguir estão descritos, de uma maneira mais detalhada, os materiais, equipamentos e metodologia utilizados em cada uma destas três etapas.

\subsubsection{Ensaios preliminares}

Os painéis ensaiados foram fabricados pela MASISA do Brasil. Foi escolhido o painel MASISA OSB Home, certificado pela TECO (Timber Company), por 
apresentar valores mais elevados para as propriedades físico-mecânicas, bem como por ser indicado para uso na construção de edificações.

Dentre os diversos parâmetros para escolha dos painéis, optou-se por fixar, inicialmente, a espessura de $15 \mathrm{~mm}$, por ser este um dos painéis mais comercializados e por apresentar valor intermediário de espessura. Foram utilizados dois painéis $\mathrm{OSB} / 3$, cujos requisitos para as propriedades mecânicas e de inchamento estão na Tabela 3.

Os painéis estudados são constituídos de três camadas, sendo as externas com as partículas longas e orientadas (strands) paralelas entre si, na direção do comprimento do painel, e a camada interior com os strands dispostos na direção perpendicular aos das camadas externas. A proporção face-miolo-face destes painéis é de 1:2:1.

Nos ensaios de flexão estática para a determinação dos módulos de elasticidade e de resistência, consideram-se duas situações para os painéis OSB:

a) Direção longitudinal: Direção onde as partículas das camadas exteriores estão dispostas longitudinalmente em relação ao comprimento do painel.

b) Direção transversal: Direção perpendicular à direção longitudinal.

Primeiramente os painéis foram demarcados em suas larguras e comprimentos, de 50 em $50 \mathrm{~mm}$. Nestas posições foram feitas medições com o aparelho de ultra-som (Figuras 9, 10(a) e (b)).

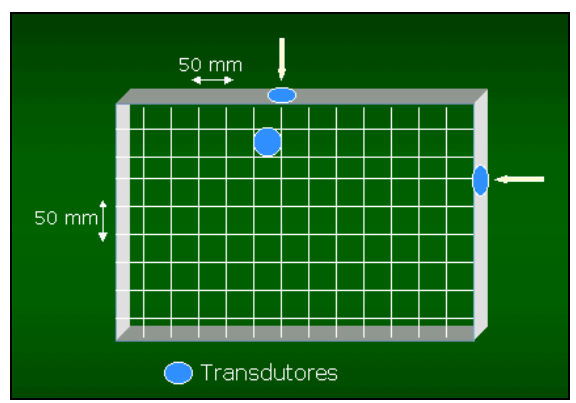

Figura 9 - Esquema da medição do tempo de propagação das ondas utilizando aparelho de ultra-som. 


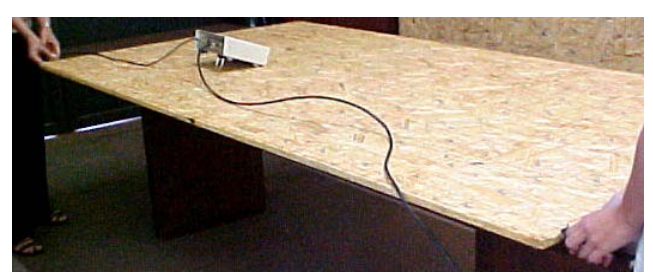

(a)

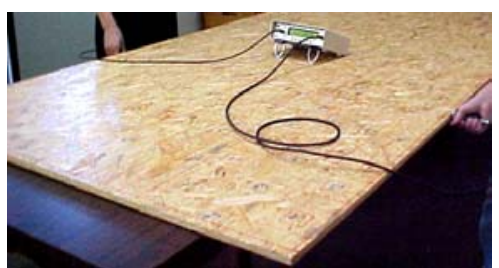

(b)

Figura 10 - Medições de tempo de propagação com o aparelho de ultra-som: (a) Direção longitudinal do painel e (b) Direção transversal do painel.

O equipamento de ultra-som utilizado foi o STEINKAMP (Figura 11), modelo BP-7, com transdutores planos, de freqüência $45 \mathrm{kHz}$ e gel medicinal como acoplante. Este aparelho pertence ao Laboratório de Acustoelástica, da Faculdade de Engenharia Agrícola (FEAGRI), da Universidade Estadual de Campinas (UNICAMP), local onde esta etapa de ensaios foi conduzida.

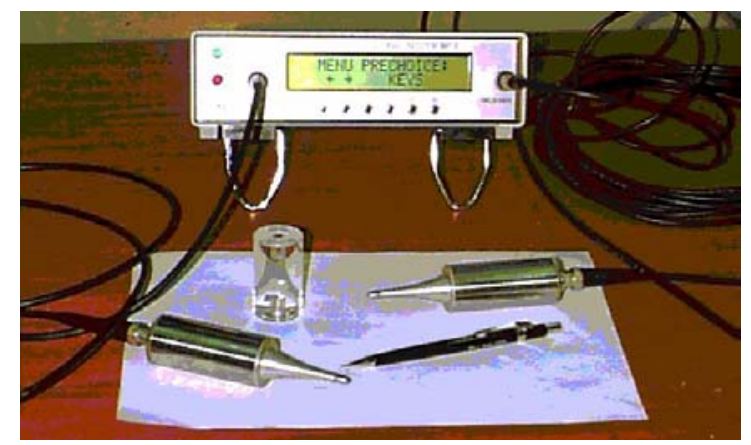

Figura 11 - Equipamento de ultra-som STEINKAMP, modelo BP-7.

Depois, foi esquematizado o maior número de corpos-de-prova possível por painel, seguindo as prescrições da EN 326-1/ 1994 e o esquema da Figura 8, resumidas na Tabela 6.

Tabela 6 - Número mínimo de corpos-de-prova m a serem ensaiados de cada painel e número de corpos-de-prova $\mathrm{m}_{\mathrm{u}}$ ensaiados em cada painel

\begin{tabular}{cccc}
\hline Propriedade do painel & Norma EM & $\mathbf{m}$ & $\mathbf{m}_{\mathbf{u}}$ \\
\hline $\mathrm{H}$ & EN 322 & 4 & 8 \\
$\rho$ & EN 323 & 6 & 12 \\
$\mathrm{E}_{\mathrm{m}} \mathrm{ef}_{\mathrm{m}}$ & EN 310 & 6 & 12 \\
$\mathrm{Al}$ & EN 319 & 8 & 16 \\
$\mathrm{G}_{\mathrm{t}}$ & EN 317 & 8 & 16
\end{tabular}

* Para painéis com propriedades diferentes, de acordo com a direção, devem ser utilizados 2 grupos de m corpos-de-prova.

Fonte: Adaptado da EN 326-1 (1994). 
Também foram feitas medições do tempo de propagação de ondas na espessura dos painéis, nos locais correspondentes aos corpos-de-prova de tração perpendicular às faces, densidade, inchamento e absorção de água, para posterior correlação dos valores de velocidades e de constantes dinâmicas calculados com os obtidos nos ensaios destrutivos correspondentes, como pode ser visto na Figura 12.

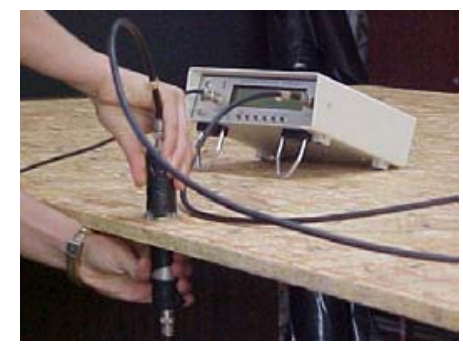

Figura 12 - Medições de tempo na espessura do painel.

Em prosseguimento, foram realizados os ensaios físico-mecânicos dos painéis na máquina universal de ensaios Dartec, no Laboratório de Madeiras e de Estruturas de Madeira (LaMEM), do Departamento de Engenharia de Estruturas (SET), da Escola de Engenharia de São Carlos (EESC), da Universidade de São Paulo (USP), Campus de São Carlos.

As Figuras 13(a) e 13(b) mostram, respectivamente, exemplos dos ensaios realizados de flexão estática e de tração perpendicular às faces.
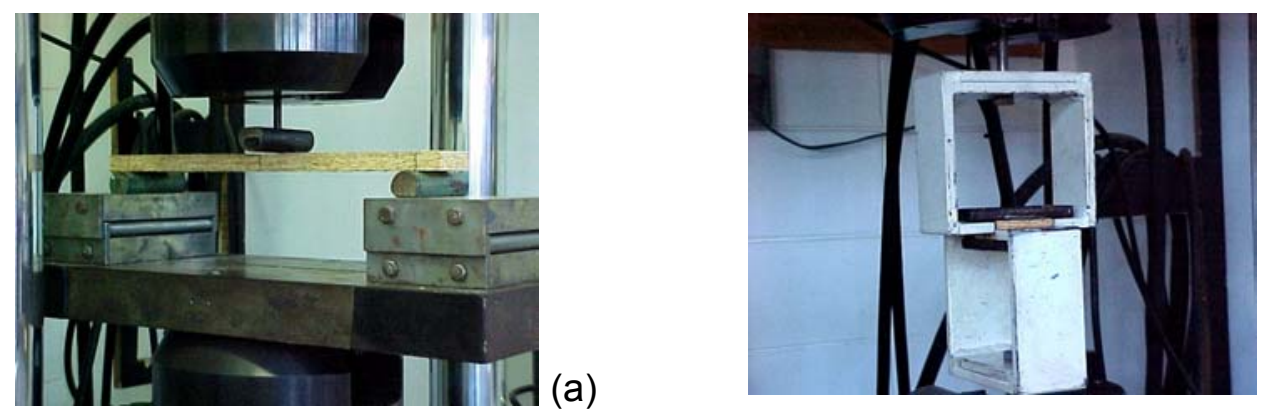

Figura 13 - Exemplos de ensaios mecânicos nos painéis OSB: (a) Flexão estática e (b) Tração perpendicular às faces.

A princípio, objetivava-se obter modelos de regressão e correlações entre os valores obtidos por meio dos métodos de ensaios destrutivos e não-destrutivos. 
Como analisado posteriormente, na discussão dos resultados, no item 6.1, os coeficientes de correlação obtidos em ambos os métodos, destrutivo convencional e de ultra-som, mostram a homogeneidade dos painéis OSB. Devido a essa homogeneidade os intervalos de variação dessas propriedades não permitiram a obtenção de modelos de correlações entre os valores obtidos por meio desses dois métodos de ensaios.

Para investigação mais detalhada a respeito das eventuais correlações, fez-se necessário planejamento que permitisse suficiente variabilidade de propriedades dos painéis, como por exemplo, no estudo de painéis OSB de diferentes valores nominais de espessuras, o que se tornou o objeto dos ensaios principais - primeira etapa.

\subsubsection{Ensaios Principais - primeira etapa}

A partir dos resultados dos ensaios preliminares e obtidas indicações para o prosseguimento do trabalho, foram realizados novos ensaios com a utilização dos métodos não-destrutivos de ultra-som e stress wave, em painéis de espessuras nominais diferentes.

Foram ensaiados painéis OSB/3, fabricados pela MASISA do Brasil: um de espessura 6mm; dois de espessura 15mm, denotados por 15(1) e 15(2), e um de espessura $25 \mathrm{~mm}$.

Os referidos painéis são constituídos de três camadas, sendo as externas com os strands paralelos entre si, na direção do comprimento do painel, e a camada interior com os strands dispostos na direção perpendicular aos das camadas externas. A proporção face-miolo-face destes painéis é de 1:2:1.

Inicialmente os painéis foram demarcados em suas larguras e comprimentos, de 50 em $50 \mathrm{~mm}$ e foi esquematizado o maior número possível de corpos-de-prova (Figura 9) para os ensaios físico-mecânicos posteriores, por painel, seguindo as 
prescrições da EN 326-1/ 1994. Adotou-se o critério de ter no mínimo 30 corpos-deprova em cada tipo de ensaio, para se obter grandes amostras, como mostram as Figuras 14 (a), (b) e (c), em representações dos painéis seccionados, que estão apresentados de maneira completa no Apêndice A.
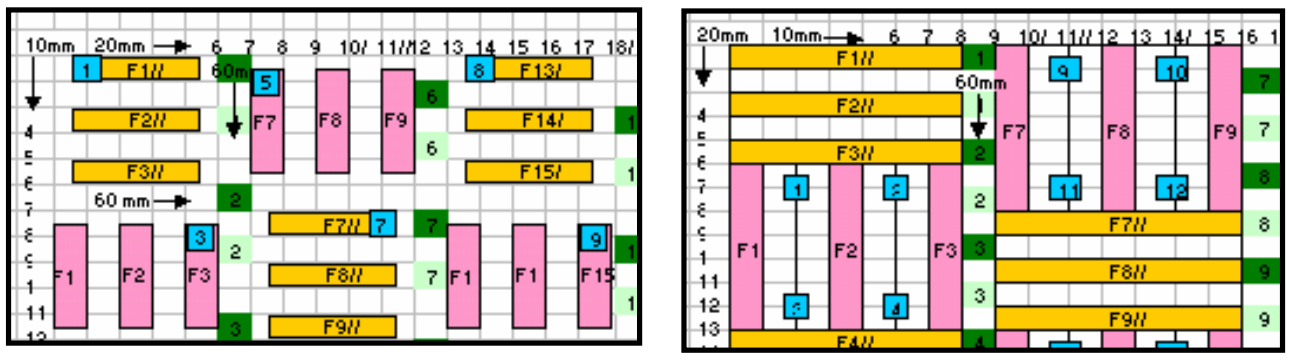

(a)

(b)

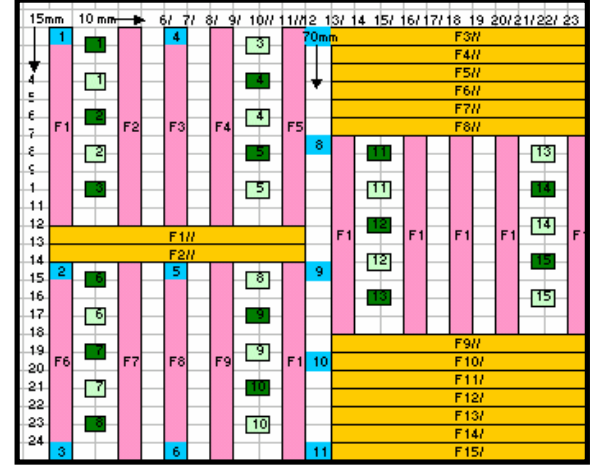

(c)

Figura 14 - Esquema de plano de corte para os painéis OSB. (a) Espessura $6 \mathrm{~mm}$, (b) Espessura $15 \mathrm{~mm}$ e (c) Espessura $25 \mathrm{~mm}$.

Posteriormente foram conduzidos ensaios não-destrutivos com o equipamento de ultra-som nos painéis de $6 \mathrm{~mm}, 15 \mathrm{~mm}(1)$ e $25 \mathrm{~mm}$, no Laboratório de Acustoelástica, da Faculdade de Engenharia Agrícola (FEAGRI), da Universidade Estadual de Campinas (UNICAMP). O aparelho utilizado foi o STEINKAMP, modelo BP-7, com transdutores planos de freqüência $45 \mathrm{kHz}$, com gel medicinal como acoplante, pertencentes a esse laboratório.

Procedeu-se à medição do tempo de propagação da onda ao longo dos painéis para a determinação dos valores das velocidades e constantes dinâmicas, e subseqüentes correlações com os valores dos módulos de elasticidade e de resistência na flexão estática, Figuras 10 (a) e (b). Também foi medido o tempo de 
propagação da onda na espessura dos dois últimos painéis (Figura 12), nos locais correspondentes aos corpos-de-prova de tração perpendicular às faces, densidade, inchamento e absorção de água, para posterior correlação com os valores obtidos nos ensaios destrutivos correspondentes.

As medições na espessura não foram realizadas no painel de $6 \mathrm{~mm}$ por não haver transdutores de maiores freqüências disponíveis, mais adequadas a essa espessura. Não foram realizadas medições ao longo do painel de espessura $15(2) \mathrm{mm}$.

$\mathrm{Na}$ continuação, foram realizados os ensaios não-destrutivos utilizando equipamento de stress wave (Figura 15) ao longo do painel de espessura 15(2)mm e nos corpos-de-prova de flexão estática longitudinal e transversal dos painéis de espessura $6 \mathrm{~mm}, 15(1) \mathrm{mm}$ e (2) e $25 \mathrm{~mm}$ (Figura 16). Tais ensaios foram realizados, depois que os corpos-de-prova foram usinados, no Laboratório de Ensaio de Materiais (LEM), do Departamento de Engenharia Rural, na Faculdade de Ciências Agrícolas (FCA), da Universidade Estadual Paulista (UNESP), Campus de Botucatu, instituição a qual o aparelho pertence.
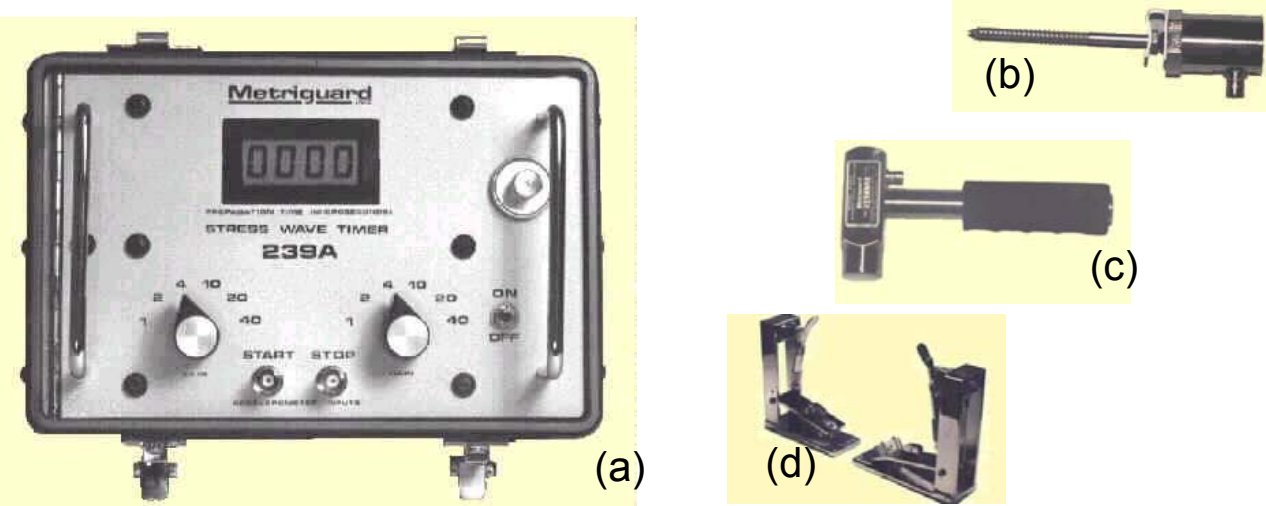

Figura 15 - (a) Aparelho Stress Wave Timer, modelo 239 A - METRIGUARD e seus acessórios: (b) acelerômetro (madeira), (c) martelo de impacto (madeira) e (d) conjunto de presilhas (derivados de madeira). Fonte: http://www.metriguard.com/239A.HTM.

Em prosseguimento, foram realizados os ensaios para a obtenção dos valores dos módulos de elasticidade e de resistência na flexão estática, Figura 13 (a), de resistência à tração perpendicular às faces, Figura 13 (b), densidade, 
inchamento e absorção de água, no Laboratório de Madeiras e de Estruturas de Madeiras (LaMEM), do SET-EESC-USP. Os ensaios mecânicos foram realizados na máquina universal de ensaios Dartec.

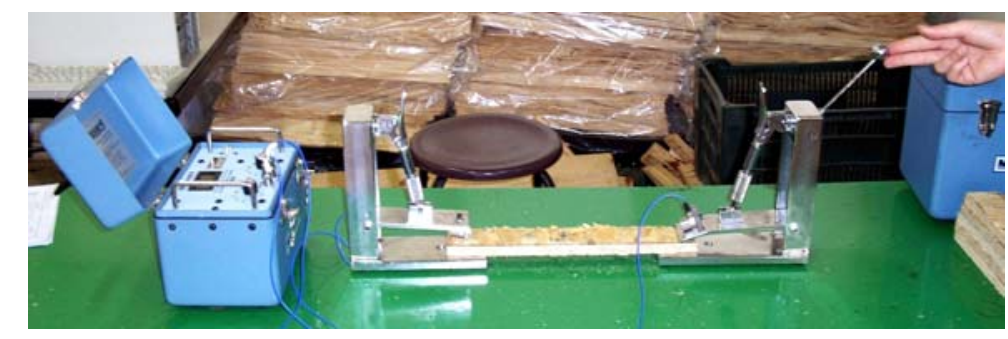

Figura 16 - Exemplo de posicionamento dos transdutores do aparelho stress wave para a medição do tempo no painel OSB e nos corpos-de-prova.

Os resultados foram analisados estatisticamente através de gráficos, valores de coeficientes de correlações, cálculos de médias, desvios padrão e coeficientes de variação, pelos métodos de Kolmogorov-Smirnov, Barttlet e Análise de Variância, pelos programas MINITAB, versão 13 e EXCEL, 2003.

\subsubsection{Ensaios Principais - segunda etapa}

A partir dos resultados obtidos nos ensaios principais - primeira etapa, e obtidas indicações para a continuidade do trabalho, foram realizados novos ensaios com a utilização dos métodos não-destrutivos de ultra-som e stress wave, em painéis de espessuras nominais de $15 \mathrm{~mm}$, pertencentes a dois grupos (1 - maiores valores de resistência e de módulos de elasticidade na flexão estática, e 2 - menores valores).

Todos os painéis utilizados foram fabricados pela MASISA do Brasil, sendo 11 deles por ela cedidos e os outros 11 comprados. Foram analisados 10 painéis OSB/3 de cada um desses níveis, previamente caracterizados por amostragem.

Tais painéis são constituídos de três camadas, sendo as externas com as partículas longas e orientadas paralelas entre si, na direção do comprimento do 
painel, e a camada interior com os strands dispostos na direção perpendicular aos das camadas externas. A proporção face-miolo-face destes painéis é de 1:2:1.

Como nas outras etapas, os painéis foram demarcados em suas larguras e comprimentos, de 50 em 50mm (Figura 9), e foi esquematizado o maior número possível de corpos-de-prova para os ensaios físico-mecânicos posteriores, por painel, seguindo as prescrições da EN 326-1/1994 (Apêndice A).

Foram realizados os ensaios não-destrutivos com o equipamento de ultra-som nos painéis inteiros, na espessura, nas posições correspondentes aos corpos-deprova de densidade, tração perpendicular às faces, inchamento e absorção de água, com o aparelho Panametrics, modelo EPOCH 4, Figura 17 (a), do Laboratório de Acustoelástica, da Faculdade de Engenharia Agrícola (FEAGRI), da Universidade Estadual de Campinas (UNICAMP).

Os painéis foram colocados em pé com o auxílio de dois cavaletes móveis para eliminar problemas de interferências na propagação das ondas, Figura 17 (b). Os transdutores utilizados foram planos, de freqüência $80 \mathrm{kHz}$, com gel medicinal como acoplante. Além dos valores de velocidade e de constantes dinâmicas, foi calculada também a atenuação (Atn) em cada ponto de medição.
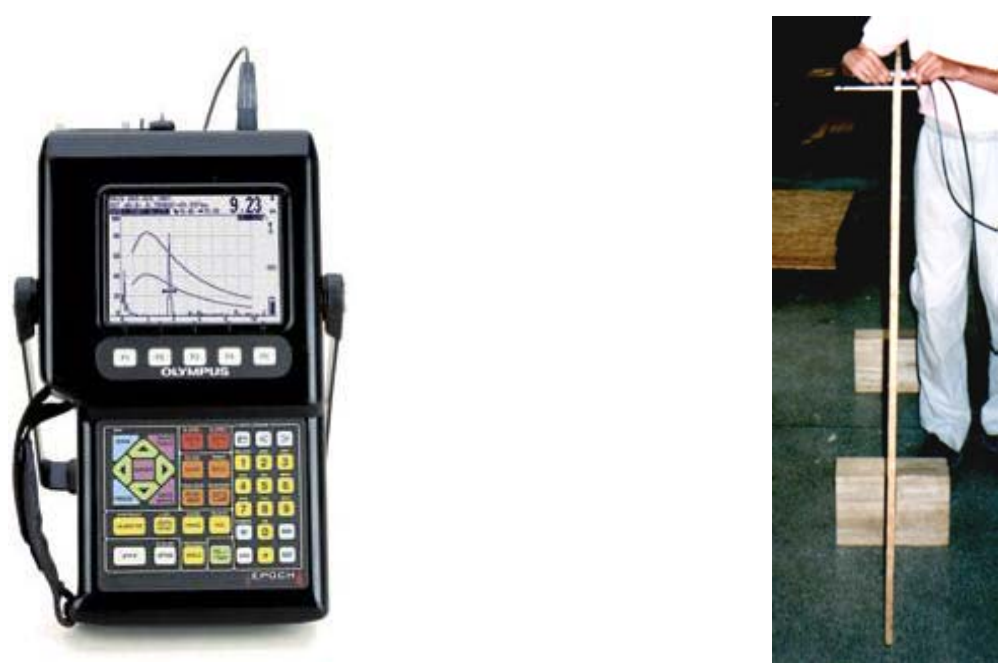

Figura 17: (a) Equipamento de ultra-som PANAMETRICS, modelo EPOCH4 e (b) esquema para medição do tempo de propagação de onda através da espessura dos painéis através do equipamento PANAMETRICS, modelo EPOCH4. 
As espessuras foram medidas em quatro pontos dos painéis, em ambas as direções. Posteriormente, foi calculada a média desses 16 valores, o que se considerou a espessura de cada painel.

Com o aparelho Panametrics, modelo EPOCH 4 (aparelho projetado para ser utilizado em metais), foi possível fazer as medições de tempo somente na espessura dos painéis OSB, mas não nas direções longitudinal e transversal dos mesmos, pois as distâncias de propagação das ondas eram muito longas, Figuras $10(a)$ e (b), e os seus sinais foram atenuados.

Assim, para as medições do tempo de propagação das ondas nas direções transversal e longitudinal dos painéis, Figuras 10 (a) e (b), foi utilizado o aparelho STEIKAMP, modelo BP-7 (projetado para ser utilizado em madeira ou em seus derivados), com transdutores planos de freqüência $45 \mathrm{kHz}$ e gel medicinal como acoplante.

Nessas duas direções também foram conduzidos ensaios utilizando o equipamento de stress wave Timer METRIGUARD, modelo 239 A, Figuras 18 (a) e (b).

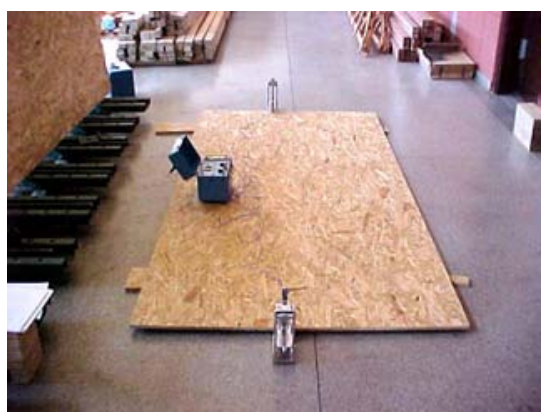

(a)

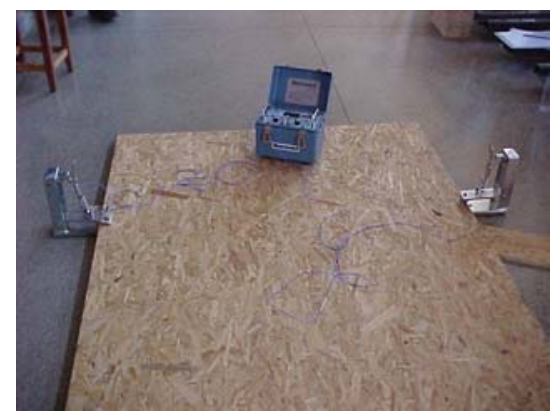

(b)

Figura 18 - Exemplo de posicionamento dos transdutores do aparelho stress wave para a medição do tempo nos painéis OSB nas direções: (a) longitudinal e (b) transversal.

Nesta etapa foi mais importante caracterizar os painéis por grupos, tendo sido empregados dez painéis por grupo. Assim, optou-se por ensaiar o número mínimo dos corpos-de-prova exigidos pelo documento normativo EN 326-1/1994 (Tabela 5) para as propriedades físico-mecânicas de cada painel, ou seja, para a 
determinação dos valores de $E_{m}, f_{m}, H, \rho, A l, G_{t}$ e $A_{m}$ foram ensaiados, respectivamente, 12, 4, 6, 8, 8 e 8 corpos-de-prova de cada painel.

No total, para a realização desta etapa foram realizados 240 ensaios de flexão estática (120 em cada direção) e 80, 120, 160, 160 e 160 para a determinação do teor de umidade, da densidade, da resistência à tração perpendicular às faces, inchamento em espessura e da absorção de água, respectivamente.

$\mathrm{Na}$ continuação, foram realizados os ensaios para a obtenção dos valores da resistência à tração perpendicular às faces, dos módulos de elasticidade e de resistência na flexão estática na Máquina Universal de Ensaios EMIC (30 toneladas), no Laboratório de Construção Civil, do Departamento de Engenharia Civil, da Faculdade de Engenharia de Bauru (FEB), da Universidade Estadual Paulista (UNESP), Campus de Bauru,

Os ensaios para a determinação dos valores da densidade, inchamento e absorção de água, bem como os ensaios não-destrutivos desta fase, foram conduzidos no Laboratório de Madeiras e de Estruturas de Madeiras (LaMEM), do SETEESC-USP.

Os resultados foram analisados estatisticamente através de gráficos, coeficientes de correlação, cálculos de médias, desvios padrão e coeficientes de variação e dos métodos de Kolmogorov-Smirnov e Kruskal-Wallis, pelos programas MINITAB, versão 13 e EXCEL, 2003. 


\section{Papitulo 5 - Qesultados}

Neste capítulo serão explicitados os resultados obtidos nos Ensaios Preliminares - etapa preliminar e Ensaios Principais - primeira e segunda etapas.

\subsection{Ensaios Preliminares}

A Tabela 7 apresenta os valores médios de propriedades físicas dos painéis, onde $H$,

$\rho, \mathrm{G}_{\mathrm{t}}, \mathrm{A}_{\mathrm{m}}, \bar{x}$, s e CV significam, respectivamente, teor de umidade, densidade, inchamento, absorção de água (24h), média aritmética, desvio padrão e coeficiente de variação (\%).

Tabela 7 - Propriedades físicas dos painéis OSB 1 e 2

\begin{tabular}{c|ccccc}
\hline \multicolumn{2}{c}{ Painel } & $\mathbf{H ~ ( \% )}$ & $\boldsymbol{\rho}\left(\mathbf{k g} / \mathbf{m}^{\mathbf{3}}\right)$ & $\mathbf{G}_{\mathbf{t}} \mathbf{( \% )}$ & $\mathbf{A}_{\mathbf{m}} \mathbf{( \% )}$ \\
\hline \hline \multirow{3}{*}{$\mathbf{1}$} & $\bar{x}$ & 9 & 589 & 14 & 54 \\
& $S$ & 1 & 17 & 3 & 9 \\
& $C V$ & 11 & 3 & 20 & 16 \\
\hline \multirow{3}{*}{$\mathbf{2}$} & $\bar{x}$ & 9 & 612 & 15 & 52 \\
& $S$ & 1 & 77 & 2 & 10 \\
& $C V$ & 10 & 13 & 15 & 19 \\
\hline
\end{tabular}

Os resultados obtidos nos ensaios de propriedades mecânicas são apresentados na Tabela 8, onde $E_{m / /}, E_{m \perp}, f_{m / /}, f_{m \perp}$ e Al significam, respectivamente, módulos de elasticidade e de resistência na flexão estática nas direções longitudinal e transversal e adesão interna.

Tabela 8 - Propriedades mecânicas dos painéis OSB 1 e 2

\begin{tabular}{c|cccccc}
\hline \multicolumn{2}{c}{ Painel } & $\mathbf{E}_{\mathrm{m} / /}(\mathbf{M P a})$ & $\mathbf{E}_{\mathrm{m} \perp}(\mathbf{M P a})$ & $\mathbf{f}_{\mathrm{m} / /}(\mathbf{M P a})$ & $\mathbf{f}_{\mathrm{m} \perp}(\mathbf{M P a})$ & $\mathbf{A l}(\mathbf{M P a})$ \\
\hline \hline \multirow{3}{*}{$\mathbf{1}$} & $\bar{x}$ & 4795 & 1800 & 28 & 15 & 0,43 \\
& $S$ & 619 & 363 & 5 & 3 & 0,2 \\
& $C V$ & 13 & 20 & 18 & 16 & 38 \\
\hline \multirow{3}{*}{$\mathbf{2}$} & $\bar{x}$ & 5079 & 1747 & 30 & 14 & 0,43 \\
& $S$ & 719 & 296 & 4 & 2 & 0,1 \\
& $C V$ & 14 & 17 & 13 & 15 & 28 \\
\hline
\end{tabular}


Os valores médios referentes às velocidades e constantes dinâmicas obtidas por medições do tempo de propagação de ondas na espessura dos painéis, nos locais correspondentes aos corpos-de-prova de tração perpendicular às faces, densidade, inchamento e absorção de água, respectivamente representados por $V_{A l}, V_{d}$ e $V_{G t / A m}$ e $C_{A l}, C_{d}$ e $C_{G t / A m}$, estão apresentados nas Tabelas 9 e 10.

Tabela 9 - Velocidades de propagação das ondas: espessura dos painéis

\begin{tabular}{c|cccc}
\hline \multicolumn{2}{c}{ Painel } & $\mathbf{V}_{\mathbf{A l}}(\mathbf{m} / \mathbf{s})$ & $\mathbf{V}_{\mathbf{d}}(\mathbf{m} / \mathbf{s})$ & $\mathbf{V}_{\mathbf{G t} / \mathbf{A m}}(\mathbf{m} / \mathbf{s})$ \\
\hline \hline \multirow{3}{*}{$\mathbf{1}$} & $\bar{x}$ & 1084 & 1091 & 1108 \\
& $S$ & 77 & 78 & 80 \\
& $C V$ & 7 & 7 & 7 \\
\hline \multirow{3}{*}{$\mathbf{2}$} & $\bar{x}$ & 1140 & 1154 & 1116 \\
& $S$ & 116 & 104 & 105 \\
& $C V$ & 10 & 9 & 9 \\
\hline
\end{tabular}

Tabela 10 - Constantes dinâmicas de propagação de ondas: espessura dos painéis

\begin{tabular}{c|cccc}
\hline \multicolumn{2}{c}{ Painel } & $\mathbf{C}_{\mathrm{Al}}(\mathbf{M P a})$ & $\mathbf{C}_{\mathrm{d}}(\mathbf{M P a})$ & $\mathbf{C}_{\mathrm{Gt} / \mathbf{A m}}(\mathbf{M P a})$ \\
\hline \hline \multirow{1}{*}{$\mathbf{c}$} & $\bar{x}$ & 695 & 706 & 725 \\
& $S$ & 98 & 115 & 103 \\
& $C V$ & 14 & 16 & 14 \\
\hline \multirow{3}{*}{$\mathbf{2}$} & $\bar{x}$ & 803 & 826 & 767 \\
& $S$ & 165 & 206 & 145 \\
& $C V$ & 20 & 25 & 19 \\
\hline
\end{tabular}

Os valores médios referentes às velocidades e constantes dinâmicas obtidas por medições de tempo nas direções longitudinal e perpendicular dos painéis estão apresentados na Tabela 11, onde $V_{/ /}, C_{/ /}, V_{\perp}$ e $C_{\perp}$ representam, respectivamente, as velocidades e as constantes dinâmicas nas direções longitudinal e transversal dos painéis.

Tabela 11 - Velocidades e constantes dinâmicas de propagação de ondas: direções longitudinal e transversal dos painéis

\begin{tabular}{c|ccccc}
\hline \multicolumn{2}{c}{ Painel } & $\mathbf{V}_{\|}(\mathbf{m} / \mathbf{s})$ & $\mathbf{V}_{\perp}(\mathbf{m} / \mathbf{s})$ & $\mathbf{C}_{\| /}(\mathbf{M P a})$ & $\mathbf{C}_{\perp}(\mathbf{M P a})$ \\
\hline \hline \multirow{3}{*}{1} & $\bar{x}$ & 3347 & 2661 & 6534 & 4135 \\
& $S$ & 46 & 27 & 187 & 74 \\
& $C V$ & 1 & 1 & 3 & 2 \\
\hline \multirow{3}{*}{2} & $\bar{x}$ & 3308 & 2686 & 6600 & 4403 \\
& $S$ & 65 & 35 & 255 & 119 \\
& $C V$ & 2 & 1 & 4 & 3 \\
\hline
\end{tabular}




\subsection{Ensaios Principais - primeira etapa}

Os resultados médios das propriedades físico-mecânicas determinados na primeira etapa são apresentados nas Tabelas 12 e 13. Nestas, t é a espessura do painel e, $F_{\max / /}, F_{\max \perp}$ e $F_{\operatorname{maxAl}}$, força de ruptura na flexão estática, nas direções longitudinal e transversal, e força de ruptura na adesão interna, respectivamente.

Tabela 12 - Propriedades físicas dos painéis OSB

\begin{tabular}{c|c|c|c|c|c|c|c|}
\hline \multicolumn{2}{c}{$\mathbf{t}(\mathbf{m m})$} & $\mathbf{H}(\mathbf{\%})$ & $\left.\rho \mathbf{( k g} / \mathbf{m}^{\mathbf{3}}\right)$ & $\mathbf{G}_{\mathbf{t}} \mathbf{( \% )}$ & $\mathbf{A}_{\mathbf{m}} \mathbf{( \% )}$ & $\mathbf{A l} \mathbf{( M P a )}$ & $\mathbf{F}_{\operatorname{maxAl}}(\mathbf{N})$ \\
\hline \hline \multirow{3}{*}{$\mathbf{6}$} & $\bar{x}$ & 10 & 614 & 18 & 60 & 0.47 & 1191 \\
& $S$ & 0.4 & 45 & 4 & 6 & 0.2 & 380 \\
& $C V$ & 4 & 7 & 22 & 11 & 32 & 32 \\
\hline \multirow{3}{*}{$\mathbf{1 5 ( 1 )}$} & $\overline{1})$ & 9 & 595 & 15 & 71 & 0.44 & 1084 \\
& $S$ & 0.1 & 44 & 3 & 9 & 0.1 & 324 \\
& $C V$ & 1 & 7 & 21 & 13 & 30 & 30 \\
\hline \multirow{3}{*}{$\mathbf{1 5 ( 2 )}$} & $\bar{x}$ & 9 & 589 & 14 & 75 & 0.36 & 941 \\
& $S$ & 0.1 & 38 & 4 & 10 & 0.1 & 358 \\
& $C V$ & 1 & 6 & 28 & 13 & 37 & 38 \\
\hline \multirow{3}{*}{$\mathbf{2 5}$} & $\bar{x}$ & 9 & 595 & 19 & 87 & 0.18 & 453 \\
& $S$ & 0.2 & 21 & 1 & 6 & 0.1 & 207 \\
& $C V$ & 2 & 4 & 7 & 7 & 46 & 46 \\
\hline
\end{tabular}

Tabela 13 - Propriedades mecânicas dos painéis OSB

\begin{tabular}{c|c|c|c|c|c|c|c|}
\hline \multicolumn{1}{c}{$\mathbf{t}(\mathbf{m m})$} & $\mathbf{E}_{\mathbf{m} / /}(\mathbf{M P a})$ & $\mathbf{E}_{\mathbf{m} \perp}(\mathbf{M P a})$ & $\mathbf{f}_{\mathbf{m} / /}(\mathbf{M P a})$ & $\mathbf{f}_{\mathbf{m} \perp}(\mathbf{M P a})$ & $\mathbf{F}_{\max / /}(\mathbf{N})$ & $\mathbf{F}_{\max \perp}(\mathbf{N})$ \\
\hline \hline \multirow{3}{*}{$\mathbf{6}$} & $\bar{x}$ & 3661 & 1376 & 32 & 16 & 404 & 204 \\
& $S$ & 725 & 380 & 8 & 5 & 107 & 60 \\
& $C V$ & 20 & 28 & 26 & 29 & 26 & 29 \\
\hline \multirow{3}{*}{$\mathbf{1 5 ( 1 )}$} & $\overline{1}$ & 4142 & 1652 & 25 & 14 & 658 & 355 \\
& $S$ & 590 & 231 & 6 & 2 & 162 & 63 \\
& $C V$ & 14 & 14 & 25 & 18 & 25 & 18 \\
\hline \multirow{3}{*}{$\mathbf{1 5 ( 2 )}$} & $\bar{x}$ & 4069 & 1386 & 25 & 10 & 661 & 263 \\
& $S$ & 525 & 206 & 5 & 2 & 135 & 55 \\
& $C V$ & 13 & 15 & 20 & 21 & 20 & 21 \\
\hline \multirow{3}{*}{$\mathbf{2 5}$} & $\bar{x}$ & 4553 & 1817 & 26 & 13 & 1135 & 560 \\
& $S$ & 680 & 132 & 4 & 2 & 169 & 72 \\
& $C V$ & 15 & 7 & 15 & 13 & 15 & 13 \\
\hline
\end{tabular}

Os valores médios referentes às velocidades e constantes dinâmicas obtidas por medições do tempo de propagação, pelo aparelho de ultra-som, na espessura dos painéis, nos locais correspondentes aos corpos-de-prova de tração perpendicular às faces, densidade, inchamento e absorção de água estão 
apresentados nas Tabelas 14 e 15. Por problemas técnicos não foi possível realizar as medições nas espessuras dos painéis de espessuras 6 e 15(2)mm.

Tabela 14 - Velocidades de propagação das ondas: espessura dos painéis

\begin{tabular}{c|cccc}
\hline \multicolumn{1}{c}{$\mathbf{t}(\mathbf{m m})$} & $\mathbf{V}_{\mathbf{A l}}(\mathbf{m} / \mathbf{s})$ & $\mathbf{V}_{\mathbf{d}}(\mathbf{m} / \mathbf{s})$ & $\mathbf{V}_{\mathbf{G t} / \mathbf{A m}}(\mathbf{m} / \mathbf{s})$ \\
\hline \hline \multirow{4}{*}{$\mathbf{1 5 ( 1 )}$} & $\overline{1}$ & 1086 & 1091 & 1102 \\
& $S$ & 80 & 108 & 76 \\
& $C V$ & 7 & 10 & 7 \\
\hline \multirow{4}{*}{25} & $\bar{x}$ & 963 & 965 & 966 \\
& $S$ & 71 & 50 & 55 \\
& $C V$ & 7 & 5 & 6 \\
\hline
\end{tabular}

Tabela 15 - Constantes dinâmicas de propagação de ondas: espessura dos painéis

\begin{tabular}{c|cccc}
\hline \multicolumn{1}{c}{$\mathbf{t}(\mathbf{m m})$} & $\mathbf{C}_{\mathrm{Al}}$ (MPa) & $\mathbf{C}_{\mathrm{d}}(\mathbf{M P a})$ & $\mathbf{C}_{\mathrm{Gt} / \mathbf{A m}}(\mathbf{M P a})$ \\
\hline \hline \multirow{3}{*}{$\mathbf{1 5 ( 1 )}$} & $\overline{1})$ & 706 & 722 & 726 \\
& $S$ & 104 & 174 & 99 \\
& $C V$ & 15 & 24 & 14 \\
\hline \multirow{4}{*}{25} & $\bar{x}$ & 554 & 555 & 556 \\
& $S$ & 81 & 66 & 62 \\
& $C V$ & 15 & 12 & 11 \\
\hline
\end{tabular}

Os valores médios referentes às velocidades e constantes dinâmicas obtidas por medições de tempo nas direções longitudinal e transversal dos painéis, estão apresentados na Tabela 16.

Tabela 16 - Velocidades e constantes dinâmicas de propagação de ondas: direções longitudinal e transversal dos painéis

\begin{tabular}{c|ccccc}
\hline \multicolumn{2}{c}{$\mathbf{t}(\mathbf{m m})$} & $\mathbf{V}_{\| /}(\mathbf{m} / \mathbf{s})$ & $\mathbf{V}_{\perp}(\mathbf{m} / \mathbf{s})$ & $\mathbf{C}_{\|}(\mathbf{M P a})$ & $\mathbf{C}_{\perp}(\mathbf{M P a})$ \\
\hline \hline \multirow{3}{*}{6} & $\bar{x}$ & 3251 & 2084 & 6491 & 2816 \\
& $S$ & 43 & 498 & 169 & 1089 \\
& $C V$ & 1 & 24 & 3 & 39 \\
\hline \multirow{4}{*}{$\mathbf{1 5 ( 1 )}$} & $\bar{x}$ & 3039 & 2575 & 5498 & 3946 \\
& $S$ & 21 & 28 & 76 & 86 \\
& $C V$ & 1 & 1 & 1 & 2 \\
\hline \multirow{4}{*}{25} & $\bar{x}$ & 3216 & 2658 & 6150 & 4201 \\
& $S$ & 44 & 24 & 166 & 76 \\
& $C V$ & 1 & 1 & 3 & 2 \\
\hline
\end{tabular}

Os valores médios referentes às velocidades e constantes dinâmicas obtidas por medições de tempo, pelo aparelho de stress wave, nas direções longitudinal e transversal do painel de espessura 15(2)mm estão apresentados na Tabela 17. 
Tabela 17 - Velocidades e constantes dinâmicas de propagação de ondas: direções longitudinal e transversal do painel de espessura 15(2) $\mathrm{mm}$ - stress wave

\begin{tabular}{c|ccccc}
\hline \multicolumn{2}{c}{$\mathbf{t}(\mathbf{m m})$} & $\mathbf{V}_{/ /}(\mathbf{m} / \mathbf{s})$ & $\mathbf{V}_{\perp}(\mathbf{m} / \mathbf{s})$ & $\mathbf{C}_{/ /}(\mathbf{M P a})$ & $\mathbf{C}_{\perp}(\mathbf{M P a})$ \\
\hline \hline \multirow{3}{*}{$\mathbf{1 5 ( 2 )}$} & $\bar{x}$ & 2889 & 2040 & 4915 & 2450 \\
& $s$ & 33 & 30 & 97 & 72 \\
& $C V$ & 1 & 1 & 2 & 3 \\
\hline
\end{tabular}

Os valores médios referentes às velocidades e constantes dinâmicas obtidas por medições de tempo, pelo aparelho de stress wave, nos corpos-de-prova de flexão estática, nas direções transversal e longitudinal (15(1) - cp, 15(2) - cp e 25 cp), estão apresentados na Tabela 18.

Tabela 18 - Velocidades e constantes dinâmicas de propagação de ondas: corpos-de-prova de flexão dos painéis - stress wave

\begin{tabular}{c|ccccc}
\hline \multicolumn{2}{c}{$\mathbf{t}(\mathbf{m m})$} & $\mathbf{V}_{/ /}(\mathbf{m} / \mathbf{s})$ & $\mathbf{V}_{\perp}(\mathbf{m} / \mathbf{s})$ & $\mathbf{C}_{/ /}(\mathbf{M P a})$ & $\mathbf{C}_{\perp}(\mathbf{M P a})$ \\
\hline \hline \multirow{2}{*}{$\mathbf{1 5 ( 1 )}$} & $\bar{x}$ & 3116 & 2439 & 5780 & 3544 \\
$\mathbf{c p}$ & $s$ & 54 & 66 & 200 & 191 \\
& $C V$ & 2 & 3 & 3 & 5 \\
\hline \multirow{2}{*}{$\mathbf{1 5 ( 2 )}$} & $\bar{x}$ & 3139 & 2187 & 5804 & 2818 \\
$\mathbf{c p}$ & $S$ & 69 & 45 & 253 & 116 \\
& $C V$ & 2 & 2 & 4 & 4 \\
\hline \multirow{2}{*}{$\mathbf{2 5}$} & $\bar{x}$ & 3216 & 2496 & 6150 & 3703 \\
$\mathbf{c p}$ & $S$ & 90 & 43 & 355 & 125 \\
& $C V$ & 3 & 2 & 6 & 3 \\
\hline
\end{tabular}

As Figuras 19 e 20 mostram exemplos gráficos, de retas de regressão, encontrados entre os valores obtidos nos ensaios destrutivos e nos ensaios nãodestrutivos, utilizando os métodos de ultra-som e de stress wave, respectivamente. Todos os gráficos de reta de regressão são apresentados nos Apêndices F e G.

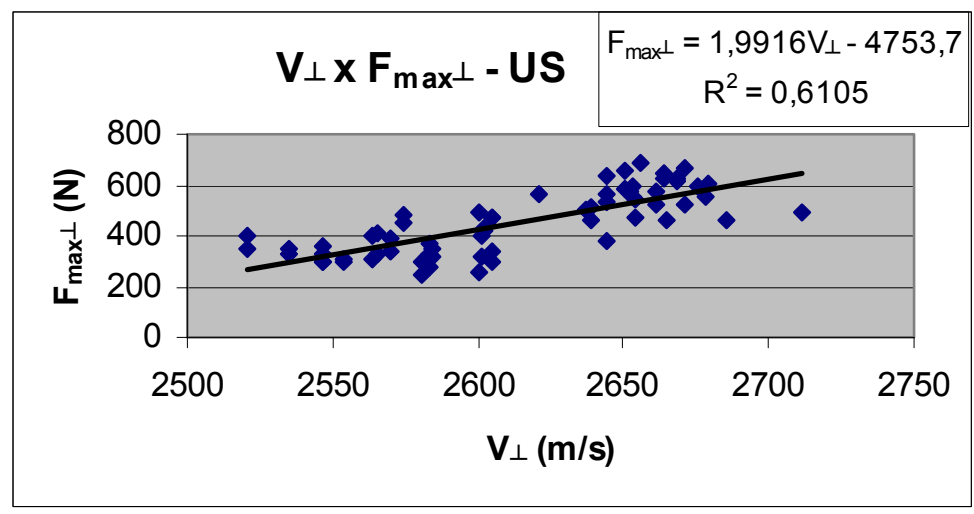

Figura 19 - Velocidade x força máxima na flexão estática, na direção transversal, com medições realizadas pelo ultra-som. 


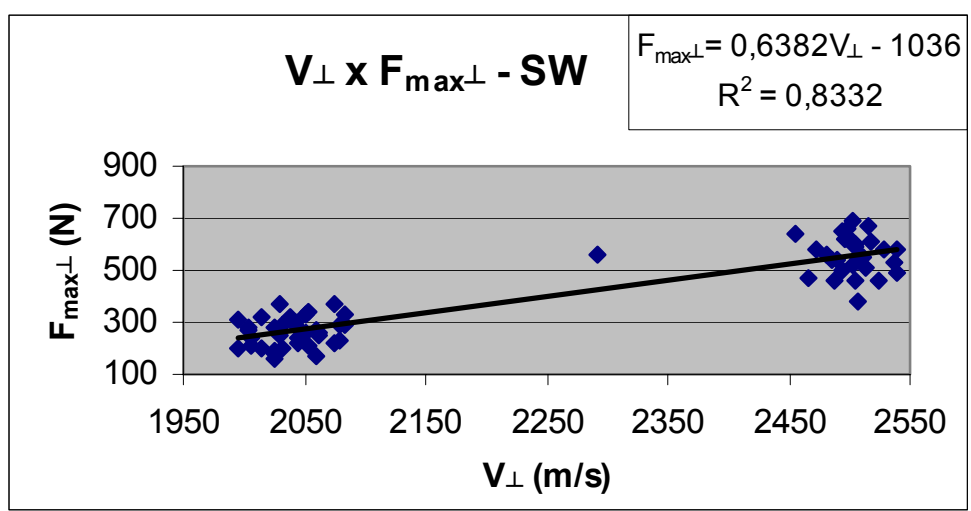

Figura 20 - Velocidade x força máxima na flexão estática, na direção transversal, com medições realizadas pelo stress wave - painéis $15(2)$ e $25 \mathrm{~mm}$.

As Tabelas 19, 20, 21 e 22 apresentam os modelos de regressão (equações) e coeficientes de correlação $(R)$ e de determinação $\left(R^{2}\right)$ encontrados entre os valores obtidos nos ensaios destrutivos e nos ensaios não-destrutivos através dos métodos de ultra-som e de stress wave, respectivamente. O símbolo * significa que as correlações, bem como os seus respectivos modelos de regressão, não foram significativos entre as propriedades estudadas.

Tabela 19 - Equações, $R$ e $R^{2}$ entre os valores dos ensaios físico-mecânicos e nãodestrutivos pelo método de ultra-som

\begin{tabular}{cccccc}
\hline $\mathbf{R}$ & $\mathbf{R}^{2}$ & Equação & $\mathbf{R}$ & $\mathbf{R}^{2}$ & Equação \\
\hline \hline 0,30 & 0,09 & $\mathrm{f}_{\mathrm{m} / /}=0,0169 \mathrm{~V}_{/ /}-27,095^{*}$ & 0,62 & 0,38 & $\mathrm{Al}=0,0011 \mathrm{~V}_{\mathrm{Al}}-0,7668$ \\
0,75 & 0,56 & $\mathrm{~F}_{\mathrm{max} / /}=2,693 \mathrm{~V}_{/ /}-7523,4$ & 0,62 & 0,38 & $\mathrm{Al}=0,0009 \mathrm{C}_{\mathrm{Al}}-0,234$ \\
0,49 & 0,24 & $\mathrm{E}_{\mathrm{m} / /}=0,9531 \mathrm{C}_{/ /}-1189,8$ & 0,61 & 0,38 & $\mathrm{~F}_{\mathrm{maxAl}}=2,6173 \mathrm{~V}_{\mathrm{Al}}-1912,1$ \\
0,00 & 0,00 & $\mathrm{f}_{\mathrm{m} \perp}=-0,0011 \mathrm{~V}_{\perp}+16,297^{*}$ & 0,48 & 0,23 & $\mathrm{G}_{\mathrm{t}}=-0,0168 \mathrm{~V}_{\mathrm{Gt}}+34,475$ \\
0,78 & 0,61 & $\mathrm{~F}_{\max \perp}=1,9916 \mathrm{~V}_{\perp}-4753,7$ & 0,49 & 0,24 & $\mathrm{G}_{\mathrm{t}}=-0,0137 \mathrm{C}_{\mathrm{Gt}}+25,887$ \\
0,48 & 0,23 & $\mathrm{E}_{\mathrm{m} \perp}=0,6698 \mathrm{C}_{\perp}-992,74$ & 0,74 & 0,55 & $\mathrm{~A}_{\mathrm{m}}=-0,0856 \mathrm{~V}_{\mathrm{Am}}+168,01$ \\
0,39 & 0,15 & $\mathrm{~d}=0,1286 \mathrm{~V}_{\mathrm{d}}+460,93$ & 0,74 & 0,55 & $\mathrm{~A}_{\mathrm{m}}=-0,0686 \mathrm{C}_{\mathrm{Am}}+123,53$ \\
\hline
\end{tabular}

Tabela 20 - Equações, $R$ e $R^{2}$ entre os valores dos ensaios físico-mecânicos e nãodestrutivos pelo método de stress wave - painéis $15(1) \times 15(2) \mathrm{mm}$

\begin{tabular}{cccccc}
\hline $\mathbf{R}$ & $\mathbf{R}^{2}$ & Equação & $\mathbf{R}$ & $\mathbf{R}^{2}$ & Equação \\
\hline \hline 0,15 & 0,02 & $\mathrm{f}_{\mathrm{m} / /}=0,0055 \mathrm{~V}_{/ /}+8,5302^{*}$ & 0,68 & 0,46 & $\mathrm{f}_{\mathrm{m} \perp}=0,0091 \mathrm{~V}_{\perp}-8,7585$ \\
0,06 & 0,00 & $\mathrm{~F}_{\max / /}=0,0747 \mathrm{~V}_{/ /}+435,49^{*}$ & 0,67 & 0,44 & $\mathrm{~F}_{\max }=0,2403 \mathrm{~V}_{\perp}-228,76$ \\
0,51 & 0,26 & $\mathrm{E}_{\mathrm{m} / /}=0,3375 \mathrm{C}_{/ /}+2204,9$ & 0,56 & 0,32 & $\mathrm{E}_{\mathrm{m}}=0,2516 \mathrm{C}_{\perp}+762,99$ \\
\hline
\end{tabular}


Tabela 21 - Equações, $R$ e $R^{2}$ entre os valores dos ensaios físico-mecânicos e nãodestrutivos pelo método de stress wave - painéis $15(1) \times 25 \mathrm{~mm}$

\begin{tabular}{cccccc}
\hline $\mathbf{R}$ & $\mathbf{R}^{2}$ & Equação & $\mathbf{R}$ & $\mathbf{R}^{2}$ & Equação \\
\hline \hline 0,22 & 0,05 & $\mathrm{f}_{\mathrm{m} / /}=0,0168 \mathrm{~V}_{/ /}-27,462^{*}$ & 0,22 & 0,05 & $\mathrm{f}_{\mathrm{m} \perp}=0,0072 \mathrm{~V}_{\perp}-4,4546^{*}$ \\
0,61 & 0,38 & $\mathrm{~F}_{\max / /}=2,5569 \mathrm{~V}_{/ /}-7188,7$ & 0,49 & 0,24 & $\mathrm{~F}_{\max }=0,9555 \mathrm{~V}_{\perp}-1903,7$ \\
0,28 & 0,08 & $\mathrm{E}_{\mathrm{m} / /}=0,7125 \mathrm{C}_{/ /}+117,04^{*}$ & 0,40 & 0,16 & $\mathrm{E}_{\mathrm{m} \perp}=0,4556 \mathrm{C}_{\perp}+79,347$ \\
\hline
\end{tabular}

Tabela 22 - Equações, $R$ e $R^{2}$ entre os valores dos ensaios físico-mecânicos e nãodestrutivos pelo método de stress wave - painéis $15(2) \times 25 \mathrm{~mm}$

\begin{tabular}{cccccc}
\hline $\mathbf{R}$ & $\mathbf{R}^{2}$ & Equação & $\mathbf{R}$ & $\mathbf{R}^{2}$ & Equação \\
\hline \hline 0,24 & 0,06 & $\mathrm{f}_{\mathrm{m} / /}=0,0066 \mathrm{~V}_{/ /}+5,3741^{*}$ & 0,64 & 0,41 & $\mathrm{f}_{\mathrm{m} \perp}=0,0068 \mathrm{~V}_{\perp}-4,0173$ \\
0,87 & 0,75 & $\mathrm{~F}_{\max / /}=1,4883 \mathrm{~V}_{/ /}-3634,4$ & 0,91 & 0,83 & $\mathrm{~F}_{\max } \perp=0,6382 \mathrm{~V}_{\perp}-1036$ \\
0,56 & 0,32 & $\mathrm{E}_{\mathrm{m} / /}=0,3945 \mathrm{C}_{/ /}+2007,9$ & 0,78 & 0,61 & $\mathrm{E}_{\mathrm{m} \perp}=0,3418 \mathrm{C}_{\perp}+549,27$ \\
\hline
\end{tabular}

\subsection{Ensaios Principais - segunda etapa}

As Tabelas 23 e 24 apresentam os resultados médios obtidos nos ensaios de propriedades físico-mecânicas para os painéis de amostragem dos grupos 1 e 2 .

Tabela 23 - Propriedades físicas dos painéis OSB dos grupos 1 e 2

\begin{tabular}{c|ccccc}
\hline \multicolumn{2}{c}{ Painel } & $\mathbf{H}(\%)$ & $\rho\left(\mathbf{k g} / \mathbf{m}^{\mathbf{3}}\right)$ & $\mathbf{G}_{\mathbf{t}} \mathbf{( \% )}$ & $\mathbf{A}_{\mathbf{m}} \mathbf{( \% )}$ \\
\hline \hline \multirow{3}{*}{$\mathbf{1}$} & $\bar{x}$ & 8 & 601 & 13 & 46 \\
& $S$ & 1 & 34 & 2 & 5 \\
& $C V$ & 18 & 6 & 13 & 10 \\
\hline \multirow{3}{*}{$\mathbf{2}$} & $\bar{x}$ & 7 & 598 & 19 & 52 \\
& $S$ & 4 & 39 & 4 & 4 \\
& $C V$ & 6 & 7 & 22 & 7 \\
\hline
\end{tabular}

Tabela 24 - Propriedades mecânicas das chapas OSB dos grupos 1 e 2

\begin{tabular}{c|cccccc}
\hline \multicolumn{2}{c}{ Painel } & $\mathbf{E}_{\mathrm{m} / /}(\mathbf{M P a})$ & $\mathbf{E}_{\mathbf{m} \perp}(\mathbf{M P a})$ & $\mathbf{f}_{\mathbf{m} / /}(\mathbf{M P a})$ & $\mathbf{f}_{\mathrm{m} \perp}(\mathbf{M P a})$ & $\mathbf{A l}(\mathbf{M P a})$ \\
\hline \hline \multirow{3}{*}{$\mathbf{1}$} & $\bar{x}$ & 5290 & 1601 & 31 & 11 & 0,33 \\
& $S$ & 783 & 273 & 7 & 3 & 0,2 \\
& $C V$ & 15 & 17 & 22 & 24 & 54 \\
\hline \multirow{3}{*}{$\mathbf{2}$} & $\bar{x}$ & 3401 & 1794 & 19 & 13 & 0,27 \\
& $S$ & 801 & 259 & 5 & 2 & 0,1 \\
& $C V$ & 24 & 14 & 27 & 18 & 32 \\
\hline
\end{tabular}

As Tabelas 25, 26, 27 e 28 apresentam os resultados médios obtidos nos ensaios de propriedades físico-mecânicas para os painéis dos grupos 1 e 2 . Os valores totais obtidos nesses ensaios são apresentados no Apêndice B. 
Tabela 25 - Teor de umidade e densidade dos painéis OSB dos grupos 1 e 2

\begin{tabular}{|c|c|c|c|c|c|c|c|}
\hline \multicolumn{2}{|c|}{$\begin{array}{l}\text { Painéis } \\
\text { Grupo } 1\end{array}$} & \multirow{2}{*}{$\begin{array}{c}\begin{array}{c}H \\
(\%)\end{array} \\
7\end{array}$} & \multirow{2}{*}{$\begin{array}{c}\begin{array}{c}\rho \\
\left(\mathrm{kg} / \mathrm{m}^{3}\right)\end{array} \\
574\end{array}$} & \multicolumn{2}{|c|}{$\begin{array}{l}\text { Painéis } \\
\text { Grupo } 2 \\
\end{array}$} & \multirow{2}{*}{$\begin{array}{c}\begin{array}{c}H \\
(\%)\end{array} \\
6\end{array}$} & \multirow{2}{*}{$\begin{array}{c}\frac{\rho}{\rho} \\
\left(\mathrm{kg} / \mathrm{m}^{3}\right)\end{array}$} \\
\hline & $\bar{x}$ & & & & $\bar{x}$ & & \\
\hline \multirow[t]{3}{*}{11} & $s$ & 1 & 39 & 21 & $s$ & 0 & 22 \\
\hline & $C V$ & 10 & 7 & & $C V$ & 7 & 4 \\
\hline & $\bar{x}$ & 7 & 573 & & $\bar{x}$ & 6 & 597 \\
\hline \multirow[t]{3}{*}{12} & $S$ & 1 & 52 & 22 & $S$ & 1 & 18 \\
\hline & $C V$ & 10 & 9 & & $C V$ & 11 & 3 \\
\hline & $\bar{x}$ & 7 & 583 & & $\bar{x}$ & 7 & 603 \\
\hline \multirow[t]{3}{*}{13} & $S$ & 1 & 21 & 23 & $s$ & 0 & 56 \\
\hline & $C V$ & 9 & 4 & & $C V$ & 3 & 9 \\
\hline & $\bar{x}$ & 7 & 565 & & $\bar{x}$ & 7 & 631 \\
\hline \multirow[t]{3}{*}{14} & $s$ & 1 & 26 & 24 & $s$ & 0 & 22 \\
\hline & $C V$ & 15 & 5 & & $C V$ & 7 & 4 \\
\hline & $\overline{\bar{x}}$ & 6 & 594 & & $\overline{\bar{x}}$ & 7 & 591 \\
\hline \multirow[t]{3}{*}{15} & $s$ & 0 & 32 & 25 & $s$ & 0 & 35 \\
\hline & $C V$ & 6 & 5 & & $C V$ & 2 & 6 \\
\hline & $\bar{x}$ & 7 & 559 & & $\bar{x}$ & 6 & 593 \\
\hline \multirow[t]{3}{*}{16} & $s$ & 0 & 34 & 26 & $S$ & 0 & 21 \\
\hline & $C V$ & 4 & 6 & & $C V$ & 7 & 4 \\
\hline & $\bar{x}$ & 7 & 582 & & $\bar{x}$ & 7 & 596 \\
\hline \multirow[t]{3}{*}{17} & $s$ & 1 & 35 & 27 & $s$ & 0 & 32 \\
\hline & $C V$ & 8 & 6 & & $C V$ & 2 & 5 \\
\hline & $\bar{x}$ & 7 & 570 & & $\bar{x}$ & 7 & 555 \\
\hline \multirow[t]{3}{*}{18} & $s$ & 0 & 30 & 28 & $S$ & 0 & 30 \\
\hline & $C V$ & 5 & 5 & & $C V$ & 4 & 5 \\
\hline & $\bar{x}$ & 7 & 563 & & $\bar{x}$ & 7 & 555 \\
\hline \multirow[t]{3}{*}{19} & $s$ & 0 & 32 & 29 & $S$ & 1 & 36 \\
\hline & $C V$ & 5 & 6 & & $C V$ & 14 & 6 \\
\hline & $\bar{x}$ & 6 & 594 & & $\bar{x}$ & 7 & 586 \\
\hline \multirow[t]{2}{*}{110} & $S$ & 0 & 55 & 210 & $S$ & 1 & 22 \\
\hline & $C V$ & 5 & 9 & & $C V$ & 8 & 4 \\
\hline
\end{tabular}


Tabela 26 - Valores de inchamento e absorção de água (24h), de força de ruptura e de resistência à tração perpendicular às faces, dos painéis OSB dos grupos 1 e 2

\begin{tabular}{|c|c|c|c|c|c|c|c|c|c|c|c|}
\hline \multicolumn{2}{|c|}{$\begin{array}{l}\text { Painéis } \\
\text { Grupo } 1 \\
\end{array}$} & \multirow{2}{*}{$\begin{array}{c}\begin{array}{c}\mathbf{G}_{\mathrm{t}} \\
(\mathbf{\%})\end{array} \\
10\end{array}$} & \multirow{2}{*}{$\begin{array}{c}\begin{array}{c}A_{m} \\
(\%)\end{array} \\
41\end{array}$} & \multirow{2}{*}{$\begin{array}{c}\begin{array}{c}\mathrm{Al} \\
(\mathrm{MPa})\end{array} \\
0,46\end{array}$} & \multirow{2}{*}{$\begin{array}{c}\mathbf{F}_{\operatorname{maxAl}} \\
(\mathbf{N})\end{array}$} & \multicolumn{2}{|c|}{$\begin{array}{l}\text { Painéis } \\
\text { Grupo } 2 \\
\end{array}$} & \multirow{2}{*}{$\begin{array}{c}\begin{array}{c}\mathbf{G}_{\mathrm{t}} \\
(\mathbf{\%})\end{array} \\
17\end{array}$} & \multirow{2}{*}{$\begin{array}{c}\begin{array}{c}A_{m} \\
(\%)\end{array} \\
46\end{array}$} & \multirow{2}{*}{$\begin{array}{c}\begin{array}{c}\mathrm{Al} \\
(\mathrm{MPa})\end{array} \\
0,46\end{array}$} & \multirow{2}{*}{$\frac{\begin{array}{c}\mathbf{F}_{\operatorname{maxAI}} \\
(\mathbf{N})\end{array}}{1152}$} \\
\hline & $\bar{x}$ & & & & & & $\bar{x}$ & & & & \\
\hline \multirow[t]{3}{*}{11} & $S$ & 2 & 4 & 0,1 & 187 & 21 & $S$ & 4 & 6 & 0,1 & 343 \\
\hline & $C V$ & 19 & 10 & 17 & 17 & & $C V$ & 23 & 13 & 30 & 30 \\
\hline & $\bar{x}$ & 10 & 39 & 0,40 & 1005 & & $\bar{x}$ & 16 & 48 & 0,41 & 1021 \\
\hline \multirow[t]{3}{*}{12} & $s$ & 6 & 5 & 0,2 & 446 & 22 & $S$ & 4 & 7 & 0,1 & 218 \\
\hline & $C V$ & 1 & 10 & 44 & 44 & & $C V$ & 23 & 15 & 21 & 21 \\
\hline & $\bar{x}$ & 13 & 39 & 0,49 & 1239 & & $\bar{x}$ & 21 & 49 & 0,39 & 960 \\
\hline \multirow[t]{3}{*}{13} & $s$ & 5 & 4 & 0,1 & 209 & 23 & $s$ & 5 & 5 & 0,1 & 216 \\
\hline & $C V$ & 41 & 11 & 23 & 23 & & $C V$ & 26 & 9 & 23 & 23 \\
\hline & $\bar{x}$ & 12 & 42 & 0,52 & 1296 & & $\bar{x}$ & 19 & 45 & 0,46 & 1149 \\
\hline \multirow[t]{3}{*}{14} & $s$ & 2 & 4 & 0,2 & 366 & 24 & $s$ & 4 & 5 & 0,1 & 239 \\
\hline & $C V$ & 18 & 9 & 28 & 28 & & $C V$ & 21 & 11 & 21 & 21 \\
\hline & $\bar{x}$ & 16 & 39 & 0,55 & 1376 & & $\bar{x}$ & 18 & 47 & 0,39 & 970 \\
\hline \multirow[t]{3}{*}{15} & $s$ & 5 & 7 & 0,2 & 392 & 25 & $s$ & 2 & 9 & 0,1 & 263 \\
\hline & $C V$ & 31 & 17 & 28 & 28 & & $C V$ & 11 & 20 & 27 & 27 \\
\hline & $\bar{x}$ & 14 & 43 & 0,58 & 1405 & & $\bar{x}$ & 17 & 48 & 0,40 & 973 \\
\hline \multirow[t]{3}{*}{16} & $s$ & 3 & 7 & 0,2 & 526 & 26 & $s$ & 4 & 6 & 0,1 & 211 \\
\hline & $C V$ & 22 & 16 & 37 & 37 & & $C V$ & 25 & 12 & 24 & 22 \\
\hline & $\bar{x}$ & 12 & 44 & 0,55 & 1345 & & $\bar{x}$ & 17 & 49 & 0,40 & 996 \\
\hline \multirow[t]{3}{*}{17} & $s$ & 2 & 4 & 0,1 & 219 & 27 & $s$ & 4 & 6 & 0,2 & 378 \\
\hline & $C V$ & 16 & 9 & 16 & 16 & & $C V$ & 25 & 12 & 38 & 38 \\
\hline & $\bar{x}$ & 13 & 42 & 0,43 & 1032 & & $\bar{x}$ & 17 & 46 & 0,46 & 134 \\
\hline \multirow[t]{3}{*}{18} & $s$ & 2 & 6 & 0,1 & 253 & 28 & $s$ & 4 & 6 & 0,1 & 285 \\
\hline & $C V$ & 19 & 14 & 24 & 25 & & $C V$ & 25 & 13 & 25 & 25 \\
\hline & $\bar{x}$ & 13 & 48 & 0,53 & 1289 & & $\overline{\bar{x}}$ & 17 & 46 & 0,47 & 1191 \\
\hline \multirow[t]{3}{*}{19} & $s$ & 5 & 7 & 0,2 & 357 & 29 & $s$ & 2 & 7 & 0,1 & 156 \\
\hline & $C V$ & 36 & 15 & 27 & 28 & & $C V$ & 13 & 15 & 14 & 13 \\
\hline & $\bar{x}$ & 15 & 42 & 0,51 & 1265 & & $\bar{x}$ & 17 & 51 & 0,46 & 1160 \\
\hline \multirow[t]{2}{*}{110} & $s$ & 3 & 3 & 0,1 & 302 & 210 & $s$ & 4 & 9 & 0,1 & 166 \\
\hline & $C V$ & 22 & 7 & 24 & 24 & & $C V$ & 26 & 17 & 15 & 14 \\
\hline
\end{tabular}


Tabela 27 - Valores de força de ruptura, de módulos de elasticidade e de resistência na flexão estática na direção longitudinal dos painéis OSB dos grupos 1 e 2

\begin{tabular}{|c|c|c|c|c|c|c|c|c|c|}
\hline \multicolumn{2}{|c|}{$\begin{array}{l}\text { Painéis } \\
\text { Grupo } 1 \\
\end{array}$} & \multirow{2}{*}{$\begin{array}{c}\begin{array}{c}\mathbf{f}_{\mathrm{m} / /} \\
(\mathbf{M P a})\end{array} \\
31\end{array}$} & \multirow{2}{*}{$\begin{array}{c}\begin{array}{c}\mathrm{E}_{\mathrm{m} / /} \\
(\mathrm{MPa})\end{array} \\
4745\end{array}$} & \multirow{2}{*}{$\begin{array}{c}\mathbf{F}_{\max / /} \\
(\mathbf{N})\end{array}$} & \multicolumn{2}{|c|}{$\begin{array}{l}\text { Painéis } \\
\text { Grupo } 2 \\
\end{array}$} & \multirow{2}{*}{$\begin{array}{c}\begin{array}{c}\mathbf{f}_{\mathrm{m} / /} \\
(\mathrm{MPa})\end{array} \\
20\end{array}$} & \multirow{2}{*}{$\begin{array}{c}\begin{array}{c}\mathrm{E}_{\mathrm{m} / /} \\
(\mathrm{MPa})\end{array} \\
4108\end{array}$} & \multirow{2}{*}{$\begin{array}{l}\frac{F_{\text {max } / l}}{(\mathbf{N})} \\
517\end{array}$} \\
\hline & $\bar{x}$ & & & & & $\bar{x}$ & & & \\
\hline \multirow[t]{3}{*}{11} & $S$ & 5 & 569 & 132 & 21 & $s$ & 3 & 330 & 76 \\
\hline & $C V$ & 17 & 12 & 16 & & $C V$ & 15 & 8 & 15 \\
\hline & $\bar{x}$ & 32 & 5187 & 819 & & $\bar{x}$ & 18 & 3694 & 464 \\
\hline \multirow[t]{3}{*}{12} & $S$ & 5 & 589 & 124 & 22 & $S$ & 4 & 639 & 88 \\
\hline & $C V$ & 16 & 11 & 15 & & $C V$ & 21 & 17 & 19 \\
\hline & $\bar{x}$ & 32 & 5526 & 844 & & $\bar{x}$ & 23 & 4344 & 591 \\
\hline \multirow[t]{3}{*}{13} & $S$ & 5 & 692 & 120 & 23 & $S$ & 4 & 436 & 99 \\
\hline & $C V$ & 15 & 13 & 14 & & $C V$ & 16 & 10 & 17 \\
\hline & $\bar{x}$ & 33 & 5225 & 871 & & $\bar{x}$ & 22 & 4326 & 572 \\
\hline \multirow[t]{3}{*}{14} & $S$ & 3 & 235 & 58 & 24 & $S$ & 2 & 282 & 51 \\
\hline & $C V$ & 8 & 5 & 7 & & $C V$ & 9 & 7 & 9 \\
\hline & $\bar{x}$ & 31 & 5187 & 792 & & $\bar{x}$ & 20 & 4012 & 520 \\
\hline \multirow[t]{3}{*}{15} & $S$ & 2 & 384 & 64 & 25 & $S$ & 4 & 613 & 95 \\
\hline & $C V$ & 7 & 7 & 8 & & $C V$ & 20 & 15 & 18 \\
\hline & $\bar{x}$ & 31 & 5046 & 807 & & $\bar{x}$ & 21 & 3882 & 537 \\
\hline \multirow[t]{3}{*}{16} & $s$ & 2 & 648 & 81 & 26 & $s$ & 5 & 705 & 133 \\
\hline & $C V$ & 7 & 13 & 10 & & $C V$ & 25 & 18 & 25 \\
\hline & $\bar{x}$ & 29 & 5028 & 721 & & $\bar{x}$ & 23 & 4134 & 596 \\
\hline \multirow[t]{3}{*}{17} & $S$ & 5 & 400 & 131 & 27 & $S$ & 4 & 531 & 104 \\
\hline & $C V$ & 19 & 8 & 18 & & $C V$ & 18 & 13 & 17 \\
\hline & $\bar{x}$ & 30 & 4840 & 764 & & $\bar{x}$ & 21 & 4121 & 548 \\
\hline \multirow[t]{3}{*}{18} & $S$ & 7 & 722 & 199 & 28 & $S$ & 4 & 581 & 119 \\
\hline & $C V$ & 25 & 15 & 26 & & $C V$ & 21 & 14 & 22 \\
\hline & $\bar{x}$ & 29 & 4948 & 737 & & $\bar{x}$ & 21 & 4115 & 568 \\
\hline \multirow[t]{3}{*}{19} & $s$ & 7 & 782 & 191 & 29 & $s$ & 5 & 531 & 130 \\
\hline & $C V$ & 24 & 16 & 26 & & $C V$ & 24 & 13 & 23 \\
\hline & $\bar{x}$ & 29 & 4928 & 753 & & $\bar{x}$ & 22 & 4015 & 580 \\
\hline \multirow[t]{2}{*}{110} & $S$ & 5 & 778 & 114 & 210 & $S$ & 3 & 320 & 81 \\
\hline & $C V$ & 16 & 16 & 15 & & $C V$ & 15 & 8 & 14 \\
\hline
\end{tabular}


Tabela 28 - Valores de força de ruptura, de módulos de elasticidade e de resistência na flexão estática na direção transversal dos painéis OSB dos grupos 1 e 2

\begin{tabular}{|c|c|c|c|c|c|c|c|c|c|}
\hline \multicolumn{2}{|c|}{$\begin{array}{l}\text { Painéis } \\
\text { Grupo } 1 \\
\end{array}$} & \multirow{2}{*}{$\begin{array}{c}\begin{array}{c}\mathbf{f}_{\mathrm{m} \perp} \\
(\mathrm{MPa})\end{array} \\
14\end{array}$} & \multirow{2}{*}{$\begin{array}{c}\begin{array}{c}\mathrm{E}_{\mathrm{m} \perp} \\
(\mathrm{MPa})\end{array} \\
1838\end{array}$} & \multirow{2}{*}{$\begin{array}{c}\begin{array}{c}\mathbf{F}_{\text {max } \perp} \\
(\mathbf{N})\end{array} \\
358\end{array}$} & \multicolumn{2}{|c|}{\begin{tabular}{|l|} 
Painéis \\
Grupo 2 \\
\end{tabular}} & \multirow{2}{*}{$\begin{array}{c}\begin{array}{c}\mathbf{f}_{\mathbf{m} \perp} \\
(\mathrm{MPa})\end{array} \\
14\end{array}$} & \multirow{2}{*}{$\begin{array}{c}\begin{array}{c}\mathrm{E}_{\mathrm{m} \perp} \\
(\mathrm{MPa})\end{array} \\
2099\end{array}$} & \multirow{2}{*}{$\begin{array}{c}\begin{array}{c}\mathbf{F}_{\max \perp} \\
(\mathbf{N})\end{array} \\
356\end{array}$} \\
\hline & $x$ & & & & & $\bar{x}$ & & & \\
\hline \multirow[t]{3}{*}{11} & $s$ & 1 & 174 & 34 & 21 & $s$ & 3 & 365 & 89 \\
\hline & $C V$ & 10 & 9 & 10 & & $C V$ & 25 & 17 & 25 \\
\hline & $\bar{x}$ & 14 & 1915 & 357 & & $\bar{x}$ & 14 & 2023 & 348 \\
\hline \multirow[t]{3}{*}{12} & $S$ & 4 & 375 & 114 & 22 & $s$ & 2 & 271 & 60 \\
\hline & $C V$ & 33 & 20 & 32 & & $C V$ & 17 & 13 & 17 \\
\hline & $\bar{x}$ & 15 & 1926 & 397 & & $\bar{x}$ & 12 & 1885 & 311 \\
\hline \multirow[t]{3}{*}{13} & $S$ & 3 & 213 & 83 & 23 & $s$ & 3 & 366 & 67 \\
\hline & $C V$ & 21 & 11 & 21 & & $C V$ & 22 & 19 & 22 \\
\hline & $\bar{x}$ & 11 & 1651 & 295 & & $\bar{x}$ & 14 & 2039 & 353 \\
\hline \multirow[t]{3}{*}{14} & $S$ & 2 & 159 & 41 & 24 & $S$ & 2 & 198 & 49 \\
\hline & $C V$ & 17 & 10 & 14 & & $C V$ & 13 & 10 & 14 \\
\hline & $\bar{x}$ & 14 & 1828 & 365 & & $\bar{x}$ & 14 & 2001 & 357 \\
\hline \multirow[t]{3}{*}{15} & $S$ & 1 & 80 & 28 & 25 & $S$ & 3 & 230 & 69 \\
\hline & $C V$ & 6 & 4 & 8 & & $C V$ & 18 & 12 & 19 \\
\hline & $\bar{x}$ & 14 & 1870 & 374 & & $\bar{x}$ & 14 & 1979 & 357 \\
\hline \multirow[t]{3}{*}{16} & $s$ & 2 & 188 & 64 & 26 & $S$ & 3 & 241 & 84 \\
\hline & $C V$ & 17 & 10 & 17 & & $C V$ & 22 & 12 & 23 \\
\hline & $\bar{x}$ & 2 & 1777 & 304 & & $\bar{x}$ & 14 & 1961 & 348 \\
\hline \multirow[t]{3}{*}{17} & $s$ & 2 & 213 & 46 & 27 & $s$ & 3 & 391 & 70 \\
\hline & $C V$ & 14 & 12 & 15 & & $C V$ & 19 & 20 & 20 \\
\hline & $x$ & 13 & 1653 & 334 & & $\bar{x}$ & 13 & 1812 & 321 \\
\hline \multirow[t]{3}{*}{18} & $s$ & 3 & 123 & 79 & 28 & $s$ & 2 & 193 & 56 \\
\hline & $C V$ & 20 & 7 & 24 & & $C V$ & 17 & 11 & 18 \\
\hline & $\bar{x}$ & 12 & 1629 & 298 & & $\bar{x}$ & 13 & 1870 & 349 \\
\hline \multirow[t]{3}{*}{19} & $S$ & 3 & 342 & 65 & 29 & $S$ & 3 & 270 & 73 \\
\hline & $C V$ & 25 & 21 & 22 & & $C V$ & 21 & 14 & 21 \\
\hline & $\bar{x}$ & 12 & 1665 & 311 & & $\bar{x}$ & 14 & 1984 & 360 \\
\hline \multirow[t]{2}{*}{110} & $S$ & 2 & 179 & 56 & 210 & $S$ & 1 & 208 & 35 \\
\hline & $C V$ & 19 & 11 & 18 & & $C V$ & 9 & 10 & 10 \\
\hline
\end{tabular}

Os valores médios referentes às velocidades e atenuações obtidas por medições do tempo de propagação, pelo aparelho de ultra-som, na espessura dos painéis, nos locais 
correspondentes aos corpos-de-prova de tração perpendicular às faces, densidade, inchamento e absorção de água estão apresentados nas Tabelas 29, 30 e 31. Os valores totais são apresentados no Apêndice C.

Tabela 29 - Velocidades de propagação de ondas: espessuras dos painéis OSB dos grupos 1 e 2

\begin{tabular}{|c|c|c|c|c|c|c|c|c|c|}
\hline \multicolumn{2}{|c|}{$\begin{array}{l}\text { Painéis } \\
\text { Grupo } 1 \\
\end{array}$} & \multirow{2}{*}{$\frac{\begin{array}{c}\mathbf{V}_{\mathrm{d}} \\
(\mathrm{m} / \mathrm{s})\end{array}}{849}$} & \multirow{2}{*}{$\begin{array}{c}\begin{array}{c}\mathrm{V}_{\mathrm{Al}} \\
(\mathbf{m} / \mathbf{s})\end{array} \\
840\end{array}$} & \multirow{2}{*}{$\begin{array}{c}\begin{array}{c}\mathbf{V}_{\text {Gt/Am }} \\
(\mathbf{m} / \mathbf{s})\end{array} \\
\frac{854}{2}\end{array}$} & \multicolumn{2}{|c|}{$\begin{array}{l}\text { Painéis } \\
\text { Grupo } 2 \\
\end{array}$} & \multirow{2}{*}{$\begin{array}{c}\begin{array}{c}V_{d} \\
(\mathrm{~m} / \mathrm{s})\end{array} \\
843\end{array}$} & \multirow{2}{*}{$\begin{array}{c}\begin{array}{c}\mathrm{V}_{\mathrm{Al}} \\
(\mathrm{m} / \mathbf{s})\end{array} \\
862\end{array}$} & \multirow{2}{*}{$\begin{array}{r}\begin{array}{r}\mathbf{V}_{\mathrm{Gt} / \mathrm{Am}} \\
(\mathrm{m} / \mathrm{s})\end{array} \\
856\end{array}$} \\
\hline & $\bar{x}$ & & & & & $\bar{x}$ & & & \\
\hline \multirow[t]{3}{*}{11} & $s$ & 90 & 75 & 67 & 21 & $s$ & 80 & 97 & 106 \\
\hline & $C V$ & 11 & 9 & 8 & & $C V$ & 9 & 11 & 12 \\
\hline & $\bar{x}$ & 927 & 855 & 841 & & $\bar{x}$ & 846 & 840 & 863 \\
\hline \multirow[t]{3}{*}{12} & $S$ & 91 & 101 & 111 & 22 & $S$ & 84 & 100 & 94 \\
\hline & $C V$ & 10 & 12 & 25 & & $C V$ & 11 & 12 & 11 \\
\hline & $\bar{x}$ & 862 & 865 & 883 & & $\bar{x}$ & 904 & 896 & 895 \\
\hline \multirow[t]{3}{*}{13} & $s$ & 76 & 90 & 82 & 23 & $s$ & 95 & 97 & 73 \\
\hline & $C V$ & 9 & 10 & 9 & & $C V$ & 10 & 11 & 8 \\
\hline & $\bar{x}$ & 880 & 904 & 911 & & $\bar{x}$ & 917 & 903 & 915 \\
\hline \multirow[t]{3}{*}{14} & $s$ & 74 & 115 & 108 & 24 & $S$ & 86 & 63 & 91 \\
\hline & $C V$ & 8 & 13 & 12 & & $C V$ & 9 & 7 & 10 \\
\hline & $\bar{x}$ & 902 & 884 & 855 & & $\bar{x}$ & 874 & 860 & 829 \\
\hline \multirow[t]{3}{*}{15} & $S$ & 96 & 85 & 71 & 25 & $S$ & 104 & 57 & 75 \\
\hline & $C V$ & 11 & 10 & 8 & & $C V$ & 12 & 7 & 9 \\
\hline & $\bar{x}$ & 874 & 881 & 873 & & $\bar{x}$ & 900 & 879 & 882 \\
\hline \multirow[t]{3}{*}{16} & $s$ & 73 & 75 & 76 & 26 & $S$ & 76 & 97 & 83 \\
\hline & $C V$ & 8 & 9 & 9 & & $C V$ & 8 & 11 & 9 \\
\hline & $\bar{x}$ & 916 & 885 & 899 & & $\bar{x}$ & 881 & 855 & 896 \\
\hline \multirow[t]{3}{*}{17} & $S$ & 56 & 94 & 105 & 27 & $S$ & 66 & 76 & 58 \\
\hline & $C V$ & 6 & 11 & 12 & & $C V$ & 7 & 9 & 6 \\
\hline & $\bar{x}$ & 836 & 842 & 851 & & $\bar{x}$ & 864 & 928 & 866 \\
\hline \multirow[t]{3}{*}{18} & $S$ & 73 & 80 & 76 & 28 & $s$ & 75 & 72 & 78 \\
\hline & $C V$ & 9 & 9 & 9 & & $C V$ & 9 & 8 & 9 \\
\hline & $\bar{x}$ & 850 & 851 & 854 & & $\bar{x}$ & 851 & 860 & 873 \\
\hline \multirow[t]{3}{*}{19} & $s$ & 73 & 71 & 95 & 29 & $S$ & 96 & 59 & 70 \\
\hline & $C V$ & 9 & 8 & 11 & & $C V$ & 11 & 7 & 8 \\
\hline & $\bar{x}$ & 921 & 872 & 892 & & $\bar{x}$ & 848 & 857 & 874 \\
\hline \multirow[t]{2}{*}{110} & $S$ & 66 & 121 & 111 & 210 & $S$ & 69 & 53 & 60 \\
\hline & $C V$ & 7 & 14 & 12 & & $C V$ & 8 & 6 & 7 \\
\hline
\end{tabular}


Tabela 30 - Constantes dinâmicas de propagação de ondas: espessura dos painéis OSB dos grupos 1 e 2

\begin{tabular}{|c|c|c|c|c|c|c|c|c|c|}
\hline \multicolumn{2}{|c|}{$\begin{array}{l}\text { Painéis } \\
\text { Grupo } 1\end{array}$} & \multirow{2}{*}{$\begin{array}{c}\begin{array}{c}\mathrm{C}_{\mathrm{d}} \\
(\mathrm{MPa})\end{array} \\
418\end{array}$} & \multirow{2}{*}{$\begin{array}{c}\begin{array}{c}\mathrm{C}_{\mathrm{Al}} \\
(\mathrm{MPa})\end{array} \\
408\end{array}$} & \multirow{2}{*}{$\begin{array}{c}\begin{array}{c}\mathrm{C}_{\mathrm{Gt} / \mathrm{Am}} \\
(\mathrm{MPa})\end{array} \\
421\end{array}$} & \multicolumn{2}{|c|}{$\begin{array}{l}\text { Painéis } \\
\text { Grupo } 2\end{array}$} & \multirow{2}{*}{$\begin{array}{c}\begin{array}{c}\mathrm{C}_{\mathrm{d}} \\
(\mathrm{MPa})\end{array} \\
424\end{array}$} & \multirow{2}{*}{$\begin{array}{c}\begin{array}{c}\mathrm{C}_{\mathrm{Al}} \\
(\mathrm{MPa})\end{array} \\
446\end{array}$} & \multirow{2}{*}{$\begin{array}{c}\begin{array}{c}\mathrm{C}_{\mathrm{Gt} / \mathrm{Am}} \\
(\mathrm{MPa})\end{array} \\
440\end{array}$} \\
\hline & $\bar{x}$ & & & & & $\bar{x}$ & & & \\
\hline \multirow[t]{3}{*}{11} & $S$ & 85 & 71 & 63 & 21 & $S$ & 81 & 98 & 99 \\
\hline & $C V$ & 20 & 17 & 15 & & $C V$ & 19 & 22 & 22 \\
\hline & $\bar{x}$ & 497 & 424 & 441 & & $\bar{x}$ & 432 & 427 & 449 \\
\hline \multirow[t]{3}{*}{12} & $S$ & 98 & 96 & 111 & 22 & $S$ & 94 & 99 & 97 \\
\hline & $C V$ & 20 & 23 & 25 & & $C V$ & 22 & 23 & 22 \\
\hline & $\bar{x}$ & 437 & 441 & 458 & & $\bar{x}$ & 498 & 489 & 486 \\
\hline \multirow[t]{3}{*}{13} & $S$ & 77 & 91 & 84 & 23 & $S$ & 103 & 102 & 77 \\
\hline & $C V$ & 18 & 21 & 18 & & $C V$ & 21 & 21 & 16 \\
\hline & $\bar{x}$ & 440 & 465 & 475 & & $\overline{\bar{x}}$ & 535 & 517 & 533 \\
\hline \multirow[t]{3}{*}{14} & $s$ & 75 & 76 & 104 & 24 & $s$ & 97 & 72 & 102 \\
\hline & $C V$ & 17 & 16 & 22 & & $\mathrm{CV}$ & 18 & 14 & 19 \\
\hline & $\bar{x}$ & 489 & 469 & 437 & & $\bar{x}$ & 458 & 439 & 410 \\
\hline \multirow[t]{3}{*}{15} & $s$ & 104 & 88 & 74 & 25 & $s$ & 108 & 57 & 74 \\
\hline & $C V$ & 21 & 19 & 17 & & $\mathrm{CV}$ & 24 & 13 & 18 \\
\hline & $\bar{x}$ & 430 & 437 & 429 & & $\bar{x}$ & 484 & 463 & 465 \\
\hline \multirow[t]{3}{*}{16} & $s$ & 72 & 71 & 77 & 26 & $s$ & 81 & 102 & 88 \\
\hline & $C V$ & 17 & 16 & 18 & & $C V$ & 17 & 22 & 19 \\
\hline & $\bar{x}$ & 491 & 461 & 477 & & $\bar{x}$ & 465 & 439 & 481 \\
\hline \multirow[t]{3}{*}{17} & $s$ & 62 & 98 & 105 & 27 & $S$ & 69 & 78 & 64 \\
\hline & $C V$ & 13 & 21 & 22 & & $C V$ & 15 & 18 & 13 \\
\hline & $\bar{x}$ & 401 & 407 & 416 & & $\bar{x}$ & 417 & 481 & 419 \\
\hline \multirow[t]{3}{*}{18} & $s$ & 71 & 77 & 75 & 28 & $s$ & 71 & 76 & 72 \\
\hline & $C V$ & 18 & 19 & 18 & & $C V$ & 17 & 16 & 17 \\
\hline & $\bar{x}$ & 410 & 410 & 415 & & $\bar{x}$ & 407 & 412 & 426 \\
\hline \multirow[t]{3}{*}{19} & $s$ & 78 & 65 & 94 & 29 & $s$ & 85 & 56 & 70 \\
\hline & $C V$ & 19 & 16 & 23 & & $C V$ & 21 & 14 & 16 \\
\hline & $\bar{x}$ & 506 & 459 & 480 & & $\bar{x}$ & 425 & 432 & 449 \\
\hline \multirow[t]{2}{*}{110} & $s$ & 72 & 125 & 108 & 210 & $s$ & 69 & 53 & 62 \\
\hline & $C V$ & 14 & 27 & 22 & & $C V$ & 16 & 12 & 14 \\
\hline
\end{tabular}


Na Tabela $31 \operatorname{Atn}_{\mathrm{d}}, \operatorname{Atn}_{\mathrm{Al}}$ e $A \operatorname{tn}_{\mathrm{Gt} / \mathrm{Am}}$ significam, respectivamente, as atenuações medidas nos locais referentes aos corpos-de-prova de densidade, tração perpendicular às faces e inchamento / absorção de água.

Tabela 31 - Atenuações de propagação de ondas: espessura dos painéis OSB dos grupos 1 e 2

\begin{tabular}{|c|c|c|c|c|c|c|c|c|c|}
\hline \multicolumn{2}{|c|}{$\begin{array}{l}\text { Painéis } \\
\text { Grupo } 1\end{array}$} & \multirow{2}{*}{$\begin{array}{c}\begin{array}{c}\text { Atn }_{\mathrm{d}} \\
(\mathrm{d} \boldsymbol{\beta} \text { loss })\end{array} \\
59\end{array}$} & \multirow{2}{*}{$\begin{array}{c}\begin{array}{c}\text { Atn } \\
\text { Al } \\
(\mathrm{d} \beta \text { loss })\end{array} \\
58\end{array}$} & \multirow{2}{*}{$\begin{array}{c}\begin{array}{c}\text { Atn } \\
\text { (d } \beta \text { loss } / A m\end{array} \\
61\end{array}$} & \multicolumn{2}{|c|}{$\begin{array}{l}\text { Painéis } \\
\text { Grupo } 2 \\
\end{array}$} & \multirow{2}{*}{$\begin{array}{c}\begin{array}{c}\text { Atn }_{\mathrm{d}} \\
\text { (dß loss) }\end{array} \\
59\end{array}$} & \multirow{2}{*}{$\frac{\begin{array}{c}\text { Atn }_{\mathrm{Al}} \\
\text { (d } \boldsymbol{\beta} \text { loss })\end{array}}{58}$} & \multirow{2}{*}{$\begin{array}{c}\begin{array}{c}\text { Atn } \\
\text { (dt/Am }\end{array} \\
\frac{d \beta \text { loss) }}{60}\end{array}$} \\
\hline & $\bar{x}$ & & & & \multirow{3}{*}{21} & $\bar{x}$ & & & \\
\hline \multirow[t]{3}{*}{11} & $s$ & 6 & 6 & 6 & & $s$ & 5 & 5 & 4 \\
\hline & $C V$ & 9 & 10 & 10 & & $C V$ & 9 & 9 & 7 \\
\hline & $\bar{x}$ & 56 & 59 & 59 & \multirow{3}{*}{22} & $\bar{x}$ & 58 & 59 & 58 \\
\hline \multirow[t]{3}{*}{12} & $s$ & 5 & 6 & 5 & & $s$ & 5 & 6 & 6 \\
\hline & $C V$ & 9 & 10 & 9 & & $C V$ & 9 & 10 & 10 \\
\hline & $\bar{x}$ & 56 & 58 & 54 & \multirow{3}{*}{23} & $\bar{x}$ & 57 & 59 & 56 \\
\hline \multirow[t]{3}{*}{13} & $s$ & 7 & 5 & 4 & & $s$ & 5 & 5 & 6 \\
\hline & $C V$ & 12 & 9 & 8 & & $C V$ & 9 & 8 & 10 \\
\hline & $\bar{x}$ & 56 & 56 & 58 & \multirow{3}{*}{24} & $\bar{x}$ & 57 & 57 & 56 \\
\hline \multirow[t]{3}{*}{14} & $s$ & 6 & 9 & 4 & & $s$ & 5 & 6 & 4 \\
\hline & $C V$ & 10 & 15 & 7 & & $C V$ & 9 & 10 & 8 \\
\hline & $\bar{x}$ & 56 & 56 & 57 & \multirow{3}{*}{25} & $\bar{x}$ & 58 & 59 & 59 \\
\hline \multirow[t]{3}{*}{15} & $S$ & 5 & 7 & 6 & & $S$ & 5 & 5 & 4 \\
\hline & $C V$ & 9 & 12 & 11 & & $C V$ & 8 & 8 & 6 \\
\hline & $\bar{x}$ & 56 & 55 & 56 & \multirow{3}{*}{26} & $\bar{x}$ & 56 & 58 & 56 \\
\hline \multirow[t]{3}{*}{16} & $S$ & 5 & 5 & 5 & & $S$ & 5 & 5 & 5 \\
\hline & $C V$ & 8 & 9 & 9 & & $C V$ & 8 & 9 & 8 \\
\hline & $\bar{x}$ & 53 & 54 & 56 & \multirow{3}{*}{27} & $\bar{x}$ & 58 & 57 & 58 \\
\hline \multirow[t]{3}{*}{17} & $S$ & 4 & 6 & 5 & & $S$ & 5 & 5 & 5 \\
\hline & $C V$ & 7 & 10 & 9 & & $C V$ & 9 & 8 & 8 \\
\hline & $\bar{x}$ & 58 & 55 & 57 & \multirow{3}{*}{28} & $\bar{x}$ & 58 & 56 & 59 \\
\hline \multirow[t]{3}{*}{18} & $S$ & 6 & 11 & 6 & & $S$ & 5 & 5 & 5 \\
\hline & $C V$ & 10 & 20 & 10 & & $C V$ & 9 & 10 & 8 \\
\hline & $\bar{x}$ & 57 & 58 & 57 & \multirow{3}{*}{29} & $\bar{x}$ & 58 & 59 & 58 \\
\hline \multirow[t]{3}{*}{19} & $s$ & 6 & 5 & 5 & & $s$ & 4 & 4 & 4 \\
\hline & $C V$ & 10 & 9 & 8 & & $C V$ & 6 & 7 & 6 \\
\hline & $\bar{x}$ & 55 & 57 & 57 & \multirow{3}{*}{210} & $\bar{x}$ & 59 & 58 & 58 \\
\hline \multirow[t]{2}{*}{110} & $S$ & 6 & 5 & 5 & & $S$ & 4 & 4 & 4 \\
\hline & $C V$ & 10 & 9 & 8 & & $C V$ & 7 & 6 & 7 \\
\hline
\end{tabular}


As Tabelas 32 e 33 apresentam os valores médios de velocidade e constantes dinâmicas de propagação de ondas nas direções longitudinal e transversal, obtidos através do método de ultra-som. No Apêndice C estão contidos os valores totais.

Tabela 32 - Velocidades de propagação de ondas: direções longitudinal e transversal dos painéis OSB dos grupos 1 e 2 - ultra-som

\begin{tabular}{|c|c|c|c|c|c|c|c|}
\hline \multicolumn{2}{|c|}{$\begin{array}{l}\text { Painéis } \\
\text { Grupo } 1\end{array}$} & \multirow{2}{*}{$\begin{array}{c}\begin{array}{c}V_{/ l} \\
(\mathrm{~m} / \mathrm{s})\end{array} \\
3157\end{array}$} & \multirow{2}{*}{$\begin{array}{c}\begin{array}{c}\mathbf{V}_{\perp} \\
(\mathrm{m} / \mathrm{s})\end{array} \\
2497\end{array}$} & \multicolumn{2}{|c|}{$\begin{array}{l}\text { Painéis } \\
\text { Grupo } 2 \\
\end{array}$} & \multirow{2}{*}{$\begin{array}{c}\begin{array}{c}V_{/ l} \\
(\mathrm{~m} / \mathrm{s})\end{array} \\
2853\end{array}$} & \multirow{2}{*}{$\begin{array}{c}\begin{array}{c}V_{\perp} \\
(\mathrm{m} / \mathrm{s}\end{array} \\
2496\end{array}$} \\
\hline & $\bar{x}$ & & & & $\bar{x}$ & & \\
\hline \multirow[t]{3}{*}{11} & $s$ & 25 & 33 & 21 & $s$ & 27 & 43 \\
\hline & $C V$ & 1 & 1 & & $C V$ & 1 & 2 \\
\hline & $\bar{x}$ & 3182 & 2487 & & $\bar{x}$ & 2866 & 2516 \\
\hline \multirow[t]{3}{*}{12} & $s$ & 19 & 31 & 22 & $s$ & 20 & 47 \\
\hline & $C V$ & 1 & 1 & & $C V$ & 1 & 2 \\
\hline & $\bar{x}$ & 3179 & 2494 & & $\bar{x}$ & 2867 & 2535 \\
\hline \multirow[t]{3}{*}{13} & $s$ & 21 & 45 & 23 & $s$ & 24 & 42 \\
\hline & $C V$ & 1 & 2 & & $C V$ & 1 & 2 \\
\hline & $\bar{x}$ & 3184 & 2479 & & $\bar{x}$ & 2869 & 2510 \\
\hline \multirow[t]{3}{*}{14} & $s$ & 21 & 26 & 24 & $s$ & 18 & 44 \\
\hline & $C V$ & 1 & 1 & & $C V$ & 1 & 2 \\
\hline & $\bar{x}$ & 3151 & 2486 & & $\bar{x}$ & 2864 & 2506 \\
\hline \multirow[t]{3}{*}{15} & $s$ & 29 & 32 & 25 & $S$ & 21 & 52 \\
\hline & $C V$ & 1 & 1 & & $C V$ & 1 & 2 \\
\hline & $x$ & 3160 & 2472 & & $x$ & 2848 & 259 \\
\hline \multirow[t]{3}{*}{16} & $s$ & 25 & 36 & 26 & $s$ & 16 & 37 \\
\hline & $C V$ & 1 & 1 & & $C V$ & 1 & 1 \\
\hline & $\bar{x}$ & 3017 & 2232 & & $\bar{x}$ & 2856 & 2519 \\
\hline \multirow[t]{3}{*}{17} & $s$ & 32 & 27 & 27 & $s$ & 14 & 45 \\
\hline & $C V$ & 1 & 1 & & $C V$ & 0 & 2 \\
\hline & $\bar{x}$ & 3162 & 2478 & & $\bar{x}$ & 2859 & 2507 \\
\hline \multirow[t]{3}{*}{18} & $s$ & 20 & 35 & 28 & $s$ & 29 & 48 \\
\hline & $C V$ & 1 & 1 & & $C V$ & 1 & 2 \\
\hline & $\bar{x}$ & 3135 & 2459 & & $\bar{x}$ & 2851 & 2487 \\
\hline \multirow[t]{3}{*}{19} & $s$ & 25 & 46 & 29 & $s$ & 35 & 44 \\
\hline & $C V$ & 1 & 2 & & $C V$ & 1 & 2 \\
\hline & $\overline{\bar{x}}$ & 3148 & 2469 & & $\overline{\bar{x}}$ & 2837 & 2481 \\
\hline \multirow[t]{2}{*}{110} & $s$ & 48 & 34 & 210 & $s$ & 34 & 41 \\
\hline & $C V$ & 2 & 1 & & $C V$ & 1 & 2 \\
\hline
\end{tabular}


Tabela 33 - Constantes dinâmicas de propagação de ondas: direções longitudinal e transversal dos painéis OSB dos grupos 1 e 2 - ultra-som

\begin{tabular}{|c|c|c|c|c|c|c|c|}
\hline \multicolumn{2}{|c|}{$\begin{array}{l}\text { Painéis } \\
\text { Grupo } 1\end{array}$} & \multirow{2}{*}{$\begin{array}{c}\begin{array}{c}\mathbf{C}_{/ /} \\
(\mathrm{MPa})\end{array} \\
5721\end{array}$} & \multirow{2}{*}{$\begin{array}{c}\begin{array}{c}\mathbf{C}_{\perp} \\
(\mathrm{MPa})\end{array} \\
3580\end{array}$} & \multicolumn{2}{|c|}{$\begin{array}{l}\text { Painéis } \\
\text { Grupo } 2 \\
\end{array}$} & \multirow{2}{*}{$\begin{array}{c}\begin{array}{c}\mathbf{C}_{/ I} \\
(\mathbf{M P a})\end{array} \\
4845\end{array}$} & \multirow{2}{*}{$\begin{array}{c}\begin{array}{c}\mathbf{C}_{\perp} \\
(\mathbf{M P a})\end{array} \\
3707\end{array}$} \\
\hline & $\bar{x}$ & & & & $\bar{x}$ & & \\
\hline \multirow[t]{3}{*}{11} & $s$ & 89 & 95 & 21 & $s$ & 92 & 127 \\
\hline & $C V$ & 2 & 3 & & $C V$ & 2 & 3 \\
\hline & $\bar{x}$ & 5802 & 3534 & & $\bar{x}$ & 4905 & 3780 \\
\hline \multirow[t]{3}{*}{12} & $S$ & 69 & 88 & 22 & $S$ & 69 & 141 \\
\hline & $C V$ & 1 & 2 & & $C V$ & 1 & 4 \\
\hline & $\bar{x}$ & 5891 & 3628 & & $\bar{x}$ & 4955 & 3876 \\
\hline \multirow[t]{3}{*}{13} & $s$ & 78 & 132 & 23 & $s$ & 81 & 129 \\
\hline & $C V$ & 1 & 4 & & $C V$ & 2 & 3 \\
\hline & $\bar{x}$ & 5727 & 3472 & & $\bar{x}$ & 5194 & 3977 \\
\hline \multirow[t]{3}{*}{14} & $s$ & 75 & 73 & 24 & $S$ & 65 & 141 \\
\hline & $C V$ & 1 & 2 & & $C V$ & 1 & 4 \\
\hline & $\bar{x}$ & 5899 & 3670 & & $\bar{x}$ & 4848 & 3712 \\
\hline \multirow[t]{3}{*}{15} & $S$ & 108 & 95 & 25 & $S$ & 70 & 155 \\
\hline & $C V$ & 2 & 3 & & $C V$ & 1 & 4 \\
\hline & $\bar{x}$ & 5582 & 3415 & & $\bar{x}$ & 4810 & 3765 \\
\hline \multirow[t]{3}{*}{16} & $S$ & 89 & 100 & 26 & $S$ & 53 & 110 \\
\hline & $C V$ & 2 & 3 & & $C V$ & 1 & 3 \\
\hline & $\bar{x}$ & 5297 & 2900 & & $\bar{x}$ & 4863 & 3784 \\
\hline \multirow[t]{3}{*}{17} & $s$ & 112 & 71 & 27 & $s$ & 47 & 135 \\
\hline & $C V$ & 2 & 2 & & $C V$ & 1 & 4 \\
\hline & $\bar{x}$ & 5699 & 3501 & & $\bar{x}$ & 4537 & 3490 \\
\hline \multirow[t]{3}{*}{18} & $s$ & 71 & 98 & 28 & $s$ & 93 & 135 \\
\hline & $C V$ & 1 & 3 & & $C V$ & 2 & 4 \\
\hline & $\bar{x}$ & 5533 & 3406 & & $\bar{x}$ & 4513 & 3433 \\
\hline \multirow[t]{3}{*}{19} & $s$ & 87 & 127 & 29 & $S$ & 112 & 120 \\
\hline & $C V$ & 2 & 4 & & $C V$ & 2 & 3 \\
\hline & $\overline{\bar{x}}$ & 5889 & 3621 & & $\overline{\bar{x}}$ & 4717 & 3608 \\
\hline \multirow[t]{2}{*}{110} & $S$ & 178 & 98 & 210 & $s$ & 114 & 118 \\
\hline & $C V$ & 3 & 3 & & $C V$ & 2 & 3 \\
\hline
\end{tabular}


Os valores médios de velocidade e constantes dinâmicas de propagação de ondas nas direções longitudinal e transversal, obtidos através do método de stress wave, são apresentados nas Tabelas 34 e 35. O Apêndice C apresenta os valores totais.

Tabela 34 - Velocidades de propagação de ondas: direções longitudinal e transversal dos painéis OSB dos grupos 1 e 2 - stress wave

\begin{tabular}{|c|c|c|c|c|c|c|c|}
\hline \multicolumn{2}{|c|}{$\begin{array}{l}\text { Painéis } \\
\text { Grupo } 1 \\
\end{array}$} & \multirow{2}{*}{$\begin{array}{c}\begin{array}{c}V_{/ I} \\
(\mathrm{~m} / \mathrm{s})\end{array} \\
2986\end{array}$} & \multirow{2}{*}{$\begin{array}{c}\begin{array}{c}\mathbf{V}_{\perp} \\
(\mathrm{m} / \mathrm{s})\end{array} \\
2212\end{array}$} & \multicolumn{2}{|c|}{$\begin{array}{l}\text { Painéis } \\
\text { Grupo } 2\end{array}$} & \multirow{2}{*}{$\begin{array}{c}\begin{array}{c}\mathbf{V}_{/ I} \\
(\mathrm{~m} / \mathrm{s})\end{array} \\
2727\end{array}$} & \multirow{2}{*}{$\begin{array}{c}\begin{array}{c}\mathbf{V}_{\perp} \\
(\mathbf{m} / \mathbf{s})\end{array} \\
2215\end{array}$} \\
\hline & $\bar{x}$ & & & & $\bar{x}$ & & \\
\hline \multirow[t]{3}{*}{11} & $s$ & 18 & 49 & 21 & $S$ & 21 & 35 \\
\hline & $C V$ & 1 & 2 & & $C V$ & 1 & 2 \\
\hline & $\bar{x}$ & 3009 & 2227 & & $\bar{x}$ & 2706 & 2041 \\
\hline \multirow[t]{3}{*}{12} & $s$ & 26 & 31 & 22 & $S$ & 34 & 356 \\
\hline & $C V$ & 1 & 1 & & $C V$ & 1 & 17 \\
\hline & $\bar{x}$ & 3034 & 2233 & & $\bar{x}$ & 2729 & 2230 \\
\hline \multirow[t]{3}{*}{13} & $S$ & 14 & 26 & 23 & $S$ & 22 & 36 \\
\hline & $C V$ & 0 & 1 & & $C V$ & 1 & 2 \\
\hline & $\bar{x}$ & 3030 & 2232 & & $\bar{x}$ & 2667 & 2220 \\
\hline \multirow[t]{3}{*}{14} & $s$ & 19 & 23 & 24 & $s$ & 252 & 32 \\
\hline & $C V$ & 1 & 1 & & $C V$ & 9 & 1 \\
\hline & $\bar{x}$ & 3023 & 2228 & & $\bar{x}$ & 2723 & 2236 \\
\hline \multirow[t]{3}{*}{15} & $s$ & 17 & 35 & 25 & $s$ & 18 & 40 \\
\hline & $C V$ & 1 & 2 & & $C V$ & 1 & 2 \\
\hline & $\bar{x}$ & 3013 & 2222 & & $\bar{x}$ & 2738 & 2233 \\
\hline \multirow[t]{3}{*}{16} & $s$ & 18 & 24 & 26 & $s$ & 18 & 48 \\
\hline & $C V$ & 1 & 1 & & $C V$ & 1 & 2 \\
\hline & $\bar{x}$ & 2901 & 2046 & & $\bar{x}$ & 2740 & 2219 \\
\hline \multirow[t]{3}{*}{17} & $s$ & 25 & 31 & 27 & $S$ & 21 & 49 \\
\hline & $C V$ & 1 & 2 & & $C V$ & 1 & 2 \\
\hline & $\bar{x}$ & 3007 & 2228 & & $\bar{x}$ & 2752 & 2220 \\
\hline \multirow[t]{3}{*}{18} & $s$ & 27 & 23 & 28 & $S$ & 54 & 46 \\
\hline & $C V$ & 1 & 1 & & $C V$ & 2 & 2 \\
\hline & $\bar{x}$ & 3005 & 2216 & & $\bar{x}$ & 2726 & 2220 \\
\hline \multirow[t]{3}{*}{19} & $s$ & 29 & 27 & 29 & $S$ & 21 & 48 \\
\hline & $C V$ & 1 & 1 & & $C V$ & 1 & 2 \\
\hline & $\bar{x}$ & 3000 & 2236 & & $\bar{x}$ & 2746 & 2232 \\
\hline \multirow[t]{2}{*}{110} & $s$ & 62 & 44 & 210 & $S$ & 34 & 35 \\
\hline & $C V$ & 2 & 2 & & $C V$ & 1 & 2 \\
\hline
\end{tabular}


Tabela 35 - Constantes dinâmicas de propagação de ondas: direções longitudinal e transversal dos painéis OSB dos grupos 1 e 2 - stress wave

\begin{tabular}{|c|c|c|c|c|c|c|c|}
\hline \multicolumn{2}{|c|}{$\begin{array}{l}\text { Painéis } \\
\text { Grupo } 1\end{array}$} & \multirow{2}{*}{$\begin{array}{c}\begin{array}{c}\mathbf{C}_{/ /} \\
(\mathrm{MPa})\end{array} \\
5118\end{array}$} & \multirow{2}{*}{$\begin{array}{c}\begin{array}{c}\mathrm{C}_{\perp} \\
(\mathrm{MPa})\end{array} \\
2809\end{array}$} & \multicolumn{2}{|c|}{$\begin{array}{l}\text { Painéis } \\
\text { Grupo } 2 \\
\end{array}$} & \multirow{2}{*}{$\begin{array}{c}\begin{array}{c}\mathbf{C}_{/ /} \\
(\mathrm{MPa})\end{array} \\
4402\end{array}$} & \multirow{2}{*}{$\begin{array}{c}\begin{array}{c}\mathbf{C}_{\perp} \\
\text { (MPa) }\end{array} \\
2904\end{array}$} \\
\hline & $\bar{x}$ & & & & $\bar{x}$ & & \\
\hline \multirow[t]{3}{*}{11} & $s$ & 61 & 120 & 21 & $S$ & 69 & 92 \\
\hline & $C V$ & 1 & 4 & & $C V$ & 2 & 3 \\
\hline & $\bar{x}$ & 5189 & 2843 & & $\bar{x}$ & 4373 & 2561 \\
\hline \multirow[t]{3}{*}{12} & $s$ & 91 & 80 & 22 & $S$ & 109 & 701 \\
\hline & $C V$ & 2 & 3 & & $C V$ & 2 & 27 \\
\hline & $\bar{x}$ & 5369 & 2907 & & $\bar{x}$ & 4492 & 2999 \\
\hline \multirow[t]{3}{*}{13} & $s$ & 39 & 67 & 23 & $s$ & 73 & 97 \\
\hline & $C V$ & 1 & 2 & & $C V$ & 2 & 3 \\
\hline & $\bar{x}$ & 5189 & 2815 & & $\bar{x}$ & 4527 & 3111 \\
\hline \multirow[t]{3}{*}{14} & $s$ & 64 & 60 & 24 & $s$ & 731 & 90 \\
\hline & $C V$ & 1 & 2 & & $C V$ & 16 & 3 \\
\hline & $\bar{x}$ & 5430 & 2950 & & $\bar{x}$ & 4384 & 2955 \\
\hline \multirow[t]{3}{*}{15} & $s$ & 59 & 93 & 25 & $s$ & 56 & 106 \\
\hline & $C V$ & 1 & 3 & & $C V$ & 1 & 4 \\
\hline & $\bar{x}$ & 5075 & 2760 & & $\bar{x}$ & 4447 & 2959 \\
\hline \multirow[t]{3}{*}{16} & $s$ & 62 & 59 & 26 & $s$ & 59 & 126 \\
\hline & $C V$ & 1 & 2 & & $C V$ & 1 & 4 \\
\hline & $\bar{x}$ & 4898 & 2438 & & $\bar{x}$ & 4475 & 2935 \\
\hline \multirow[t]{3}{*}{17} & $s$ & 85 & 75 & 27 & $s$ & 67 & 129 \\
\hline & $C V$ & 2 & 3 & & $C V$ & 1 & 4 \\
\hline & $\bar{x}$ & 5153 & 2829 & & $\bar{x}$ & 4204 & 2737 \\
\hline \multirow[t]{3}{*}{18} & $s$ & 93 & 59 & 28 & $s$ & 167 & 113 \\
\hline & $C V$ & 2 & 2 & & $C V$ & 4 & 4 \\
\hline & $\bar{x}$ & 5086 & 2765 & & $\bar{x}$ & 4123 & 2736 \\
\hline \multirow[t]{3}{*}{19} & $S$ & 97 & 67 & 29 & $S$ & 64 & 118 \\
\hline & $C V$ & 2 & 2 & & $C V$ & 2 & 4 \\
\hline & $\bar{x}$ & 5348 & 2971 & & $\bar{x}$ & 4418 & 2920 \\
\hline \multirow[t]{2}{*}{110} & $s$ & 218 & 116 & 210 & $s$ & 108 & 91 \\
\hline & $C V$ & 4 & 4 & & $C V$ & 2 & 3 \\
\hline
\end{tabular}

Os coeficientes de determinação obtidos para os painéis do Grupo 1, quando comparados os valores dos ensaios destrutivos aos dos não-destrutivos, pelos 
métodos de ultra-som e stress wave, variaram de 0,0081 a 0,1209 e os de correlação variaram de 0,09 a 0,35. Para os painéis do Grupo 2 esses valores variaram de 0,0008 a 0,3146 e de 0,03 a 0,56 , respectivamente.

No ponto de medição 13 , para o método de stress wave, na direção longitudinal, o tempo de propagação da onda $(1717 \mu \mathrm{s})$ mostrou-se discrepante dentre os demais (em média, na faixa de $880 \mu \mathrm{s}$ ) interferindo nos valores de $\mathrm{V}$ e $\mathrm{C}$ para as correlações com os valores de módulos de resistência e de elasticidade do corpo-de-prova $\mathrm{F}_{9 / /}$.

Nos pontos de medição 12, 28 e 29, para o método de stress wave, na

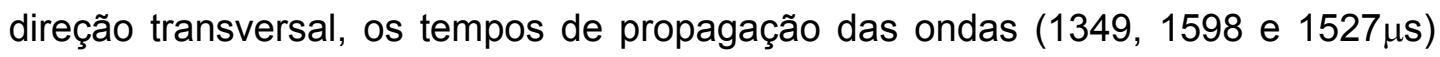
mostraram-se discrepantes dentre os demais (em média, na faixa de 610 $\mu$ s) interferindo nos valores de $\mathrm{V}$ e C para as correlações com os valores de módulos de resistência e de elasticidade com os corpos-de-prova $F_{11 \perp}$ e $F 20_{\perp}$.

As Figuras 21 e 22 mostram exemplos gráficos, de retas de regressão, encontrados entre os valores médios obtidos nos ensaios destrutivos e nos nãodestrutivos, através dos métodos de ultra-som e de stress wave, respectivamente. Todos os gráficos de retas de regressão são apresentados nos Apêndices H, I, J e L.

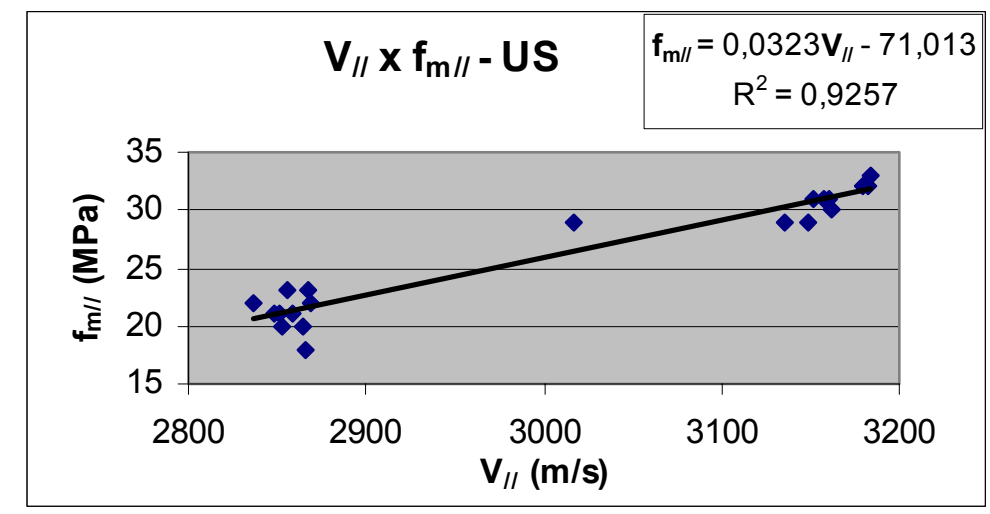

Figura 21 - Velocidade x resistência na flexão estática, na direção longitudinal, com medições realizadas pelo ultra-som - valores médios. 


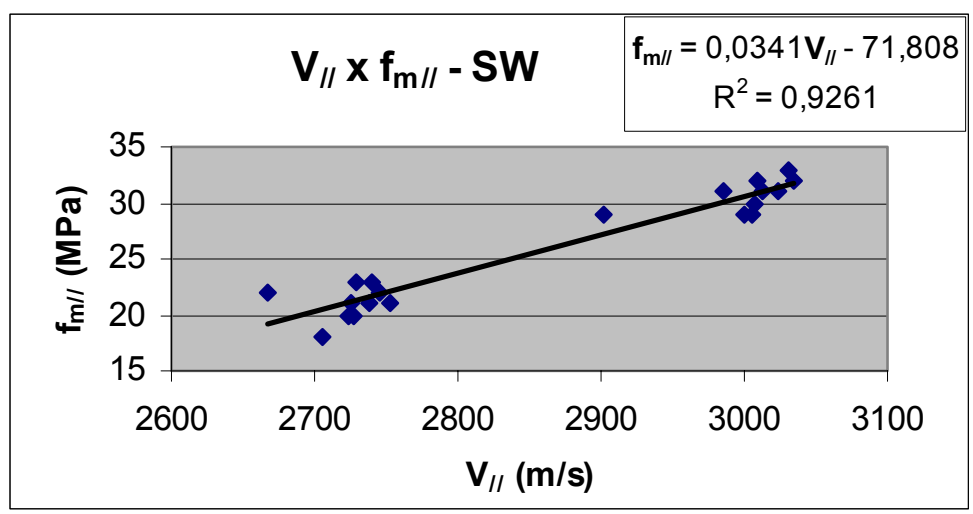

Figura 22 - Velocidade x resistência na flexão estática, na direção longitudinal, com medições realizadas pelo stress wave - valores médios.

As Tabelas 36 e 37 apresentam os modelos de regressão e os coeficientes de correlação e de determinação encontrados entre os valores totais, obtidos nos ensaios físico-mecânicos e não-destrutivos, através dos métodos de ultra-som e de stress wave, quando comparados os painéis dos grupos 1 e 2. O símbolo * significa que as correlações, bem como os seus respectivos modelos de regressão, não foram significativos entre as propriedades estudadas.

Tabela 36 - Equações, $R$ e $R^{2}$ entre os valores obtidos nos ensaios físicomecânicos e não-destrutivos pelo método de ultra-som

\begin{tabular}{cccccc}
\hline $\mathbf{R}$ & $\mathbf{R}^{2}$ & Equação & $\mathbf{R}$ & $\mathbf{R}^{2}$ & Equação \\
\hline \hline 0,75 & 0,56 & $\mathrm{f}_{\mathrm{m} / /}=0,0311 \mathrm{~V}_{/ /}-67,542$ & 0,38 & 0,14 & $\mathrm{~F}_{\operatorname{maxAl}}=1,3192 \mathrm{~V}_{\mathrm{Al}}+11,019$ \\
0,75 & 0,56 & $\mathrm{~F}_{\mathrm{max} / /}=0,8256 \mathrm{~V}_{/ /}-1806,7$ & 0,33 & 0,11 & $\mathrm{Al}=0,0005 \mathrm{C}_{\mathrm{Al}}+0,2644$ \\
0,68 & 0,46 & $\mathrm{E}_{\mathrm{m} / /}=1,0212 \mathrm{C}_{/ /}-806,89$ & 0,26 & 0,07 & $\mathrm{Al}=-0,0085 \mathrm{Atn} \mathrm{Al}_{\mathrm{Al}}+0,7783$ \\
0,27 & 0,07 & $\mathrm{f}_{\mathrm{m} \perp}=0,0094 \mathrm{~V}_{\perp}-9,9829$ & 0,08 & 0,01 & $\mathrm{G}_{\mathrm{t}}=0,004 \mathrm{~V}_{\mathrm{Gt}}+11,705^{*}$ \\
0,29 & 0,09 & $\mathrm{~F}_{\max \perp}=0,2707 \mathrm{~V}_{\perp}-329,43$ & 0,11 & 0,01 & $\mathrm{G}_{\mathrm{t}}=0,0055 \mathrm{C}_{\mathrm{Gt}}+12,708^{*}$ \\
0,40 & 0,16 & $\mathrm{E}_{\mathrm{m} \perp}=0,431 \mathrm{C}_{\perp}+320,15$ & 0,05 & 0,00 & $\mathrm{G}_{\mathrm{t}}=-0,0663 \mathrm{Atn}_{\mathrm{Gt}}+17,607^{*}$ \\
0,36 & 0,13 & $\mathrm{~d}=0,1436 \mathrm{~V}_{\mathrm{d}}+458,87$ & 0,16 & 0,03 & $\mathrm{~A}_{\mathrm{m}}=-0,013 \mathrm{~V}_{\mathrm{Am}}+55,858^{*}$ \\
0,35 & 0,12 & $\mathrm{~d}=-3,4798 \mathrm{Atn} \mathrm{d}_{\mathrm{d}}+709,5$ & 0,15 & 0,02 & $\mathrm{~A}_{\mathrm{m}}=-0,0112 \mathrm{C}_{\mathrm{Am}}+49,57^{*}$ \\
0,37 & 0,14 & $\mathrm{Al}=0,0005 \mathrm{~V}_{\mathrm{Al}}+0,0042$ & 0,17 & 0,03 & $\mathrm{~A}_{\mathrm{m}}=0,3489 \operatorname{Atn}_{\mathrm{Am}}+31,792^{*}$ \\
\hline
\end{tabular}


Tabela 37 - Equações, $R$ e $R^{2}$ entre os valores obtidos nos ensaios físicomecânicos e não-destrutivos pelo método de stress wave - todos os valores

\begin{tabular}{cccccc}
\hline $\mathbf{R}$ & $\mathbf{R}^{2}$ & Equação & $\mathbf{R}$ & $\mathbf{R}^{2}$ & Equação \\
\hline \hline 0,65 & 0,42 & $\mathrm{f}_{\mathrm{m} / /}=0,0243 \mathrm{~V}_{/ /}-43,475$ & 0,10 & 0,01 & $\mathrm{f}_{\mathrm{m} \perp}=0,0016 \mathrm{~V}_{\perp}+9,965^{*}$ \\
0,65 & 0,43 & $\mathrm{~F}_{\max / /}=0,6467 \mathrm{~V}_{/ /}-1177$ & 0,13 & 0,02 & $\mathrm{~F}_{\max \perp}=0,0525 \mathrm{~V}_{\perp}+227,34^{*}$ \\
0,60 & 0,36 & $\mathrm{E}_{\mathrm{m} / /}=0,8948 \mathrm{C}_{/ /}+295,34$ & 0,13 & 0,02 & $\mathrm{E}_{\mathrm{m} \perp}=0,1105 \mathrm{C}_{\perp}+1557,8^{*}$ \\
\hline
\end{tabular}

A Tabela 38 apresenta os modelos de regressão e coeficientes de correlação e de determinação encontrados entre todos os valores obtidos nos ensaios destrutivos e nos não-destrutivos, através do método de stress wave, quando comparados os painéis dos grupos 1 e 2 . Destes valores, foram excluídos os de velocidades e de constantes dinâmicas relacionados às leituras discrepantes de tempo no painel 24 , na direção longitudinal (ponto de leitura $12 /$ ) e no painel 22 , na

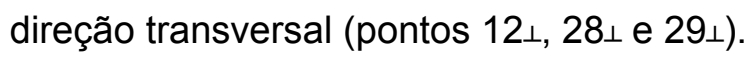

Tabela 38 - Equações, $R$ e $R^{2}$ entre os valores obtidos nos ensaios físicomecânicos e não-destrutivos pelo método de stress wave

\begin{tabular}{cccccc}
\hline $\mathbf{R}$ & $\mathbf{R}^{2}$ & Equação & $\mathbf{R}$ & $\mathbf{R}^{2}$ & Equação \\
\hline \hline 0,76 & 0,57 & $\mathrm{f}_{\mathrm{m} / /}=0,034 \mathrm{~V}_{/ /}-71,632$ & 0,24 & 0,06 & $\mathrm{f}_{\mathrm{m} \perp}=0,0123 \mathrm{~V}_{\perp}-13,861$ \\
0,76 & 0,58 & $\mathrm{~F}_{\max / /}=0,9017 \mathrm{~V}_{/ /}-1913,1$ & 0,28 & 0,08 & $\mathrm{~F}_{\max \perp}=0,3761 \mathrm{~V}_{\perp}-491,2$ \\
0,69 & 0,48 & $\mathrm{E}_{\mathrm{m} / /}=1,1715 \mathrm{C}_{/ /}-1050,3$ & 0,33 & 0,11 & $\mathrm{E}_{\mathrm{m} \perp}=0,5507 \mathrm{C}_{\perp}+290,42$ \\
\hline
\end{tabular}

A Tabela 39 apresenta os modelos de regressão e coeficientes de correlação e de determinação encontrados entre os valores obtidos nos métodos de ultra-som e de stress wave, quando comparados os painéis dos grupos 1 e 2. A Tabela 40 apresenta o mesmo, excluindo-se os valores de velocidades e de constantes dinâmicas relacionados às leituras discrepantes de tempo no painel 24 , na direção longitudinal

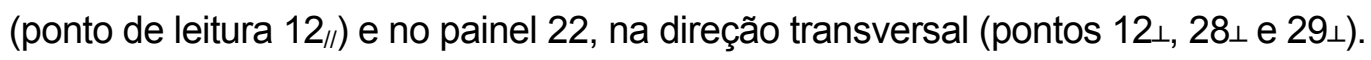

Tabela 39 - Equações, $R$ e $R^{2}$ entre os métodos de ultra-som e stress wave (todos os valores)

\begin{tabular}{cccccc}
\hline $\mathbf{R}$ & $\mathbf{R}^{2}$ & Equação & $\mathbf{R}$ & $\mathbf{R}^{2}$ & Equação \\
\hline \hline 0,85 & 0,73 & $\mathrm{~V}_{/ / S W}=0,9438 \mathrm{~V}_{/ / U S}+25,253$ & 0,85 & 0,73 & $\mathrm{C}_{/ / S W}=0,8627 \mathrm{C}_{/ / \mathrm{US}}+233$ \\
0,14 & 0,02 & $\mathrm{~V}_{\perp \text { SW }}=0,3144 \mathrm{~V}_{\perp \text { US }}+1416,8$ & 0,29 & 0,08 & $\mathrm{C}_{\perp_{S W}}=0,3774 \mathrm{C}_{\perp_{\text {US }}}+1471,6$ \\
\hline
\end{tabular}


Tabela 40 - Equações, $R$ e $R^{2}$ entre os métodos de ultra-som e stress wave

\begin{tabular}{cccccc}
\hline $\mathbf{R}$ & $\mathbf{R}^{2}$ & Equação & $\mathbf{R}$ & $\mathbf{R}^{2}$ & Equação \\
\hline \hline 0,97 & 0,95 & $\mathrm{~V}_{/ / S W}=0,9027 \mathrm{~V}_{/ / U S}+156,08$ & 0,97 & 0,94 & $\mathrm{C}_{/ / U S}=0,8591 \mathrm{C}_{/ / S W}+273,78$ \\
0,79 & 0,62 & $\mathrm{~V}_{\perp \text { US }}=0,5575 \mathrm{~V}_{\perp \text { SW }}+833,95$ & 0,86 & 0,74 & $\mathrm{C}_{\perp \text { US }}=0,5491 \mathrm{C}_{\perp \text { SW }}+893,73$ \\
\hline
\end{tabular}

As Tabelas 41 e 42 apresentam os modelos de regressão e coeficientes de correlação e de determinação encontrados entre os valores médios, obtidos nos ensaios destrutivos e nos não-destrutivos através dos métodos de ultra-som e de stress wave, quando comparados os painéis dos grupos 1 e 2. O símbolo * significa que as correlações, bem como os seus respectivos modelos de regressão, não foram significativos entre as propriedades estudadas.

Tabela 41 - Equações, $R$ e $R^{2}$ entre os valores obtidos nos ensaios físicomecânicos e não-destrutivos pelo método de ultra-som - valores médios

\begin{tabular}{cccccc}
\hline $\mathbf{R}$ & $\mathbf{R}^{2}$ & Equação & $\mathbf{R}$ & $\mathbf{R}^{2}$ & Equação \\
\hline \hline 0,96 & 0,93 & $\mathrm{f}_{\mathrm{m} / /}=0,0323 \mathrm{~V}_{/ /}-71,013$ & 0,26 & 0,07 & $\mathrm{~F}_{\operatorname{maxAl}}=1,5895 \mathrm{~V}_{\mathrm{Al}}-230,21^{*}$ \\
0,90 & 0,91 & $\mathrm{E}_{\mathrm{m} / /}=1,0004 \mathrm{C}_{/ /}-693,04$ & 0,04 & 0,00 & $\mathrm{Al}=9 \mathrm{E}-05 \mathrm{C}_{\mathrm{Al}}+0,4277^{*}$ \\
0,96 & 0,92 & $\mathrm{~F}_{\mathrm{max} / /}=0,8294 \mathrm{~V}_{/ /}-1819,1$ & 0,64 & 0,40 & $\mathrm{Al}=-0,0305 \mathrm{Atn}_{\mathrm{Al}}+1,5762$ \\
0,17 & 0,03 & $\mathrm{f}_{\mathrm{m} \perp}=0,0028 \mathrm{~V}_{\perp}+6,4172^{*}$ & 0,42 & 0,18 & $\mathrm{G}_{\mathrm{t}}=0,0116 \mathrm{~V}_{\mathrm{Gt}}+5,1193^{*}$ \\
0,55 & 0,13 & $\mathrm{E}_{\mathrm{m} \perp}=0,3389 \mathrm{C}_{\perp}+652,68$ & 0,24 & 0,06 & $\mathrm{G}_{\mathrm{t}}=0,0211 \mathrm{C}_{\mathrm{Gt}}+5,4855^{*}$ \\
0,36 & 0,30 & $\mathrm{~F}_{\max \perp}=0,1588 \mathrm{~V}_{\perp}-51,452^{*}$ & 0,45 & 0,20 & $\mathrm{G}_{\mathrm{t}}=1,037 \mathrm{Atn}_{\mathrm{Gt}}-22,852^{*}$ \\
0,43 & 0,18 & $\mathrm{~d}=0,2722 \mathrm{~V}_{\mathrm{d}}+344^{*}$ & 0,35 & 0,13 & $\mathrm{~A}_{\mathrm{m}}=0,0133 \mathrm{~V}_{\mathrm{Am}}+33,434^{*}$ \\
0,18 & 0,03 & $\mathrm{~d}=2,6555 \mathrm{Atn}_{\mathrm{d}}+486,54^{*}$ & 0,06 & 0,00 & $\mathrm{~A}_{\mathrm{m}}=0,0077 \mathrm{C}_{\mathrm{Am}}+41,324^{*}$ \\
0,26 & 0,07 & $\mathrm{Al}=0,0006 \mathrm{~V}_{\mathrm{Al}}-0,0896^{*}$ & 0,57 & 0,32 & $\mathrm{~A}_{\mathrm{m}}=1,7778 \mathrm{Atn}$ \\
$\mathrm{Am}$ & $-20,089^{*}$ \\
\hline
\end{tabular}

Tabela 42 - Equações, $R$ e $R^{2}$ entre os valores obtidos nos ensaios físicomecânicos e não-destrutivos pelo método de stress wave - valores médios

\begin{tabular}{cccccc}
\hline $\mathbf{R}$ & $\mathbf{R}^{2}$ & Equação & $\mathbf{R}$ & $\mathbf{R}^{2}$ & Equação \\
\hline \hline 0,96 & 0,93 & $\mathrm{f}_{\mathrm{m} / /}=0,0341 \mathrm{~V}_{/ /}-71,808$ & 0,05 & 0,00 & $\mathrm{f}_{\mathrm{m} \perp}=-0,0009 \mathrm{~V}_{\perp}+15,345^{*}$ \\
0,95 & 0,91 & $\mathrm{~F}_{\max / /}=0,8748 \mathrm{~V}_{/ /}-1833,5$ & 0,20 & 0,04 & $\mathrm{~F}_{\max \perp}=0,0983 \mathrm{~V}_{\perp}+125,62^{*}$ \\
0,92 & 0,85 & $\mathrm{E}_{\mathrm{m} / /}=1,1597 \mathrm{C}_{/ /}-978,53$ & 0,27 & 0,07 & $\mathrm{E}_{\mathrm{m} \perp}=0,2396 \mathrm{C}_{\perp}+1188,6^{*}$ \\
\hline
\end{tabular}

A Tabela 43 apresenta os modelos de regressão e coeficientes de correlação e de determinação encontrados entre os métodos de ultra-som e de stress wave, 
em valores médios, quando comparados os painéis dos grupos 1 e 2. A Tabela 44 apresenta o mesmo, excluindo-se os valores de velocidades e de constantes dinâmicas relacionados às leituras discrepantes de tempo no painel 22 , na direção

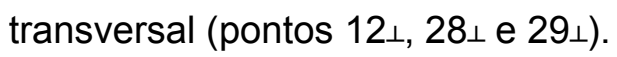

Tabela 43 - Equações, $\mathrm{R}$ e $\mathrm{R}^{2}$ entre os métodos de ultra-som e stress wave valores médios (todos os valores)

\begin{tabular}{cccccc}
\hline $\mathbf{R}$ & $\mathbf{R}^{2}$ & Equação & $\mathbf{R}$ & $\mathbf{R}^{2}$ & Equação \\
\hline \hline 0,99 & 0,97 & $\mathrm{~V}_{/ / S W}=0,9328 \mathrm{~V}_{/ / U S}+62,494$ & 0,99 & 0,97 & $\mathrm{C}_{/ / S W}=0,8703 \mathrm{C}_{/ / U S}+206,25$ \\
0,58 & 0,34 & $\mathrm{~V}_{\perp_{S W}}=0,5293 \mathrm{~V}_{\perp_{\mathrm{US}}}+893,78$ & 0,77 & 0,59 & $\mathrm{C}_{\perp_{S W}}=0,5243 \mathrm{C}_{\perp_{\mathrm{US}}}+961,46$ \\
\hline
\end{tabular}

Tabela 44 - Equações, $R$ e $R^{2}$ entre os métodos de ultra-som e stress wave valores médios

\begin{tabular}{cccccc}
\hline $\mathbf{R}$ & $\mathbf{R}^{2}$ & Equação & $\mathbf{R}$ & $\mathbf{R}^{2}$ & Equação \\
\hline \hline 0,94 & 0,88 & $\mathrm{~V}_{\perp_{S W}}=0,6234 \mathrm{~V}_{\perp U S}+670,29$ & 0,96 & 0,93 & $\mathrm{C}_{\perp_{S W}}=0,6046 C_{\perp U S}+693,74$ \\
\hline
\end{tabular}




\section{Oapitulo 6 - Discussã̃o dos Qesultados}

\subsection{Ensaios Preliminares}

Os valores obtidos nos ensaios de caracterização físico-mecânica dos dois painéis atingiram, e até superaram, os valores estipulados pelo documento normativo EN 300/2002, para painéis OSB/3.

Os maiores coeficientes de variação (CV) foram obtidos para a resistência à tração perpendicular às faces, $38 \%$ e $28 \%$ para os painéis 1 e 2 , respectivamente. Para a densidade, os valores de CV foram $1 \%$ e $7 \%$. Para todas as outras propriedades CV variou entre $13 \%$ e $20 \%$.

Os valores médios das velocidades na espessura e nas direções longitudinal e transversal dos dois painéis mostraram-se diferentes, $1116 \mathrm{~m} / \mathrm{s}, 3327 \mathrm{~m} / \mathrm{s}$ e $2674 \mathrm{~m} / \mathrm{s}$, com coeficientes de variação muito baixos, de $8 \%, 2 \%$ e $1 \%$. Esses valores de velocidades nas direções longitudinal e transversal estão de acordo com os encontrados por Bekhta et al (2002).

Os valores das constantes dinâmicas na espessura e nas direções longitudinal e transversal dos dois painéis também se mostraram diferentes, $755 \mathrm{MPa}, 6567 \mathrm{MPa}$ e $4269 \mathrm{MPa}$, com coeficientes de variação $19 \%$, 3\% e $4 \%$, os dois últimos muito baixos.

Como era de se esperar, os valores da constante dinâmica, obtidos no ensaio não-destrutivo, foram superiores aos valores do módulo de elasticidade obtidos a partir dos ensaios de flexão estática, $75 \%$ na direção longitudinal e 41,5\% na transversal. 
Os baixos coeficientes de correlação obtidos entre os métodos destrutivos convencionais e o de ultra-som evidenciam a homogeneidade dos painéis OSB ensaiados, uma vez que os intervalos de variação dessas propriedades não foram suficientes. Além disso, o intervalo de confiança das propriedades indica que os painéis são estatisticamente equivalentes.

\subsection{Ensaios Principais - primeira etapa}

Os valores obtidos nos ensaios de caracterização físico-mecânica dos painéis atingiram o estipulado pelo documento normativo EN 300/2002, para painéis OSB/3, com exceção dos valores de: módulo de elasticidade na direção transversal dos painéis de espessura $6 \mathrm{~mm}$ e de $15(2) \mathrm{mm}$, módulo de resistência à flexão na direção perpendicular do painel de espessura 15(2)mm, inchamento em espessura (24h) e adesão interna do painel de espessura $25 \mathrm{~mm}$.

Os maiores coeficientes de variação (acima de 30\%) foram obtidos para os valores de resistência à tração perpendicular às faces.

Para os ensaios realizados com o aparelho de ultra-som, os valores das velocidades na espessura e nas direções longitudinal e transversal dos painéis mostraram-se novamente diferentes, como nos ensaios preliminares, com coeficientes de variação entre $1 \%$ e $10 \%$, valores também baixos.

Os valores da velocidade foram menores na espessura por que o painel apresenta maior heterogeneidade nessa direção, devido à superposição de três camadas de partículas, e maiores na direção longitudinal por que o painel apresenta maior homogeneidade nessa direção, devido à orientação das partículas.

Os valores de velocidades nas direções longitudinal e transversal estão de acordo com os encontrados por Bekhta et al (2002), exceto para o painel de espessura $6 \mathrm{~mm}$ na direção transversal, o qual apresentou um coeficiente de variação $24 \%$. 
Os valores das velocidades medidas na espessura foram maiores para o painel de espessura $15(1) \mathrm{mm}$ do que no de $25 \mathrm{~mm}$, para o qual a atenuação de ondas é mais significativa.

O valor de velocidade na espessura do painel de espessura 15(1)mm $(1196 \mathrm{~m} / \mathrm{s})$ foi em média $41 \%$ maior do que os obtidos por Vun et al (2002) e o valor da constante dinâmica média correspondente foi de 718MPa. Para o painel de espessura $25 \mathrm{~mm}$ os valores médios da velocidade e constante dinâmica foram, respectivamente, $965 \mathrm{~m} / \mathrm{s}$ e $555 \mathrm{MPa}$.

Os valores das constantes dinâmicas na espessura e nas direções longitudinal e transversal dos dois painéis se mostraram diferentes, à semelhança do que se obteve nos ensaios preliminares.

Assim, confirma-se que é possível detectar a variação de características mecânicas dos painéis, pois os valores das velocidades de propagação de ondas, pelo método de ultra-som, são diferentes nas três direções. Além disso, confirma-se também que a maior dispersão dos valores obtidos na espessura pode indicar não homogeneidade das camadas ao longo de todo o painel.

Os valores das constantes dinâmicas, obtidos no ensaio não-destrutivo de ultra-som, foram superiores aos valores do módulo de elasticidade obtidos a partir dos ensaios de flexão estática, como era de se esperar, sendo que os valores para o painel de espessura $15(1) \mathrm{mm}$ foram equivalentes aos obtidos nos painéis dos ensaios preliminares: $75 \%$ maior que este na direção longitudinal e 41,5\% maior na direção transversal.

Para o painel de espessura $6 \mathrm{~mm}$, o método de ultra-som não se mostrou adequado, provavelmente devido ao diâmetro da superfície de contato do transdutor plano ser maior que a espessura do painel.

Como nos ensaios preliminares, os coeficientes de correlação obtidos entre ambos os métodos, destrutivo convencional e de ultra-som, na maioria das 
propriedades físico-mecânicas estudadas, mostram a homogeneidade dos painéis OSB (Tabela 19). Somente para a força de ruptura na flexão versus a velocidade, nas direções longitudinal e transversal, e para a absorção de água versus a velocidade e constante dinâmica, os coeficientes de correlação foram superiores a 0,74, excedendo 0,70, valor estipulado pela EN 326-2/ 2002.

Em relação aos ensaios realizados com o aparelho de stress wave ao longo dos corpos-de-prova, os valores das velocidades nas direções longitudinal e transversal dos painéis também se mostraram diferentes, respectivamente, 3116 a $3216 \mathrm{~m} / \mathrm{s}$ e 2187 a $2496 \mathrm{~m} / \mathrm{s}$, com baixos coeficientes de variação, de $1 \%$ a $6 \%$. Esses valores de velocidades nas direções longitudinal e transversal estão de acordo com os encontrados por Bekhta et al (2002), em ensaios conduzidos pelo método de ultra-som.

Para as medições realizadas através do método de stress wave, ao longo do painel de espessura 15(2)mm, na direção longitudinal, encontrou-se o valor médio de velocidade $2889 \mathrm{~m} / \mathrm{s}$, que está em conformidade com os valores encontrados por Bekhta et al (2002). Já na direção transversal, onde a velocidade foi de $2040 \mathrm{~m} / \mathrm{s}$, isso não ocorreu. Esse painel foi o que não alcançou os valores estabelecidos para a flexão estática na direção transversal de painéis $\mathrm{OSB} / 3$, espessura $15 \mathrm{~mm}$, e o que apresentou menor valor de densidade.

Os valores médios obtidos para a velocidade e a constante dinâmica foram maiores nos corpos-de-prova de flexão estática do que nas medições ao longo do painel de espessura 15(2)mm, nas direções perpendicular e longitudinal, provavelmente devido à distância de propagação da onda ser menor nos corposde-prova.

Os valores das constantes dinâmicas nas direções longitudinal e transversal dos painéis de espessura $15(1) \mathrm{mm}$ e $25 \mathrm{~mm}$ também se mostraram diferentes e 
superiores aos valores do módulo de elasticidade obtidos a partir dos ensaios de flexão estática.

Os coeficientes de correlação obtidos em ambos os métodos, destrutivo convencional e de stress wave, nos painéis de espessura 15(2)mm e 25mm, para a força de ruptura na flexão estática versus a velocidade, nas direções longitudinal e transversal, acima de 0,87 , bem como do módulo de elasticidade na flexão estática versus constante dinâmica, igual a 0,78 , foram superiores a 0,70 , estipulado pela EN 326-2/ 2002.

Por outro lado, os valores de módulos de resistência e de elasticidade na flexão estática, bem como de velocidades e de constantes dinâmicas, na direção transversal, indicaram diferença entre os painéis de espessura 15(2)mm e os de $15(1) \mathrm{mm}$ e $25 \mathrm{~mm}$. Para o primeiro painel, que apresentou menores valores de módulos de resistência e de elasticidade na flexão estática do que os outros, na direção transversal, também foram menores os valores de velocidades e de constantes dinâmicas. Um exemplo é mostrado no gráfico da Figura 23.

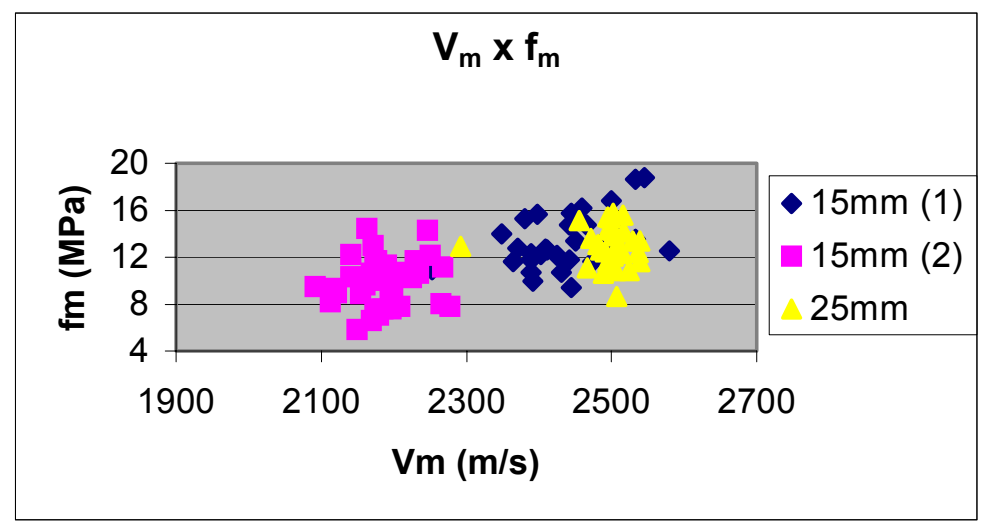

Figura 23 - Valores de módulos de resistência x velocidades para os três painéis.

O próximo passo foi, então, analisar a equivalência estatística entre as populações de velocidades e constantes dinâmicas dos painéis de espessura 15(1)mm, 15(2)mm e $25 \mathrm{~mm}$. 
A normalidade dos dados foi confirmada como pode ser visto, por exemplo, na Figura 24, através do teste de Kolmogorov-Smirnov. A homogeneidade das variâncias foi verificada por meio do Teste Estatístico de Barttlet.

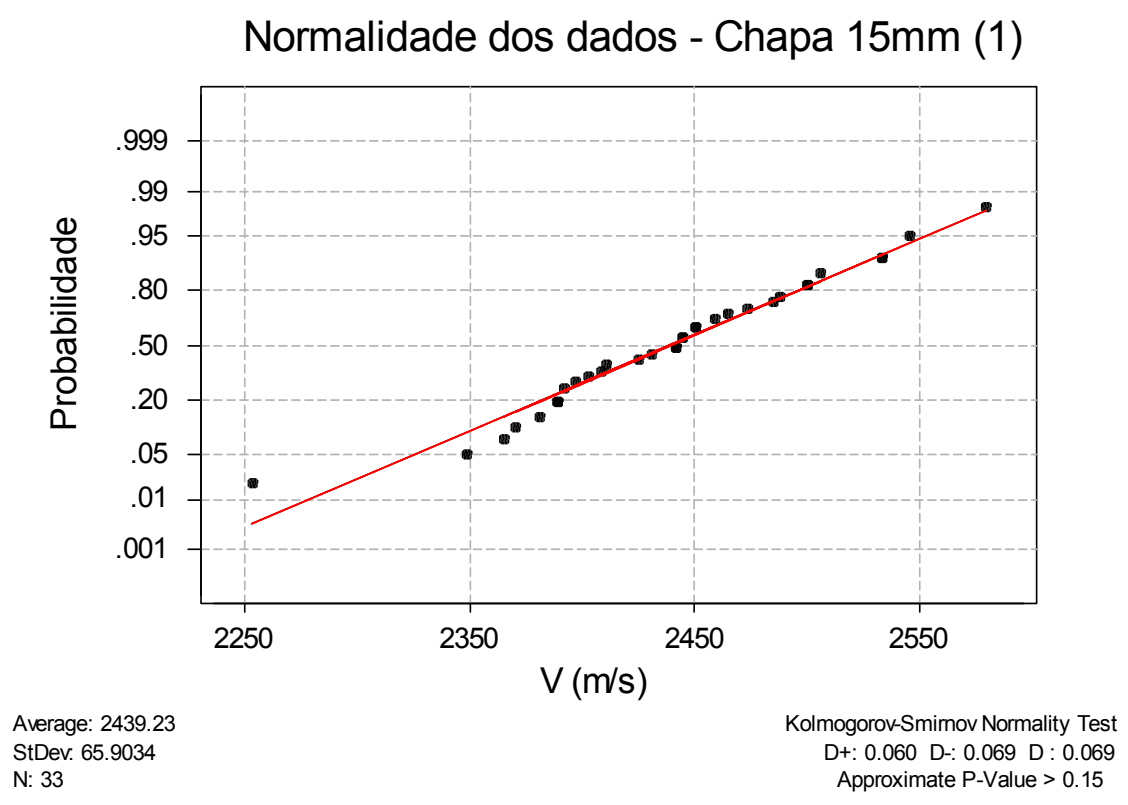

Figura 24 - Normalidade dos valores das velocidades determinadas na direção transversal do painel de espessura $15(1) \mathrm{mm}$.

Na Análise de Variância das médias de velocidades e constantes dinâmicas foram encontrados, respectivamente, os valores de F: 402,7 e 422,34, superiores a $F_{2,291,0,05}=3,37$, Isto mostrou haver pelo menos uma das médias estatisticamente diferente. A análise detalhada está contida no Anexo 1.

O próximo passo foi utilizar o Teste de Tukey, para $\alpha=0,05$ e 291 graus de liberdade $(k=3$ e $n=98)$.

As diferenças entre as médias das velocidades e das constantes dinâmicas dos painéis de espessura 15(1)mm e 15(2)mm, 15(1)mm e $25 \mathrm{~mm}$ e $15(2) \mathrm{mm}$ e $25 \mathrm{~mm}$ foram de, respectivamente: $251,9 \mathrm{~m} / \mathrm{s}, 315,4 \mathrm{~m} / \mathrm{s}, 63,5 \mathrm{~m} / \mathrm{s}, 725,6 \mathrm{MPa}$, $904,4 \mathrm{MPa}$ e $178,8 \mathrm{MPa}$, todas superiores às diferenças mínimas significativas 
(d.m.s.) encontradas para cada um desses parâmetros: 16,4m/s e 45,97MPa. O Anexo 2 apresenta essa análise de maneira detalhada.

Assim, provou-se que as três populações não são estatisticamente equivalentes entre si.

\subsection{Ensaios Principais - segunda etapa}

Os valores obtidos nos ensaios de caracterização físico-mecânica por amostragem dos painéis dos grupos 1 e 2 mostram que, para estes dois grupos de painéis $\mathrm{OSB} / 3$, há diferenças significativas para os módulos de elasticidade e de resistência na flexão estática na direção longitudinal, objetivo para essa etapa do trabalho, o qual poderia ter prosseguimento com esses dois grupos de painéis.

Os valores obtidos nos ensaios de caracterização físico-mecânica dos painéis atingiram os valores estipulados pelo documento normativo EN 300/2002 para painéis $\mathrm{OSB} / 3$, sendo os valores apresentados pelos painéis do grupo 1, em média, superiores aos valores apresentados pelos painéis do grupo 2, com exceção das propriedades densidade e módulos de resistência e de elasticidade na flexão estática, na direção transversal (Tabelas 45 e 46).

Tabela 45 - Diferenças, em médias, entre valores de propriedades físico-mecânicas dos painéis dos grupos 1 e 2: maiores valores para os painéis do grupo 1

\begin{tabular}{c|cccccc}
\hline Grupo & $\mathbf{E}_{\mathrm{m} / /}(\mathbf{M P a})$ & $\mathbf{f}_{\mathrm{m} / /}(\mathbf{M P a})$ & $\mathbf{A l}(\mathbf{M P a})$ & $\mathbf{G}_{\mathbf{t}}(\mathbf{\%})$ & $\mathbf{A}_{\mathrm{m}}(\%)$ \\
\hline \hline $\mathbf{1}$ & - & 5066 & 31 & 0,50 & 13 & 42 \\
$\mathbf{2}$ & $x$ & 4075 & 21 & 0,43 & 17 & 48 \\
Diferença (\%) & & 20 & 32 & 14 & 31 & 14 \\
\hline
\end{tabular}

Tabela 46 - Diferenças, em médias, entre valores de propriedades físico-mecânicas dos painéis dos grupos 1 e 2: maiores valores para os painéis do grupo 2

\begin{tabular}{ccccc}
\hline Grupo & $\mathbf{E}_{\mathbf{m} \perp}(\mathbf{M P a})$ & $\mathbf{f}_{\mathbf{m} \perp}(\mathbf{M P a})$ & $\rho\left(\mathbf{k g} / \mathbf{m}^{\mathbf{3}}\right)$ \\
\hline \hline $\mathbf{1}$ & - & 1775 & 13 & 576 \\
$\mathbf{2}$ & $x$ & 1965 & 14 & 590 \\
Diferença & & 11 & 8 & 2 \\
\hline
\end{tabular}


Considerando-se os dez painéis de cada grupo estudado, os maiores coeficientes de variação foram obtidos entre os valores de resistência à tração perpendicular às faces e inchamento em espessura (24h).

Os coeficientes de correlação obtidos para os painéis do Grupo 1, quando comparados os valores dos ensaios físico-mecânicos aos dos não-destrutivos, pelos métodos de ultra-som e stress wave, variaram de 0,09 a 0,35 , e para os painéis do Grupo 2 esses valores variaram de 0,03 a 0,56 , respectivamente. Isto mostra a homogeneidade entre painéis de um mesmo lote.

Para os ensaios realizados com o aparelho de ultra-som, os valores das velocidades mostraram-se novamente diferentes de acordo com a direção de propagação das ondas nos painéis, como nas outras duas etapas, com coeficientes de variação entre $6 \%$ e $25 \%$, na espessura, e entre $0 \%$ a $2 \%$ nas direções longitudinal e transversal, sendo muito baixos estes últimos valores.

Os valores de velocidades na espessura dos painéis foram em média $24 \%$ maiores do que os obtidos por Vun et al (2002) e variaram de 836 a 928m/s. Entre os dois grupos de painéis, os valores das velocidades referentes a medidas de tempo na espessura mostraram pequena diferença de magnitude: $2 \%$. Os valores de constantes dinâmicas correspondentes variaram de 407 a 535MPa.

Esses valores de velocidades, obtidos por leituras realizadas pelo aparelho Panametrics, modelo EPOCH4, foram maiores do que os obtidos nas duas outras etapas, onde as leituras foram conduzidas pelo aparelho STEINKAMP, modelo BP7.

Para os dois grupos de painéis os coeficientes de correlação obtidos entre os valores de velocidades e de constantes dinâmicas, na espessura dos painéis, e os de propriedades físico-mecânicas, em corpos-de-prova correspondentes, variaram de 0,08 a 0,38 e, em valores médios, de 0,04 a 0,43. Assim, não atingiram o valor 0,70, estipulado pela EN 326-2/ 2002. 
Em média, os valores de atenuação, que variaram de 53 a $61 \mathrm{~d} \beta$ loss, foram cerca de $25 \%$ menores do que os encontrados por Vun et al (2002) e muito próximos nos grupos 1 e 2 de painéis: $3 \%$. Os coeficientes de variação para essa propriedade foram de $6 \%$ a $20 \%$.

Os coeficientes de correlação entre os valores de atenuação, na espessura dos painéis, e os de propriedades físico-mecânicas, em corpos-de-prova correspondentes, variaram de 0,05 a 0,17 e, entre os valores médios, de 0,18 a 0,64. Assim, não atingiram o valor 0,70, estipulado pela EN 326-2/ 2002.

Algumas leituras de tempo na direção longitudinal, nos painéis do grupo 2, que também apresentaram menores valores de módulos de elasticidade e de resistência na flexão estática, foram mais difíceis de serem obtidas. Nestes casos foi necessária a utilização de maior quantidade de gel medicinal e várias tentativas até se obter o sinal da onda. Isto indicou maior atenuação e que os métodos nãodestrutivos utilizados são sensíveis a eventuais problemas nos painéis que possam ocasionar redução nos valores das propriedades mecânicas de flexão estática.

Os valores médios de velocidades para a propagação de ondas nas direções longitudinal (2837 a $3184 \mathrm{~m} / \mathrm{s})$ e transversal $(2232$ a $2535 \mathrm{~m} / \mathrm{s})$, para os dois grupos de painéis, estão de acordo com os encontrados por Bekhta et al (2002), como nas outras duas etapas.

Os valores das constantes dinâmicas nas direções longitudinal e transversal dos dois grupos de painéis também se mostraram diferentes, sendo semelhantes aos obtidos nos ensaios preliminares. Os intervalos de valores médios, nas direções longitudinal e transversal, foram, respectivamente: 4513 a 5899MPa e 2900 a $3977 \mathrm{MPa}$.

Os coeficientes de correlação obtidos entre os valores de força de ruptura e módulos de resistência e de elasticidade na flexão estática e os de velocidades e de constantes dinâmicas, na direção longitudinal foram, respectivamente, iguais a 
$0,75,0,75$ e 0,68 e, na direção transversal, 0,29, 0,27 e 0,40. Assim, só as duas primeiras correlações superaram 0,70 , estipulado pela EN 326-2/ 2002, na direção longitudinal, onde houve diferenças significativas relacionadas aos valores das propriedades de flexão estática dos painéis pertencentes aos dois grupos.

Os coeficientes de correlação obtidos entre os valores médios de força de ruptura e módulos de resistência e de elasticidade na flexão estática e os de velocidades e de constantes dinâmicas, na direção longitudinal foram, respectivamente, iguais a 0,96, 0,96 e 0,90 e, na direção transversal, 0,36, 0,17 e 0,55. Esses valores foram maiores do que quando comparados os valores totais. Outra vez as correlações correspondentes à direção longitudinal superaram o valor 0,70, estipulado pela EN 326-2/ 2002

Assim, novamente confirma-se que é possível detectar a variação de características mecânicas dos painéis, nas duas direções, pelo método de ultrasom. E, além disso, que a maior dispersão dos valores obtidos na espessura pode indicar menor homogeneidade das camadas ao longo de todo o painel.

Em relação aos ensaios realizados com o aparelho de stress wave, os valores das velocidades nas direções longitudinal (2667 a 3034m/s) e transversal (2041 a $2236 \mathrm{~m} / \mathrm{s}$ ) dos painéis também se mostraram diferentes, com coeficientes de variação de $1 \%$ a $2 \%$, com exceção do painel 2.2 , na direção transversal, devido a leituras discrepantes de tempo em alguns pontos de medição.

As faixas de valores médios obtidos nas direções de propagação longitudinal e transversal para as constantes dinâmicas foram, respectivamente, de: 4123 a 5430MPa e 2438 a $3111 \mathrm{MPa}$.

Os coeficientes de correlação obtidos entre os valores de força de ruptura e módulos de resistência e de elasticidade na flexão estática e os de velocidades e de constantes dinâmicas, na direção longitudinal foram, respectivamente, iguais a 0,65, 0,65 e 0,60 e, na direção transversal, 0,13, 0,10 e 0,13. 
Quando não foram consideradas as velocidades e constantes dinâmicas relacionadas a tempos discrepantes de propagação de ondas, esses valores foram 0,76, 0,76 e 0,69, na direção longitudinal, e 0,28, 0,24 e 0,33, na direção transversal. Assim, só as duas primeiras correlações, relacionadas à direção longitudinal, atingiram o valor 0,70, estipulado pela EN 326-2/ 2002.

Os coeficientes de correlação obtidos entre os valores médios de força de ruptura e módulos de resistência e de elasticidade na flexão estática e os de velocidades e de constantes dinâmicas, na direção longitudinal foram, respectivamente, iguais a 0,96, 0,95 e 0,92 e, na direção transversal, 0,20, 0,05 e 0,27 .

As correlações, relacionadas à direção longitudinal, atingiram 0,70 , estipulado pela EN 326-2/ 2002 e, quando consideradas em relação a valores médios, não foram afetadas pelos valores de tempo de propagação de ondas discrepantes.

Esses dois métodos de ensaios não-destrutivos detectaram diferença nos valores das propriedades mecânicas de flexão na direção longitudinal dos painéis dos grupos 1 e 2, em relação às velocidades e constantes dinâmicas. Um exemplo é mostrado, em valores médios, obtidos pelo método de ultra-som, no gráfico da Figura 25.

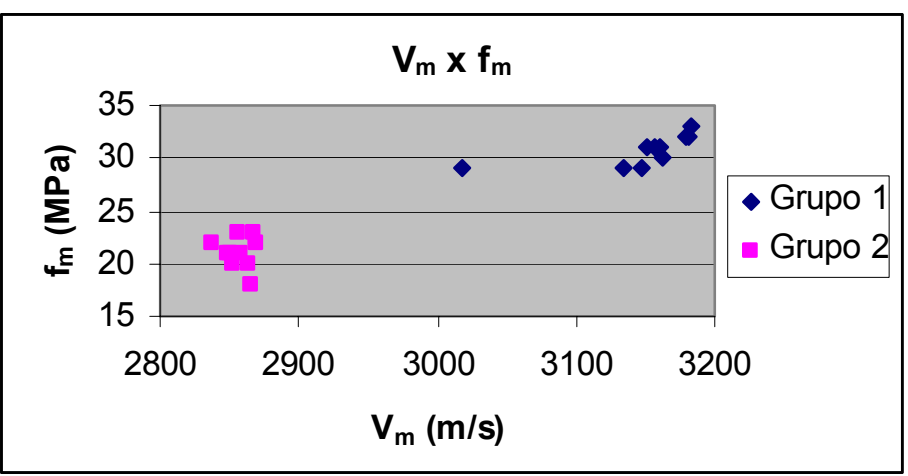

Figura 25 - Módulos de resistência x velocidades para os dois grupos de painéis.

A análise da normalidade dos dados por meio do método de KolmogorovSmirnov não levou a resultados positivos. Desta forma optou-se por utilizar a prova 
não-paramétrica de Kruskal-Wallis, baseada na estatística $H$, ao invés da correspondente prova paramétrica $\mathrm{F}$ (análise de variância).

Os valores dos módulos de resistência e de elasticidade na flexão estática bem como das velocidades e constantes dinâmicas, na direção longitudinal, para os métodos de ultra-som e stress wave, nos grupos 1 e 2, foram comparados.

Em todos os casos o valor da probabilidade $p=0,000$, associada à estatística H e a 1 grau de liberdade, foi menor do que o nível de confiança adotado $\alpha=0,05$. Assim, a diferença estatística entre cada propriedade dos grupos de painéis 1 e 2 foi constatada. As planilhas das referidas análises são apresentadas no Anexo 2.

Os valores médios de velocidades e constantes dinâmicas de propagação da onda, com o ensaio de ultra-som, na direção longitudinal, apresentaram uma diferença de $290 \mathrm{~m} / \mathrm{s}$ e $885 \mathrm{MPa}$, respectivamente, entre os dois grupos. Para o ensaio de stress wave essas diferenças de valores foram de $275 \mathrm{~m} / \mathrm{s}$ e $800 \mathrm{MPa}$.

Quando comparados os valores de velocidades e de constantes dinâmicas referentes à direção longitudinal obtidos pelos métodos de ultra-som e de stress wave, os coeficientes de correlação foram iguais a 0,85 e, na direção transversal, 0,14 e 0,29 . Desconsiderando os valores discrepantes para o stress wave, esses coeficientes foram iguais a 0,97, na direção longitudinal, e 0,79 e 0,86, na direção transversal.

Para essa mesma comparação, em relação aos valores médios de velocidades e de constantes dinâmicas referentes à direção longitudinal, os coeficientes de correlação foram iguais a 0,99, e na direção transversal, foram iguais a 0,77 e 0,59. Desconsiderando os valores discrepantes para o stress wave, esses coeficientes foram iguais 0,94 e 0,96, na direção transversal.

Esses valores de coeficientes de correlação mostram que é equivalente o estudo de painéis OSB, ou até mesmo a estimativa de parâmetros mecânicos na 
flexão estática, com a utilização dos métodos de ensaio não-destrutivos de ultrasom e de stress wave. 


\section{Papitulo 7 - Ponclusões}

Através deste trabalho pode-se concluir que:

a) Os baixos coeficientes de correlação entre os valores obtidos pelos métodos de ensaio não-destrutivos, de ultra-som e stress wave, e destrutivos, quando comparados painéis de um mesmo grupo, mostram a homogeneidade entre painéis $\mathrm{OSB} / 3$ pertencentes a um mesmo lote;

b) Os métodos de ultra-som e de stress wave mostraram-se sensíveis à detecção de painéis OSB pertencentes a lotes com valores de propriedades mecânicas distintas entre si, em relação à flexão estática. Na direção em que os valores dos módulos de resistência e de elasticidade, bem como da força de ruptura, foram menores, os valores de velocidades e constantes dinâmicas também o foram;

c) Os painéis estudados, com os métodos de ensaio não-destrutivos de ultra-som e de stress wave, apresentaram valores de velocidades e constantes dinâmicas diferenciados na espessura e nas direções longitudinal e transversal;

d) Os valores de velocidades na espessura dos painéis, através do método de ultra-som, variaram de 836 a $928 \mathrm{~m} / \mathrm{s}$, e os de constantes dinâmicas correspondentes variaram de 407 a $535 \mathrm{MPa}$;

e) Os coeficientes de correlação obtidos entre os valores de velocidades e de constantes dinâmicas dos dois grupos de painéis, na espessura dos painéis, não atingiram o valor 0,70, estipulado pela EN 326-2/ 2002; 
f) Os valores de atenuação, referentes a medidas realizadas na espessura dos painéis estudados, variaram de 53 a $61 \mathrm{~d} \beta$ loss. Os coeficientes de correlação entre os valores de atenuação, na espessura dos painéis, e os de propriedades físico-mecânicas, em corpos-de-prova correspondentes, não atingiram o valor 0,70, estipulado pela EN 326-2/ 2002;

g) Para os painéis estudados, os valores médios de velocidades de propagação de ondas nas direções longitudinal e transversal foram 2837 a $3184 \mathrm{~m} / \mathrm{s}$ e 2232 a $2535 \mathrm{~m} / \mathrm{s}$, para o método de ultra-som, e 2667 a $3034 \mathrm{~m} / \mathrm{s}$ e 2041 a $2236 \mathrm{~m} / \mathrm{s}$, para o método de stress wave, que estão de acordo com os já encontrados por outros autores;

h) Para os painéis estudados, os valores médios de constantes dinâmicas nas direções longitudinal e transversal foram 4513 a 5899MPa e 2900 a $3977 \mathrm{MPa}$, para o método de ultra-som, e 4123 a $5430 \mathrm{MPa}$ e 2438 a $3111 \mathrm{MPa}$, para o método de stress wave;

i) Os coeficientes de correlação obtidos entre os valores médios de propriedades na flexão estática e os de velocidades e de constantes dinâmicas, na direção longitudinal, para o método de ultra-som, foram superiores a 0,90. Também foram maiores do que quando comparados com todos os valores. Na direção transversal, para valores médios, o maior coeficiente de correlação foi 0,55 . Evidencia-se, então, a correlação entre parâmetros destrutivos e nãodestrutivos na direção em que os painéis dos grupos estudados apresentam valores diferentes de propriedades na flexão estática;

j) Os coeficientes de correlação obtidos entre os valores médios de propriedades na flexão estática e os de velocidades e de constantes dinâmicas, na direção longitudinal, para o método de stress wave, foram superiores a 0,92. Também foram maiores do que quando comparados com todos os valores. Na direção transversal, para valores médios, o maior coeficiente de correlação foi 0,27 , 
valor este muito baixo. Evidencia-se, também para este método não-destrutivo, a correlação entre parâmetros destrutivos e não-destrutivos na direção em que os painéis dos grupos estudados apresentam valores diferentes de propriedades na flexão estática;

k) Para os painéis estudados, quando comparados os métodos de ultra-som e de stress wave, em relação aos valores médios de velocidades e de constantes dinâmicas correspondentes, o coeficiente de correlação foi igual a 0,99, na direção longitudinal, e maior que 0,94 na direção transversal. Esses coeficientes de correlação mostram que é equivalente a estimativa de parâmetros mecânicos na flexão estática, ou até mesmo o estudo de painéis OSB, com a utilização dos métodos de ensaio não-destrutivos de ultra-som e de stress wave;

I) Os resultados obtidos indicam a possibilidade da utilização dos métodos de ultra-som e de stress wave no controle de qualidade de parâmetros mecânicos de painéis OSB comerciais, em linha de produção, através dos modelos de regressão determinados;

m) Os resultados obtidos mostram a necessidade de estudos entre painéis OSB de diferentes espessuras e de valores distintos de propriedades físico-mecânicas, como na flexão estática (direção transversal), na resistência à tração perpendicular às faces, densidade, inchamento em espessura e absorção de água $-24 h$, para subseqüente determinação de modelos de regressão com o método não-destrutivo utilizado, de ultra-som ou de stress wave. 
Anexo 1 
No Anexo 1 estão contidas as análises de variância e testes de Tukey referentes às populações das velocidades e constantes dinâmicas.

\section{Análise de Variância e Teste de Tukey para as populações de velocidades}

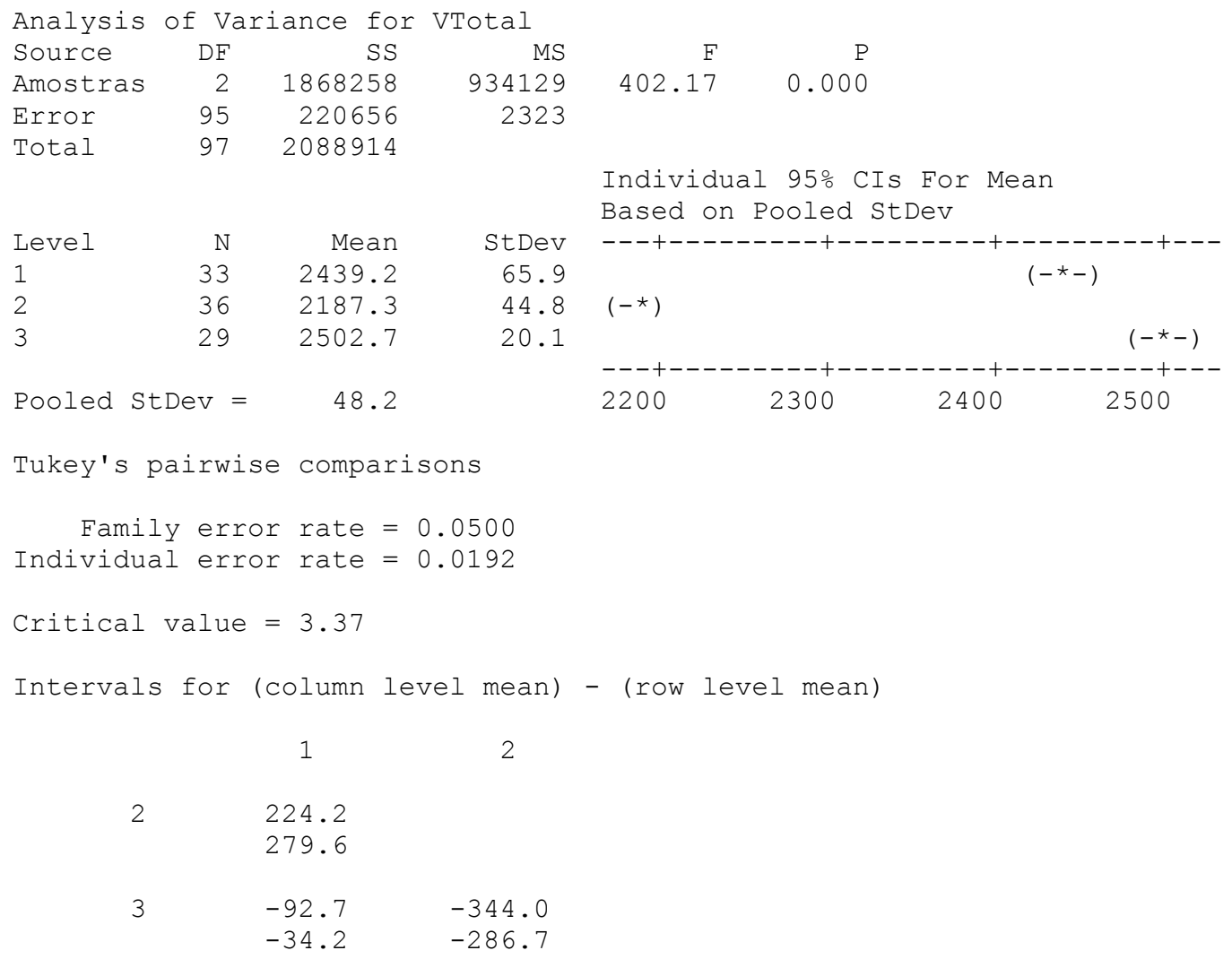

*sinais iguais significam que os tratamentos não são estatisticamente equivalentes. d.m.s.

$n=98 \quad s_{R}^{2}=2323 \mathrm{~m} / \mathrm{s} \quad q_{3,291,0,05}=3,37 \quad$ d.m.s. $=3,37 \cdot \sqrt{\frac{2323}{98}}=16,4 \mathrm{~m} / \mathrm{s}$

$\bar{x}_{151}=2439,2 \mathrm{~m} / \mathrm{s} \quad \bar{x}_{152}=2187,3 \mathrm{~m} / \mathrm{s} \quad \bar{x}_{25}=2502,7 \mathrm{~m} / \mathrm{s}$

$|2439,2-2187,3|=251,9 m / s \geq 16,4 m / s$

$|2439,2-2502,7|=63,5 \mathrm{~m} / \mathrm{s} \geq 16,4 \mathrm{~m} / \mathrm{s}$

$|2502,7-2187,3|=315,4 m / s \geq 16,4 m / s$

$\therefore$ As três populações de velocidades das chapas analisadas não podem ser consideradas estatisticamente equivalentes. 


\section{Análise de Variância e Teste de Tukey para as populações de constantes dinâmicas}

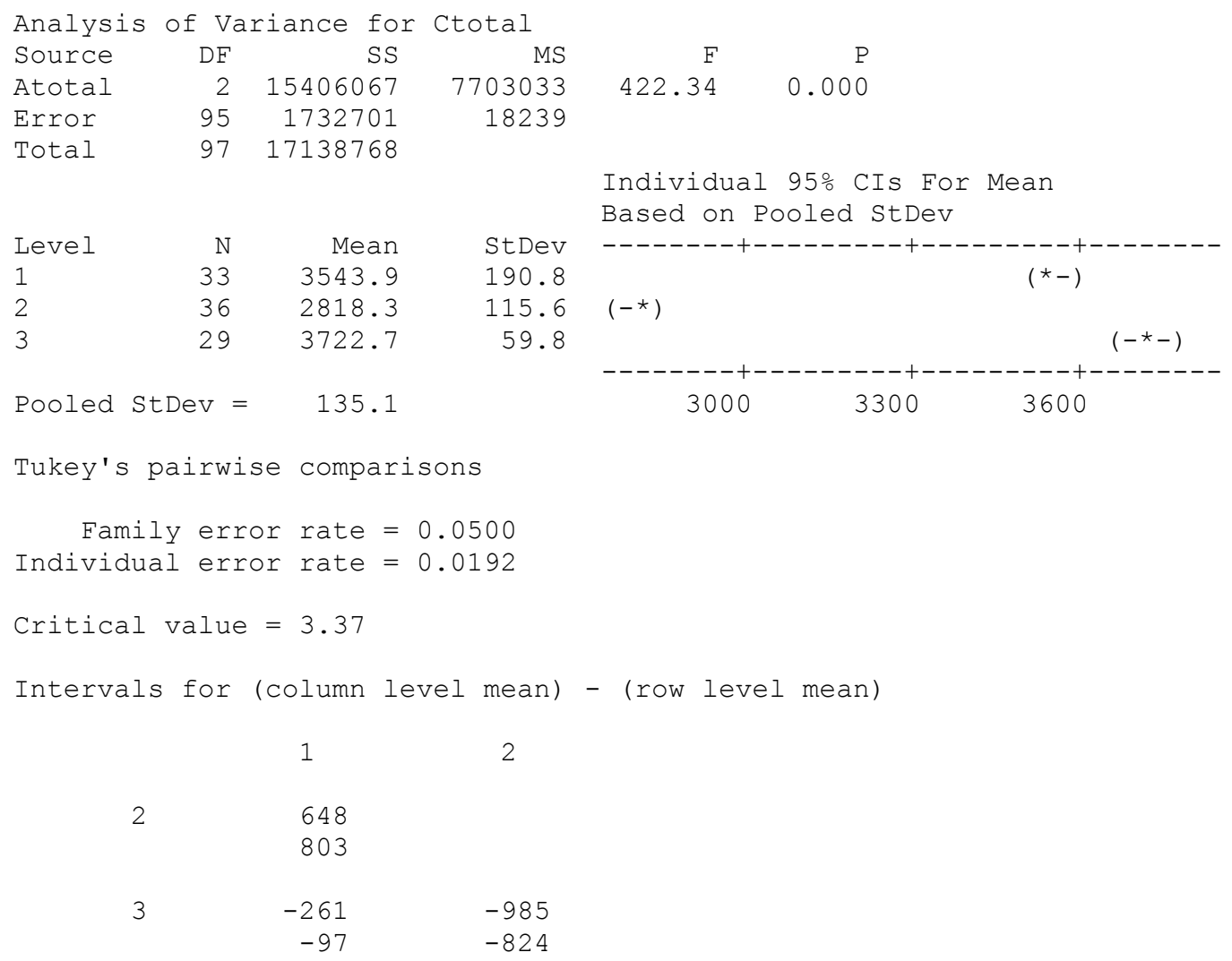

$\therefore$ As três populações de constantes dinâmicas das chapas analisadas não podem ser consideradas estatisticamente equivalentes. 
Anexo 2 
No Anexo 2 estão contidas as análises de equivalência estatística pelo teste de Kruskal-Wallis referentes às populações das velocidades, constantes dinâmicas para os métodos de propagação de ondas de ultra-som e de stress wave, bem como os módulos de elasticidade e de resistência na flexão estática, na direção longitudinal, para os grupos 1 e 2 .

Kruskal-Wallis Test - comparação de velocidades entre grupos 1 e 2 - ultra-som

$\begin{array}{lrrrr}\text { C20 } & \mathrm{N} & \text { Median } & \text { Ave Rank } & \mathrm{Z} \\ 1 & 240 & 3159 & 360,5 & 18,95 \\ 2 & 240 & 2862 & 120,5 & -18,95 \\ \text { Overal1 } & 480 & & 240,5 & \\ \mathrm{H}=359,25 & \mathrm{DF}=1 & \mathrm{P}=0,000 \\ \mathrm{H}=359,28 & \mathrm{DF}=1 & \mathrm{P}=0,000 & \text { (adjusted for ties) }\end{array}$

Kruskal-Wallis Test - comparação de velocidades entre grupos 1 e 2 - stress wave

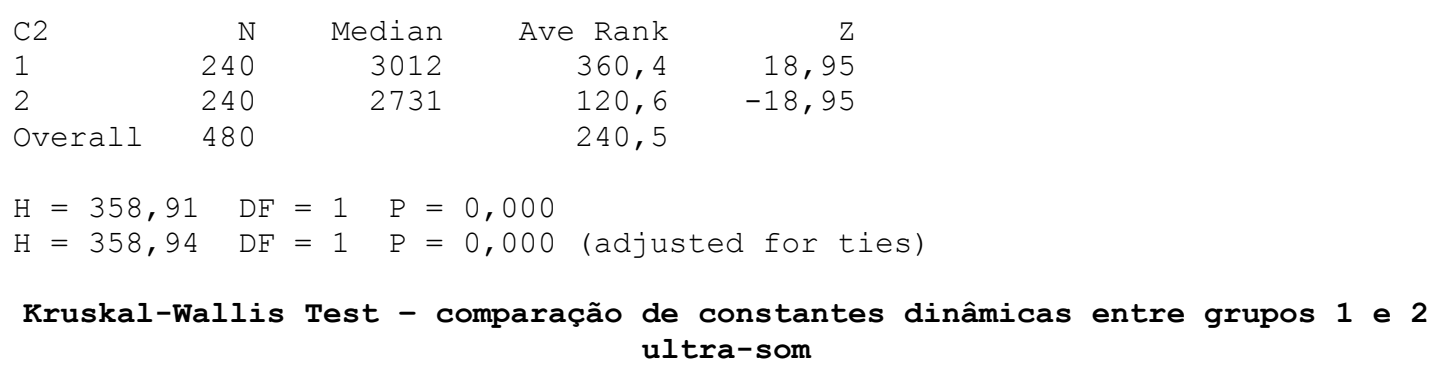

$\begin{array}{lrrrr}\text { C2 } & \mathrm{N} & \text { Median } & \text { Ave Rank } & \text { Z } \\ 1 & 240 & 5729 & 360,0 & 18,87 \\ 2 & 240 & 4841 & 121,1 & -18,87 \\ \text { Overall } & 480 & & 240,5 & \end{array}$

$\mathrm{H}=355,97 \quad \mathrm{DF}=1 \quad \mathrm{P}=0,000$

$\mathrm{H}=355,97 \mathrm{DF}=1 \mathrm{P}=0,000$ (adjusted for ties)

Kruskal-Wallis Test - comparação de constantes dinâmicas entre grupos 1 e 2 stress wave

$\begin{array}{lrrrr}\text { C2 } & \mathrm{N} & \text { Median } & \text { Ave Rank } & \text { Z } \\ 1 & 240 & 5155 & 360,2 & 18,91 \\ 2 & 240 & 4417 & 120,8 & -18,91 \\ \text { Overall } & 480 & & 240,5 & \end{array}$

$\mathrm{H}=357,41 \quad \mathrm{DF}=1 \quad \mathrm{P}=0,000$

$\mathrm{H}=357,41 \mathrm{DF}=1 \mathrm{P}=0,000$ (adjusted for ties)

Kruskal-Wallis Test - comparação de módulos de elaticidade na flexão estática entre grupos 1 e 2

$\begin{array}{lrrrr}\text { C2 } & \text { N } & \text { Median } & \text { Ave Rank } & \text { Z } \\ 1 & 60 & 5128 & 84,6 & 7,59 \\ 2 & 60 & 4114 & 36,4 & -7,59 \\ \text { Overall } & 120 & & 60,5 & \\ & & & & \\ H=57,56 & D F=1 & P=0,000 & \\ H=57,56 & D F=1 & P=0,000 & \text { (adjusted for ties) }\end{array}$


Kruskal-Wallis Test - comparação de módulos de resistência na flexão estática entre grupos 1 e 2

$\begin{array}{lrrrr}\text { C2 } & N & \text { Median } & \text { Ave Rank } & \mathrm{Z} \\ 1 & 60 & 31,00 & 85,9 & 7,99 \\ 2 & 60 & 21,00 & 35,1 & -7,99 \\ \text { Overall } & 120 & & 60,5 & \\ & \\ \mathrm{H}=63,81 & \mathrm{DF}=1 & \mathrm{P}=0,000 & \\ \mathrm{H}=64,06 & \mathrm{DF}=1 & \mathrm{P}=0,000 & \text { (adjusted for ties) }\end{array}$




\section{Papitulo 8 - Qeferências ®ibliográficas}

American Plywood Association (APA): http://www.apawood.org/. Acesso em: 03 de jul. 2003.

AMERICAN SOCIETY FOR TESTING AND MATERIALS. ASTM D - 1037-96 Standard test methods for evaluating properties of wood-base fiber and particle panel materials, Philadelphia, USA, p. 137-166, 1996.

BALLARIN, A. W.; GONÇALVES, R. (2001). Ensaios não destrutivos aplicados aos produtos à base de madeira: a situação brasileira. In: Conferência sobre Tecnologia de Equipamentos, V, 2001. Anais. São Paulo, SP, 11p, Cd rom, arquivo digital.

BARTHOLOMEU, A. Classificação de peças estruturais de madeira através do ultra-som. Tese (Doutorado em Construções Rurais e Ambiência). Faculdade de Engenharia Agrícola, Universidade Estadual de Campinas, Campinas, SP, 2001, 105p.

BEKHTA, P. A.; NIEMZ, P.; KUCERA, L. The study of sound propagation in the wood-based composite materials. In: Symposium on nondestructive testing of wood, 12, Sopron, 2000. Anais, Western Hungary, Sopron.

BODIG, J. The process of NDE research for wood and wood composites. The eJournal of Nondestructive Testing, v.6, n.03, mar. 2001. http://www.ndt.net/index.html / Apresentado no 12 th. International Symposium on Nondestructive Testing of Wood, Sopron, 2000/

BUCUR, V. Acoustics as a Tool for the Nondestructive Testing of Wood. The eJournal of Nondestructive Testing, v.4, n.11, nov. 1999. http://www.ndt.net/index.html /Apresentado no 11 th. International Symposium on Nondestructive Testing of Wood, Brasil, 1999/

CLOUTIER, A. Oriented Strand Board (OSB): Raw material, manufacturing process, properties and uses. In: SEMINÁRIO INTERNACIONAL SOBRE PRODUTOS SÓLIDOS DE MADEIRA DE ALTA TECNOLOGIA - ENCONTRO SOBRE TECNOLOGIAS APROPRIADAS DE DESDOBRO, SECAGEM E UTILIZAÇÃO DA MADEIRA DE EUCALIPTO, I.,1998, Viçosa. Anais. Viçosa, UFV, 1998. p. $173-85$.

COSTA NETO, P. L. O. Estatística. São Paulo. Editora Edgard Blücher Ltda, 1977. $262 p$. 
EINSFELD, R. A. et al. Manufatura e características das chapas OSB (ORIENTED STRAND BOARD). In: ENCONTRO BRASILEIRO EM MADEIRAS E ESTRUTURAS DE MADEIRA, VI., 1998, Florianópolis. Anais. Florianópolis, UFSC, 1998. v.3, p. $387-93$.

DEUTSCHES INSTITUT FÜR NURMUNG: Biegeversuch - DIN 52 183. Testing of wood: determination of moisture content. Berlin, 1977.

DEUTSCHES INSTITUT FÜR NURMUNG: Biegeversuch - DIN 52 182. Testing of wood: determination of density. Berlin, 1978.

DEUTSCHES INSTITUT FÜR NURMUNG: Biegeversuch - DIN 52 186. Testing of wood: bending test. Berlin, 1978.

EUROPEAN COMMITTEE FOR STANDARDIZATION. EUROCODE 5 - Design of Timber Structures. Part 1-1: General rules and rules for buildings, Brussels, 110p, 1995.

EUROPEAN COMMITTEE FOR STANDARDIZATION. European Standard - EN 300. Aglomerado de partículas de madeira longas e orientadas (OSB) Definições, classificação e especificações. Portugal, 2002.

EUROPEAN COMMITTEE FOR STANDARDIZATION. European Standard - EN 310. Placas de derivados de madeira. Determinação do módulo de elasticidade em flexão e da resistência à flexão. Portugal, 2000.

EUROPEAN COMMITTEE FOR STANDARDIZATION. European Standard - EN 319. Particleboards and Fiberboards - Determination of internal adhesion. Bruxelas, 1993.

EUROPEAN COMMITTEE FOR STANDARDIZATION. European Standard - EN 317. Particleboards and Fiberboards - Determination of swelling in thickness after immersion in water. Bruxelas, 1993.

EUROPEAN COMMITTEE FOR STANDARDIZATION. European Standard - EN 322. Placas de derivados de madeira. Determinação do teor de água. Portugal, 2000.

EUROPEAN COMMITTEE FOR STANDARDIZATION. European Standard - EN 323. Placas de derivados de madeira. Determinação da massa volúmica. Portugal, 2000.

EUROPEAN COMMITTEE FOR STANDARDIZATION. European Standard - EN 326-1. Placas de derivados de madeira. Amostragem, corte e inspeção. Parte 1: Amostragem e corte dos provetes e expressão dos resultados de ensaio.Portugal, 2000.

EUROPEAN COMMITTEE FOR STANDARDIZATION. European Standard - EN 326-2. Placas de derivados de madeira. Amostragem, corte e inspeção. Parte 2: Controle de qualidade em fábrica. Portugal, 2002.

Forest Products Laboratory (1999). Wood handbook - Wood as an engineering material. Gen. Tech. Rep. FPL - GTR - 113. Madison, WI: US. Departament of Agriculture, Forest Service, Forest Products Laboratory, 463p. 
JANSSENS, D., P. The increasing recognition of Oriented Strand Board (OSB) as a preferred structural panel. In: SEMINÁRIO INTERNACIONAL SOBRE PRODUTOS SÓLIDOS DE MADEIRA DE ALTA TECNOLOGIA - ENCONTRO SOBRE TECNOLOGIAS APROPRIADAS DE DESDOBRO, SECAGEM E UTILIZAÇÃO DA MADEIRA DE EUCALIPTO, I,1998, Viçosa. Anais. Viçosa, UFV, 1998.

KAWAMOTO, S.; WILLIAMS, R. S. Acoustic emission and acousto-ultrasonic techniques for wood and wood-based composites - A review. Gen. Tech. Rep. FPL - GTR - 134. Madison, WI: U.S. Department of Agriculture, Forest Products Laboratory. 2002, 16p.

KRAUTKRAMER, J.; KRAUTKRAMER, H. (1983). Ultrasonic Testing of Materials. Springer Verlag, New York, Third Edition.

MARTINEZ, M. E.; CALIL, C. J. (2000). Determinação do valor característico da resistência da madeira: Distribuições de probabilidades simétricas e assimétricas. In: ENCONTRO BRASILEIRO DE MADEIRAS E EM ESTRUTURAS DE MADEIRA, VII, São Carlos, 2000. Anais. São Carlos, SP, Cd rom, arquivo digital.

MASISA Brasil: http://www.masisa.com.br. Acesso em: 05 nov. 2002.

MATOS, J. L. M. Estudos sobre a produção de painéis estruturais de lâminas paralelas de Pinus taeda. L. Tese (Doutorado em Engenharia Florestal). Setor de Ciências Agrárias, Universidade Federal do Paraná, Curitiba, PR, 1997, $117 p$.

MATOS, J. L. M.; KEINERT Jr., S.; ROSA, G. M. (2000). Uso de métodos de emissão acústica para determinação não destrutiva de propriedades de Painéis compensados de madeira. In: ENCONTRO BRASILEIRO DE MADEIRAS E EM ESTRUTURAS DE MADEIRA, VII, São Carlos, 2000. Anais. São Carlos, SP, 6 $p$, Cd rom, arquivo digital.

MENDES, L. M.; ALBUQUERQUE, C. E. C.; IWAKIRI, S. Indústria brasileira de painéis de madeira. Revista da Madeira, ABPM - Associação Brasileira de Produtores de Madeira, Curitiba, ano 10, n.56, 2001, p. 67-72.

MENDES; L. M. MATOS, J. L. M.; IWAKIRI, S., MORI, F. A., TRUGUILHO, P. F. (2002). Uso de métodos de emissão acústica para determinação não destrutiva de propriedades de painéis OSB (Oriented Strand Board). In: Congresso IberoAmericano de Pesquisa e Desenvolvimento de Produtos Florestais, II Seminário em Tecnologia da Madeira e Produtos Florestais Não-Madeiráveis, I, Curitiba, 2002. Anais. Curitiba, PR, 10 p.

New basics for professional panel engineering: http://www.osb-info.org. Acesso em 10 out. 2002.

OLIVEIRA, F. G. R.; SALES, A. (2000). Propagação de ondas acústicas na madeira. In: ENCONTRO BRASILEIRO DE MADEIRAS E EM ESTRUTURAS DE MADEIRA, VII, São Carlos, 2000. Anais. São Carlos, SP, 10 p, Cd rom, arquivo digital. 
OLIVEIRA, F. R. G. Estudo de propriedades mecânicas de dicotiledôneas por meio de ensaio não destrutivo utilizando equipamentos de ultra-som. Dissertação (Mestrado em Ciências e Engenharia de Materiais). Escola de Engenharia de São Carlos, Universidade de São Paulo, Interunidades, São Carlos, SP, 2001, 55p.

ROSS, R. J.; PELLERIN, R. F. NDE of wood-based composites with longitudinal stress waves. Forest Products Journal, v. 38, n. 5, p. $39-45,1985$.

ROSS, R. J.; BRASHWA, B. K; PELLERIN, R. F. Nondestructive evaluation of wood. Forest Products Journal, v. 48, n.1, p.14-19, 1998.

SILVA, S., A., M. Chapa de média densidade (MDF) fabricada com poliuretana mono-componente derivada de óleo de mamona - caracterização por método destrutivo e por ultra-som. Tese (Doutorado em Construções Rurais e Ambiência). Faculdade de Engenharia Agrícola, Universidade Estadual de Campinas, Campinas, SP, 2003, 234p.

STRUCTURAL BOARD ASSOCIATION. (2003). Oriented strand board: performance by design - Manufactured housing. Canadá. Disponível em: $<$ http://www.osbguide.com/osbliterature.html>. Acesso em: 02 de jul. 2003.

STRUCTURAL BOARD ASSOCIATION. http://www.osbguide.com/. Acesso em: 24 nov. 2002.

VUN, R. Y.; WU, Q.; BHARDWAJ, M.; STEAD, G. Through-thickness ultrasonic transmission properties of oriented strand board. In: Symposium on nondestructive testing of wood, 12, Sopron, 2000. Anais, Western Hungary, Sopron, p. $77-86$. 
Apêndice A 


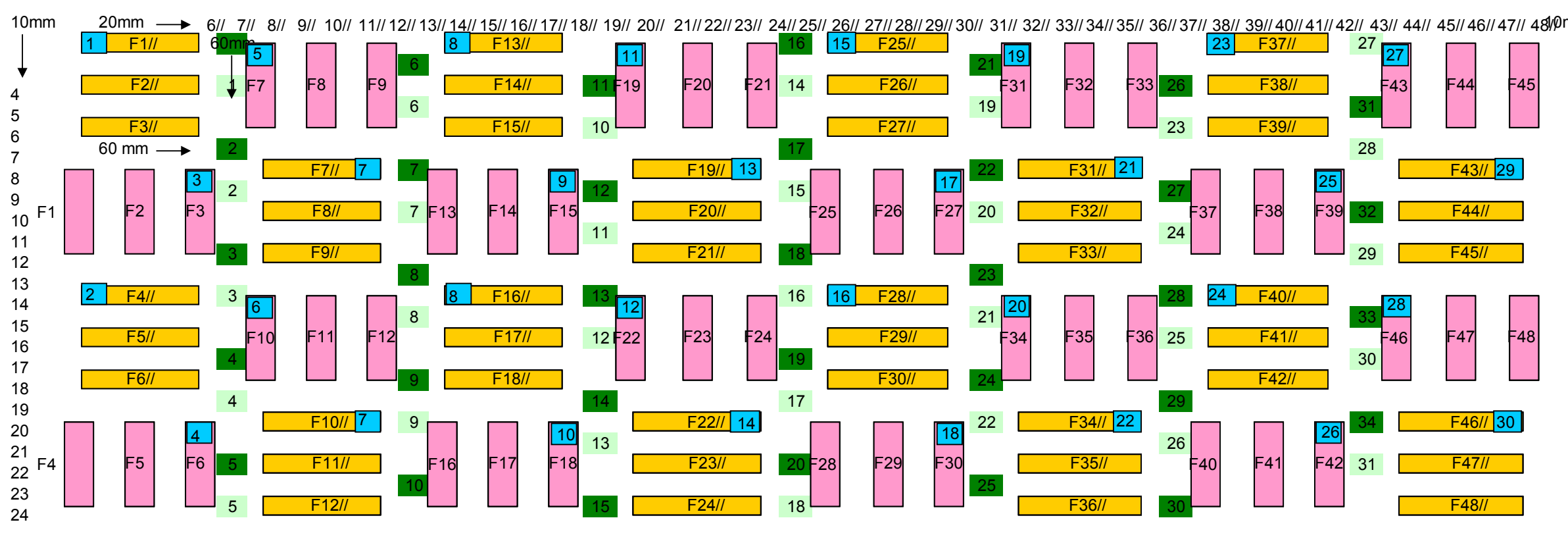

densidade

Plano de corte para os painéis de espessura $6 \mathrm{~mm}$

Inchamento e absorção de água

Adesão Interna

Flexão (longitudinal)

Flexão (transversal) 


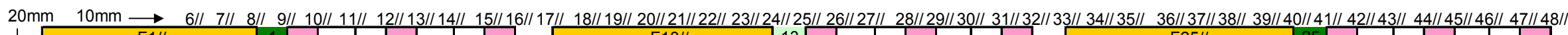

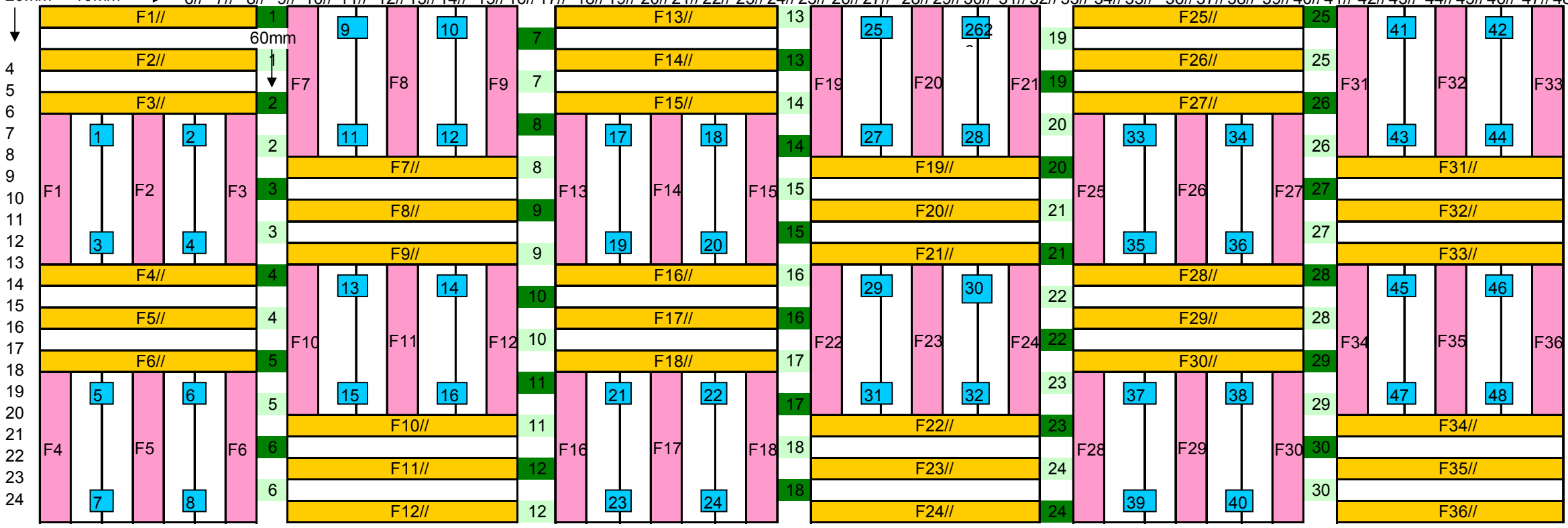

densidade

Plano de corte para os painéis de espessura $15 \mathrm{~mm}$

Inchamento e absorção de água

Adesão Interna

Flexão (longitudinal)

Flexão (transversal) 


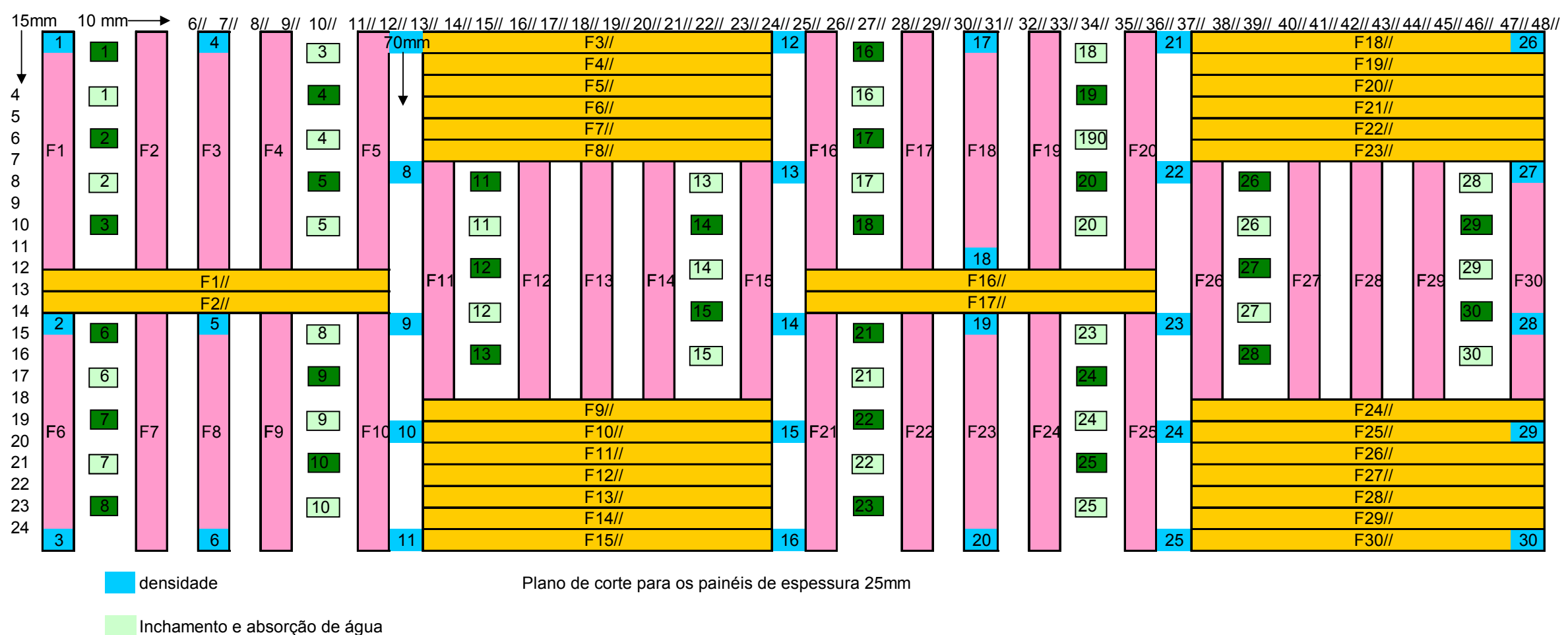

Inchamento e absorção de água

Adesão Interna

Flexão (Iongitudinal)

Flexão (transversal) 
Apênatice ه 
Tabela B1 - Valores de $\mathrm{H}$ e $\rho$ para os painéis OSB dos grupos 1 e 2

\begin{tabular}{|c|c|c|c|c|c|}
\hline Painéis & H (\%) & $\rho\left(\mathrm{kg} / \mathrm{m}^{3}\right)$ & Painéis & H (\%) & $\rho\left(\mathrm{kg} / \mathrm{m}^{3}\right)$ \\
\hline \multirow{6}{*}{11} & & 557 & \multirow{6}{*}{21} & & $\overline{554}$ \\
\hline & 6 & 593 & & 6 & 598 \\
\hline & 7 & 531 & & 6 & 596 \\
\hline & 7 & 642 & & 7 & 584 \\
\hline & 7 & 555 & & 7 & 600 \\
\hline & & 566 & & & 622 \\
\hline \multirow{6}{*}{12} & & 511 & \multirow{6}{*}{22} & & 596 \\
\hline & 7 & 538 & & 7 & 599 \\
\hline & 6 & 585 & & 6 & 582 \\
\hline & 7 & 540 & & 7 & 578 \\
\hline & 7 & 650 & & 6 & 628 \\
\hline & & 612 & & & 601 \\
\hline \multirow{6}{*}{13} & & 584 & \multirow{6}{*}{23} & & 620 \\
\hline & 6 & 552 & & 7 & 636 \\
\hline & 7 & 603 & & 7 & 540 \\
\hline & 8 & 562 & & 7 & 526 \\
\hline & 6 & 598 & & 7 & 647 \\
\hline & & 596 & & & 651 \\
\hline \multirow{6}{*}{14} & & 557 & \multirow{6}{*}{24} & & 590 \\
\hline & 8 & 542 & & 7 & 635 \\
\hline & 7 & 559 & & 7 & 641 \\
\hline & 9 & 617 & & 8 & 629 \\
\hline & 6 & 563 & & 6 & 655 \\
\hline & & 553 & & & 640 \\
\hline \multirow{6}{*}{15} & & 624 & \multirow{6}{*}{25} & & 562 \\
\hline & 6 & 588 & & 7 & 617 \\
\hline & 6 & 567 & & 6 & 624 \\
\hline & 7 & 566 & & 7 & 625 \\
\hline & 7 & 642 & & 7 & 554 \\
\hline & & 577 & & & 562 \\
\hline \multirow{6}{*}{16} & & 583 & \multirow{6}{*}{26} & & 564 \\
\hline & 7 & 581 & & 6 & 578 \\
\hline & 7 & 565 & & 6 & 600 \\
\hline & 6 & 592 & & 6 & 620 \\
\hline & 6 & 533 & & 5 & 611 \\
\hline & & 504 & & & 584 \\
\hline \multirow{6}{*}{17} & & 586 & \multirow{6}{*}{27} & & 632 \\
\hline & 8 & 526 & & 7 & 626 \\
\hline & 6 & 627 & & 7 & 590 \\
\hline & 7 & 603 & & 7 & 545 \\
\hline & 7 & 586 & & 7 & 607 \\
\hline & & 564 & & & 579 \\
\hline \multirow{6}{*}{18} & & 575 & \multirow{6}{*}{28} & & 557 \\
\hline & 7 & 623 & & 7 & 538 \\
\hline & 7 & 568 & & 7 & 567 \\
\hline & 8 & 541 & & 7 & 520 \\
\hline & 7 & 543 & & 7 & 542 \\
\hline & & 572 & & & 607 \\
\hline
\end{tabular}


Tabela B1 - Valores de H e $\rho$ para os painéis OSB dos grupos 1 e 2 (continuação)

\begin{tabular}{|c|c|c|c|c|c|}
\hline \multirow{6}{*}{19} & & 555 & \multirow{6}{*}{29} & & 530 \\
\hline & 7 & 516 & & 7 & 517 \\
\hline & 7 & 555 & & 7 & 597 \\
\hline & 6 & 562 & & 7 & 562 \\
\hline & 7 & 612 & & 5 & 595 \\
\hline & & 578 & & & 526 \\
\hline \multirow{6}{*}{110} & & 643 & \multirow{6}{*}{210} & & 578 \\
\hline & 7 & 669 & & 6 & 570 \\
\hline & 6 & 597 & & 7 & 602 \\
\hline & 7 & 558 & & 8 & 622 \\
\hline & 6 & 574 & & 7 & 562 \\
\hline & & 1306 & & & 584 \\
\hline
\end{tabular}


Tabela B2 - Valores de $G_{t}, A_{m}$ e Al para os painéis OSB dos grupos 1 e 2

\begin{tabular}{|c|c|c|c|c|c|c|c|}
\hline Painéis & $G_{t}(\%)$ & $A_{m}(\%)$ & $\mathrm{Al}(\mathrm{MPa})$ & Painéis & $G_{t}(\%)$ & $A_{m}(\%)$ & $\mathrm{Al}(\mathrm{MPa})$ \\
\hline \multirow{8}{*}{11} & 8 & 38 & 0,41 & \multirow{8}{*}{21} & 21 & 44 & 0,40 \\
\hline & 14 & 36 & 0,44 & & 25 & 34 & 0,46 \\
\hline & 10 & 37 & 0,61 & & 18 & 51 & 0,35 \\
\hline & 9 & 37 & 0,37 & & 15 & 47 & 0,22 \\
\hline & 12 & 45 & 0,49 & & 17 & 52 & 0,48 \\
\hline & 12 & 35 & 0,47 & & 13 & 42 & 0,54 \\
\hline & 7 & 33 & 0,42 & & 17 & 49 & 0,59 \\
\hline & 11 & 44 & * & & 13 & 48 & 0,65 \\
\hline \multirow{8}{*}{12} & 3 & 38 & 0,18 & \multirow{8}{*}{22} & 9 & 53 & 0,22 \\
\hline & 2 & 36 & 0,11 & & 16 & 45 & 0,44 \\
\hline & 15 & 37 & 0,58 & & 17 & 56 & 0,38 \\
\hline & 11 & 37 & 0,36 & & 19 & 58 & 0,42 \\
\hline & 12 & 45 & 0,55 & & 18 & 47 & 0,47 \\
\hline & 18 & 35 & 0,40 & & 20 & 49 & 0,51 \\
\hline & 9 & 33 & 0,57 & & 13 & 42 & 0,43 \\
\hline & 14 & 44 & 0,48 & & 20 & 36 & 0,39 \\
\hline \multirow{8}{*}{13} & 10 & 37 & 0,46 & \multirow{8}{*}{23} & 17 & 44 & 0,36 \\
\hline & 16 & 37 & 0,69 & & 17 & 42 & 0,50 \\
\hline & 7 & 35 & 0,31 & & 26 & 57 & 0,43 \\
\hline & 11 & 40 & 0,55 & & 26 & 49 & 0,41 \\
\hline & 22 & 44 & 0,40 & & 24 & 47 & 0,47 \\
\hline & 9 & 46 & 0,52 & & 16 & 45 & 0,36 \\
\hline & 15 & 38 & 0,55 & & 16 & 51 & 0,24 \\
\hline & 13 & 33 & 0,45 & & 15 & 45 & 0,31 \\
\hline \multirow{8}{*}{14} & 13 & 44 & 0,56 & \multirow{8}{*}{24} & 14 & 47 & 0,43 \\
\hline & 10 & 39 & 0,69 & & 18 & 46 & 0,31 \\
\hline & 10 & 38 & 0,42 & & 18 & 53 & 0,39 \\
\hline & 10 & 46 & 0,34 & & 13 & 39 & 0,54 \\
\hline & 14 & 39 & 0,38 & & 24 & 47 & 0,55 \\
\hline & 11 & 47 & 0,71 & & 24 & 50 & 0,49 \\
\hline & 15 & 45 & 0,50 & & 20 & 39 & 0,39 \\
\hline & 11 & 37 & $*$ & & 21 & 43 & 0,59 \\
\hline \multirow{8}{*}{15} & 13 & 36 & 0,44 & \multirow{8}{*}{25} & 17 & 44 & 0,26 \\
\hline & 16 & 45 & 0,51 & & 19 & 68 & 0,35 \\
\hline & 13 & 52 & 0,63 & & 18 & 43 & 0,50 \\
\hline & 26 & 41 & 0,76 & & 18 & 46 & 0,45 \\
\hline & 17 & 39 & 0,44 & & 19 & 46 & * \\
\hline & 20 & 38 & 0,32 & & 14 & 36 & * \\
\hline & 14 & 35 & 0,55 & & 20 & 48 & * \\
\hline & 10 & 29 & 0,76 & & 16 & 43 & * \\
\hline \multirow{8}{*}{16} & 18 & 42 & 0,84 & \multirow{8}{*}{26} & 19 & 52 & 0,38 \\
\hline & 17 & 46 & 0,73 & & 24 & 50 & 0,38 \\
\hline & 9 & 57 & 0,75 & & 10 & 55 & 0,28 \\
\hline & 13 & 34 & 0,54 & & 16 & 48 & 0,38 \\
\hline & 12 & 38 & 0,36 & & 13 & 51 & 0,31 \\
\hline & 12 & 41 & 0,67 & & 19 & 40 & 0,38 \\
\hline & 14 & 47 & 0,20 & & 16 & 38 & 0,59 \\
\hline & 17 & 42 & 0,53 & & 21 & 46 & 0,49 \\
\hline
\end{tabular}


Tabela B2 - Valores de $G_{t}, A_{m}$ e Al para os painéis OSB dos grupos 1 e 2 (continuação)

\begin{tabular}{|c|c|c|c|c|c|c|c|}
\hline \multirow{8}{*}{17} & 11 & 40 & 0,45 & \multirow{8}{*}{27} & 11 & 58 & 0,25 \\
\hline & 13 & 43 & 0,71 & & 19 & 50 & 0,42 \\
\hline & 14 & 47 & 0,48 & & 23 & 47 & 0,52 \\
\hline & 13 & 46 & 0,51 & & 17 & 41 & 0,40 \\
\hline & 11 & 38 & 0,61 & & 20 & 49 & 0,67 \\
\hline & 9 & 51 & 0,49 & & 17 & 49 & 0,46 \\
\hline & 15 & 44 & 0,64 & & 14 & 55 & 0,29 \\
\hline & 14 & 45 & 0,53 & & 12 & 40 & 0,21 \\
\hline \multirow{8}{*}{18} & 15 & 39 & 0,41 & \multirow{8}{*}{28} & 20 & 58 & 0,51 \\
\hline & 15 & 42 & 0,61 & & 14 & 49 & 0,47 \\
\hline & 14 & 55 & 0,55 & & 18 & 51 & 0,65 \\
\hline & 15 & 41 & 0,36 & & 18 & 38 & 0,51 \\
\hline & 10 & 41 & 0,40 & & 20 & 39 & 0,50 \\
\hline & 10 & 43 & 0,32 & & 9 & 48 & 0,31 \\
\hline & 9 & 34 & 0,35 & & 22 & 51 & 0,33 \\
\hline & 13 & 37 & 0,40 & & 18 & 46 & 0,36 \\
\hline \multirow{8}{*}{19} & 18 & 42 & 0,41 & \multirow{8}{*}{29} & 14 & 43 & 0,48 \\
\hline & 10 & 61 & 0,78 & & 18 & 46 & 0,57 \\
\hline & 17 & 50 & 0,55 & & 16 & 46 & 0,54 \\
\hline & 18 & 42 & 0,33 & & 16 & 40 & 0,49 \\
\hline & 16 & 51 & 0,65 & & 18 & 53 & 0,45 \\
\hline & 15 & 40 & 0,42 & & 19 & 41 & 0,48 \\
\hline & 9 & 52 & 0,61 & & 19 & 59 & 0,35 \\
\hline & 5 & 46 & 0,51 & & 14 & 40 & 0,42 \\
\hline \multirow{8}{*}{110} & 19 & 38 & 0,31 & \multirow{8}{*}{210} & 27 & 41 & 0,45 \\
\hline & 15 & 40 & 0,58 & & 19 & 53 & 0,50 \\
\hline & 13 & 40 & 0,64 & & 16 & 59 & 0,32 \\
\hline & 11 & 44 & 0,50 & & 17 & 49 & 0,44 \\
\hline & 16 & 44 & 0,62 & & 12 & 50 & 0,47 \\
\hline & 15 & 44 & 0,40 & & 18 & 47 & 0,45 \\
\hline & 18 & 39 & 0,58 & & 13 & 41 & 0,54 \\
\hline & 9 & 45 & 0,40 & & 17 & 67 & 0,51 \\
\hline
\end{tabular}

* Representam corpos-de-prova em que houve problemas e não foi possível obter os resultados dos ensaios. 
Tabela B3 - Valores de $f_{m}$ e $E_{m}$ para os painéis OSB dos grupos 1 e 2 na direção longitudinal

\begin{tabular}{|c|c|c|c|c|c|}
\hline Painéis & $\mathbf{f}_{\mathrm{m}}(\mathrm{MPa})$ & $\mathrm{E}_{\mathrm{m}}(\mathrm{MPa})$ & Painéis & $\mathbf{f}_{\mathrm{m}}(\mathrm{MPa})$ & $E_{m}(\mathrm{MPa})$ \\
\hline \multirow{6}{*}{11} & 33 & 4424 & \multirow{6}{*}{21} & 17 & 3591 \\
\hline & 27 & 4007 & & 21 & 3936 \\
\hline & 36 & 5398 & & 24 & 4461 \\
\hline & 36 & 5387 & & 21 & 4269 \\
\hline & 31 & 4401 & & 17 & 3994 \\
\hline & 23 & 4852 & & 22 & 4397 \\
\hline \multirow{6}{*}{12} & 24 & 4135 & \multirow{6}{*}{22} & 13 & 2577 \\
\hline & 34 & 5183 & & 23 & 4270 \\
\hline & 32 & 5777 & & 22 & 4224 \\
\hline & 32 & 4976 & & 17 & 3406 \\
\hline & 28 & 5558 & & 17 & 4007 \\
\hline & 39 & 5494 & & 19 & 3682 \\
\hline \multirow{6}{*}{13} & 37 & 6456 & \multirow{6}{*}{23} & 21 & 4097 \\
\hline & 32 & 5219 & & 20 & 4098 \\
\hline & 29 & 4962 & & 21 & 4165 \\
\hline & 39 & 6273 & & 23 & 4691 \\
\hline & 26 & 5465 & & 22 & 3946 \\
\hline & 31 & 4782 & & 30 & 5066 \\
\hline \multirow{6}{*}{14} & 34 & 4822 & \multirow{6}{*}{24} & 25 & 4505 \\
\hline & 34 & 5316 & & 24 & 4600 \\
\hline & 34 & 5451 & & 21 & 4516 \\
\hline & 30 & 5098 & & 21 & 4003 \\
\hline & 29 & 5244 & & 23 & 4390 \\
\hline & 35 & 5418 & & 20 & 3945 \\
\hline \multirow{6}{*}{15} & 29 & 4436 & \multirow{6}{*}{25} & 15 & 3139 \\
\hline & 33 & 5202 & & 21 & 4403 \\
\hline & 28 & 5283 & & 21 & 4354 \\
\hline & 30 & 5534 & & 27 & 4775 \\
\hline & 32 & 5329 & & 17 & 3890 \\
\hline & 31 & 5337 & & 21 & 3510 \\
\hline \multirow{6}{*}{16} & 30 & 4533 & \multirow{6}{*}{26} & 15 & 3234 \\
\hline & 30 & 4699 & & 29 & 4961 \\
\hline & 26 & 4494 & & 25 & 4412 \\
\hline & 31 & 4827 & & 20 & 3693 \\
\hline & 32 & 5987 & & 16 & 3115 \\
\hline & 33 & 5734 & & 21 & 3875 \\
\hline \multirow{6}{*}{17} & 31 & 4972 & \multirow{6}{*}{27} & 17 & 3129 \\
\hline & 26 & 4657 & & 29 & 4686 \\
\hline & 18 & 4610 & & 24 & 4398 \\
\hline & 32 & 4634 & & 24 & 4121 \\
\hline & 31 & 4935 & & 23 & 4284 \\
\hline & 33 & 5357 & & 19 & 4187 \\
\hline \multirow{6}{*}{18} & 30 & 5139 & \multirow{6}{*}{28} & 19 & 3407 \\
\hline & 28 & 4422 & & 20 & 4515 \\
\hline & 31 & 5328 & & 16 & 3435 \\
\hline & 41 & 5816 & & 21 & 4107 \\
\hline & 18 & 3817 & & 24 & 4514 \\
\hline & 29 & 4521 & & 29 & 4749 \\
\hline
\end{tabular}


Tabela B3 - Valores de $f_{m}$ e $E_{m}$ para os painéis OSB dos grupos 1 e 2 na direção longitudinal (continuação)

\begin{tabular}{ccc||ccc} 
& 20 & 3846 & & 16 & 3398 \\
\multirow{4}{*}{19} & 26 & 4852 & & 24 & 4523 \\
& 36 & 6233 & \multirow{2}{*}{29} & 27 & 4584 \\
& 22 & 4605 & & 25 & 4602 \\
& 36 & 5155 & & 21 & 3970 \\
& 33 & 5116 & & 15 & 3613 \\
\hline \multirow{4}{*}{110} & 21 & 3701 & & 25 & 3771 \\
& 29 & 5892 & & 21 & 4545 \\
& 31 & 4723 & \multirow{2}{*}{210} & 26 & 4035 \\
& 31 & 5252 & & 21 & 4205 \\
& 30 & 4533 & & 18 & 3841 \\
& 35 & 5465 & & 19 & 3694 \\
\hline
\end{tabular}


Tabela B4 - Valores de $f_{m}$ e $E_{m}$ para os painéis OSB dos grupos 1 e 2 na direção transversal

\begin{tabular}{|c|c|c|c|c|c|}
\hline Painéis & $\mathbf{f}_{\mathrm{m}}(\mathrm{MPa})$ & $E_{m}(\mathrm{MPa})$ & Painéis & $\mathbf{f}_{\mathrm{m}}(\mathrm{MPa})$ & $E_{m}(M P a)$ \\
\hline \multirow{6}{*}{11} & 12 & 1742 & \multirow{6}{*}{21} & 16 & 2456 \\
\hline & 13 & 1597 & & 14 & 2357 \\
\hline & 16 & 1949 & & 18 & 2111 \\
\hline & 13 & 2040 & & 10 & 1554 \\
\hline & 14 & 1973 & & 10 & 1764 \\
\hline & 14 & 1730 & & 17 & 2352 \\
\hline \multirow{6}{*}{12} & 14 & 2101 & \multirow{6}{*}{22} & 15 & 2029 \\
\hline & 21 & 2470 & & 17 & 2393 \\
\hline & 9 & 1645 & & 12 & 1967 \\
\hline & 12 & 1518 & & 10 & 1559 \\
\hline & 11 & 1625 & & 13 & 2090 \\
\hline & 17 & 2128 & & 15 & 2100 \\
\hline \multirow{6}{*}{13} & 11 & 1766 & \multirow{6}{*}{23} & 13 & 2082 \\
\hline & 13 & 1964 & & 15 & 2147 \\
\hline & 18 & 2265 & & 8 & 1242 \\
\hline & 18 & 2069 & & 11 & 1650 \\
\hline & 16 & 1760 & & 14 & 2057 \\
\hline & 13 & 1734 & & 14 & 2133 \\
\hline \multirow{6}{*}{14} & 13 & 1774 & \multirow{6}{*}{24} & 16 & 2147 \\
\hline & 12 & 1656 & & 16 & 2396 \\
\hline & 8 & 1393 & & 12 & 1929 \\
\hline & 11 & 1551 & & 14 & 1892 \\
\hline & 11 & 1707 & & 12 & 1953 \\
\hline & 13 & 1827 & & 14 & 1916 \\
\hline \multirow{6}{*}{15} & 15 & 1747 & \multirow{6}{*}{25} & 16 & 2058 \\
\hline & 15 & 1951 & & 15 & 1960 \\
\hline & 13 & 1835 & & 15 & 2196 \\
\hline & 14 & 1847 & & 17 & 2294 \\
\hline & 13 & 1732 & & 11 & 1826 \\
\hline & 13 & 1859 & & 11 & 1675 \\
\hline \multirow{6}{*}{16} & 15 & 2139 & \multirow{6}{*}{26} & 17 & 2001 \\
\hline & 14 & 1898 & & 17 & 1945 \\
\hline & 10 & 1666 & & 15 & 2038 \\
\hline & 17 & 1822 & & 9 & 1571 \\
\hline & 13 & 1677 & & 15 & 2325 \\
\hline & 17 & 2019 & & 12 & 1997 \\
\hline \multirow{6}{*}{17} & 11 & 1430 & \multirow{6}{*}{27} & 13 & 1833 \\
\hline & 13 & 1741 & & 16 & 2432 \\
\hline & 14 & 1803 & & 12 & 1671 \\
\hline & 10 & 1886 & & 10 & 1403 \\
\hline & 13 & 1724 & & 16 & 2171 \\
\hline & 14 & 2077 & & 16 & 2254 \\
\hline \multirow{6}{*}{18} & 13 & 1615 & \multirow{6}{*}{28} & 13 & 1726 \\
\hline & 13 & 1823 & & 15 & 1985 \\
\hline & 17 & 1771 & & 14 & 1884 \\
\hline & 14 & 1581 & & 10 & 1511 \\
\hline & 10 & 1638 & & 13 & 2029 \\
\hline & 11 & 1491 & & 11 & 1739 \\
\hline
\end{tabular}


Tabela B4 - Valores de $f_{m}$ e $E_{m}$ para os painéis OSB dos grupos 1 e 2 na direção transversal (continuação)

\begin{tabular}{ccc||rrr} 
& 12 & 1583 & & 13 & 1876 \\
& 9 & 1374 & & 12 & 1626 \\
19 & 14 & 2169 & \multirow{2}{*}{29} & 12 & 1777 \\
& 16 & 1905 & & 19 & 2385 \\
& 9 & 1282 & & 12 & 1695 \\
& 10 & 1459 & & 12 & 1863 \\
\hline \multirow{4}{*}{110} & 12 & 1646 & & 13 & 1798 \\
& 10 & 1460 & & 14 & 1831 \\
& 9 & 1445 & \multirow{2}{*}{210} & 15 & 2253 \\
& 15 & 1764 & & 16 & 2215 \\
& 13 & 1849 & & 12 & 2004 \\
& 14 & 1827 & & 13 & 1805 \\
\hline
\end{tabular}


Apêntice 0 
Tabela $C 1$ - Valores de $V_{A l}, V_{G t / A m}, C_{A l}, C_{G t / A m}, \operatorname{Atn}_{A l}$ e $A t_{G t / A m}$ para os painéis 11 e 12, através do método de ultra-som

\begin{tabular}{|c|c|c|c|c|c|c|c|c|c|c|c|c|c|}
\hline CP & $\begin{array}{c}\mathrm{V}_{\mathrm{Al}} \\
(\mathrm{m} / \mathrm{s})\end{array}$ & $\begin{array}{l}V_{\mathrm{Gt} / \mathrm{Am}} \\
(\mathrm{m} / \mathrm{s})\end{array}$ & $\begin{array}{c}\mathrm{C}_{\mathrm{Al}} \\
(\mathrm{MPa})\end{array}$ & $\begin{array}{l}\mathrm{C}_{\mathrm{Gt} / \mathrm{Am}} \\
(\mathrm{MPa}) \\
\end{array}$ & $\begin{array}{c}\text { Atn }_{\text {Al }} \\
\text { (dß|loss) }\end{array}$ & $\begin{array}{l}\text { Atn } \text { Att/Am } \\
\text { (dß|oss) }\end{array}$ & CP & $\begin{array}{c}\begin{array}{c}V_{A l} \\
(\mathrm{~m} / \mathrm{s})\end{array} \\
\end{array}$ & $\begin{array}{l}\mathrm{V}_{\mathrm{Gt} / \mathrm{Am}} \\
(\mathrm{m} / \mathrm{s})\end{array}$ & $\begin{array}{c}\mathrm{C}_{\mathrm{Al}} \\
(\mathrm{MPa}) \\
\end{array}$ & $\begin{array}{l}\mathrm{C}_{\mathrm{G} t / \mathrm{Am}} \\
(\mathrm{MPa}) \\
\end{array}$ & $\begin{array}{c}\text { Atn }_{\text {Al }} \\
\text { (d } \beta \text { loss) } \\
\end{array}$ & $\begin{array}{l}\text { Atn }{ }_{\mathrm{Gt} / \mathrm{Am}} \\
\text { (d/3loss) }\end{array}$ \\
\hline 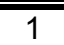 & 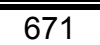 & 896 & 258 & 4661 & 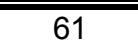 & 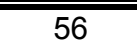 & 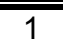 & "615 & 765 & 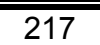 & ב335 & $\bar{~} 67$ & 60 \\
\hline 2 & 755 & 938 & 327 & 505 & 58 & 52 & 2 & 721 & 717 & 298 & 295 & 57 & 68 \\
\hline 3 & 907 & 720 & 472 & 297 & 54 & 63 & 3 & 896 & 757 & 460 & 328 & 52 & 55 \\
\hline 4 & 800 & 674 & 368 & 260 & 58 & 70 & 4 & 951 & 951 & 518 & 518 & 54 & 50 \\
\hline 5 & 766 & 776 & 337 & 346 & 66 & 63 & 5 & 926 & 1067 & 492 & 652 & 52 & 52 \\
\hline 6 & 845 & 823 & 410 & 389 & 60 & 55 & 6 & 934 & 1058 & 500 & 641 & 58 & 52 \\
\hline 7 & 891 & 889 & 456 & 454 & 52 & 56 & 7 & 1006 & 975 & 580 & 545 & 58 & 57 \\
\hline 8 & 942 & 886 & 510 & 451 & 65 & 52 & 8 & 889 & 877 & 453 & 441 & 59 & 55 \\
\hline 9 & 935 & 836 & 502 & 401 & 57 & 68 & 9 & 901 & 779 & 465 & 347 & 50 & 65 \\
\hline 10 & 888 & 797 & 453 & 365 & 69 & 65 & 10 & 881 & 855 & 445 & 419 & 69 & 58 \\
\hline 11 & 872 & 842 & 437 & 407 & 55 & 60 & 11 & 876 & 1030 & 440 & 608 & 54 & 54 \\
\hline 12 & 874 & 922 & 438 & 488 & 56 & 49 & 12 & 1011 & 1049 & 585 & 630 & 55 & 55 \\
\hline 13 & 884 & 922 & 449 & 488 & 53 & 59 & 13 & 910 & 958 & 474 & 525 & 51 & 60 \\
\hline 14 & 931 & 884 & 498 & 448 & 62 & 58 & 14 & 854 & 874 & 418 & 437 & 53 & 57 \\
\hline 15 & 748 & 934 & 321 & 501 & 69 & 61 & 15 & 726 & 766 & 302 & 336 & 70 & 70 \\
\hline 16 & 746 & 902 & 319 & 467 & 51 & 68 & 16 & 737 & 725 & 311 & 301 & 58 & 65 \\
\hline 17 & 913 & 856 & 479 & 421 & 58 & 60 & 17 & 938 & 835 & 504 & 400 & 55 & 59 \\
\hline 18 & 896 & 847 & 461 & 411 & 62 & 58 & 18 & 956 & 864 & 524 & 428 & 60 & 59 \\
\hline 19 & 884 & 803 & 449 & 370 & 55 & 61 & 19 & 863 & 883 & 427 & 447 & 61 & 60 \\
\hline 20 & 870 & 886 & 434 & 451 & 55 & 53 & 20 & 764 & 892 & 335 & 456 & 63 & 58 \\
\hline 21 & 770 & 912 & 340 & 478 & 60 & 68 & 21 & 714 & 817 & 292 & 383 & 68 & 57 \\
\hline 22 & 760 & 801 & 331 & 369 & 54 & 70 & 22 & 784 & 838 & 352 & 402 & 67 & 59 \\
\hline 23 & 831 & 854 & 397 & 419 & 47 & 67 & 23 & 832 & 800 & 397 & 366 & 64 & 65 \\
\hline 24 & 779 & 882 & 349 & 446 & 60 & 60 & 24 & 829 & 768 & 394 & 338 & 58 & 55 \\
\hline 25 & 805 & 837 & 372 & 402 & 55 & 68 & 25 & 828 & 831 & 393 & 395 & 56 & 64 \\
\hline 26 & 905 & 869 & 470 & 433 & 52 & 61 & 26 & 858 & 875 & 422 & 439 & 67 & 56 \\
\hline 27 & 876 & 794 & 440 & 362 & 61 & 69 & 27 & 888 & 940 & 451 & 507 & 65 & 55 \\
\hline 28 & 811 & 788 & 378 & 357 & 52 & 60 & 28 & 854 & 1053 & 418 & 635 & 68 & 47 \\
\hline 29 & 855 & 892 & 419 & 457 & 58 & 60 & 29 & 861 & 1114 & 424 & 711 & 60 & 51 \\
\hline 30 & 935 & 903 & 501 & 468 & 67 & 50 & 30 & 791 & 942 & 358 & 508 & 60 & 52 \\
\hline
\end{tabular}


Tabela $C 2$ - Valores de $V_{A l}, V_{G t / A m}, C_{A l}, C_{G t / A m}, \operatorname{Atn}_{A l}$ e $A t_{G t / A m}$ para os painéis 13 e 14, através do método de ultra-som

\begin{tabular}{|c|c|c|c|c|c|c|c|c|c|c|c|c|c|}
\hline CP & $\begin{array}{c}\mathrm{V}_{\mathrm{Al}} \\
(\mathrm{m} / \mathrm{s})\end{array}$ & $\begin{array}{l}V_{\mathrm{Gt} / \mathrm{Am}} \\
(\mathrm{m} / \mathrm{s})\end{array}$ & $\begin{array}{c}\mathrm{C}_{\mathrm{Al}} \\
(\mathrm{MPa})\end{array}$ & $\begin{array}{l}\mathrm{C}_{\mathrm{Gt} / \mathrm{Am}} \\
(\mathrm{MPa}) \\
\end{array}$ & $\begin{array}{c}\text { Atn }_{\text {Al }} \\
\text { (dß|loss) }\end{array}$ & $\begin{array}{l}\text { Atn } \text { Att/Am } \\
\text { (dß|oss) }\end{array}$ & CP & $\begin{array}{c}\begin{array}{c}V_{A l} \\
(\mathrm{~m} / \mathrm{s})\end{array} \\
\end{array}$ & $\begin{array}{l}\mathrm{V}_{\mathrm{Gt} / \mathrm{Am}} \\
(\mathrm{m} / \mathrm{s})\end{array}$ & $\begin{array}{c}\mathrm{C}_{\mathrm{Al}} \\
(\mathrm{MPa}) \\
\end{array}$ & $\begin{array}{l}\mathrm{C}_{\mathrm{G} t / \mathrm{Am}} \\
(\mathrm{MPa}) \\
\end{array}$ & $\begin{array}{c}\text { Atn }_{\text {Al }} \\
\text { (d } \beta \text { loss) } \\
\end{array}$ & $\begin{array}{l}\text { Atn }{ }_{\mathrm{Gt} / \mathrm{Am}} \\
\text { (d/3loss) }\end{array}$ \\
\hline 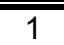 & $\overline{7881}$ & 907 & ב356 & 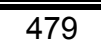 & $\overline{53}$ & $\bar{~} 59$ & 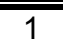 & 894 & 746 & 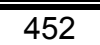 & 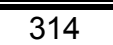 & 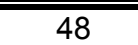 & 60 \\
\hline 2 & 870 & 900 & 442 & 472 & 51 & 60 & 2 & 880 & 807 & 438 & 368 & 58 & 58 \\
\hline 3 & 990 & 923 & 571 & 497 & 58 & 58 & 3 & 893 & 924 & 450 & 482 & 57 & 55 \\
\hline 4 & 990 & 892 & 572 & 464 & 53 & 58 & 4 & 920 & 1024 & 478 & 592 & 54 & 48 \\
\hline 5 & 879 & 757 & 451 & 334 & 68 & 64 & 5 & 1016 & 965 & 583 & 526 & 47 & 60 \\
\hline 6 & 763 & 754 & 340 & 331 & 55 & 47 & 6 & 1069 & 912 & 645 & 470 & 53 & 63 \\
\hline 7 & 768 & 901 & 344 & 474 & 58 & 50 & 7 & 960 & 1001 & 521 & 567 & 58 & 52 \\
\hline 8 & 851 & 1015 & 422 & 601 & 59 & 52 & 8 & 910 & 1009 & 468 & 575 & 67 & 59 \\
\hline 9 & 915 & 1007 & 489 & 591 & 58 & 48 & 9 & 971 & 946 & 533 & 506 & 52 & 60 \\
\hline 10 & 727 & 969 & 308 & 547 & 65 & 48 & 10 & 945 & 1025 & 505 & 593 & 60 & 55 \\
\hline 11 & 706 & 934 & 290 & 508 & 70 & 57 & 11 & 877 & 1051 & 435 & 624 & 60 & 52 \\
\hline 12 & 878 & 792 & 450 & 366 & 55 & 58 & 12 & 1026 & 891 & 594 & 449 & 50 & 53 \\
\hline 13 & 968 & 816 & 547 & 388 & 54 & 55 & 13 & 909 & 789 & 467 & 352 & 57 & 65 \\
\hline 14 & 1024 & 942 & 611 & 518 & 57 & 57 & 14 & 797 & 628 & 359 & 223 & 61 & 62 \\
\hline 15 & 940 & 967 & 515 & 546 & 59 & 55 & 15 & 746 & 683 & 314 & 264 & 69 & 55 \\
\hline 16 & 768 & 871 & 343 & 442 & 60 & 58 & 16 & 796 & 921 & 358 & 479 & 32 & 65 \\
\hline 17 & 744 & 762 & 323 & 338 & 58 & 52 & 17 & 958 & 899 & 518 & 456 & 61 & 59 \\
\hline 18 & 869 & 756 & 440 & 333 & 47 & 51 & 18 & 897 & 942 & 454 & 501 & 51 & 58 \\
\hline 19 & 905 & 800 & 478 & 373 & 59 & 49 & 19 & 857 & 1007 & 415 & 573 & 65 & 56 \\
\hline 20 & 933 & 906 & 507 & 479 & 53 & 57 & 20 & 830 & 956 & 389 & 517 & 62 & 55 \\
\hline 21 & 931 & 967 & 505 & 545 & 62 & 54 & 21 & 870 & 899 & 428 & 456 & 68 & 58 \\
\hline 22 & 902 & 960 & 474 & 538 & 63 & 50 & 22 & 909 & 928 & 466 & 486 & 60 & 55 \\
\hline 23 & 867 & 861 & 438 & 432 & 57 & 51 & 23 & 904 & 968 & 462 & 529 & 42 & 60 \\
\hline 24 & 796 & 834 & 369 & 406 & 57 & 52 & 24 & 874 & 938 & 432 & 497 & 55 & 58 \\
\hline 25 & 823 & 938 & 395 & 513 & 48 & 52 & 25 & 881 & 785 & 439 & 348 & 52 & 58 \\
\hline 26 & 901 & 987 & 473 & 568 & 55 & 57 & 26 & 873 & 772 & 430 & 337 & 47 & 61 \\
\hline 27 & 948 & 946 & 524 & 522 & 50 & 54 & 27 & 839 & 798 & 398 & 360 & 64 & 61 \\
\hline 28 & 955 & 930 & 531 & 505 & 55 & 49 & 28 & 818 & 736 & 378 & 306 & 60 & 69 \\
\hline 29 & 937 & 826 & 512 & 398 & 55 & 60 & 29 & 807 & 850 & 368 & 408 & 65 & 59 \\
\hline 30 & 920 & 738 & 494 & 318 & 67 & 63 & 30 & 838 & 914 & 397 & 472 & 68 & 55 \\
\hline
\end{tabular}


Tabela $C 3$ - Valores de $V_{A l}, V_{G t / A m}, C_{A l}, C_{G t / A m}, \operatorname{Atn}_{A l}$ e $A t_{G t / A m}$ para os painéis 15 e 16, através do método de ultra-som

\begin{tabular}{|c|c|c|c|c|c|c|c|c|c|c|c|c|c|}
\hline CP & $\begin{array}{c}\mathrm{V}_{\mathrm{Al}} \\
(\mathrm{m} / \mathrm{s})\end{array}$ & $\begin{array}{l}V_{G t / A m} \\
(\mathrm{~m} / \mathrm{s})\end{array}$ & $\begin{array}{c}\mathrm{C}_{\mathrm{Al}} \\
(\mathrm{MPa})\end{array}$ & $\begin{array}{l}\mathrm{C}_{\mathrm{Gt} / \mathrm{Am}} \\
(\mathrm{MPa})\end{array}$ & $\begin{array}{c}\text { Atn }_{\mathrm{Al}} \\
\text { (dß)loss) }\end{array}$ & $\begin{array}{l}\text { Atn }{ }_{\mathrm{Gt} / \mathrm{Am}} \\
\text { (dß|loss) }\end{array}$ & CP & $\begin{array}{c}\mathrm{V}_{\mathrm{Al}} \\
(\mathrm{m} / \mathrm{s})\end{array}$ & $\begin{array}{l}\mathrm{V}_{\mathrm{Gt} / \mathrm{Am}} \\
(\mathrm{m} / \mathrm{s})\end{array}$ & $\begin{array}{c}\mathrm{C}_{\mathrm{Al}} \\
(\mathrm{MPa})\end{array}$ & $\begin{array}{l}\mathrm{C}_{\mathrm{Gt} / \mathrm{Am}} \\
(\mathrm{MPa})\end{array}$ & 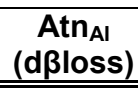 & $\begin{array}{l}\text { Atn } \text { At/Am } \\
\text { (dß/oss) }\end{array}$ \\
\hline 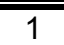 & 871 & 985 & 4450 & 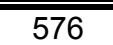 & 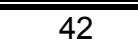 & $\overline{449}$ & 1 & 970 & 812 & $\overline{526}$ & 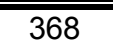 & 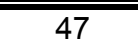 & 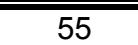 \\
\hline 2 & 907 & 975 & 489 & 565 & 61 & 49 & 2 & 891 & 870 & 444 & 423 & 55 & 52 \\
\hline 3 & 951 & 793 & 538 & 374 & 49 & 65 & 3 & 907 & 880 & 460 & 433 & 53 & 56 \\
\hline 4 & 1026 & 752 & 625 & 336 & 51 & 59 & 4 & 923 & 883 & 477 & 436 & 58 & 54 \\
\hline 5 & 998 & 885 & 591 & 465 & 52 & 49 & 5 & 891 & 949 & 443 & 503 & 47 & 56 \\
\hline 6 & 856 & 819 & 436 & 399 & 52 & 68 & 6 & 949 & 811 & 503 & 367 & 53 & 68 \\
\hline 7 & 866 & 830 & 446 & 409 & 50 & 52 & 7 & 827 & 793 & 382 & 351 & 58 & 58 \\
\hline 8 & 993 & 952 & 586 & 538 & 55 & 50 & 8 & 793 & 838 & 352 & 393 & 51 & 60 \\
\hline 9 & 973 & 893 & 562 & 473 & 63 & 58 & 9 & 871 & 897 & 424 & 450 & 61 & 58 \\
\hline 10 & 933 & 751 & 517 & 335 & 58 & 63 & 10 & 949 & 1091 & 504 & 665 & 55 & 58 \\
\hline 11 & 860 & 794 & 439 & 374 & 58 & 53 & 11 & 971 & 1006 & 527 & 566 & 56 & 57 \\
\hline 12 & 765 & 823 & 347 & 402 & 52 & 65 & 12 & 936 & 887 & 490 & 439 & 59 & 59 \\
\hline 13 & 824 & 762 & 403 & 345 & 52 & 63 & 13 & 915 & 822 & 468 & 378 & 47 & 51 \\
\hline 14 & 954 & 851 & 540 & 430 & 55 & 47 & 14 & 880 & 824 & 432 & 380 & 53 & 49 \\
\hline 15 & 780 & 869 & 361 & 448 & 69 & 61 & 15 & 721 & 882 & 291 & 435 & 58 & 63 \\
\hline 16 & 727 & 809 & 314 & 389 & 63 & 60 & 16 & 693 & 864 & 268 & 418 & 48 & 58 \\
\hline 17 & 859 & 820 & 438 & 400 & 47 & 58 & 17 & 775 & 828 & 336 & 383 & 53 & 42 \\
\hline 18 & 898 & 881 & 479 & 461 & 53 & 53 & 18 & 873 & 815 & 426 & 371 & 55 & 53 \\
\hline 19 & 992 & 958 & 584 & 546 & 55 & 55 & 19 & 998 & 750 & 556 & 314 & 55 & 55 \\
\hline 20 & 860 & 973 & 439 & 563 & 61 & 50 & 20 & 899 & 779 & 452 & 340 & 50 & 60 \\
\hline 21 & 741 & 852 & 326 & 431 & 64 & 61 & 21 & 877 & 912 & 430 & 465 & 60 & 60 \\
\hline 22 & 795 & 842 & 375 & 422 & 65 & 52 & 22 & 900 & 914 & 453 & 467 & 65 & 61 \\
\hline 23 & 865 & 857 & 444 & 437 & 53 & 65 & 23 & 867 & 893 & 420 & 445 & 50 & 51 \\
\hline 24 & 931 & 786 & 514 & 367 & 63 & 60 & 24 & 878 & 956 & 431 & 511 & 60 & 56 \\
\hline 25 & 989 & 871 & 581 & 451 & 47 & 55 & 25 & 962 & 930 & 517 & 484 & 56 & 60 \\
\hline 26 & 1033 & 1033 & 634 & 633 & 52 & 47 & 26 & 827 & 810 & 382 & 367 & 65 & 56 \\
\hline 27 & 1061 & 984 & 668 & 575 & 47 & 55 & 27 & 697 & 776 & 272 & 337 & 63 & 60 \\
\hline 28 & 1034 & 906 & 635 & 487 & 56 & 58 & 28 & 749 & 770 & 314 & 332 & 63 & 53 \\
\hline 29 & 884 & 788 & 464 & 369 & 60 & 60 & 29 & 813 & 805 & 369 & 362 & 52 & 58 \\
\hline 30 & 791 & 855 & 372 & 435 & 59 & 52 & 30 & 873 & 821 & 426 & 377 & 57 & 60 \\
\hline
\end{tabular}


Tabela C4 - Valores de $V_{A l}, V_{G t / A m}, C_{A l}, C_{G t / A m}, \operatorname{Atn}_{A l}$ e $A t_{G t / A m}$ para os painéis 17 e 18, através do método de ultra-som

\begin{tabular}{|c|c|c|c|c|c|c|c|c|c|c|c|c|c|}
\hline CP & $\begin{array}{c}\mathrm{V}_{\mathrm{Al}} \\
(\mathrm{m} / \mathrm{s})\end{array}$ & $\begin{array}{l}V_{G t / A m} \\
(\mathrm{~m} / \mathrm{s})\end{array}$ & $\begin{array}{c}\mathrm{C}_{\mathrm{Al}} \\
(\mathrm{MPa})\end{array}$ & $\begin{array}{l}\mathrm{C}_{\mathrm{Gt} / \mathrm{Am}} \\
(\mathrm{MPa})\end{array}$ & $\begin{array}{c}\text { Atn }_{\mathrm{Al}} \\
\text { (dß)loss) }\end{array}$ & $\begin{array}{l}\text { Atn } \mathrm{Gt/Am} \\
\text { (dß|loss) }\end{array}$ & CP & $\begin{array}{c}\mathrm{V}_{\mathrm{Al}} \\
(\mathrm{m} / \mathrm{s})\end{array}$ & $\begin{array}{l}\mathrm{V}_{\mathrm{Gt} / \mathrm{Am}} \\
(\mathrm{m} / \mathrm{s})\end{array}$ & $\begin{array}{c}\mathrm{C}_{\mathrm{Al}} \\
(\mathrm{MPa})\end{array}$ & $\begin{array}{l}\mathrm{C}_{\mathrm{Gt} / \mathrm{Am}} \\
(\mathrm{MPa}) \\
\end{array}$ & 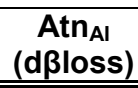 & $\begin{array}{l}\text { Atn } \text { At/Am } \\
\text { (dß/oss) }\end{array}$ \\
\hline 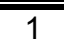 & 1063 & 966 & 2657 & 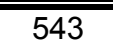 & 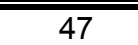 & $\bar{~} 58$ & 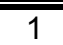 & 7771 & 844 & 339 & 406 & 35 & 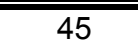 \\
\hline 2 & 990 & 963 & 570 & 539 & 49 & 52 & 2 & 776 & 825 & 343 & 388 & 63 & 60 \\
\hline 3 & 972 & 903 & 549 & 474 & 56 & 60 & 3 & 792 & 857 & 358 & 418 & 54 & 63 \\
\hline 4 & 835 & 888 & 406 & 459 & 60 & 63 & 4 & 852 & 932 & 413 & 495 & 62 & 60 \\
\hline 5 & 827 & 783 & 399 & 357 & 63 & 60 & 5 & 852 & 815 & 414 & 379 & 63 & 65 \\
\hline 6 & 793 & 691 & 366 & 278 & 55 & 57 & 6 & 841 & 720 & 403 & 296 & 59 & 63 \\
\hline 7 & 804 & 879 & 377 & 450 & 55 & 52 & 7 & 844 & 798 & 406 & 363 & 55 & 50 \\
\hline 8 & 1050 & 1059 & 642 & 653 & 53 & 53 & 8 & 800 & 826 & 365 & 389 & 68 & 51 \\
\hline 9 & 1032 & 1005 & 620 & 588 & 57 & 51 & 9 & 791 & 734 & 357 & 307 & 54 & 68 \\
\hline 10 & 938 & 980 & 512 & 559 & 53 & 55 & 10 & 846 & 797 & 408 & 362 & 61 & 57 \\
\hline 11 & 927 & 930 & 501 & 504 & 50 & 47 & 11 & 943 & 1007 & 507 & 577 & 53 & 50 \\
\hline 12 & 918 & 716 & 490 & 298 & 56 & 65 & 12 & 1014 & 1025 & 586 & 599 & 53 & 57 \\
\hline 13 & 823 & 702 & 394 & 287 & 58 & 60 & 13 & 959 & 939 & 524 & 502 & 62 & 51 \\
\hline 14 & 860 & 874 & 430 & 445 & 58 & 63 & 14 & 788 & 854 & 354 & 416 & 58 & 53 \\
\hline 15 & 882 & 929 & 452 & 502 & 54 & 55 & 15 & 653 & 810 & 243 & 374 & 65 & 64 \\
\hline 16 & 692 & 987 & 278 & 568 & 64 & 52 & 16 & 727 & 890 & 301 & 452 & 17 & 56 \\
\hline 17 & 752 & 992 & 329 & 573 & 44 & 51 & 17 & 913 & 933 & 475 & 496 & 50 & 60 \\
\hline 18 & 850 & 981 & 420 & 560 & 42 & 50 & 18 & 928 & 894 & 491 & 456 & 48 & 51 \\
\hline 19 & 822 & 973 & 393 & 551 & 57 & 52 & 19 & 923 & 854 & 486 & 416 & 48 & 58 \\
\hline 20 & 860 & 977 & 431 & 556 & 58 & 55 & 20 & 887 & 812 & 448 & 375 & 47 & 60 \\
\hline 21 & 856 & 969 & 427 & 546 & 63 & 55 & 21 & 864 & 781 & 426 & 347 & 57 & 59 \\
\hline 22 & 958 & 863 & 534 & 433 & 50 & 63 & 22 & 819 & 780 & 382 & 347 & 58 & 58 \\
\hline 23 & 909 & 808 & 481 & 380 & 54 & 53 & 23 & 792 & 833 & 357 & 395 & 68 & 52 \\
\hline 24 & 822 & 765 & 393 & 341 & 53 & 63 & 24 & 828 & 852 & 391 & 414 & 55 & 59 \\
\hline 25 & 842 & 833 & 413 & 404 & 60 & 53 & 25 & 789 & 811 & 355 & 375 & 58 & 50 \\
\hline 26 & 947 & 912 & 522 & 484 & 52 & 58 & 26 & 772 & 836 & 340 & 399 & 47 & 58 \\
\hline 27 & 823 & 936 & 394 & 510 & 58 & 50 & 27 & 858 & 800 & 420 & 365 & 65 & 63 \\
\hline 28 & 824 & 879 & 396 & 450 & 58 & 57 & 28 & 880 & 758 & 442 & 327 & 37 & 58 \\
\hline 29 & 945 & 825 & 520 & 396 & 60 & 53 & 29 & 877 & 966 & 438 & 532 & 60 & 45 \\
\hline 30 & 847 & 957 & 417 & 533 & 53 & 52 & 30 & 904 & 1009 & 466 & 580 & 48 & 55 \\
\hline
\end{tabular}


Tabela C5 - Valores de $V_{A l}, V_{G t / A m}, C_{A l}, C_{G t / A m}$, Atn $A_{A l}$ e $A_{t n} t_{G t / A m}$ para os painéis 19 e 110, através do método de ultra-som

\begin{tabular}{|c|c|c|c|c|c|c|c|c|c|c|c|c|c|}
\hline CP & $\begin{array}{c}\begin{array}{c}V_{A l} \\
(\mathrm{~m} / \mathrm{s})\end{array} \\
\end{array}$ & $\begin{array}{l}V_{\mathrm{Gt} / \mathrm{Am}} \\
(\mathrm{m} / \mathrm{s})\end{array}$ & $\begin{array}{c}\mathrm{C}_{\mathrm{Al}} \\
(\mathrm{MPa}) \\
\end{array}$ & $\begin{array}{l}\mathrm{C}_{\mathrm{Gt} / \mathrm{Am}} \\
(\mathrm{MPa})\end{array}$ & $\begin{array}{c}\text { Atn }_{\text {Al }} \\
\text { (dß|loss) }\end{array}$ & $\begin{array}{l}\text { Atn } \text { Att/Am } \\
\text { (dß|oss) }\end{array}$ & CP & $\begin{array}{c}\begin{array}{c}V_{A l} \\
(\mathrm{~m} / \mathrm{s})\end{array} \\
\end{array}$ & $\begin{array}{l}\mathrm{V}_{\mathrm{Gt} / \mathrm{Am}} \\
(\mathrm{m} / \mathrm{s})\end{array}$ & $\begin{array}{c}\mathrm{C}_{\mathrm{Al}} \\
(\mathrm{MPa}) \\
\end{array}$ & $\begin{array}{l}\mathrm{C}_{\mathrm{Gt} / \mathrm{Am}} \\
(\mathrm{MPa})\end{array}$ & $\begin{array}{c}\text { Atn }_{\mathrm{Al}} \\
\text { (d) } \beta \text { loss) }\end{array}$ & $\begin{array}{l}\text { Atn }{ }_{\text {Gt/Am }} \\
\text { (dß|oss) }\end{array}$ \\
\hline$\overline{\overline{1} 1}$ & 919 & 855 & 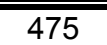 & 412 & 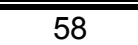 & $\bar{~} 55$ & 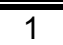 & $\overline{5955}$ & 972 & 210 & $\bar{~} 561$ & 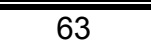 & $\bar{~} 55$ \\
\hline 2 & 814 & 885 & 373 & 441 & 52 & 61 & 2 & 715 & 998 & 304 & 592 & 59 & 61 \\
\hline 3 & 771 & 924 & 335 & 480 & 55 & 58 & 3 & 981 & 1007 & 571 & 602 & 55 & 58 \\
\hline 4 & 832 & 880 & 389 & 436 & 62 & 60 & 4 & 1063 & 984 & 672 & 575 & 60 & 60 \\
\hline 5 & 910 & 793 & 467 & 354 & 50 & 58 & 5 & 864 & 844 & 443 & 423 & 62 & 58 \\
\hline 6 & 717 & 760 & 289 & 326 & 65 & 61 & 6 & 781 & 615 & 362 & 224 & 69 & 61 \\
\hline 7 & 667 & 815 & 250 & 374 & 55 & 53 & 7 & 786 & 677 & 367 & 273 & 58 & 53 \\
\hline 8 & 853 & 905 & 410 & 461 & 53 & 58 & 8 & 781 & 898 & 362 & 479 & 57 & 58 \\
\hline 9 & 899 & 774 & 455 & 337 & 61 & 65 & 9 & 858 & 684 & 437 & 278 & 64 & 65 \\
\hline 10 & 924 & 677 & 481 & 258 & 53 & 67 & 10 & 804 & 699 & 384 & 291 & 52 & 67 \\
\hline 11 & 888 & 757 & 444 & 322 & 61 & 55 & 11 & 805 & 922 & 385 & 505 & 60 & 55 \\
\hline 12 & 844 & 741 & 401 & 309 & 58 & 57 & 12 & 952 & 958 & 539 & 546 & 52 & 57 \\
\hline 13 & 930 & 795 & 487 & 356 & 55 & 50 & 13 & 1068 & 936 & 678 & 521 & 48 & 50 \\
\hline 14 & 936 & 1007 & 494 & 571 & 65 & 55 & 14 & 1073 & 908 & 684 & 489 & 49 & 55 \\
\hline 15 & 910 & 1033 & 466 & 601 & 52 & 59 & 15 & 961 & 957 & 549 & 544 & 52 & 59 \\
\hline 16 & 911 & 1030 & 467 & 598 & 63 & 60 & 16 & 739 & 900 & 324 & 481 & 55 & 60 \\
\hline 17 & 860 & 883 & 416 & 439 & 50 & 55 & 17 & 792 & 876 & 373 & 456 & 58 & 55 \\
\hline 18 & 844 & 781 & 401 & 343 & 57 & 52 & 18 & 911 & 947 & 493 & 533 & 57 & 52 \\
\hline 19 & 873 & 797 & 429 & 357 & 53 & 55 & 19 & 798 & 912 & 378 & 494 & 58 & 55 \\
\hline 20 & 838 & 793 & 396 & 354 & 60 & 63 & 20 & 852 & 920 & 431 & 503 & 57 & 63 \\
\hline 21 & 867 & 888 & 423 & 444 & 48 & 52 & 21 & 862 & 1002 & 442 & 596 & 58 & 52 \\
\hline 22 & 895 & 994 & 451 & 557 & 60 & 60 & 22 & 898 & 966 & 479 & 555 & 55 & 60 \\
\hline 23 & 774 & 870 & 337 & 426 & 68 & 58 & 23 & 981 & 890 & 572 & 471 & 55 & 58 \\
\hline 24 & 756 & 850 & 322 & 407 & 63 & 47 & 24 & 996 & 941 & 589 & 526 & 47 & 47 \\
\hline 25 & 856 & 949 & 412 & 508 & 55 & 55 & 25 & 1015 & 988 & 612 & 580 & 54 & 55 \\
\hline 26 & 917 & 937 & 473 & 494 & 45 & 50 & 26 & 918 & 996 & 501 & 589 & 60 & 50 \\
\hline 27 & 915 & 861 & 472 & 417 & 51 & 61 & 27 & 833 & 762 & 412 & 345 & 65 & 61 \\
\hline 28 & 882 & 857 & 438 & 413 & 65 & 65 & 28 & 779 & 669 & 361 & 266 & 58 & 65 \\
\hline 29 & 873 & 721 & 429 & 293 & 59 & 65 & 29 & 865 & 847 & 444 & 427 & 51 & 65 \\
\hline 30 & 665 & 586 & 249 & 193 & 68 & 58 & 30 & 928 & 975 & 512 & 565 & 67 & 58 \\
\hline
\end{tabular}


Tabela C6 - Valores de $V_{A l}, V_{G t / A m}, C_{A l}, C_{G t / A m}, \operatorname{Atn}_{A l}$ e $A t_{G t / A m}$ para os painéis 21 e 22, através do método de ultra-som

\begin{tabular}{|c|c|c|c|c|c|c|c|c|c|c|c|c|c|}
\hline CP & $\begin{array}{c}\begin{array}{c}V_{A l} \\
(\mathrm{~m} / \mathrm{s})\end{array} \\
\end{array}$ & $\begin{array}{l}V_{\mathrm{Gt} / \mathrm{Am}} \\
(\mathrm{m} / \mathrm{s})\end{array}$ & $\begin{array}{c}\mathrm{C}_{\mathrm{Al}} \\
(\mathrm{MPa}) \\
\end{array}$ & $\begin{array}{l}\mathrm{C}_{\mathrm{Gt} / \mathrm{Am}} \\
(\mathrm{MPa})\end{array}$ & $\begin{array}{c}\text { Atn }_{\text {Al }} \\
\text { (dß|loss) }\end{array}$ & $\begin{array}{l}\text { Atn } \text { Att/Am } \\
\text { (dß|oss) }\end{array}$ & CP & $\begin{array}{c}\begin{array}{c}V_{A l} \\
(\mathrm{~m} / \mathrm{s})\end{array} \\
\end{array}$ & $\begin{array}{l}\mathrm{V}_{\mathrm{Gt} / \mathrm{Am}} \\
(\mathrm{m} / \mathrm{s})\end{array}$ & $\begin{array}{c}\mathrm{C}_{\mathrm{Al}} \\
(\mathrm{MPa}) \\
\end{array}$ & $\begin{array}{l}\mathrm{C}_{\mathrm{Gt} / \mathrm{Am}} \\
(\mathrm{MPa})\end{array}$ & $\begin{array}{c}\text { Atn }_{\mathrm{Al}} \\
\text { (d) } \beta \text { loss) }\end{array}$ & $\begin{array}{l}\text { Atn }{ }_{\text {Gt/Am }} \\
\text { (dß|oss) }\end{array}$ \\
\hline$\overline{\overline{1} 1}$ & 823 & 905 & 401 & 4885 & 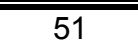 & $\bar{~} 54$ & 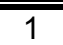 & 726 & 7771 & 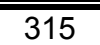 & 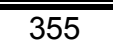 & 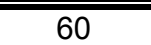 & 263 \\
\hline 2 & 784 & 933 & 364 & 516 & 65 & 59 & 2 & 710 & 819 & 301 & 401 & 65 & 65 \\
\hline 3 & 823 & 935 & 401 & 517 & 63 & 61 & 3 & 773 & 877 & 357 & 459 & 58 & 60 \\
\hline 4 & 931 & 908 & 513 & 488 & 60 & 66 & 4 & 856 & 933 & 437 & 519 & 67 & 58 \\
\hline 5 & 958 & 898 & 543 & 478 & 50 & 65 & 5 & 759 & 804 & 344 & 386 & 67 & 55 \\
\hline 6 & 814 & 793 & 392 & 372 & 63 & 60 & 6 & 666 & 703 & 265 & 295 & 66 & 65 \\
\hline 7 & 758 & 774 & 340 & 355 & 63 & 60 & 7 & 754 & 751 & 340 & 337 & 58 & 60 \\
\hline 8 & 838 & 665 & 416 & 262 & 61 & 64 & 8 & 837 & 746 & 418 & 332 & 64 & 62 \\
\hline 9 & 707 & 548 & 296 & 178 & 52 & 69 & 9 & 710 & 694 & 301 & 288 & 60 & 50 \\
\hline 10 & 641 & 666 & 243 & 262 & 63 & 58 & 10 & 678 & 784 & 274 & 367 & 65 & 59 \\
\hline 11 & 781 & 941 & 361 & 524 & 61 & 53 & 11 & 834 & 925 & 415 & 511 & 60 & 52 \\
\hline 12 & 947 & 945 & 530 & 529 & 51 & 58 & 12 & 968 & 870 & 559 & 451 & 59 & 63 \\
\hline 13 & 837 & 871 & 415 & 449 & 65 & 58 & 13 & 926 & 860 & 512 & 442 & 47 & 59 \\
\hline 14 & 794 & 878 & 374 & 457 & 60 & 58 & 14 & 908 & 872 & 492 & 454 & 58 & 61 \\
\hline 15 & 851 & 876 & 428 & 454 & 61 & 64 & 15 & 855 & 927 & 436 & 513 & 65 & 65 \\
\hline 16 & 877 & 813 & 456 & 392 & 55 & 65 & 16 & 886 & 830 & 469 & 411 & 55 & 68 \\
\hline 17 & 964 & 851 & 550 & 429 & 58 & 58 & 17 & 933 & 844 & 520 & 425 & 55 & 47 \\
\hline 18 & 992 & 937 & 583 & 520 & 50 & 58 & 18 & 899 & 1084 & 482 & 701 & 56 & 52 \\
\hline 19 & 959 & 858 & 544 & 436 & 58 & 58 & 19 & 912 & 978 & 497 & 571 & 52 & 55 \\
\hline 20 & 955 & 912 & 540 & 492 & 52 & 53 & 20 & 961 & 910 & 551 & 495 & 55 & 58 \\
\hline 21 & 832 & 989 & 410 & 579 & 63 & 60 & 21 & 819 & 919 & 400 & 505 & 55 & 51 \\
\hline 22 & 821 & 815 & 399 & 393 & 51 & 61 & 22 & 819 & 945 & 400 & 533 & 49 & 53 \\
\hline 23 & 1008 & 851 & 602 & 429 & 52 & 57 & 23 & 983 & 971 & 576 & 562 & 54 & 50 \\
\hline 24 & 1003 & 967 & 595 & 554 & 53 & 57 & 24 & 993 & 888 & 589 & 470 & 55 & 52 \\
\hline 25 & 906 & 925 & 486 & 507 & 53 & 55 & 25 & 943 & 854 & 530 & 435 & 60 & 59 \\
\hline 26 & 914 & 966 & 495 & 552 & 53 & 58 & 26 & 872 & 912 & 454 & 496 & 52 & 54 \\
\hline 27 & 955 & 951 & 540 & 536 & 60 & 65 & 27 & 850 & 865 & 431 & 447 & 54 & 65 \\
\hline 28 & 975 & 973 & 563 & 561 & 52 & 60 & 28 & 817 & 806 & 399 & 388 & 55 & 65 \\
\hline 29 & 1107 & 996 & 726 & 587 & 47 & 51 & 29 & 765 & 914 & 349 & 499 & 58 & 56 \\
\hline 30 & 1235 & 905 & 903 & 485 & 47 & 59 & 30 & 913 & 974 & 497 & 567 & 53 & 58 \\
\hline
\end{tabular}


Tabela $C 7$ - Valores de $V_{A l}, V_{G t / A m}, C_{A l}, C_{G t / A m}, \operatorname{Atn}_{A l}$ e $A t_{G t / A m}$ para os painéis 23 e 24, através do método de ultra-som

\begin{tabular}{|c|c|c|c|c|c|c|c|c|c|c|c|c|c|}
\hline CP & $\begin{array}{c}\mathrm{V}_{\mathrm{Al}} \\
(\mathrm{m} / \mathrm{s})\end{array}$ & $\begin{array}{l}V_{G t / A m} \\
(\mathrm{~m} / \mathrm{s})\end{array}$ & $\begin{array}{c}\mathrm{C}_{\mathrm{Al}} \\
(\mathrm{MPa})\end{array}$ & $\begin{array}{l}\mathrm{C}_{\mathrm{Gt} / \mathrm{Am}} \\
(\mathrm{MPa})\end{array}$ & $\begin{array}{c}\text { Atn }_{\mathrm{Al}} \\
\text { (dß)loss) }\end{array}$ & $\begin{array}{l}\text { Atn }{ }_{\mathrm{Gt} / \mathrm{Am}} \\
\text { (dß|loss) }\end{array}$ & CP & $\begin{array}{c}\mathrm{V}_{\mathrm{Al}} \\
(\mathrm{m} / \mathrm{s})\end{array}$ & $\begin{array}{l}\mathrm{V}_{\mathrm{Gt} / \mathrm{Am}} \\
(\mathrm{m} / \mathrm{s})\end{array}$ & $\begin{array}{c}\mathrm{C}_{\mathrm{Al}} \\
(\mathrm{MPa})\end{array}$ & $\begin{array}{l}\mathrm{C}_{\mathrm{Gt} / \mathrm{Am}} \\
(\mathrm{MPa})\end{array}$ & 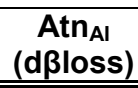 & $\begin{array}{l}\text { Atn } \text { At/Am } \\
\text { (dß/oss) }\end{array}$ \\
\hline 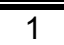 & $\overline{7787}$ & 893 & 373 & 4881 & 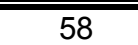 & $\bar{~} 57$ & 1 & 943 & 931 & 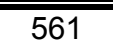 & 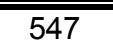 & $\overline{50}$ & 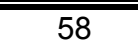 \\
\hline 2 & 853 & 921 & 438 & 512 & 61 & 56 & 2 & 942 & 955 & 560 & 576 & 55 & 55 \\
\hline 3 & 732 & 939 & 323 & 531 & 65 & 58 & 3 & 964 & 830 & 587 & 435 & 53 & 65 \\
\hline 4 & 667 & 894 & 268 & 482 & 65 & 58 & 4 & 902 & 835 & 513 & 440 & 65 & 56 \\
\hline 5 & 864 & 791 & 450 & 377 & 66 & 65 & 5 & 854 & 888 & 460 & 498 & 53 & 61 \\
\hline 6 & 837 & 734 & 423 & 325 & 68 & 63 & 6 & 827 & 698 & 432 & 308 & 61 & 63 \\
\hline 7 & 753 & 776 & 342 & 363 & 58 & 56 & 7 & 833 & 734 & 437 & 340 & 54 & 55 \\
\hline 8 & 842 & 870 & 427 & 457 & 59 & 54 & 8 & 923 & 982 & 537 & 608 & 56 & 59 \\
\hline 9 & 919 & 812 & 510 & 397 & 57 & 53 & 9 & 826 & 880 & 430 & 489 & 68 & 50 \\
\hline 10 & 923 & 841 & 514 & 427 & 58 & 55 & 10 & 797 & 805 & 401 & 409 & 65 & 53 \\
\hline 11 & 909 & 987 & 498 & 588 & 65 & 52 & 11 & 862 & 889 & 469 & 498 & 57 & 52 \\
\hline 12 & 963 & 956 & 559 & 551 & 53 & 52 & 12 & 814 & 842 & 419 & 447 & 58 & 59 \\
\hline 13 & 906 & 954 & 495 & 549 & 55 & 55 & 13 & 867 & 879 & 474 & 487 & 53 & 55 \\
\hline 14 & 873 & 933 & 460 & 525 & 58 & 52 & 14 & 984 & 1008 & 611 & 642 & 53 & 56 \\
\hline 15 & 899 & 959 & 488 & 555 & 65 & 64 & 15 & 987 & 971 & 614 & 595 & 60 & 59 \\
\hline 16 & 951 & 918 & 545 & 509 & 56 & 65 & 16 & 1001 & 977 & 633 & 603 & 47 & 55 \\
\hline 17 & 1027 & 893 & 636 & 480 & 53 & 52 & 17 & 982 & 935 & 608 & 551 & 59 & 59 \\
\hline 18 & 1059 & 988 & 677 & 589 & 52 & 46 & 18 & 883 & 913 & 492 & 526 & 58 & 60 \\
\hline 19 & 979 & 824 & 578 & 410 & 58 & 64 & 19 & 930 & 976 & 546 & 602 & 52 & 50 \\
\hline 20 & 865 & 792 & 451 & 378 & 63 & 60 & 20 & 979 & 1015 & 605 & 650 & 59 & 52 \\
\hline 21 & 886 & 944 & 473 & 538 & 60 & 55 & 21 & 851 & 1075 & 457 & 730 & 47 & 55 \\
\hline 22 & 975 & 963 & 573 & 559 & 63 & 59 & 22 & 876 & 1004 & 484 & 636 & 63 & 47 \\
\hline 23 & 1014 & 948 & 621 & 542 & 55 & 54 & 23 & 960 & 973 & 582 & 597 & 55 & 50 \\
\hline 24 & 1005 & 948 & 609 & 542 & 55 & 42 & 24 & 885 & 963 & 494 & 586 & 58 & 55 \\
\hline 25 & 819 & 856 & 405 & 442 & 60 & 60 & 25 & 854 & 958 & 460 & 579 & 57 & 53 \\
\hline 26 & 796 & 853 & 382 & 439 & 55 & 58 & 26 & 948 & 1018 & 567 & 654 & 50 & 47 \\
\hline 27 & 823 & 895 & 409 & 483 & 61 & 60 & 27 & 941 & 1081 & 559 & 737 & 58 & 49 \\
\hline 28 & 823 & 910 & 409 & 499 & 61 & 52 & 28 & 988 & 1138 & 615 & 817 & 45 & 47 \\
\hline 29 & 964 & 816 & 560 & 401 & 55 & 63 & 29 & 1031 & 944 & 671 & 562 & 58 & 65 \\
\hline 30 & 799 & 762 & 385 & 350 & 58 & 60 & 30 & 907 & 881 & 519 & 490 & 63 & 55 \\
\hline
\end{tabular}


Tabela C8 - Valores de $V_{A l}, V_{G t / A m}, C_{A l}, C_{G t / A m}, \operatorname{Atn}_{A l}$ e $A t_{G t / A m}$ para os painéis 25 e 26, através do método de ultra-som

\begin{tabular}{|c|c|c|c|c|c|c|c|c|c|c|c|c|c|}
\hline CP & $\begin{array}{c}\mathrm{V}_{\mathrm{Al}} \\
(\mathrm{m} / \mathrm{s})\end{array}$ & $\begin{array}{l}V_{G t / A m} \\
(\mathrm{~m} / \mathrm{s})\end{array}$ & $\begin{array}{c}\mathrm{C}_{\mathrm{Al}} \\
(\mathrm{MPa})\end{array}$ & $\begin{array}{l}\mathrm{C}_{\mathrm{Gt} / \mathrm{Am}} \\
(\mathrm{MPa})\end{array}$ & $\begin{array}{c}\text { Atn }_{\mathrm{Al}} \\
\text { (dß)loss) }\end{array}$ & $\begin{array}{l}\text { Atn }{ }_{\mathrm{Gt} / \mathrm{Am}} \\
\text { (dß|loss) }\end{array}$ & CP & $\begin{array}{c}\mathrm{V}_{\mathrm{Al}} \\
(\mathrm{m} / \mathrm{s})\end{array}$ & $\begin{array}{l}\mathrm{V}_{\mathrm{Gt} / \mathrm{Am}} \\
(\mathrm{m} / \mathrm{s})\end{array}$ & $\begin{array}{c}\mathrm{C}_{\mathrm{Al}} \\
(\mathrm{MPa})\end{array}$ & $\begin{array}{l}\mathrm{C}_{\mathrm{Gt} / \mathrm{Am}} \\
(\mathrm{MPa})\end{array}$ & 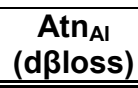 & $\begin{array}{l}\text { Atn } \text { At/Am } \\
\text { (dß/oss) }\end{array}$ \\
\hline 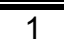 & 820 & 989 & 398 & $\overline{c 578}$ & 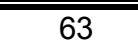 & $\overline{52}$ & 1 & 732 & 947 & "318 & "532 & 60 & 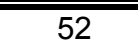 \\
\hline 2 & 897 & 925 & 475 & 506 & 58 & 59 & 2 & 775 & 935 & 356 & 518 & 60 & 55 \\
\hline 3 & 913 & 804 & 493 & 382 & 63 & 60 & 3 & 870 & 874 & 449 & 453 & 63 & 59 \\
\hline 4 & 889 & 767 & 467 & 347 & 53 & 59 & 4 & 843 & 748 & 422 & 331 & 62 & 64 \\
\hline 5 & 930 & 767 & 511 & 348 & 65 & 63 & 5 & 728 & 784 & 315 & 365 & 68 & 53 \\
\hline 6 & 770 & 679 & 351 & 273 & 68 & 69 & 6 & 773 & 901 & 354 & 481 & 62 & 55 \\
\hline 7 & 739 & 716 & 323 & 303 & 61 & 59 & 7 & 799 & 848 & 379 & 426 & 61 & 55 \\
\hline 8 & 819 & 833 & 396 & 410 & 65 & 65 & 8 & 739 & 790 & 324 & 370 & 60 & 55 \\
\hline 9 & 803 & 825 & 381 & 402 & 60 & 57 & 9 & 783 & 774 & 363 & 355 & 61 & 63 \\
\hline 10 & 868 & 886 & 445 & 464 & 55 & 55 & 10 & 867 & 874 & 446 & 453 & 58 & 52 \\
\hline 11 & 880 & 932 & 458 & 513 & 55 & 60 & 11 & 933 & 995 & 516 & 587 & 52 & 52 \\
\hline 12 & 868 & 889 & 445 & 467 & 47 & 58 & 12 & 979 & 910 & 568 & 491 & 50 & 63 \\
\hline 13 & 817 & 793 & 394 & 371 & 58 & 63 & 13 & 943 & 839 & 527 & 417 & 58 & 61 \\
\hline 14 & 814 & 765 & 391 & 346 & 61 & 58 & 14 & 864 & 813 & 442 & 392 & 55 & 60 \\
\hline 15 & 897 & 797 & 475 & 375 & 60 & 59 & 15 & 850 & 821 & 429 & 400 & 59 & 60 \\
\hline 16 & 928 & 783 & 509 & 363 & 57 & 63 & 16 & 867 & 839 & 446 & 417 & 55 & 60 \\
\hline 17 & 976 & 803 & 563 & 381 & 58 & 55 & 17 & 839 & 802 & 418 & 381 & 63 & 60 \\
\hline 18 & 889 & 801 & 467 & 379 & 52 & 55 & 18 & 880 & 833 & 459 & 412 & 63 & 56 \\
\hline 19 & 837 & 766 & 414 & 346 & 57 & 60 & 19 & 974 & 917 & 562 & 499 & 55 & 52 \\
\hline 20 & 884 & 812 & 462 & 390 & 55 & 57 & 20 & 1004 & 914 & 598 & 496 & 47 & 55 \\
\hline 21 & 906 & 900 & 485 & 479 & 55 & 54 & 21 & 1003 & 973 & 596 & 562 & 58 & 49 \\
\hline 22 & 880 & 887 & 458 & 465 & 62 & 60 & 22 & 1011 & 1064 & 606 & 671 & 51 & 50 \\
\hline 23 & 828 & 868 & 405 & 446 & 58 & 56 & 23 & 1035 & 979 & 635 & 568 & 52 & 55 \\
\hline 24 & 789 & 920 & 368 & 500 & 61 & 63 & 24 & 992 & 996 & 584 & 588 & 59 & 50 \\
\hline 25 & 754 & 900 & 336 & 479 & 63 & 55 & 25 & 861 & 998 & 439 & 591 & 60 & 57 \\
\hline 26 & 812 & 893 & 389 & 472 & 60 & 50 & 26 & 877 & 947 & 456 & 532 & 49 & 58 \\
\hline 27 & 926 & 956 & 506 & 541 & 55 & 58 & 27 & 990 & 977 & 581 & 566 & 53 & 52 \\
\hline 28 & 954 & 915 & 538 & 495 & 55 & 58 & 28 & 942 & 997 & 527 & 589 & 55 & 62 \\
\hline 29 & 976 & 923 & 563 & 503 & 52 & 57 & 29 & 827 & 970 & 405 & 558 & 65 & 60 \\
\hline 30 & 1027 & 921 & 623 & 501 & 55 & 53 & 30 & 850 & 924 & 428 & 507 & 55 & 52 \\
\hline
\end{tabular}


Tabela C9 - Valores de $V_{A l}, V_{G t / A m}, C_{A l}, C_{G t / A m}, \operatorname{Atn}_{A l}$ e $A t_{G t / A m}$ para os painéis 27 e 28, através do método de ultra-som

\begin{tabular}{|c|c|c|c|c|c|c|c|c|c|c|c|c|c|}
\hline CP & $\begin{array}{c}\begin{array}{c}V_{A l} \\
(\mathrm{~m} / \mathrm{s})\end{array} \\
\end{array}$ & $\begin{array}{l}V_{\mathrm{Gt} / \mathrm{Am}} \\
(\mathrm{m} / \mathrm{s})\end{array}$ & $\begin{array}{c}\mathrm{C}_{\mathrm{Al}} \\
(\mathrm{MPa}) \\
\end{array}$ & $\begin{array}{l}\mathrm{C}_{\mathrm{Gt} / \mathrm{Am}} \\
(\mathrm{MPa})\end{array}$ & $\begin{array}{c}\text { Atn }_{\text {Al }} \\
\text { (dß|loss) }\end{array}$ & $\begin{array}{l}\text { Atn } \text { Att/Am } \\
\text { (dß|oss) }\end{array}$ & CP & $\begin{array}{c}\begin{array}{c}V_{A l} \\
(\mathrm{~m} / \mathrm{s})\end{array} \\
\end{array}$ & $\begin{array}{l}\mathrm{V}_{\mathrm{Gt} / \mathrm{Am}} \\
(\mathrm{m} / \mathrm{s})\end{array}$ & $\begin{array}{c}\mathrm{C}_{\mathrm{Al}} \\
(\mathrm{MPa}) \\
\end{array}$ & $\begin{array}{l}\mathrm{C}_{\mathrm{Gt} / \mathrm{Am}} \\
(\mathrm{MPa})\end{array}$ & $\begin{array}{c}\text { Atn }_{\mathrm{Al}} \\
\text { (d) } \beta \text { loss) }\end{array}$ & $\begin{array}{l}\text { Atn }{ }_{\text {Gt/Am }} \\
\text { (dß|oss) }\end{array}$ \\
\hline$\overline{\overline{1} 1}$ & 766 & 840 & $\bar{~} 350$ & 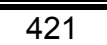 & 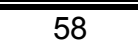 & $\overline{58}$ & 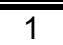 & 820 & 931 & 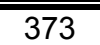 & $4 \quad 481$ & $\overline{52}$ & $\bar{~} 58$ \\
\hline 2 & 850 & 835 & 431 & 416 & 52 & 58 & 2 & 887 & 863 & 437 & 414 & 51 & 59 \\
\hline 3 & 950 & 893 & 538 & 476 & 59 & 55 & 3 & 924 & 871 & 474 & 421 & 60 & 55 \\
\hline 4 & 894 & 925 & 477 & 510 & 54 & 58 & 4 & 898 & 901 & 448 & 451 & 55 & 65 \\
\hline 5 & 880 & 897 & 462 & 479 & 57 & 62 & 5 & 910 & 863 & 460 & 413 & 52 & 60 \\
\hline 6 & 746 & 834 & 332 & 414 & 68 & 66 & 6 & 983 & 830 & 536 & 382 & 55 & 65 \\
\hline 7 & 708 & 813 & 299 & 394 & 60 & 58 & 7 & 1069 & 846 & 634 & 397 & 58 & 56 \\
\hline 8 & 835 & 860 & 415 & 441 & 58 & 62 & 8 & 1079 & 891 & 646 & 441 & 45 & 62 \\
\hline 9 & 752 & 857 & 337 & 437 & 61 & 65 & 9 & 1030 & 935 & 589 & 486 & 55 & 63 \\
\hline 10 & 792 & 948 & 374 & 535 & 57 & 50 & 10 & 890 & 1000 & 439 & 555 & 61 & 55 \\
\hline 11 & 847 & 1013 & 427 & 611 & 52 & 58 & 11 & 840 & 880 & 392 & 430 & 55 & 60 \\
\hline 12 & 865 & 906 & 446 & 489 & 49 & 55 & 12 & 905 & 814 & 455 & 368 & 51 & 61 \\
\hline 13 & 1025 & 902 & 626 & 485 & 55 & 52 & 13 & 979 & 828 & 532 & 380 & 53 & 58 \\
\hline 14 & 885 & 954 & 467 & 542 & 55 & 55 & 14 & 940 & 861 & 490 & 412 & 59 & 52 \\
\hline 15 & 836 & 910 & 417 & 493 & 61 & 63 & 15 & 960 & 938 & 512 & 488 & 55 & 55 \\
\hline 16 & 909 & 859 & 493 & 440 & 58 & 62 & 16 & 997 & 934 & 551 & 485 & 49 & 63 \\
\hline 17 & 895 & 852 & 477 & 433 & 55 & 65 & 17 & 956 & 907 & 507 & 457 & 53 & 63 \\
\hline 18 & 849 & 922 & 430 & 507 & 55 & 53 & 18 & 891 & 937 & 440 & 487 & 57 & 54 \\
\hline 19 & 911 & 1002 & 495 & 599 & 51 & 60 & 19 & 836 & 909 & 388 & 459 & 58 & 65 \\
\hline 20 & 972 & 895 & 563 & 477 & 55 & 58 & 20 & 875 & 670 & 425 & 249 & 68 & 49 \\
\hline 21 & 804 & 860 & 385 & 441 & 68 & 58 & 21 & 862 & 668 & 412 & 248 & 65 & 65 \\
\hline 22 & 764 & 835 & 348 & 416 & 58 & 65 & 22 & 854 & 783 & 405 & 341 & 53 & 63 \\
\hline 23 & 871 & 878 & 452 & 459 & 57 & 50 & 23 & 1009 & 821 & 565 & 374 & 50 & 55 \\
\hline 24 & 902 & 1021 & 485 & 622 & 53 & 55 & 24 & 888 & 897 & 438 & 447 & 63 & 57 \\
\hline 25 & 893 & 946 & 476 & 534 & 58 & 56 & 25 & 797 & 810 & 353 & 364 & 57 & 65 \\
\hline 26 & 887 & 760 & 469 & 344 & 50 & 61 & 26 & 915 & 782 & 464 & 339 & 55 & 63 \\
\hline 27 & 830 & 765 & 411 & 349 & 65 & 55 & 27 & 885 & 829 & 435 & 381 & 63 & 65 \\
\hline 28 & 866 & 943 & 446 & 530 & 58 & 55 & 28 & 889 & 857 & 439 & 408 & 55 & 60 \\
\hline 29 & 869 & 984 & 451 & 577 & 65 & 60 & 29 & 900 & 905 & 449 & 455 & 60 & 58 \\
\hline 30 & 721 & 897 & 310 & 480 & 68 & 65 & 30 & 800 & 918 & 355 & 468 & 68 & 67 \\
\hline
\end{tabular}


Tabela $\mathrm{C} 10$ - Valores de $\mathrm{V}_{\mathrm{Al}}, \mathrm{V}_{\mathrm{Gt} / \mathrm{Am}}, \mathrm{C}_{\mathrm{Al}}, \mathrm{C}_{\mathrm{Gt} / \mathrm{Am}}, \mathrm{Atn}_{\mathrm{Al}}$ e $\mathrm{Atn}_{\mathrm{Gt} / \mathrm{Am}}$ para os painéis 29 e 210, através do método de ultra-som

\begin{tabular}{|c|c|c|c|c|c|c|c|c|c|c|c|c|c|}
\hline $\mathrm{CP}$ & 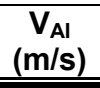 & $\begin{array}{l}V_{\mathrm{Gt} / \mathrm{Am}} \\
(\mathrm{m} / \mathrm{s}) \\
\end{array}$ & $\begin{array}{c}\mathrm{C}_{\mathrm{Al}} \\
(\mathrm{MPa})\end{array}$ & $\begin{array}{l}\mathrm{C}_{\mathrm{Gt} / \mathrm{Am}} \\
(\mathrm{MPa})\end{array}$ & $\begin{array}{c}\text { Atn }_{\mathrm{Al}} \\
\text { (dßloss) } \\
\end{array}$ & $\begin{array}{l}\text { Atn }{ }_{\mathrm{Gt} / \mathrm{Am}} \\
\text { (d/3loss) }\end{array}$ & CP & $\begin{array}{c}\begin{array}{c}V_{\mathrm{Al}} \\
(\mathrm{m} / \mathrm{s})\end{array} \\
\end{array}$ & $\begin{array}{l}V_{\mathrm{Gt} / \mathrm{Am}} \\
(\mathrm{m} / \mathrm{s}) \\
\end{array}$ & $\begin{array}{c}\mathrm{C}_{\mathrm{Al}} \\
(\mathrm{MPa}) \\
\end{array}$ & $\begin{array}{l}\mathrm{C}_{\mathrm{G} t / \mathrm{Am}} \\
(\mathrm{MPa}) \\
\end{array}$ & $\begin{array}{c}\text { Atn }_{\mathrm{Al}} \\
\text { (dßloss) } \\
\end{array}$ & $\begin{array}{l}\text { Atn }{ }_{\mathrm{Gt} / \mathrm{Am}} \\
\text { (d/3loss) } \\
\end{array}$ \\
\hline 1 & 818 & 832 & 371 & 384 & 55 & 57 & 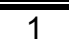 & 916 & 937 & 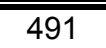 & $\bar{~} 514$ & 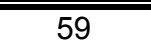 & 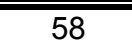 \\
\hline 2 & 834 & 891 & 386 & 440 & 59 & 60 & 2 & 962 & 920 & 542 & 496 & 50 & 53 \\
\hline 3 & 913 & 994 & 463 & 548 & 68 & 59 & 3 & 860 & 900 & 434 & 474 & 58 & 60 \\
\hline 4 & 882 & 1002 & 432 & 558 & 60 & 63 & 4 & 766 & 845 & 344 & 419 & 65 & 68 \\
\hline 5 & 874 & 985 & 424 & 538 & 55 & 50 & 5 & 861 & 924 & 435 & 500 & 53 & 58 \\
\hline 6 & 856 & 832 & 407 & 384 & 63 & 58 & 6 & 834 & 1026 & 407 & 617 & 63 & 57 \\
\hline 7 & 795 & 817 & 351 & 370 & 56 & 60 & 7 & 797 & 896 & 373 & 471 & 55 & 61 \\
\hline 8 & 829 & 881 & 381 & 431 & 58 & 60 & 8 & 899 & 787 & 474 & 363 & 58 & 63 \\
\hline 9 & 872 & 745 & 422 & 308 & 52 & 65 & 9 & 829 & 813 & 403 & 388 & 59 & 52 \\
\hline 10 & 944 & 811 & 494 & 365 & 63 & 53 & 10 & 785 & 845 & 361 & 419 & 65 & 60 \\
\hline 11 & 981 & 934 & 534 & 484 & 55 & 58 & 11 & 812 & 799 & 387 & 374 & 60 & 60 \\
\hline 12 & 876 & 876 & 426 & 425 & 61 & 56 & 12 & 803 & 767 & 378 & 345 & 57 & 63 \\
\hline 13 & 823 & 804 & 376 & 359 & 59 & 59 & 13 & 841 & 821 & 414 & 395 & 57 & 53 \\
\hline 14 & 882 & 804 & 432 & 359 & 58 & 60 & 14 & 843 & 928 & 417 & 504 & 62 & 55 \\
\hline 15 & 892 & 864 & 441 & 414 & 56 & 63 & 15 & 799 & 900 & 374 & 475 & 58 & 58 \\
\hline 16 & 908 & 881 & 458 & 431 & 57 & 54 & 16 & 797 & 939 & 372 & 516 & 58 & 51 \\
\hline 17 & 890 & 896 & 440 & 445 & 63 & 58 & 17 & 866 & 920 & 440 & 496 & 54 & 60 \\
\hline 18 & 745 & 804 & 308 & 359 & 65 & 58 & 18 & 860 & 851 & 433 & 424 & 61 & 55 \\
\hline 19 & 732 & 817 & 298 & 371 & 63 & 61 & 19 & 912 & 842 & 487 & 416 & 60 & 55 \\
\hline 20 & 854 & 846 & 405 & 397 & 55 & 62 & 20 & 930 & 891 & 507 & 465 & 55 & 53 \\
\hline 21 & 865 & 827 & 416 & 380 & 63 & 59 & 21 & 870 & 836 & 443 & 410 & 60 & 62 \\
\hline 22 & 903 & 902 & 453 & 452 & 53 & 54 & 22 & 898 & 833 & 472 & 406 & 57 & 55 \\
\hline 23 & 894 & 997 & 444 & 552 & 61 & 52 & 23 & 904 & 906 & 479 & 481 & 55 & 59 \\
\hline 24 & 767 & 918 & 327 & 467 & 58 & 58 & 24 & 924 & 845 & 500 & 418 & 55 & 55 \\
\hline 25 & 677 & 776 & 254 & 334 & 65 & 60 & 25 & 919 & 914 & 495 & 489 & 53 & 52 \\
\hline 26 & 764 & 744 & 324 & 307 & 55 & 65 & 26 & 955 & 1009 & 534 & 596 & 57 & 52 \\
\hline 27 & 829 & 858 & 382 & 409 & 63 & 52 & 27 & 909 & 1002 & 485 & 588 & 63 & 52 \\
\hline 28 & 746 & 890 & 309 & 440 & 63 & 61 & 28 & 706 & 948 & 292 & 527 & 68 & 61 \\
\hline 29 & 807 & 822 & 362 & 375 & 68 & 68 & 29 & 737 & 865 & 318 & 438 & 55 & 58 \\
\hline 30 & 829 & 873 & 381 & 423 & 59 & 64 & 30 & 901 & 788 & 475 & 363 & 60 & 62 \\
\hline
\end{tabular}


Tabela $\mathrm{C} 11$ - Valores de $V_{d}, C_{d}$ e $A t_{d}$ para os painéis 11 e 12, através do método de ultra-som

\begin{tabular}{|c|c|c|c|c|c|c|c|}
\hline CP & $\begin{array}{c}\begin{array}{c}V_{d} \\
(\mathrm{~m} / \mathrm{s})\end{array} \\
\end{array}$ & $\begin{array}{c}\mathrm{C}_{\mathrm{d}} \\
(\mathrm{MPa})\end{array}$ & $\begin{array}{c}\text { Atn }_{\mathrm{d}} \\
\text { (d } \beta \text { loss })\end{array}$ & CP & $\begin{array}{c}V_{d} \\
(m / s)\end{array}$ & $\begin{array}{c}\mathrm{C}_{\mathrm{d}} \\
(\mathrm{MPa})\end{array}$ & $\begin{array}{c}\text { Atn }_{\mathrm{d}} \\
\text { (d } \beta \text { loss) }\end{array}$ \\
\hline$\overline{1} 1$ & 939 & $\overline{c 506}$ & $\overline{36}$ & $\overline{1} 1$ & 836 & 401 & $\overline{c 59}$ \\
\hline 2 & 929 & 495 & 36 & 2 & 938 & 504 & 47 \\
\hline 3 & 918 & 484 & 32 & 3 & 1036 & 614 & 53 \\
\hline 4 & 903 & 468 & 34 & 4 & 1028 & 605 & 52 \\
\hline 5 & 848 & 412 & 41 & 5 & 1103 & 697 & 55 \\
\hline 6 & 812 & 379 & 37 & 6 & 1109 & 705 & 47 \\
\hline 7 & 813 & 379 & 36 & 7 & 1042 & 622 & 58 \\
\hline 8 & 921 & 487 & 32 & 8 & 1081 & 670 & 50 \\
\hline 9 & 844 & 409 & 39 & 9 & 1029 & 607 & 58 \\
\hline 10 & 760 & 332 & 33 & 10 & 873 & 437 & 53 \\
\hline 11 & 924 & 490 & 34 & 11 & 875 & 439 & 55 \\
\hline 12 & 1013 & 589 & 33 & 12 & 875 & 439 & 56 \\
\hline 13 & 984 & 555 & 37 & 13 & 844 & 408 & 55 \\
\hline 14 & 911 & 476 & 40 & 14 & 858 & 422 & 60 \\
\hline 15 & 836 & 401 & 39 & 15 & 951 & 518 & 55 \\
\hline 16 & 854 & 419 & 37 & 16 & 1087 & 678 & 52 \\
\hline 17 & 919 & 485 & 42 & 17 & 1023 & 600 & 57 \\
\hline 18 & 868 & 432 & 36 & 18 & 972 & 542 & 51 \\
\hline 19 & 782 & 351 & 44 & 19 & 1008 & 583 & 52 \\
\hline 20 & 780 & 349 & 41 & 20 & 962 & 530 & 52 \\
\hline 21 & 794 & 362 & 37 & 21 & 931 & 497 & 61 \\
\hline 22 & 816 & 382 & 36 & 22 & 982 & 553 & 60 \\
\hline 23 & 868 & 432 & 33 & 23 & 931 & 496 & 63 \\
\hline 24 & 901 & 466 & 34 & 24 & 921 & 486 & 57 \\
\hline 25 & 924 & 490 & 37 & 25 & 936 & 502 & 53 \\
\hline 26 & 966 & 536 & 36 & 26 & 859 & 423 & 53 \\
\hline 27 & 926 & 492 & 31 & 27 & 764 & 335 & 60 \\
\hline 28 & 910 & 476 & 32 & 28 & 790 & 358 & 60 \\
\hline 29 & 862 & 426 & 41 & 29 & 917 & 481 & 60 \\
\hline 30 & 725 & 302 & 39 & 30 & 966 & 534 & 69 \\
\hline 31 & 787 & 355 & 34 & 31 & 894 & 458 & 57 \\
\hline 32 & 879 & 443 & 34 & 32 & 932 & 497 & 55 \\
\hline 33 & 946 & 513 & 31 & 33 & 1028 & 605 & 55 \\
\hline 34 & 1007 & 582 & 37 & 34 & 844 & 408 & 58 \\
\hline 35 & 699 & 281 & 42 & 35 & 771 & 341 & 55 \\
\hline 36 & 619 & 220 & 41 & 36 & 872 & 436 & 61 \\
\hline 37 & 706 & 286 & 42 & 37 & 961 & 530 & 56 \\
\hline 38 & 778 & 348 & 37 & 38 & 946 & 513 & 61 \\
\hline 39 & 845 & 410 & 34 & 39 & 802 & 369 & 65 \\
\hline 40 & 823 & 389 & 31 & 40 & 796 & 363 & 60 \\
\hline 41 & 802 & 369 & 36 & 41 & 926 & 491 & 40 \\
\hline 42 & 643 & 237 & 35 & 42 & 982 & 552 & 50 \\
\hline 43 & 714 & 292 & 34 & 43 & 917 & 482 & 56 \\
\hline 44 & 898 & 462 & 38 & 44 & 826 & 391 & 55 \\
\hline 45 & 829 & 395 & 41 & 45 & 840 & 405 & 57 \\
\hline 46 & 928 & 494 & 33 & 46 & 801 & 368 & 60 \\
\hline 47 & 831 & 396 & 40 & 47 & 833 & 397 & 52 \\
\hline 48 & 774 & 344 & 42 & 48 & 998 & 571 & 46 \\
\hline
\end{tabular}


Tabela $C 12$ - Valores de $V_{d}, C_{d}$ e $A t_{d}$ para os painéis 13 e 14, através do método de ultra-som

\begin{tabular}{|c|c|c|c|c|c|c|c|}
\hline CP & $\begin{array}{c}\begin{array}{c}V_{d} \\
(\mathrm{~m} / \mathrm{s})\end{array} \\
\end{array}$ & $\begin{array}{c}\mathrm{C}_{\mathrm{d}} \\
(\mathrm{MPa})\end{array}$ & $\begin{array}{c}\text { Atn }_{\mathrm{d}} \\
\text { (d } \beta \text { loss })\end{array}$ & CP & $\begin{array}{c}V_{d} \\
(m / s)\end{array}$ & $\begin{array}{c}\mathrm{C}_{\mathrm{d}} \\
(\mathrm{MPa})\end{array}$ & $\begin{array}{c}\text { Atn }_{\mathrm{d}} \\
\text { (d } \beta \text { loss) }\end{array}$ \\
\hline$\overline{1} 1$ & 916 & 489 & 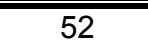 & $\overline{\overline{1}}$ & 7991 & 354 & 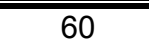 \\
\hline 2 & 915 & 488 & 51 & 2 & 785 & 348 & 60 \\
\hline 3 & 906 & 478 & 55 & 3 & 809 & 370 & 58 \\
\hline 4 & 814 & 386 & 65 & 4 & 868 & 425 & 51 \\
\hline 5 & 728 & 309 & 54 & 5 & 905 & 463 & 57 \\
\hline 6 & 794 & 368 & 65 & 6 & 912 & 470 & 63 \\
\hline 7 & 890 & 462 & 42 & 7 & 929 & 488 & 50 \\
\hline 8 & 917 & 490 & 54 & 8 & 977 & 540 & 55 \\
\hline 9 & 997 & 580 & 48 & 9 & 894 & 451 & 50 \\
\hline 10 & 909 & 482 & 67 & 10 & 830 & 389 & 58 \\
\hline 11 & 927 & 501 & 58 & 11 & 800 & 361 & 57 \\
\hline 12 & 1105 & 711 & 53 & 12 & 789 & 352 & 57 \\
\hline 13 & 931 & 506 & 60 & 13 & 839 & 398 & 60 \\
\hline 14 & 864 & 435 & 63 & 14 & 784 & 347 & 68 \\
\hline 15 & 929 & 504 & 49 & 15 & 811 & 371 & 50 \\
\hline 16 & 894 & 466 & 55 & 16 & 979 & 542 & 52 \\
\hline 17 & 888 & 460 & 59 & 17 & 916 & 474 & 47 \\
\hline 18 & 926 & 500 & 50 & 18 & 836 & 395 & 55 \\
\hline 19 & 919 & 492 & 58 & 19 & 882 & 440 & 45 \\
\hline 20 & 910 & 483 & 50 & 20 & 926 & 485 & 55 \\
\hline 21 & 836 & 408 & 49 & 21 & 945 & 504 & 52 \\
\hline 22 & 801 & 374 & 59 & 22 & 954 & 515 & 58 \\
\hline 23 & 768 & 344 & 59 & 23 & 940 & 499 & 52 \\
\hline 24 & 748 & 327 & 60 & 24 & 973 & 535 & 57 \\
\hline 25 & 857 & 428 & 57 & 25 & 881 & 438 & 50 \\
\hline 26 & 883 & 455 & 59 & 26 & 787 & 350 & 60 \\
\hline 27 & 862 & 433 & 55 & 27 & 840 & 398 & 56 \\
\hline 28 & 902 & 475 & 55 & 28 & 893 & 450 & 42 \\
\hline 29 & 885 & 457 & 50 & 29 & 992 & 556 & 55 \\
\hline 30 & 819 & 391 & 58 & 30 & 1093 & 675 & 52 \\
\hline 31 & 838 & 409 & 45 & 31 & 995 & 559 & 68 \\
\hline 32 & 830 & 402 & 52 & 32 & 919 & 477 & 58 \\
\hline 33 & 889 & 461 & 51 & 33 & 894 & 451 & 55 \\
\hline 34 & 937 & 512 & 47 & 34 & 802 & 363 & 58 \\
\hline 35 & 855 & 426 & 63 & 35 & 802 & 364 & 53 \\
\hline 36 & 824 & 396 & 65 & 36 & 898 & 456 & 63 \\
\hline 37 & 804 & 377 & 50 & 37 & 975 & 537 & 48 \\
\hline 38 & 819 & 391 & 59 & 38 & 934 & 492 & 63 \\
\hline 39 & 834 & 405 & 48 & 39 & 883 & 440 & 58 \\
\hline 40 & 891 & 463 & 47 & 40 & 850 & 408 & 58 \\
\hline 41 & 931 & 505 & 52 & 41 & 799 & 360 & 63 \\
\hline 42 & 926 & 500 & 63 & 42 & 851 & 410 & 59 \\
\hline 43 & 806 & 379 & 57 & 43 & 941 & 501 & 49 \\
\hline 44 & 766 & 342 & 56 & 44 & 851 & 409 & 52 \\
\hline 45 & 771 & 347 & 67 & 45 & 748 & 316 & 66 \\
\hline 46 & 761 & 338 & 61 & 46 & 765 & 330 & 58 \\
\hline 47 & 779 & 354 & 68 & 47 & 853 & 411 & 55 \\
\hline 48 & 677 & 267 & 69 & 48 & 897 & 455 & 58 \\
\hline
\end{tabular}


Tabela $C 13$ - Valores de $V_{d}, C_{d}$ e $A t_{d}$ para os painéis 15 e 16, através do método de ultra-som

\begin{tabular}{|c|c|c|c|c|c|c|c|}
\hline CP & $\begin{array}{c}\mathbf{V}_{\mathrm{d}} \\
(\mathrm{m} / \mathrm{s})\end{array}$ & $\begin{array}{c}\mathrm{C}_{\mathrm{d}} \\
(\mathrm{MPa})\end{array}$ & $\begin{array}{c}\text { Atn }_{\mathrm{d}} \\
\text { (d } \beta \text { loss) }\end{array}$ & CP & $\begin{array}{c}V_{d} \\
(m / s)\end{array}$ & $\begin{array}{c}\mathrm{C}_{\mathrm{d}} \\
(\mathrm{MPa})\end{array}$ & $\begin{array}{c}\text { Atn }_{\mathrm{d}} \\
\text { (d } \beta \text { loss) }\end{array}$ \\
\hline$\overline{1} 1$ & 936 & $\bar{~} 521$ & 499,61 & $\overline{1} 1$ & 788 & 347 & $\overline{c 53}$ \\
\hline 2 & 1023 & 622 & 51,05 & 2 & 733 & 301 & 64 \\
\hline 3 & 1022 & 620 & 60,40 & 3 & 773 & 334 & 55 \\
\hline 4 & 968 & 557 & 48,89 & 4 & 822 & 378 & 63 \\
\hline 5 & 1030 & 630 & 51,77 & 5 & 820 & 376 & 58 \\
\hline 6 & 941 & 527 & 56,08 & 6 & 851 & 404 & 58 \\
\hline 7 & 765 & 348 & 66,87 & 7 & 801 & 359 & 63 \\
\hline 8 & 726 & 313 & 56,08 & 8 & 896 & 449 & 52 \\
\hline 9 & 845 & 424 & 52,49 & 9 & 991 & 549 & 45 \\
\hline 10 & 957 & 544 & 58,96 & 10 & 907 & 460 & 55 \\
\hline 11 & 1002 & 596 & 53,21 & 11 & 894 & 446 & 52 \\
\hline 12 & 843 & 422 & 61,83 & 12 & 875 & 428 & 58 \\
\hline 13 & 765 & 347 & 61,12 & 13 & 879 & 432 & 58 \\
\hline 14 & 859 & 439 & 50,33 & 14 & 968 & 523 & 63 \\
\hline 15 & 951 & 537 & 57,52 & 15 & 1004 & 564 & 54 \\
\hline 16 & 1009 & 604 & 50,33 & 16 & 1044 & 610 & 47 \\
\hline 17 & 1051 & 656 & 51,05 & 17 & 1023 & 584 & 52 \\
\hline 18 & 1127 & 754 & 51,05 & 18 & 856 & 410 & 57 \\
\hline 19 & 960 & 547 & 47,45 & 19 & 854 & 407 & 55 \\
\hline 20 & 850 & 429 & 58,96 & 20 & 794 & 352 & 60 \\
\hline 21 & 863 & 442 & 57,52 & 21 & 742 & 308 & 58 \\
\hline 22 & 828 & 407 & 56,08 & 22 & 832 & 387 & 62 \\
\hline 23 & 840 & 420 & 60,40 & 23 & 859 & 413 & 55 \\
\hline 24 & 820 & 399 & 57,52 & 24 & 881 & 434 & 55 \\
\hline 25 & 841 & 420 & 60,40 & 25 & 854 & 408 & 56 \\
\hline 26 & 943 & 528 & 56,80 & 26 & 853 & 407 & 54 \\
\hline 27 & 873 & 453 & 60,40 & 27 & 930 & 484 & 54 \\
\hline 28 & 849 & 428 & 55,36 & 28 & 903 & 456 & 57 \\
\hline 29 & 885 & 465 & 60,40 & 29 & 908 & 460 & 59 \\
\hline 30 & 930 & 513 & 52,49 & 30 & 870 & 424 & 60 \\
\hline 31 & 1000 & 594 & 47,45 & 31 & 831 & 386 & 60 \\
\hline 32 & 890 & 470 & 53,93 & 32 & 933 & 486 & 47 \\
\hline 33 & 898 & 479 & 55,36 & 33 & 944 & 498 & 52 \\
\hline 34 & 1072 & 683 & 52,49 & 34 & 875 & 428 & 60 \\
\hline 35 & 1045 & 649 & 58,24 & 35 & 776 & 336 & 63 \\
\hline 36 & 861 & 440 & 68,31 & 36 & 780 & 340 & 54 \\
\hline 37 & 740 & 326 & 60,40 & 37 & 923 & 476 & 55 \\
\hline 38 & 782 & 363 & 60,40 & 38 & 930 & 483 & 55 \\
\hline 39 & 805 & 385 & 62,55 & 39 & 900 & 453 & 58 \\
\hline 40 & 829 & 409 & 55,36 & 40 & 983 & 541 & 50 \\
\hline 41 & 956 & 542 & 51,05 & 41 & 946 & 500 & 54 \\
\hline 42 & 957 & 544 & 53,21 & 42 & 848 & 402 & 53 \\
\hline 43 & 956 & 543 & 52,49 & 43 & 834 & 389 & 55 \\
\hline 44 & 955 & 542 & 57,52 & 44 & 812 & 369 & 63 \\
\hline 45 & 854 & 434 & 64,71 & 45 & 809 & 366 & 53 \\
\hline 46 & 869 & 448 & 49,61 & 46 & 804 & 362 & 67 \\
\hline 47 & 772 & 354 & 69,02 & 47 & 846 & 401 & 58 \\
\hline 48 & 771 & 353 & 60,40 & 48 & 955 & 510 & 51 \\
\hline
\end{tabular}


Tabela $\mathrm{C} 14$ - Valores de $V_{d}, C_{d}$ e $A t_{d}$ para os painéis 17 e 18, através do método de ultra-som

\begin{tabular}{|c|c|c|c|c|c|c|c|}
\hline CP & $\begin{array}{c}\mathbf{V}_{\mathrm{d}} \\
(\mathrm{m} / \mathrm{s})\end{array}$ & $\begin{array}{c}\mathrm{C}_{\mathrm{d}} \\
(\mathrm{MPa})\end{array}$ & $\begin{array}{c}\text { Atn }_{\mathrm{d}} \\
\text { (d } \beta \text { loss) }\end{array}$ & CP & $\begin{array}{c}V_{d} \\
(m / s)\end{array}$ & $\begin{array}{c}\mathrm{C}_{\mathrm{d}} \\
(\mathrm{MPa})\end{array}$ & $\begin{array}{c}\text { Atn }_{\mathrm{d}} \\
\text { (d } \beta \text { loss) }\end{array}$ \\
\hline$\overline{1} 1$ & 1032 & 619 & 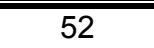 & $\overline{1} 1$ & 838 & 400 & $\bar{~} 50$ \\
\hline 2 & 1040 & 629 & 48 & 2 & 846 & 408 & 55 \\
\hline 3 & 963 & 539 & 59 & 3 & 837 & 399 & 57 \\
\hline 4 & 897 & 468 & 47 & 4 & 848 & 410 & 59 \\
\hline 5 & 884 & 455 & 50 & 5 & 848 & 410 & 57 \\
\hline 6 & 896 & 467 & 52 & 6 & 821 & 384 & 65 \\
\hline 7 & 872 & 442 & 55 & 7 & 840 & 402 & 58 \\
\hline 8 & 835 & 405 & 58 & 8 & 871 & 433 & 53 \\
\hline 9 & 868 & 439 & 55 & 9 & 744 & 316 & 58 \\
\hline 10 & 883 & 454 & 52 & 10 & 706 & 284 & 55 \\
\hline 11 & 876 & 447 & 52 & 11 & 815 & 378 & 58 \\
\hline 12 & 888 & 459 & 54 & 12 & 831 & 393 & 52 \\
\hline 13 & 913 & 485 & 52 & 13 & 898 & 460 & 51 \\
\hline 14 & 898 & 469 & 55 & 14 & 901 & 463 & 69 \\
\hline 15 & 925 & 498 & 51 & 15 & 895 & 456 & 54 \\
\hline 16 & 964 & 541 & 51 & 16 & 916 & 479 & 58 \\
\hline 17 & 996 & 578 & 51 & 17 & 858 & 420 & 52 \\
\hline 18 & 952 & 527 & 53 & 18 & 834 & 396 & 63 \\
\hline 19 & 901 & 472 & 55 & 19 & 748 & 319 & 58 \\
\hline 20 & 964 & 541 & 50 & 20 & 712 & 289 & 66 \\
\hline 21 & 980 & 559 & 51 & 21 & 810 & 374 & 55 \\
\hline 22 & 940 & 514 & 50 & 22 & 801 & 365 & 63 \\
\hline 23 & 859 & 429 & 49 & 23 & 870 & 431 & 51 \\
\hline 24 & 844 & 415 & 58 & 24 & 1013 & 585 & 55 \\
\hline 25 & 944 & 518 & 55 & 25 & 840 & 402 & 60 \\
\hline 26 & 994 & 576 & 55 & 26 & 725 & 300 & 53 \\
\hline 27 & 978 & 557 & 51 & 27 & 798 & 363 & 65 \\
\hline 28 & 997 & 578 & 47 & 28 & 847 & 409 & 60 \\
\hline 29 & 940 & 514 & 58 & 29 & 830 & 393 & 65 \\
\hline 30 & 925 & 498 & 58 & 30 & 733 & 307 & 65 \\
\hline 31 & 926 & 499 & 58 & 31 & 762 & 331 & 55 \\
\hline 32 & 897 & 468 & 55 & 32 & 968 & 535 & 61 \\
\hline 33 & 955 & 531 & 58 & 33 & 744 & 316 & 65 \\
\hline 34 & 952 & 527 & 53 & 34 & 707 & 285 & 58 \\
\hline 35 & 929 & 502 & 50 & 35 & 824 & 387 & 65 \\
\hline 36 & 862 & 432 & 50 & 36 & 810 & 374 & 65 \\
\hline 37 & 847 & 417 & 53 & 37 & 731 & 305 & 63 \\
\hline 38 & 913 & 485 & 52 & 38 & 787 & 353 & 50 \\
\hline 39 & 918 & 491 & 52 & 39 & 888 & 450 & 62 \\
\hline 40 & 910 & 482 & 55 & 40 & 948 & 512 & 52 \\
\hline 41 & 936 & 510 & 59 & 41 & 1004 & 575 & 53 \\
\hline 42 & 1032 & 619 & 52 & 42 & 928 & 491 & 55 \\
\hline 43 & 895 & 467 & 48 & 43 & 841 & 403 & 55 \\
\hline 44 & 794 & 367 & 55 & 44 & 791 & 356 & 58 \\
\hline 45 & 891 & 462 & 47 & 45 & 851 & 413 & 60 \\
\hline 46 & 833 & 403 & 64 & 46 & 872 & 434 & 55 \\
\hline 47 & 777 & 352 & 59 & 47 & 883 & 445 & 54 \\
\hline 48 & 876 & 447 & 47 & 48 & 902 & 464 & 40 \\
\hline
\end{tabular}


Tabela $C 15$ - Valores de $V_{d}, C_{d}$ e Atn $n_{d}$ para os painéis 19 e 110, através do método de ultra-som

\begin{tabular}{|c|c|c|c|c|c|c|c|}
\hline CP & $\begin{array}{c}\begin{array}{c}V_{d} \\
(\mathrm{~m} / \mathrm{s})\end{array} \\
\end{array}$ & $\begin{array}{c}\mathrm{C}_{\mathrm{d}} \\
(\mathrm{MPa})\end{array}$ & $\begin{array}{c}\text { Atn }_{\mathrm{d}} \\
\text { (d } \beta \text { loss) }\end{array}$ & CP & $\begin{array}{c}V_{d} \\
(m / s)\end{array}$ & $\begin{array}{c}\mathrm{C}_{\mathrm{d}} \\
(\mathrm{MPa})\end{array}$ & $\begin{array}{c}\text { Atn }_{\mathrm{d}} \\
\text { (d } \beta \text { loss) }\end{array}$ \\
\hline$\overline{c 1}$ & 814 & 373 & 63 & $\overline{\overline{1}}$ & 865 & $\overline{4444}$ & 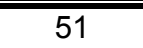 \\
\hline 2 & 859 & 416 & 50 & 2 & 919 & 502 & 50 \\
\hline 3 & 910 & 467 & 58 & 3 & 949 & 535 & 51 \\
\hline 4 & 863 & 420 & 42 & 4 & 966 & 554 & 58 \\
\hline 5 & 876 & 432 & 52 & 5 & 840 & 419 & 63 \\
\hline 6 & 956 & 514 & 53 & 6 & 883 & 463 & 47 \\
\hline 7 & 836 & 393 & 63 & 7 & 984 & 576 & 59 \\
\hline 8 & 761 & 326 & 67 & 8 & 880 & 460 & 46 \\
\hline 9 & 819 & 378 & 60 & 9 & 817 & 396 & 61 \\
\hline 10 & 881 & 437 & 58 & 10 & 749 & 333 & 59 \\
\hline 11 & 845 & 402 & 58 & 11 & 784 & 365 & 63 \\
\hline 12 & 794 & 355 & 60 & 12 & 854 & 433 & 63 \\
\hline 13 & 838 & 395 & 58 & 13 & 972 & 561 & 49 \\
\hline 14 & 624 & 219 & 68 & 14 & 935 & 520 & 52 \\
\hline 15 & 598 & 202 & 65 & 15 & 912 & 494 & 52 \\
\hline 16 & 793 & 354 & 53 & 16 & 1019 & 616 & 45 \\
\hline 17 & 833 & 390 & 60 & 17 & 872 & 452 & 63 \\
\hline 18 & 871 & 427 & 51 & 18 & 860 & 439 & 55 \\
\hline 19 & 806 & 365 & 67 & 19 & 974 & 563 & 50 \\
\hline 20 & 828 & 386 & 55 & 20 & 966 & 554 & 50 \\
\hline 21 & 902 & 458 & 58 & 21 & 942 & 527 & 57 \\
\hline 22 & 892 & 448 & 58 & 22 & 1026 & 625 & 42 \\
\hline 23 & 911 & 467 & 50 & 23 & 1081 & 694 & 57 \\
\hline 24 & 877 & 433 & 52 & 24 & 946 & 532 & 63 \\
\hline 25 & 966 & 526 & 50 & 25 & 892 & 472 & 58 \\
\hline 26 & 908 & 464 & 63 & 26 & 856 & 435 & 60 \\
\hline 27 & 781 & 344 & 63 & 27 & 844 & 423 & 52 \\
\hline 28 & 810 & 369 & 61 & 28 & 882 & 462 & 55 \\
\hline 29 & 744 & 312 & 52 & 29 & 931 & 514 & 53 \\
\hline 30 & 777 & 340 & 63 & 30 & 997 & 591 & 60 \\
\hline 31 & 941 & 499 & 60 & 31 & 963 & 551 & 57 \\
\hline 32 & 924 & 480 & 55 & 32 & 894 & 475 & 49 \\
\hline 33 & 799 & 359 & 65 & 33 & 899 & 480 & 50 \\
\hline 34 & 795 & 356 & 61 & 34 & 901 & 482 & 47 \\
\hline 35 & 902 & 458 & 55 & 35 & 1017 & 614 & 45 \\
\hline 36 & 976 & 536 & 47 & 36 & 1018 & 615 & 53 \\
\hline 37 & 958 & 517 & 52 & 37 & 995 & 588 & 48 \\
\hline 38 & 850 & 407 & 55 & 38 & 919 & 502 & 54 \\
\hline 39 & 778 & 341 & 60 & 39 & 886 & 466 & 52 \\
\hline 40 & 731 & 301 & 58 & 40 & 957 & 544 & 59 \\
\hline 41 & 781 & 343 & 54 & 41 & 879 & 459 & 55 \\
\hline 42 & 947 & 504 & 47 & 42 & 891 & 472 & 55 \\
\hline 43 & 1003 & 567 & 50 & 43 & 960 & 547 & 55 \\
\hline 44 & 936 & 493 & 50 & 44 & 926 & 509 & 55 \\
\hline 45 & 919 & 475 & 55 & 45 & 871 & 451 & 57 \\
\hline 46 & 943 & 501 & 58 & 46 & 907 & 488 & 60 \\
\hline 47 & 856 & 412 & 55 & 47 & 974 & 563 & 63 \\
\hline 48 & 776 & 339 & 66 & 48 & 948 & 534 & 63 \\
\hline
\end{tabular}


Tabela C16 - Valores de $V_{d}, C_{d}$ e $A t_{d}$ para os painéis 21 e 22, através do método de ultra-som

\begin{tabular}{|c|c|c|c|c|c|c|c|}
\hline CP & $\begin{array}{c}\begin{array}{c}V_{d} \\
(\mathrm{~m} / \mathrm{s})\end{array} \\
\end{array}$ & $\begin{array}{c}\mathrm{C}_{\mathrm{d}} \\
(\mathrm{MPa})\end{array}$ & $\begin{array}{c}\text { Atn }_{\mathrm{d}} \\
\text { (d } \beta \text { loss) }\end{array}$ & CP & $\begin{array}{c}V_{d} \\
(m / s)\end{array}$ & $\begin{array}{c}\mathrm{C}_{\mathrm{d}} \\
(\mathrm{MPa})\end{array}$ & $\begin{array}{c}\text { Atn }_{\mathrm{d}} \\
\text { (d } \beta \text { loss) }\end{array}$ \\
\hline 1 & 822 & 400 & 57 & 1 & 854 & 436 & 56 \\
\hline 2 & 789 & 368 & 65 & 2 & 864 & 446 & 53 \\
\hline 3 & 768 & 349 & 65 & 3 & 961 & 551 & 50 \\
\hline 4 & 827 & 405 & 55 & 4 & 866 & 447 & 65 \\
\hline 5 & 917 & 498 & 57 & 5 & 813 & 395 & 63 \\
\hline 6 & 951 & 536 & 52 & 6 & 804 & 386 & 61 \\
\hline 7 & 889 & 468 & 59 & 7 & 818 & 399 & 61 \\
\hline 8 & 838 & 415 & 68 & 8 & 752 & 338 & 63 \\
\hline 9 & 837 & 415 & 59 & 9 & 725 & 314 & 55 \\
\hline 10 & 775 & 356 & 55 & 10 & 891 & 474 & 58 \\
\hline 11 & 794 & 373 & 62 & 11 & 916 & 501 & 60 \\
\hline 12 & 858 & 436 & 58 & 12 & 973 & 565 & 55 \\
\hline 13 & 861 & 439 & 65 & 13 & 841 & 422 & 63 \\
\hline 14 & 772 & 353 & 65 & 14 & 694 & 287 & 58 \\
\hline 15 & 747 & 330 & 55 & 15 & 799 & 381 & 50 \\
\hline 16 & 881 & 460 & 57 & 16 & 1000 & 597 & 51 \\
\hline 17 & 961 & 547 & 58 & 17 & 967 & 559 & 58 \\
\hline 18 & 920 & 501 & 65 & 18 & 955 & 544 & 58 \\
\hline 19 & 786 & 366 & 65 & 19 & 763 & 347 & 61 \\
\hline 20 & 740 & 324 & 56 & 20 & 640 & 245 & 66 \\
\hline 21 & 882 & 460 & 51 & 21 & 766 & 350 & 55 \\
\hline 22 & 971 & 558 & 50 & 22 & 1007 & 606 & 47 \\
\hline 23 & 956 & 541 & 54 & 23 & 1008 & 607 & 56 \\
\hline 24 & 1023 & 619 & 50 & 24 & 923 & 509 & 55 \\
\hline 25 & 908 & 488 & 59 & 25 & 864 & 446 & 58 \\
\hline 26 & 816 & 394 & 71 & 26 & 809 & 391 & 63 \\
\hline 27 & 880 & 459 & 58 & 27 & 840 & 422 & 63 \\
\hline 28 & 983 & 572 & 60 & 28 & 875 & 457 & 63 \\
\hline 29 & 851 & 428 & 68 & 29 & 790 & 372 & 65 \\
\hline 30 & 758 & 340 & 66 & 30 & 696 & 289 & 57 \\
\hline 31 & 796 & 375 & 63 & 31 & 772 & 355 & 58 \\
\hline 32 & 882 & 461 & 60 & 32 & 963 & 554 & 52 \\
\hline 33 & 974 & 562 & 55 & 33 & 979 & 572 & 50 \\
\hline 34 & 868 & 446 & 63 & 34 & 885 & 468 & 60 \\
\hline 35 & 737 & 321 & 61 & 35 & 719 & 309 & 64 \\
\hline 36 & 655 & 254 & 53 & 36 & 624 & 232 & 58 \\
\hline 37 & 734 & 319 & 53 & 37 & 768 & 352 & 52 \\
\hline 38 & 900 & 479 & 55 & 38 & 870 & 452 & 65 \\
\hline 39 & 912 & 493 & 52 & 39 & 855 & 437 & 52 \\
\hline 40 & 847 & 424 & 56 & 40 & 862 & 444 & 58 \\
\hline 41 & 800 & 379 & 58 & 41 & 813 & 394 & 57 \\
\hline 42 & 774 & 355 & 65 & 42 & 805 & 387 & 55 \\
\hline 43 & 828 & 406 & 58 & 43 & 785 & 368 & 63 \\
\hline 44 & 811 & 389 & 62 & 44 & 820 & 401 & 57 \\
\hline 45 & 812 & 390 & 58 & 45 & 933 & 519 & 51 \\
\hline 46 & 750 & 333 & 63 & 46 & 873 & 455 & 65 \\
\hline 47 & 735 & 320 & 63 & 47 & 861 & 442 & 51 \\
\hline 48 & 881 & 459 & 68 & 48 & 930 & 517 & 65 \\
\hline
\end{tabular}


Tabela $\mathrm{C} 17$ - Valores de $V_{d}, C_{d}$ e $A t_{d}$ para os painéis 23 e 24, através do método de ultra-som

\begin{tabular}{|c|c|c|c|c|c|c|c|}
\hline CP & $\begin{array}{c}\mathbf{V}_{\mathrm{d}} \\
(\mathrm{m} / \mathrm{s})\end{array}$ & $\begin{array}{c}\mathrm{C}_{\mathrm{d}} \\
(\mathrm{MPa})\end{array}$ & $\begin{array}{c}\text { Atn }_{\mathrm{d}} \\
\text { (d } \beta \text { loss) }\end{array}$ & CP & $\begin{array}{c}V_{d} \\
(m / s)\end{array}$ & $\begin{array}{c}\mathrm{C}_{\mathrm{d}} \\
(\mathrm{MPa})\end{array}$ & $\begin{array}{c}\text { Atn }_{\mathrm{d}} \\
\text { (d } \beta \text { loss) }\end{array}$ \\
\hline$\overline{1} 1$ & 984 & $\bar{~} 584$ & 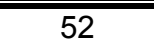 & $\overline{1} 1$ & 998 & 629 & 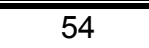 \\
\hline 2 & 937 & 530 & 58 & 2 & 993 & 622 & 52 \\
\hline 3 & 974 & 572 & 56 & 3 & 1007 & 640 & 55 \\
\hline 4 & 1080 & 703 & 55 & 4 & 999 & 630 & 55 \\
\hline 5 & 1049 & 663 & 52 & 5 & 1002 & 633 & 50 \\
\hline 6 & 969 & 566 & 67 & 6 & 984 & 610 & 65 \\
\hline 7 & 879 & 466 & 57 & 7 & 918 & 532 & 55 \\
\hline 8 & 886 & 473 & 53 & 8 & 727 & 333 & 69 \\
\hline 9 & 927 & 518 & 50 & 9 & 754 & 358 & 51 \\
\hline 10 & 925 & 516 & 50 & 10 & 1027 & 666 & 54 \\
\hline 11 & 929 & 520 & 55 & 11 & 993 & 622 & 57 \\
\hline 12 & 945 & 538 & 65 & 12 & 960 & 581 & 51 \\
\hline 13 & 922 & 513 & 62 & 13 & 1061 & 711 & 50 \\
\hline 14 & 928 & 519 & 53 & 14 & 1032 & 673 & 55 \\
\hline 15 & 1025 & 634 & 52 & 15 & 989 & 617 & 51 \\
\hline 16 & 1036 & 647 & 54 & 16 & 1018 & 654 & 53 \\
\hline 17 & 894 & 482 & 61 & 17 & 959 & 581 & 52 \\
\hline 18 & 813 & 399 & 57 & 18 & 972 & 596 & 58 \\
\hline 19 & 749 & 338 & 63 & 19 & 969 & 592 & 63 \\
\hline 20 & 658 & 261 & 64 & 20 & 955 & 575 & 59 \\
\hline 21 & 755 & 344 & 53 & 21 & 937 & 554 & 65 \\
\hline 22 & 740 & 330 & 61 & 22 & 924 & 538 & 52 \\
\hline 23 & 732 & 323 & 58 & 23 & 856 & 463 & 63 \\
\hline 24 & 861 & 447 & 58 & 24 & 823 & 427 & 53 \\
\hline 25 & 832 & 417 & 54 & 25 & 829 & 434 & 57 \\
\hline 26 & 823 & 409 & 58 & 26 & 850 & 456 & 56 \\
\hline 27 & 827 & 413 & 64 & 27 & 976 & 601 & 55 \\
\hline 28 & 791 & 377 & 65 & 28 & 978 & 604 & 58 \\
\hline 29 & 850 & 436 & 47 & 29 & 949 & 568 & 56 \\
\hline 30 & 892 & 480 & 64 & 30 & 986 & 613 & 47 \\
\hline 31 & 846 & 432 & 55 & 31 & 923 & 537 & 58 \\
\hline 32 & 876 & 462 & 59 & 32 & 861 & 468 & 63 \\
\hline 33 & 883 & 471 & 58 & 33 & 916 & 529 & 60 \\
\hline 34 & 903 & 491 & 56 & 34 & 978 & 604 & 53 \\
\hline 35 & 919 & 510 & 65 & 35 & 967 & 590 & 62 \\
\hline 36 & 823 & 409 & 52 & 36 & 844 & 450 & 59 \\
\hline 37 & 871 & 458 & 59 & 37 & 796 & 400 & 60 \\
\hline 38 & 917 & 507 & 61 & 38 & 786 & 390 & 63 \\
\hline 39 & 919 & 509 & 53 & 39 & 770 & 374 & 63 \\
\hline 40 & 982 & 582 & 57 & 40 & 736 & 341 & 61 \\
\hline 41 & 899 & 487 & 55 & 41 & 794 & 398 & 58 \\
\hline 42 & 959 & 555 & 50 & 42 & 853 & 459 & 65 \\
\hline 43 & 984 & 584 & 58 & 43 & 901 & 512 & 51 \\
\hline 44 & 886 & 473 & 60 & 44 & 936 & 553 & 55 \\
\hline 45 & 925 & 516 & 52 & 45 & 885 & 494 & 55 \\
\hline 46 & 1010 & 615 & 55 & 46 & 907 & 519 & 57 \\
\hline 47 & 1050 & 665 & 47 & 47 & 900 & 511 & 58 \\
\hline 48 & 1123 & 761 & 49 & 48 & 820 & 425 & 64 \\
\hline
\end{tabular}


Tabela $\mathrm{C} 18$ - Valores de $V_{d}, C_{d}$ e $A t_{d}$ para os painéis 25 e 26, através do método de ultra-som

\begin{tabular}{|c|c|c|c|c|c|c|c|}
\hline CP & $\begin{array}{c}\begin{array}{c}V_{d} \\
(\mathrm{~m} / \mathrm{s})\end{array} \\
\end{array}$ & $\begin{array}{c}\mathrm{C}_{\mathrm{d}} \\
(\mathrm{MPa})\end{array}$ & $\begin{array}{c}\text { Atn }_{\mathrm{d}} \\
\text { (d } \beta \text { loss) }\end{array}$ & CP & $\begin{array}{c}V_{d} \\
(m / s)\end{array}$ & $\begin{array}{c}\mathrm{C}_{\mathrm{d}} \\
(\mathrm{MPa})\end{array}$ & $\begin{array}{c}\text { Atn }_{\mathrm{d}} \\
\text { (d } \beta \text { loss) }\end{array}$ \\
\hline$\overline{1} 1$ & 762 & 343 & 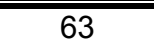 & $\overline{\overline{1}}$ & 845 & 424 & $\bar{~} 55$ \\
\hline 2 & 771 & 351 & 60 & 2 & 865 & 444 & 56 \\
\hline 3 & 887 & 465 & 50 & 3 & 912 & 494 & 57 \\
\hline 4 & 842 & 419 & 65 & 4 & 904 & 485 & 55 \\
\hline 5 & 782 & 362 & 58 & 5 & 902 & 483 & 55 \\
\hline 6 & 856 & 433 & 60 & 6 & 760 & 343 & 60 \\
\hline 7 & 814 & 392 & 60 & 7 & 738 & 323 & 65 \\
\hline 8 & 811 & 389 & 65 & 8 & 822 & 400 & 58 \\
\hline 9 & 836 & 413 & 60 & 9 & 870 & 449 & 55 \\
\hline 10 & 873 & 450 & 58 & 10 & 761 & 343 & 65 \\
\hline 11 & 970 & 556 & 59 & 11 & 792 & 372 & 52 \\
\hline 12 & 982 & 570 & 58 & 12 & 950 & 535 & 58 \\
\hline 13 & 941 & 524 & 57 & 13 & 919 & 500 & 54 \\
\hline 14 & 999 & 590 & 51 & 14 & 986 & 576 & 53 \\
\hline 15 & 991 & 580 & 57 & 15 & 1010 & 605 & 46 \\
\hline 16 & 971 & 557 & 55 & 16 & 1014 & 610 & 53 \\
\hline 17 & 978 & 566 & 58 & 17 & 902 & 483 & 51 \\
\hline 18 & 938 & 520 & 58 & 18 & 828 & 407 & 58 \\
\hline 19 & 799 & 377 & 52 & 19 & 851 & 430 & 63 \\
\hline 20 & 668 & 264 & 47 & 20 & 964 & 551 & 55 \\
\hline 21 & 824 & 401 & 50 & 21 & 1051 & 655 & 55 \\
\hline 22 & 1059 & 663 & 55 & 22 & 1043 & 645 & 46 \\
\hline 23 & 984 & 572 & 55 & 23 & 942 & 527 & 60 \\
\hline 24 & 893 & 471 & 50 & 24 & 884 & 464 & 51 \\
\hline 25 & 849 & 426 & 57 & 25 & 882 & 461 & 55 \\
\hline 26 & 907 & 486 & 55 & 26 & 907 & 488 & 55 \\
\hline 27 & 962 & 546 & 55 & 27 & 895 & 475 & 59 \\
\hline 28 & 898 & 477 & 61 & 28 & 924 & 506 & 49 \\
\hline 29 & 899 & 478 & 56 & 29 & 815 & 393 & 63 \\
\hline 30 & 1092 & 705 & 47 & 30 & 832 & 410 & 51 \\
\hline 31 & 1094 & 707 & 54 & 31 & 997 & 590 & 55 \\
\hline 32 & 1010 & 603 & 55 & 32 & 974 & 563 & 55 \\
\hline 33 & 952 & 536 & 58 & 33 & 1032 & 631 & 50 \\
\hline 34 & 869 & 447 & 52 & 34 & 975 & 564 & 63 \\
\hline 35 & 730 & 315 & 65 & 35 & 898 & 478 & 52 \\
\hline 36 & 664 & 260 & 58 & 36 & 903 & 483 & 58 \\
\hline 37 & 731 & 316 & 59 & 37 & 916 & 497 & 64 \\
\hline 38 & 888 & 466 & 55 & 38 & 947 & 531 & 54 \\
\hline 39 & 947 & 529 & 60 & 39 & 934 & 517 & 56 \\
\hline 40 & 885 & 463 & 59 & 40 & 861 & 440 & 57 \\
\hline 41 & 772 & 352 & 61 & 41 & 843 & 422 & 56 \\
\hline 42 & 725 & 310 & 58 & 42 & 791 & 371 & 65 \\
\hline 43 & 846 & 423 & 57 & 43 & 798 & 377 & 58 \\
\hline 44 & 860 & 437 & 64 & 44 & 875 & 454 & 52 \\
\hline 45 & 839 & 416 & 63 & 45 & 953 & 539 & 50 \\
\hline 46 & 758 & 340 & 68 & 46 & 954 & 540 & 60 \\
\hline 47 & 757 & 339 & 61 & 47 & 895 & 475 & 53 \\
\hline 48 & 807 & 385 & 65 & 48 & 895 & 475 & 50 \\
\hline
\end{tabular}


Tabela $\mathrm{C} 19$ - Valores de $\mathrm{V}_{d}, \mathrm{C}_{\mathrm{d}}$ e $A \operatorname{tn}_{\mathrm{d}}$ para os painéis 27 e 28, através do método de ultra-som

\begin{tabular}{|c|c|c|c|c|c|c|c|}
\hline CP & $\begin{array}{c}\begin{array}{c}V_{d} \\
(\mathrm{~m} / \mathrm{s})\end{array} \\
\end{array}$ & $\begin{array}{c}\mathrm{C}_{\mathrm{d}} \\
(\mathrm{MPa})\end{array}$ & $\begin{array}{c}\text { Atn }_{\mathrm{d}} \\
\text { (d } \beta \text { loss) }\end{array}$ & CP & $\begin{array}{c}V_{d} \\
(m / s)\end{array}$ & $\begin{array}{c}\mathrm{C}_{\mathrm{d}} \\
(\mathrm{MPa})\end{array}$ & $\begin{array}{c}\text { Atn }_{\mathrm{d}} \\
\text { (d } \beta \text { loss) }\end{array}$ \\
\hline$\overline{1} 1$ & 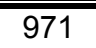 & $\overline{c 562}$ & 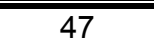 & $\overline{\overline{1}}$ & 715 & 283 & 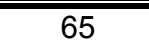 \\
\hline 2 & 884 & 466 & 55 & 2 & 795 & 350 & 58 \\
\hline 3 & 856 & 436 & 56 & 3 & 893 & 442 & 65 \\
\hline 4 & 890 & 472 & 60 & 4 & 887 & 437 & 55 \\
\hline 5 & 920 & 504 & 57 & 5 & 859 & 410 & 63 \\
\hline 6 & 929 & 515 & 68 & 6 & 876 & 426 & 63 \\
\hline 7 & 895 & 477 & 58 & 7 & 904 & 453 & 65 \\
\hline 8 & 920 & 504 & 55 & 8 & 805 & 360 & 60 \\
\hline 9 & 855 & 436 & 57 & 9 & 813 & 367 & 52 \\
\hline 10 & 789 & 371 & 63 & 10 & 838 & 390 & 57 \\
\hline 11 & 819 & 400 & 52 & 11 & 821 & 374 & 58 \\
\hline 12 & 861 & 442 & 66 & 12 & 826 & 378 & 50 \\
\hline 13 & 733 & 321 & 63 & 13 & 763 & 323 & 63 \\
\hline 14 & 759 & 343 & 65 & 14 & 742 & 305 & 50 \\
\hline 15 & 961 & 551 & 53 & 15 & 827 & 379 & 55 \\
\hline 16 & 943 & 530 & 52 & 16 & 936 & 486 & 53 \\
\hline 17 & 928 & 513 & 65 & 17 & 913 & 462 & 60 \\
\hline 18 & 952 & 540 & 55 & 18 & 848 & 399 & 63 \\
\hline 19 & 826 & 407 & 68 & 19 & 754 & 316 & 68 \\
\hline 20 & 826 & 407 & 63 & 20 & 675 & 253 & 60 \\
\hline 21 & 988 & 582 & 48 & 21 & 783 & 340 & 58 \\
\hline 22 & 1005 & 602 & 55 & 22 & 906 & 456 & 60 \\
\hline 23 & 903 & 486 & 55 & 23 & 847 & 398 & 63 \\
\hline 24 & 899 & 482 & 58 & 24 & 852 & 402 & 55 \\
\hline 25 & 853 & 433 & 62 & 25 & 761 & 322 & 60 \\
\hline 26 & 766 & 350 & 58 & 26 & 760 & 321 & 60 \\
\hline 27 & 836 & 416 & 65 & 27 & 936 & 487 & 52 \\
\hline 28 & 856 & 437 & 60 & 28 & 948 & 499 & 55 \\
\hline 29 & 751 & 336 & 65 & 29 & 976 & 529 & 49 \\
\hline 30 & 781 & 363 & 55 & 30 & 998 & 553 & 65 \\
\hline 31 & 938 & 525 & 55 & 31 & 910 & 460 & 61 \\
\hline 32 & 876 & 457 & 65 & 32 & 836 & 388 & 62 \\
\hline 33 & 860 & 441 & 57 & 33 & 843 & 394 & 50 \\
\hline 34 & 843 & 423 & 61 & 34 & 951 & 502 & 53 \\
\hline 35 & 833 & 413 & 63 & 35 & 883 & 433 & 63 \\
\hline 36 & 922 & 506 & 59 & 36 & 893 & 442 & 64 \\
\hline 37 & 955 & 543 & 55 & 37 & 1010 & 566 & 63 \\
\hline 38 & 850 & 430 & 59 & 38 & 943 & 494 & 58 \\
\hline 39 & 835 & 416 & 51 & 39 & 886 & 436 & 59 \\
\hline 40 & 940 & 527 & 55 & 40 & 880 & 429 & 58 \\
\hline 41 & 910 & 494 & 56 & 41 & 854 & 404 & 58 \\
\hline 42 & 843 & 423 & 58 & 42 & 880 & 430 & 58 \\
\hline 43 & 846 & 427 & 57 & 43 & 911 & 460 & 60 \\
\hline 44 & 889 & 471 & 51 & 44 & 865 & 415 & 55 \\
\hline 45 & 940 & 526 & 57 & 45 & 839 & 391 & 60 \\
\hline 46 & 996 & 591 & 53 & 46 & 883 & 432 & 56 \\
\hline 47 & 932 & 517 & 55 & 47 & 932 & 482 & 52 \\
\hline 48 & 911 & 495 & 53 & 48 & 1004 & 560 & 52 \\
\hline
\end{tabular}


Tabela C20 - Valores de $V_{d}, C_{d}$ e Atn $n_{d}$ para os painéis 29 e 210, através do método de ultra-som

\begin{tabular}{|c|c|c|c|c|c|c|c|}
\hline CP & $\begin{array}{c}\begin{array}{c}V_{d} \\
(\mathrm{~m} / \mathrm{s})\end{array} \\
\end{array}$ & $\begin{array}{c}\mathrm{C}_{\mathrm{d}} \\
(\mathrm{MPa})\end{array}$ & $\begin{array}{c}\text { Atn }_{\mathrm{d}} \\
\text { (d } \beta \text { loss) }\end{array}$ & CP & $\begin{array}{c}V_{d} \\
(m / s)\end{array}$ & $\begin{array}{c}\mathrm{C}_{\mathrm{d}} \\
(\mathrm{MPa})\end{array}$ & $\begin{array}{c}\text { Atn }_{\mathrm{d}} \\
\text { (d } \beta \text { loss) }\end{array}$ \\
\hline$\overline{c 1}$ & $\overline{522}$ & 151 & $\overline{50}$ & $\overline{\overline{1}}$ & 942 & $\overline{520}$ & 60 \\
\hline 2 & 651 & 235 & 58 & 2 & 875 & 449 & 60 \\
\hline 3 & 783 & 340 & 63 & 3 & 824 & 398 & 61 \\
\hline 4 & 753 & 314 & 63 & 4 & 819 & 393 & 63 \\
\hline 5 & 842 & 393 & 55 & 5 & 821 & 395 & 63 \\
\hline 6 & 896 & 446 & 65 & 6 & 813 & 388 & 60 \\
\hline 7 & 896 & 445 & 58 & 7 & 724 & 307 & 67 \\
\hline 8 & 677 & 254 & 60 & 8 & 761 & 339 & 67 \\
\hline 9 & 663 & 244 & 55 & 9 & 908 & 483 & 52 \\
\hline 10 & 850 & 401 & 60 & 10 & 822 & 396 & 60 \\
\hline 11 & 861 & 412 & 58 & 11 & 789 & 364 & 59 \\
\hline 12 & 813 & 367 & 60 & 12 & 848 & 422 & 57 \\
\hline 13 & 819 & 372 & 54 & 13 & 867 & 440 & 55 \\
\hline 14 & 888 & 438 & 60 & 14 & 915 & 490 & 58 \\
\hline 15 & 856 & 406 & 58 & 15 & 942 & 520 & 55 \\
\hline 16 & 832 & 384 & 60 & 16 & 891 & 465 & 57 \\
\hline 17 & 865 & 415 & 53 & 17 & 923 & 499 & 57 \\
\hline 18 & 832 & 384 & 57 & 18 & 981 & 564 & 55 \\
\hline 19 & 769 & 328 & 66 & 19 & 980 & 563 & 57 \\
\hline 20 & 852 & 403 & 55 & 20 & 946 & 524 & 57 \\
\hline 21 & 921 & 471 & 60 & 21 & 833 & 407 & 60 \\
\hline 22 & 942 & 493 & 56 & 22 & 786 & 362 & 60 \\
\hline 23 & 968 & 520 & 57 & 23 & 795 & 370 & 63 \\
\hline 24 & 854 & 405 & 56 & 24 & 786 & 362 & 57 \\
\hline 25 & 832 & 384 & 58 & 25 & 806 & 380 & 45 \\
\hline 26 & 889 & 439 & 59 & 26 & 886 & 460 & 55 \\
\hline 27 & 885 & 435 & 60 & 27 & 969 & 550 & 59 \\
\hline 28 & 888 & 438 & 60 & 28 & 890 & 465 & 53 \\
\hline 29 & 950 & 501 & 55 & 29 & 792 & 368 & 59 \\
\hline 30 & 894 & 443 & 60 & 30 & 835 & 409 & 60 \\
\hline 31 & 893 & 443 & 55 & 31 & 830 & 404 & 61 \\
\hline 32 & 983 & 536 & 59 & 32 & 820 & 394 & 61 \\
\hline 33 & 919 & 469 & 59 & 33 & 865 & 439 & 60 \\
\hline 34 & 930 & 480 & 55 & 34 & 993 & 578 & 53 \\
\hline 35 & 958 & 509 & 62 & 35 & 912 & 487 & 62 \\
\hline 36 & 938 & 488 & 57 & 36 & 820 & 394 & 58 \\
\hline 37 & 983 & 536 & 53 & 37 & 840 & 413 & 55 \\
\hline 38 & 1011 & 567 & 53 & 38 & 714 & 299 & 63 \\
\hline 39 & 906 & 456 & 61 & 39 & 714 & 298 & 59 \\
\hline 40 & 832 & 384 & 53 & 40 & 790 & 365 & 58 \\
\hline 41 & 825 & 378 & 63 & 41 & 799 & 374 & 60 \\
\hline 42 & 815 & 368 & 59 & 42 & 841 & 414 & 55 \\
\hline 43 & 817 & 370 & 53 & 43 & 892 & 466 & 59 \\
\hline 44 & 891 & 440 & 58 & 44 & 859 & 433 & 63 \\
\hline 45 & 922 & 472 & 59 & 45 & 824 & 398 & 65 \\
\hline 46 & 867 & 418 & 55 & 46 & 823 & 397 & 60 \\
\hline 47 & 754 & 315 & 64 & 47 & 851 & 424 & 65 \\
\hline 48 & 673 & 251 & 66 & 48 & 766 & 344 & 65 \\
\hline
\end{tabular}


Tabela C21 - Valores de V e C para os painéis 11 e 12, através dos métodos de ultra-som e stress wave, na direção longitudinal de propagação

\begin{tabular}{|c|c|c|c|c|c|c|c|c|c|}
\hline Ponto & $\begin{array}{c}V_{\text {Us }} \\
(\mathrm{m} / \mathrm{s})\end{array}$ & $\begin{array}{c}\mathrm{C}_{\text {us }} \\
\text { (MPa) }\end{array}$ & $\begin{array}{c}V_{\text {sw }} \\
(\mathrm{m} / \mathrm{s})\end{array}$ & $\begin{array}{c}\mathrm{C}_{\mathrm{sw}} \\
(\mathrm{MPa})\end{array}$ & Ponto & $\begin{array}{c}V_{\text {US }} \\
(\mathrm{m} / \mathrm{s})\end{array}$ & $\begin{array}{c}\mathrm{C}_{\mathrm{us}} \\
(\mathrm{MPa})\end{array}$ & $\begin{array}{c}V_{\mathrm{sw}} \\
(\mathrm{m} / \mathrm{s})\end{array}$ & $\begin{array}{c}\mathrm{C}_{\mathrm{sw}} \\
(\mathrm{MPa})\end{array}$ \\
\hline$\overline{\overline{1}}$ & 3142 & $\overline{c 5666}$ & 3000 & $\overline{5166}$ & 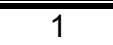 & 3169 & 25755 & 2978 & 5081 \\
\hline 2 & 3133 & 5633 & 2994 & 5147 & 2 & 3160 & 5723 & 2961 & 5024 \\
\hline 3 & 3144 & 5675 & 2988 & 5123 & 3 & 3168 & 5749 & 2953 & 4997 \\
\hline 4 & 3160 & 5733 & 2988 & 5123 & 4 & 3203 & 5877 & 2972 & 5060 \\
\hline 5 & 3168 & 5762 & 3000 & 5166 & 5 & 3186 & 5816 & 2982 & 5095 \\
\hline 6 & 3183 & 5816 & 3013 & 5209 & 6 & 3160 & 5723 & 2982 & 5095 \\
\hline 7 & 3204 & 5892 & 3015 & 5218 & 7 & 3181 & 5800 & 3003 & 5168 \\
\hline 8 & 3196 & 5862 & 2991 & 5136 & 8 & 3179 & 5792 & 3009 & 5189 \\
\hline 9 & 3183 & 5815 & 2976 & 5085 & 9 & 3178 & 5788 & 2998 & 5151 \\
\hline 10 & 3188 & 5834 & 2994 & 5145 & 10 & 3193 & 5841 & 3008 & 5185 \\
\hline 11 & 3180 & 5804 & 2991 & 5136 & 11 & 3186 & 5817 & 3023 & 5235 \\
\hline 12 & 3169 & 5763 & 2963 & 5039 & 12 & 3153 & 5696 & 3023 & 5235 \\
\hline 13 & 3170 & 5767 & 2959 & 5027 & 13 & 3139 & 5646 & 3001 & 5161 \\
\hline 14 & 3153 & 5706 & 2966 & 5050 & 14 & 3165 & 5739 & 3008 & 5183 \\
\hline 15 & 3137 & 5649 & 2971 & 5066 & 15 & 3201 & 5871 & 3024 & 5240 \\
\hline 16 & 3146 & 5681 & 2988 & 5123 & 16 & 3210 & 5905 & 3024 & 5240 \\
\hline 17 & 3139 & 5655 & 2971 & 5066 & 17 & 3198 & 5859 & 3033 & 5271 \\
\hline 18 & 3132 & 5630 & 2949 & 4992 & 18 & 3199 & 5864 & 3036 & 5282 \\
\hline 19 & 3118 & 5581 & 2963 & 5039 & 19 & 3199 & 5863 & 3046 & 5318 \\
\hline 20 & 3117 & 5577 & 2983 & 5106 & 20 & 3202 & 5874 & 3036 & 5282 \\
\hline 21 & 3125 & 5606 & 2998 & 5161 & 21 & 3195 & 5848 & 3023 & 5235 \\
\hline 22 & 3145 & 5679 & 3012 & 5206 & 22 & 3198 & 5860 & 3018 & 5220 \\
\hline 23 & 3165 & 5750 & 3003 & 5178 & 23 & 3189 & 5825 & 3032 & 5266 \\
\hline 24 & 3167 & 5758 & 2991 & 5135 & 24 & 3160 & 5722 & 3049 & 5327 \\
\hline
\end{tabular}


Tabela C22 - Valores de V e C para os painéis 13 e 14, através dos métodos de ultra-som e stress wave, na direção longitudinal de propagação

\begin{tabular}{|c|c|c|c|c|c|c|c|c|c|}
\hline Ponto & $\begin{array}{c}V_{\text {Us }} \\
(\mathrm{m} / \mathrm{s})\end{array}$ & $\begin{array}{c}\mathrm{C}_{\mathrm{us}} \\
(\mathrm{MPa})\end{array}$ & $\begin{array}{c}V_{\text {sw }} \\
(\mathrm{m} / \mathrm{s})\end{array}$ & $\begin{array}{c}\mathrm{C}_{\mathrm{sw}} \\
(\mathrm{MPa})\end{array}$ & Ponto & $\begin{array}{c}V_{\text {US }} \\
(\mathrm{m} / \mathrm{s})\end{array}$ & $\begin{array}{c}\mathrm{C}_{\mathrm{us}} \\
(\mathrm{MPa})\end{array}$ & $\begin{array}{c}V_{\mathrm{sw}} \\
(\mathrm{m} / \mathrm{s})\end{array}$ & $\begin{array}{c}\mathrm{C}_{\mathrm{sw}} \\
(\mathrm{MPa})\end{array}$ \\
\hline$\overline{\overline{1}}$ & 3198 & 25964 & 3030 & $\overline{5354}$ & 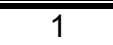 & 3184 & 5728 & 3046 & 5241 \\
\hline 2 & 3180 & 5895 & 3025 & 5336 & 2 & 3191 & 5752 & 3047 & 5245 \\
\hline 3 & 3170 & 5859 & 3020 & 5318 & 3 & 3188 & 5743 & 3038 & 5215 \\
\hline 4 & 3180 & 5894 & 3032 & 5358 & 4 & 3151 & 5610 & 3021 & 5156 \\
\hline 5 & 3168 & 5850 & 3053 & 5436 & 5 & 3167 & 5665 & 3014 & 5134 \\
\hline 6 & 3165 & 5841 & 3042 & 5397 & 6 & 3212 & 5828 & 3021 & 5156 \\
\hline 7 & 3175 & 5879 & 3022 & 5324 & 7 & 3189 & 5746 & 3020 & 5153 \\
\hline 8 & 3177 & 5885 & 3029 & 5349 & 8 & 3158 & 5636 & 3009 & 5115 \\
\hline 9 & 3175 & 5876 & 3045 & 5406 & 9 & 3160 & 5641 & 3020 & 5151 \\
\hline 10 & 3152 & 5792 & 3047 & 5413 & 10 & 3167 & 5667 & 3020 & 5153 \\
\hline 11 & 3150 & 5786 & 3044 & 5401 & 11 & 3151 & 5610 & 3018 & 5145 \\
\hline 12 & 3189 & 5929 & 3036 & 5374 & 12 & 3167 & 5667 & 3013 & 5128 \\
\hline 13 & 3204 & 5986 & 3037 & 5376 & 13 & 3195 & 5767 & 3003 & 5093 \\
\hline 14 & 3202 & 5976 & 3044 & 5403 & 14 & 3186 & 5736 & 3001 & 5089 \\
\hline 15 & 3193 & 5943 & 3035 & 5372 & 15 & 3175 & 5694 & 3020 & 5151 \\
\hline 16 & 3195 & 5953 & 3043 & 5399 & 16 & 3190 & 5751 & 3033 & 5199 \\
\hline 17 & 3211 & 6010 & 3054 & 5438 & 17 & 3205 & 5803 & 3033 & 5197 \\
\hline 18 & 3216 & 6031 & 3046 & 5410 & 18 & 3210 & 5821 & 3061 & 5292 \\
\hline 19 & 3202 & 5978 & 3024 & 5331 & 19 & 3223 & 5868 & 3074 & 5338 \\
\hline 20 & 3159 & 5819 & 3015 & 5300 & 20 & 3218 & 5849 & 3052 & 5263 \\
\hline 21 & 3137 & 5737 & 3025 & 5336 & 21 & 3176 & 5698 & 3033 & 5199 \\
\hline 22 & 3151 & 5789 & 3031 & 5356 & 22 & 3160 & 5641 & 3043 & 5232 \\
\hline 23 & 3161 & 5824 & 3027 & 5342 & 23 & 3194 & 5764 & 3053 & 5266 \\
\hline 24 & 3177 & 5883 & 3021 & 5320 & 24 & 3194 & 5764 & 3041 & 5223 \\
\hline
\end{tabular}


Tabela C23 - Valores de V e C para os painéis 15 e 16, através dos métodos de ultra-som e stress wave, na direção longitudinal de propagação

\begin{tabular}{|c|c|c|c|c|c|c|c|c|c|}
\hline Ponto & $\begin{array}{c}V_{\text {Us }} \\
(\mathrm{m} / \mathrm{s})\end{array}$ & $\begin{array}{c}\mathrm{C}_{\mathrm{us}} \\
(\mathrm{MPa})\end{array}$ & $\begin{array}{c}V_{\text {sw }} \\
(\mathrm{m} / \mathrm{s})\end{array}$ & $\begin{array}{c}\mathrm{C}_{\mathrm{sw}} \\
(\mathrm{MPa})\end{array}$ & Ponto & $\begin{array}{c}V_{\text {US }} \\
(\mathrm{m} / \mathrm{s})\end{array}$ & $\begin{array}{c}\mathrm{C}_{\mathrm{us}} \\
(\mathrm{MPa})\end{array}$ & $\begin{array}{c}V_{\mathrm{sw}} \\
(\mathrm{m} / \mathrm{s})\end{array}$ & $\begin{array}{c}\mathrm{C}_{\mathrm{sw}} \\
(\mathrm{MPa})\end{array}$ \\
\hline$\overline{\overline{1}}$ & 3066 & 25583 & 2993 & $\overline{5319}$ & $\bar{~} 1$ & 3154 & 25563 & 3000 & 5031 \\
\hline 2 & 3108 & 5737 & 3003 & 5355 & 2 & 3133 & 5488 & 2991 & 5000 \\
\hline 3 & 3144 & 5870 & 3011 & 5384 & 3 & 3134 & 5491 & 2984 & 4979 \\
\hline 4 & 3152 & 5903 & 3024 & 5432 & 4 & 3155 & 5565 & 2998 & 5025 \\
\hline 5 & 3154 & 5911 & 3030 & 5452 & 5 & 3119 & 5437 & 3014 & 5077 \\
\hline 6 & 3148 & 5886 & 3031 & 5457 & 6 & 3112 & 5415 & 3006 & 5050 \\
\hline 7 & 3176 & 5993 & 3044 & 5505 & 7 & 3125 & 5460 & 3003 & 5039 \\
\hline 8 & 3204 & 6099 & 3047 & 5515 & 8 & 3118 & 5434 & 3033 & 5144 \\
\hline 9 & 3174 & 5983 & 3043 & 5501 & 9 & 3148 & 5538 & 3032 & 5137 \\
\hline 10 & 3139 & 5854 & 3048 & 5517 & 10 & 3169 & 5613 & 3028 & 5125 \\
\hline 11 & 3162 & 5940 & 3039 & 5487 & 11 & 3182 & 5659 & 3017 & 5088 \\
\hline 12 & 3176 & 5993 & 3027 & 5443 & 12 & 3187 & 5679 & 2983 & 4975 \\
\hline 13 & 3176 & 5993 & 3037 & 5478 & 13 & 3186 & 5675 & 3019 & 5094 \\
\hline 14 & 3169 & 5965 & 3024 & 5432 & 14 & 3163 & 5592 & 3029 & 5129 \\
\hline 15 & 3134 & 5833 & 3014 & 5398 & 15 & 3158 & 5576 & 3018 & 5090 \\
\hline 16 & 3133 & 5829 & 3031 & 5456 & 16 & 3184 & 5666 & 3040 & 5166 \\
\hline 17 & 3144 & 5873 & 3043 & 5501 & 17 & 3191 & 5692 & 3031 & 5135 \\
\hline 18 & 3142 & 5864 & 3030 & 5452 & 18 & 3183 & 5664 & 3009 & 5060 \\
\hline 19 & 3122 & 5790 & 3005 & 5364 & 19 & 3183 & 5665 & 3025 & 5116 \\
\hline 20 & 3126 & 5804 & 3003 & 5358 & 20 & 3198 & 5717 & 3040 & 5166 \\
\hline 21 & 3155 & 5913 & 3008 & 5374 & 21 & 3168 & 5610 & 2991 & 5000 \\
\hline 22 & 3168 & 5960 & 3012 & 5387 & 22 & 3161 & 5586 & 2980 & 4965 \\
\hline 23 & 3180 & 6006 & 3012 & 5390 & 23 & 3166 & 5603 & 3020 & 5099 \\
\hline 24 & 3180 & 6006 & 3003 & 5356 & 24 & 3159 & 5578 & 3023 & 5109 \\
\hline
\end{tabular}


Tabela C24 - Valores de V e C para os painéis 17 e 18, através dos métodos de ultra-som e stress wave, na direção longitudinal de propagação

\begin{tabular}{|c|c|c|c|c|c|c|c|c|c|}
\hline Ponto & $\begin{array}{c}\begin{array}{c}V_{\text {Us }} \\
(\mathrm{m} / \mathrm{s})\end{array} \\
\end{array}$ & $\begin{array}{c}C_{\text {Us }} \\
\text { (MPa) }\end{array}$ & $\begin{array}{c}V_{\text {sw }} \\
(\mathrm{m} / \mathrm{s}) \\
\end{array}$ & $\begin{array}{c}\mathrm{C}_{\mathrm{sw}} \\
(\mathrm{MPa})\end{array}$ & Ponto & $\begin{array}{c}\begin{array}{c}V_{\text {Us }} \\
(\mathrm{m} / \mathrm{s})\end{array} \\
\end{array}$ & $\begin{array}{c}\mathrm{C}_{\text {Us }} \\
(\mathrm{MPa})\end{array}$ & $\begin{array}{c}V_{\mathrm{sw}} \\
(\mathrm{m} / \mathrm{s}) \\
\end{array}$ & $\begin{array}{c}C_{\text {sw }} \\
(\mathrm{MPa}) \\
\end{array}$ \\
\hline 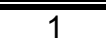 & 2995 & 5220 & 2861 & $4 \quad 4762$ & 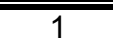 & 3155 & $\overline{55673}$ & 2989 & " 5092 \\
\hline 2 & 2980 & 5167 & 2866 & 4779 & 2 & 3146 & 5641 & 2984 & 5077 \\
\hline 3 & 2976 & 5155 & 2894 & 4874 & 3 & 3150 & 5657 & 2973 & 5039 \\
\hline 4 & 2988 & 5196 & 2893 & 4870 & 4 & 3150 & 5657 & 2977 & 5052 \\
\hline 5 & 2991 & 5205 & 2866 & 4779 & 5 & 3144 & 5634 & 2986 & 5083 \\
\hline 6 & 2993 & 5215 & 2882 & 4835 & 6 & 3130 & 5584 & 2990 & 5096 \\
\hline 7 & 2994 & 5217 & 2910 & 4927 & 7 & 3123 & 5561 & 3001 & 5134 \\
\hline 8 & 3000 & 5240 & 2902 & 4902 & 8 & 3138 & 5614 & 3006 & 5151 \\
\hline 9 & 3019 & 5305 & 2897 & 4886 & 9 & 3147 & 5643 & 3000 & 5130 \\
\hline 10 & 3022 & 5317 & 2911 & 4931 & 10 & 3155 & 5673 & 3000 & 5130 \\
\hline 11 & 3041 & 5381 & 2907 & 4919 & 11 & 3169 & 5725 & 2996 & 5117 \\
\hline 12 & 3067 & 5474 & 2924 & 4975 & 12 & 3188 & 5794 & 2986 & 5083 \\
\hline 13 & 3060 & 5449 & 2933 & 5006 & 13 & 3170 & 5729 & 3001 & 5134 \\
\hline 14 & 3018 & 5300 & 2940 & 5030 & 14 & 3164 & 5707 & 3008 & 5158 \\
\hline 15 & 3013 & 5283 & 2942 & 5037 & 15 & 3175 & 5745 & 2973 & 5037 \\
\hline 16 & 3065 & 5467 & 2911 & 4933 & 16 & 3152 & 5663 & 2970 & 5027 \\
\hline 17 & 3052 & 5420 & 2912 & 4935 & 17 & 3165 & 5711 & 3005 & 5147 \\
\hline 18 & 3031 & 5346 & 2909 & 4923 & 18 & 3197 & 5825 & 3042 & 5274 \\
\hline 19 & 3042 & 5387 & 2899 & 4892 & 19 & 3184 & 5777 & 3047 & 5292 \\
\hline 20 & 3049 & 5410 & 2929 & 4994 & 20 & 3176 & 5751 & 3042 & 5274 \\
\hline 21 & 3050 & 5414 & 2919 & 4957 & 21 & 3176 & 5750 & 3051 & 5308 \\
\hline 22 & 3024 & 5321 & 2892 & 4866 & 22 & 3189 & 5797 & 3048 & 5296 \\
\hline 23 & 2985 & 5187 & 2875 & 4812 & 23 & 3187 & 5790 & 3045 & 5285 \\
\hline 24 & 2948 & 5058 & 2846 & 4714 & 24 & 3157 & 5681 & 3037 & 5258 \\
\hline
\end{tabular}


Tabela C25 - Valores de V e C para os painéis 19 e 110, através dos métodos de ultra-som e stress wave, na direção longitudinal de propagação

\begin{tabular}{|c|c|c|c|c|c|c|c|c|c|}
\hline Ponto & $\begin{array}{c}V_{\text {Us }} \\
(\mathrm{m} / \mathrm{s})\end{array}$ & $\begin{array}{c}\mathrm{C}_{\text {Us }} \\
(\mathrm{MPa})\end{array}$ & $\begin{array}{c}V_{\mathrm{sw}} \\
(\mathrm{m} / \mathrm{s})\end{array}$ & $\begin{array}{c}C_{\text {sw }} \\
(\mathrm{MPa})\end{array}$ & Ponto & $\begin{array}{c}\begin{array}{c}V_{U S} \\
(\mathrm{~m} / \mathrm{s})\end{array} \\
\end{array}$ & $\begin{array}{c}\mathrm{C}_{\text {Us }} \\
(\mathrm{MPa})\end{array}$ & $\begin{array}{c}V_{\mathbf{s w}} \\
(\mathrm{m} / \mathrm{s})\end{array}$ & $\begin{array}{c}\mathrm{C}_{\mathrm{SW}} \\
(\mathrm{MPa})\end{array}$ \\
\hline 1 & 3126 & 5501 & 2993 & 5042 & 1 & 3035 & 5471 & 2844 & 4803 \\
\hline 2 & 3112 & 5454 & 3005 & 5084 & 2 & 3050 & 5526 & 2870 & 4894 \\
\hline 3 & 3113 & 5455 & 3010 & 5101 & 3 & 3069 & 5594 & 2910 & 5031 \\
\hline 4 & 3145 & 5567 & 3009 & 5097 & 4 & 3099 & 5706 & 2899 & 4991 \\
\hline 5 & 3135 & 5532 & 3006 & 5086 & 5 & 3132 & 5828 & 2933 & 5111 \\
\hline 6 & 3122 & 5489 & 2991 & 5038 & 6 & 3138 & 5848 & 2995 & 5328 \\
\hline 7 & 3152 & 5592 & 3003 & 5078 & 7 & 3152 & 5902 & 3015 & 5400 \\
\hline 8 & 3157 & 5611 & 3018 & 5129 & 8 & 3173 & 5980 & 3044 & 5503 \\
\hline 9 & 3157 & 5610 & 3014 & 5114 & 9 & 3193 & 6056 & 3046 & 5510 \\
\hline 10 & 3153 & 5597 & 3006 & 5086 & 10 & 3209 & 6117 & 3033 & 5466 \\
\hline 11 & 3132 & 5522 & 3020 & 5133 & 11 & 3218 & 6149 & 3023 & 5429 \\
\hline 12 & 3132 & 5523 & 3019 & 5131 & 12 & 3219 & 6154 & 3041 & 5494 \\
\hline 13 & 3132 & 5523 & 2994 & 5046 & 13 & 3202 & 6091 & 3064 & 5576 \\
\hline 14 & 3118 & 5474 & 2996 & 5052 & 14 & 3183 & 6019 & 3070 & 5597 \\
\hline 15 & 3131 & 5518 & 3032 & 5174 & 15 & 3157 & 5918 & 3056 & 5548 \\
\hline 16 & 3164 & 5635 & 3055 & 5256 & 16 & 3150 & 5893 & 3035 & 5471 \\
\hline 17 & 3179 & 5690 & 3041 & 5207 & 17 & 3158 & 5925 & 3040 & 5489 \\
\hline 18 & 3160 & 5622 & 3031 & 5172 & 18 & 3154 & 5908 & 3035 & 5473 \\
\hline 19 & 3153 & 5597 & 3027 & 5159 & 19 & 3146 & 5877 & 3013 & 5391 \\
\hline 20 & 3153 & 5596 & 3014 & 5114 & 20 & 3152 & 5902 & 2999 & 5342 \\
\hline 21 & 3141 & 5555 & 2996 & 5054 & 21 & 3158 & 5924 & 3008 & 5375 \\
\hline 22 & 3118 & 5475 & 2986 & 5019 & 22 & 3147 & 5882 & 3008 & 5373 \\
\hline 23 & 3082 & 5348 & 2959 & 4928 & 23 & 3135 & 5840 & 3002 & 5353 \\
\hline 24 & 3073 & 5317 & 2907 & 4759 & 24 & 3133 & 5832 & 3016 & 5402 \\
\hline
\end{tabular}


Tabela C26 - Valores de V e C para os painéis 21 e 22, através dos métodos de ultra-som e stress wave, na direção longitudinal de propagação

\begin{tabular}{|c|c|c|c|c|c|c|c|c|c|}
\hline Ponto & $\begin{array}{c}V_{\text {Us }} \\
(\mathrm{m} / \mathrm{s})\end{array}$ & $\begin{array}{c}\mathrm{C}_{\mathrm{us}} \\
(\mathrm{MPa})\end{array}$ & $\begin{array}{c}V_{\text {sw }} \\
(\mathrm{m} / \mathrm{s})\end{array}$ & $\begin{array}{c}\mathrm{C}_{\mathrm{sw}} \\
(\mathrm{MPa})\end{array}$ & Ponto & $\begin{array}{c}\mathrm{V}_{\mathrm{Us}} \\
(\mathrm{m} / \mathrm{s})\end{array}$ & $\begin{array}{c}\mathrm{C}_{\mathrm{us}} \\
(\mathrm{MPa})\end{array}$ & $\begin{array}{c}V_{\mathrm{sw}} \\
(\mathrm{m} / \mathrm{s})\end{array}$ & $\begin{array}{c}\mathrm{C}_{\mathrm{sw}} \\
(\mathrm{MPa})\end{array}$ \\
\hline$\overline{\overline{1}}$ & 2825 & 4748 & 2724 & 44393 & $\bar{~} 1$ & 2801 & $\bar{~} 4685$ & 2712 & 4390 \\
\hline 2 & 2812 & 4706 & 2704 & 4328 & 2 & 2822 & 4754 & 2705 & 4367 \\
\hline 3 & 2818 & 4726 & 2687 & 4274 & 3 & 2860 & 4884 & 2686 & 4306 \\
\hline 4 & 2823 & 4742 & 2712 & 4354 & 4 & 2868 & 4910 & 2637 & 4151 \\
\hline 5 & 2816 & 4717 & 2699 & 4313 & 5 & 2864 & 4898 & 2619 & 4094 \\
\hline 6 & 2823 & 4740 & 2694 & 4297 & 6 & 2867 & 4908 & 2650 & 4194 \\
\hline 7 & 2829 & 4764 & 2714 & 4360 & 7 & 2861 & 4887 & 2697 & 4343 \\
\hline 8 & 2835 & 4781 & 2717 & 4370 & 8 & 2864 & 4896 & 2680 & 4288 \\
\hline 9 & 2852 & 4840 & 2729 & 4408 & 9 & 2856 & 4869 & 2667 & 4245 \\
\hline 10 & 2865 & 4883 & 2737 & 4433 & 10 & 2873 & 4928 & 2705 & 4369 \\
\hline 11 & 2871 & 4903 & 2738 & 4437 & 11 & 2904 & 5033 & 2712 & 4390 \\
\hline 12 & 2859 & 4865 & 2713 & 4359 & 12 & 2891 & 4990 & 2727 & 4439 \\
\hline 13 & 2840 & 4799 & 2713 & 4357 & 13 & 2886 & 4973 & 2742 & 4488 \\
\hline 14 & 2833 & 4775 & 2725 & 4395 & 14 & 2882 & 4960 & 2733 & 4461 \\
\hline 15 & 2857 & 4856 & 2719 & 4377 & 15 & 2863 & 4892 & 2728 & 4442 \\
\hline 16 & 2874 & 4915 & 2725 & 4397 & 16 & 2873 & 4928 & 2744 & 4495 \\
\hline 17 & 2861 & 4870 & 2729 & 4408 & 17 & 2880 & 4953 & 2730 & 4449 \\
\hline 18 & 2867 & 4890 & 2742 & 4452 & 18 & 2868 & 4911 & 2729 & 4447 \\
\hline 19 & 2881 & 4940 & 2752 & 4483 & 19 & 2868 & 4911 & 2738 & 4474 \\
\hline 20 & 2900 & 5004 & 2742 & 4450 & 20 & 2869 & 4915 & 2721 & 4420 \\
\hline 21 & 2885 & 4953 & 2745 & 4461 & 21 & 2863 & 4894 & 2732 & 4456 \\
\hline 22 & 2884 & 4950 & 2750 & 4478 & 22 & 2867 & 4907 & 2728 & 4442 \\
\hline 23 & 2893 & 4980 & 2766 & 4529 & 23 & 2873 & 4926 & 2717 & 4409 \\
\hline 24 & 2877 & 4924 & 2769 & 4538 & 24 & 2869 & 4913 & 2710 & 4386 \\
\hline
\end{tabular}


Tabela C27 - Valores de V e C para os painéis 23 e 24, através dos métodos de ultra-som e stress wave, na direção longitudinal de propagação

\begin{tabular}{|c|c|c|c|c|c|c|c|c|c|}
\hline Ponto & $\begin{array}{c}V_{\text {Us }} \\
(\mathrm{m} / \mathrm{s})\end{array}$ & $\begin{array}{c}\mathrm{C}_{\text {us }} \\
\text { (MPa) }\end{array}$ & $\begin{array}{c}V_{\text {sw }} \\
(\mathrm{m} / \mathrm{s})\end{array}$ & $\begin{array}{c}\mathrm{C}_{\mathrm{sw}} \\
(\mathrm{MPa})\end{array}$ & Ponto & $\begin{array}{c}\mathrm{V}_{\mathrm{Us}} \\
(\mathrm{m} / \mathrm{s})\end{array}$ & $\begin{array}{c}\mathrm{C}_{\mathrm{us}} \\
(\mathrm{MPa})\end{array}$ & $\begin{array}{c}V_{\mathrm{sw}} \\
(\mathrm{m} / \mathrm{s})\end{array}$ & $\begin{array}{c}\mathrm{C}_{\mathrm{sw}} \\
(\mathrm{MPa})\end{array}$ \\
\hline$\overline{\overline{1}}$ & 2903 & 5083 & 2730 & $\overline{44495}$ & 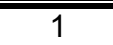 & 2836 & $\overline{c 5076}$ & 2721 & 4672 \\
\hline 2 & 2893 & 5046 & 2728 & 4489 & 2 & 2835 & 5072 & 2726 & 4690 \\
\hline 3 & 2865 & 4950 & 2724 & 4473 & 3 & 2851 & 5128 & 2699 & 4597 \\
\hline 4 & 2854 & 4910 & 2700 & 4396 & 4 & 2856 & 5146 & 2688 & 4558 \\
\hline 5 & 2863 & 4944 & 2701 & 4398 & 5 & 2843 & 5100 & 2721 & 4670 \\
\hline 6 & 2875 & 4985 & 2722 & 4468 & 6 & 2855 & 5143 & 2727 & 4693 \\
\hline 7 & 2875 & 4985 & 2736 & 4512 & 7 & 2869 & 5195 & 2712 & 4641 \\
\hline 8 & 2876 & 4989 & 2736 & 4514 & 8 & 2864 & 5176 & 2706 & 4621 \\
\hline 9 & 2889 & 5032 & 2740 & 4526 & 9 & 2868 & 5191 & 2727 & 4692 \\
\hline 10 & 2880 & 5003 & 2734 & 4507 & 10 & 2874 & 5213 & 2742 & 4744 \\
\hline 11 & 2881 & 5004 & 2705 & 4413 & 11 & 2886 & 5256 & 2754 & 4785 \\
\hline 12 & 2900 & 5071 & 2724 & 4475 & 12 & 2886 & 5256 & 2749 & 4769 \\
\hline 13 & 2888 & 5028 & 2751 & 4564 & 13 & 2876 & 5218 & 1849 & 2158 \\
\hline 14 & 2880 & 5002 & 2737 & 4516 & 14 & 2866 & 5183 & 1858 & 2178 \\
\hline 15 & 2880 & 5002 & 2749 & 4557 & 15 & 2853 & 5135 & 2770 & 4843 \\
\hline 16 & 2868 & 4961 & 2764 & 4606 & 16 & 2868 & 5190 & 2770 & 4841 \\
\hline 17 & 2862 & 4940 & 2738 & 4519 & 17 & 2886 & 5254 & 2763 & 4817 \\
\hline 18 & 2862 & 4940 & 2719 & 4456 & 18 & 2880 & 5233 & 2761 & 4811 \\
\hline 19 & 2850 & 4898 & 2680 & 4330 & 19 & 2873 & 5209 & 2758 & 4800 \\
\hline 20 & 2845 & 4880 & 2684 & 4343 & 20 & 2904 & 5320 & 2756 & 4793 \\
\hline 21 & 2828 & 4821 & 2743 & 4537 & 21 & 2898 & 5299 & 2750 & 4771 \\
\hline 22 & 2811 & 4764 & 2751 & 4563 & 22 & 2869 & 5192 & 2761 & 4811 \\
\hline 23 & 2827 & 4818 & 2748 & 4552 & 23 & 2874 & 5211 & 2779 & 4873 \\
\hline 24 & 2843 & 4876 & 2759 & 4591 & 24 & 2886 & 5255 & 2762 & 4813 \\
\hline
\end{tabular}


Tabela C28 - Valores de V e C para os painéis 25 e 26, através dos métodos de ultra-som e stress wave, na direção longitudinal de propagação

\begin{tabular}{|c|c|c|c|c|c|c|c|c|c|}
\hline Ponto & $\begin{array}{c}V_{\text {Us }} \\
(\mathrm{m} / \mathrm{s})\end{array}$ & $\begin{array}{c}\mathrm{C}_{\mathrm{US}} \\
(\mathrm{MPa})\end{array}$ & $\begin{array}{c}V_{\text {sw }} \\
(\mathrm{m} / \mathrm{s})\end{array}$ & $\begin{array}{c}C_{\text {sw }} \\
(\mathrm{MPa})\end{array}$ & Ponto & $\begin{array}{c}\begin{array}{c}V_{U S} \\
(\mathrm{~m} / \mathrm{s})\end{array} \\
\end{array}$ & $\begin{array}{c}\mathrm{C}_{\text {Us }} \\
\text { (MPa) }\end{array}$ & $\begin{array}{c}V_{\text {sw }} \\
(\mathrm{m} / \mathrm{s})\end{array}$ & $\begin{array}{c}C_{\text {sw }} \\
\text { (MPa) }\end{array}$ \\
\hline 1 & 2833 & 4744 & 2715 & 4356 & 1 & 2822 & 4724 & 2794 & 4629 \\
\hline 2 & 2833 & 4744 & 2715 & 4356 & 2 & 2818 & 4710 & 2789 & 4613 \\
\hline 3 & 2833 & 4744 & 2720 & 4371 & 3 & 2831 & 4752 & 2747 & 4473 \\
\hline 4 & 2838 & 4760 & 2727 & 4394 & 4 & 2848 & 4810 & 2739 & 4448 \\
\hline 5 & 2855 & 4818 & 2714 & 4355 & 5 & 2857 & 4842 & 2750 & 4483 \\
\hline 6 & 2849 & 4797 & 2687 & 4266 & 6 & 2862 & 4858 & 2729 & 4416 \\
\hline 7 & 2861 & 4838 & 2700 & 4307 & 7 & 2872 & 4892 & 2735 & 4434 \\
\hline 8 & 2888 & 4928 & 2731 & 4409 & 8 & 2860 & 4850 & 2737 & 4443 \\
\hline 9 & 2858 & 4827 & 2720 & 4373 & 9 & 2840 & 4784 & 2735 & 4434 \\
\hline 10 & 2850 & 4802 & 2705 & 4324 & 10 & 2846 & 4804 & 2730 & 4421 \\
\hline 11 & 2872 & 4875 & 2729 & 4403 & 11 & 2839 & 4781 & 2727 & 4409 \\
\hline 12 & 2891 & 4938 & 2739 & 4433 & 12 & 2839 & 4781 & 2731 & 4424 \\
\hline 13 & 2909 & 5002 & 2727 & 4394 & 13 & 2834 & 4761 & 2723 & 4396 \\
\hline 14 & 2880 & 4903 & 2712 & 4348 & 14 & 2828 & 4741 & 2724 & 4401 \\
\hline 15 & 2863 & 4844 & 2713 & 4350 & 15 & 2850 & 4818 & 2742 & 4458 \\
\hline 16 & 2873 & 4877 & 2728 & 4398 & 16 & 2845 & 4799 & 2742 & 4460 \\
\hline 17 & 2862 & 4841 & 2731 & 4408 & 17 & 2839 & 4780 & 2726 & 4407 \\
\hline 18 & 2863 & 4844 & 2733 & 4416 & 18 & 2862 & 4858 & 2733 & 4431 \\
\hline 19 & 2851 & 4803 & 2729 & 4403 & 19 & 2862 & 4857 & 2730 & 4421 \\
\hline 20 & 2867 & 4856 & 2703 & 4319 & 20 & 2874 & 4898 & 2715 & 4373 \\
\hline 21 & 2889 & 4932 & 2716 & 4359 & 21 & 2874 & 4899 & 2738 & 4444 \\
\hline 22 & 2855 & 4816 & 2751 & 4472 & 22 & 2857 & 4840 & 2733 & 4431 \\
\hline 23 & 2868 & 4861 & 2757 & 4491 & 23 & 2845 & 4801 & 2733 & 4431 \\
\hline 24 & 2899 & 4967 & 2761 & 4506 & 24 & 2845 & 4801 & 2737 & 4443 \\
\hline
\end{tabular}


Tabela C29 - Valores de V e C para os painéis 27 e 28, através dos métodos de ultra-som e stress wave, na direção longitudinal de propagação

\begin{tabular}{|c|c|c|c|c|c|c|c|c|c|}
\hline Ponto & $\begin{array}{c}\begin{array}{c}V_{\text {Us }} \\
(\mathrm{m} / \mathrm{s})\end{array} \\
\end{array}$ & $\begin{array}{c}\mathrm{C}_{\mathrm{US}} \\
(\mathrm{MPa})\end{array}$ & $\begin{array}{c}V_{\text {Sw }} \\
(\mathrm{m} / \mathrm{s}) \\
\end{array}$ & $\begin{array}{c}\mathrm{C}_{\mathrm{sw}} \\
(\mathrm{MPa})\end{array}$ & Ponto & $\begin{array}{c}\begin{array}{c}V_{\text {US }} \\
(\mathrm{m} / \mathrm{s})\end{array} \\
\end{array}$ & $\begin{array}{c}C_{\text {Us }} \\
\text { (MPa) }\end{array}$ & $\begin{array}{c}V_{\mathbf{s w}_{\mathrm{w}}} \\
(\mathrm{m} / \mathrm{s}) \\
\end{array}$ & $\begin{array}{c}C_{\text {sw }} \\
(\mathrm{MPa}) \\
\end{array}$ \\
\hline 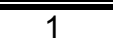 & 2836 & $4 \quad 4794$ & 2771 & 44578 & $\bar{~} 1$ & 2791 & 44323 & 2771 & 44263 \\
\hline 2 & 2852 & 4848 & 2750 & 4508 & 2 & 2805 & 4368 & 2749 & 4195 \\
\hline 3 & 2863 & 4884 & 2744 & 4487 & 3 & 2826 & 4434 & 2730 & 4136 \\
\hline 4 & 2842 & 4812 & 2751 & 4510 & 4 & 2851 & 4511 & 2738 & 4161 \\
\hline 5 & 2825 & 4757 & 2723 & 4418 & 5 & 2840 & 4476 & 2748 & 4190 \\
\hline 6 & 2846 & 4827 & 2736 & 4460 & 6 & 2827 & 4436 & 2745 & 4182 \\
\hline 7 & 2845 & 4823 & 2754 & 4520 & 7 & 2838 & 4470 & 2738 & 4161 \\
\hline 8 & 2839 & 4804 & 2730 & 4443 & 8 & 2846 & 4495 & 2714 & 4088 \\
\hline 9 & 2845 & 4825 & 2699 & 4342 & 9 & 2846 & 4495 & 2696 & 4034 \\
\hline 10 & 2844 & 4820 & 2702 & 4352 & 10 & 2835 & 4460 & 2707 & 4068 \\
\hline 11 & 2873 & 4919 & 2726 & 4428 & 11 & 2853 & 4516 & 2741 & 4171 \\
\hline 12 & 2870 & 4909 & 2721 & 4411 & 12 & 2874 & 4584 & 2725 & 4120 \\
\hline 13 & 2852 & 4849 & 2736 & 4462 & 13 & 2874 & 4583 & 2714 & 4089 \\
\hline 14 & 2857 & 4864 & 2747 & 4496 & 14 & 2886 & 4623 & 2747 & 4188 \\
\hline 15 & 2856 & 4863 & 2721 & 4413 & 15 & 2902 & 4675 & 2746 & 4185 \\
\hline 16 & 2862 & 4881 & 2716 & 4398 & 16 & 2903 & 4677 & 2743 & 4177 \\
\hline 17 & 2875 & 4926 & 2746 & 4494 & 17 & 2892 & 4642 & 2689 & 4012 \\
\hline 18 & 2875 & 4927 & 2739 & 4472 & 18 & 2880 & 4603 & 2663 & 3936 \\
\hline 19 & 2868 & 4901 & 2732 & 4448 & 19 & 2885 & 4618 & 2729 & 4134 \\
\hline 20 & 2868 & 4903 & 2748 & 4501 & 20 & 2879 & 4599 & 2870 & 4570 \\
\hline 21 & 2875 & 4928 & 2761 & 4543 & 21 & 2880 & 4603 & 2891 & 4639 \\
\hline 22 & 2863 & 4885 & 2766 & 4560 & 22 & 2874 & 4584 & 2811 & 4385 \\
\hline 23 & 2861 & 4880 & 2767 & 4563 & 23 & 2867 & 4563 & 2820 & 4414 \\
\hline 24 & 2862 & 4882 & 2775 & 4588 & 24 & 2861 & 4542 & 2811 & 4387 \\
\hline
\end{tabular}


Tabela C30 - Valores de V e C para os painéis 29 e 210, através dos métodos de ultra-som e stress wave, na direção longitudinal de propagação

\begin{tabular}{|c|c|c|c|c|c|c|c|c|c|}
\hline Ponto & $\begin{array}{c}\begin{array}{c}V_{\text {US }} \\
(\mathrm{m} / \mathrm{s})\end{array} \\
\end{array}$ & $\begin{array}{c}\mathrm{C}_{\text {Us }} \\
(\mathrm{MPa})\end{array}$ & $\begin{array}{c}V_{\mathrm{sw}} \\
(\mathrm{m} / \mathrm{s})\end{array}$ & $\begin{array}{c}C_{\text {sw }} \\
(\mathrm{MPa})\end{array}$ & Ponto & $\begin{array}{c}\begin{array}{c}V_{U S} \\
(\mathrm{~m} / \mathrm{s})\end{array} \\
\end{array}$ & $\begin{array}{c}\mathrm{C}_{\text {Us }} \\
(\mathrm{MPa})\end{array}$ & $\begin{array}{c}V_{\mathbf{s w}} \\
(\mathrm{m} / \mathrm{s})\end{array}$ & $\begin{array}{c}\mathrm{C}_{\mathrm{SW}} \\
(\mathrm{MPa})\end{array}$ \\
\hline 1 & 2789 & 4318 & 2691 & 4018 & 1 & 2880 & 4861 & 2771 & 4501 \\
\hline 2 & 2801 & 4355 & 2713 & 4085 & 2 & 2874 & 4840 & 2775 & 4513 \\
\hline 3 & 2830 & 4446 & 2744 & 4180 & 3 & 2868 & 4821 & 2766 & 4483 \\
\hline 4 & 2834 & 4456 & 2685 & 4000 & 4 & 2876 & 4847 & 2761 & 4466 \\
\hline 5 & 2804 & 4363 & 2664 & 3939 & 5 & 2858 & 4786 & 2767 & 4487 \\
\hline 6 & 2788 & 4315 & 2708 & 4069 & 6 & 2845 & 4742 & 2752 & 4439 \\
\hline 7 & 2811 & 4385 & 2717 & 4099 & 7 & 2862 & 4800 & 2753 & 4442 \\
\hline 8 & 2828 & 4438 & 2730 & 4137 & 8 & 2865 & 4811 & 2767 & 4487 \\
\hline 9 & 2839 & 4473 & 2739 & 4163 & 9 & 2855 & 4778 & 2755 & 4449 \\
\hline 10 & 2845 & 4491 & 2726 & 4125 & 10 & 2874 & 4841 & 2767 & 4487 \\
\hline 11 & 2833 & 4454 & 2721 & 4109 & 11 & 2873 & 4836 & 2790 & 4562 \\
\hline 12 & 2856 & 4527 & 2729 & 4133 & 12 & 2844 & 4739 & 2793 & 4573 \\
\hline 13 & 2868 & 4566 & 2732 & 4144 & 13 & 2845 & 4744 & 2793 & 4571 \\
\hline 14 & 2870 & 4570 & 2750 & 4198 & 14 & 2841 & 4728 & 2770 & 4496 \\
\hline 15 & 2880 & 4602 & 2735 & 4150 & 15 & 2827 & 4684 & 2728 & 4360 \\
\hline 16 & 2877 & 4593 & 2740 & 4167 & 16 & 2812 & 4633 & 2710 & 4305 \\
\hline 17 & 2902 & 4674 & 2744 & 4180 & 17 & 2795 & 4579 & 2684 & 4222 \\
\hline 18 & 2910 & 4699 & 2732 & 4142 & 18 & 2818 & 4653 & 2677 & 4198 \\
\hline 19 & 2893 & 4645 & 2752 & 4204 & 19 & 2836 & 4714 & 2716 & 4323 \\
\hline 20 & 2882 & 4611 & 2739 & 4164 & 20 & 2812 & 4633 & 2738 & 4392 \\
\hline 21 & 2870 & 4571 & 2721 & 4109 & 21 & 2787 & 4552 & 2730 & 4369 \\
\hline 22 & 2870 & 4571 & 2742 & 4174 & 22 & 2787 & 4553 & 2711 & 4306 \\
\hline 23 & 2875 & 4588 & 2735 & 4152 & 23 & 2777 & 4521 & 2700 & 4271 \\
\hline 24 & 2875 & 4588 & 2721 & 4109 & 24 & 2772 & 4502 & 2717 & 4327 \\
\hline
\end{tabular}


Tabela C31 - Valores de V e C para os painéis 11 e 12, através dos métodos de ultrasom e stress wave, na direção transversal de propagação

\begin{tabular}{|c|c|c|c|c|c|c|c|c|c|}
\hline Ponto & $\begin{array}{c}\begin{array}{c}V_{\text {Us }} \\
(\mathrm{m} / \mathrm{s})\end{array} \\
\end{array}$ & $\begin{array}{c}\mathrm{C}_{\text {Us }} \\
(\mathrm{MPa})\end{array}$ & $\begin{array}{c}V_{\mathrm{SW}} \\
(\mathrm{m} / \mathrm{s}) \\
\end{array}$ & $\begin{array}{c}\mathrm{C}_{\mathrm{sw}} \\
(\mathrm{MPa})\end{array}$ & Ponto & $\begin{array}{c}\begin{array}{c}V_{\text {Us }} \\
(\mathrm{m} / \mathrm{s})\end{array} \\
\end{array}$ & $\begin{array}{c}\mathrm{C}_{\text {Us }} \\
(\mathrm{MPa})\end{array}$ & $\begin{array}{c}V_{\mathrm{sw}} \\
(\mathrm{m} / \mathrm{s}) \\
\end{array}$ & $\begin{array}{c}\mathrm{C}_{\mathrm{sw}} \\
(\mathrm{MPa})\end{array}$ \\
\hline$\overline{\overline{1} 1}$ & 2411 & 3335 & 2210 & 2803 & $\overline{\overline{1} 1}$ & 2497 & 3574 & 2274 & 2962 \\
\hline 2 & 2436 & 3407 & 2224 & 2840 & 2 & 2513 & 3618 & 2258 & 2922 \\
\hline 3 & 2443 & 3425 & 2234 & 2865 & 3 & 2493 & 3561 & 2250 & 2901 \\
\hline 4 & 2443 & 3426 & 2217 & 2820 & 4 & 2511 & 3613 & 2260 & 2926 \\
\hline 5 & 2478 & 3526 & 2193 & 2760 & 5 & 2510 & 3611 & 2255 & 2914 \\
\hline 6 & 2469 & 3498 & 2177 & 2721 & 6 & 2450 & 3439 & 2245 & 2887 \\
\hline 7 & 2443 & 3426 & 2197 & 2770 & 7 & 2451 & 3441 & 2241 & 2878 \\
\hline 8 & 2452 & 3450 & 2229 & 2852 & 8 & 2449 & 3437 & 2237 & 2868 \\
\hline 9 & 2477 & 3522 & 2019 & 2339 & 9 & 2477 & 3515 & 2229 & 2846 \\
\hline 10 & 2492 & 3566 & 2006 & 2309 & 10 & 2532 & 3675 & 2227 & 2843 \\
\hline 11 & 2481 & 3534 & 2208 & 2798 & 11 & 2523 & 3648 & 2239 & 2873 \\
\hline 12 & 2472 & 3509 & 2195 & 2765 & 12 & 2513 & 3618 & 2247 & 2892 \\
\hline 13 & 2494 & 3570 & 2187 & 2744 & 13 & 2519 & 3636 & 2265 & 2939 \\
\hline 14 & 2512 & 3622 & 2191 & 2754 & 14 & 2490 & 3551 & 2285 & 2993 \\
\hline 15 & 2495 & 3573 & 2213 & 2810 & 15 & 2492 & 3559 & 2271 & 2955 \\
\hline 16 & 2506 & 3604 & 2230 & 2854 & 16 & 2505 & 3596 & 2257 & 2919 \\
\hline 17 & 2524 & 3656 & 2223 & 2836 & 17 & 2532 & 3672 & 2268 & 2948 \\
\hline 18 & 2528 & 3669 & 2230 & 2854 & 18 & 2557 & 3747 & 2276 & 2968 \\
\hline 19 & 2518 & 3640 & 2231 & 2856 & 19 & 2513 & 3617 & 2257 & 2920 \\
\hline 20 & 2494 & 3570 & 2208 & 2799 & 20 & 2489 & 3548 & 2225 & 2837 \\
\hline 21 & 2494 & 3571 & 2210 & 2803 & 21 & 2487 & 3545 & 2204 & 2782 \\
\hline 22 & 2524 & 3655 & 2215 & 2817 & 22 & 2492 & 3557 & 2203 & 2781 \\
\hline 23 & 2522 & 3652 & 2204 & 2789 & 23 & 2493 & 3561 & 2214 & 2808 \\
\hline 24 & 2509 & 3614 & 2222 & 2835 & 24 & 2481 & 3526 & 2200 & 2774 \\
\hline 25 & 2528 & 3669 & 2244 & 2891 & 25 & 2487 & 3543 & 2172 & 2703 \\
\hline 26 & 2520 & 3644 & 2255 & 2918 & 26 & 2484 & 3535 & 2166 & 2688 \\
\hline 27 & 2510 & 3616 & 2229 & 2852 & 27 & 2475 & 3510 & 2182 & 2728 \\
\hline 28 & 2504 & 3599 & 2179 & 2726 & 28 & 2466 & 3484 & 2200 & 2774 \\
\hline 29 & 2479 & 3527 & 2166 & 2694 & 29 & 2463 & 3476 & 2206 & 2787 \\
\hline 30 & 2495 & 3573 & 2186 & 2743 & 30 & 2440 & 3412 & 2209 & 2796 \\
\hline 31 & 2492 & 3566 & 2221 & 2831 & 31 & 2428 & 3377 & 2223 & 2832 \\
\hline 32 & 2495 & 3572 & 2251 & 2909 & 32 & 2453 & 3448 & 2225 & 2837 \\
\hline 33 & 2542 & 3708 & 2249 & 2903 & 33 & 2453 & 3448 & 2211 & 2802 \\
\hline 34 & 2560 & 3760 & 2250 & 2905 & 34 & 2451 & 3441 & 2210 & 2800 \\
\hline 35 & 2560 & 3761 & 2245 & 2894 & 35 & 2463 & 3477 & 2214 & 2808 \\
\hline 36 & 2514 & 3628 & 2217 & 2822 & 36 & 2453 & 3449 & 2187 & 2741 \\
\hline 37 & 2486 & 3549 & 2190 & 2753 & 37 & 2420 & 3355 & 2160 & 2673 \\
\hline 38 & 2468 & 3497 & 2201 & 2782 & 38 & 2411 & 3332 & 2163 & 2682 \\
\hline 39 & 2444 & 3428 & 2207 & 2796 & 39 & 2465 & 3481 & 2185 & 2734 \\
\hline 40 & 2477 & 3522 & 2206 & 2792 & 40 & 2490 & 3554 & 2213 & 2806 \\
\hline 41 & 2530 & 3673 & 2224 & 2838 & 41 & 2499 & 3578 & 2233 & 2858 \\
\hline 42 & 2536 & 3693 & 2236 & 2869 & 42 & 2522 & 3644 & 2231 & 2851 \\
\hline 43 & 2509 & 3613 & 2253 & 2915 & 43 & 2505 & 3597 & 2228 & 2844 \\
\hline 44 & 2505 & 3601 & 2243 & 2887 & 44 & 2501 & 3583 & 2245 & 2889 \\
\hline 45 & 2523 & 3655 & 2245 & 2892 & 45 & 2492 & 3559 & 2246 & 2891 \\
\hline 46 & 2541 & 3707 & 2275 & 2971 & 46 & 2459 & 3466 & 2245 & 2887 \\
\hline 47 & 2532 & 3680 & 2268 & 2952 & 47 & 2466 & 3483 & 2239 & 2873 \\
\hline 48 & 2501 & 3590 & 2254 & 2916 & 48 & 2475 & 3510 & 2219 & 2821 \\
\hline
\end{tabular}


Tabela C32 - Valores de V e C para os painéis 13 e 14, através dos métodos de ultrasom e stress wave, na direção transversal de propagação

\begin{tabular}{|c|c|c|c|c|c|c|c|c|c|}
\hline Ponto & $\begin{array}{c}\begin{array}{c}V_{\text {Us }} \\
(\mathrm{m} / \mathrm{s})\end{array} \\
\end{array}$ & $\begin{array}{c}\mathrm{C}_{\text {Us }} \\
(\mathrm{MPa})\end{array}$ & $\begin{array}{c}V_{\mathrm{SW}} \\
(\mathrm{m} / \mathrm{s}) \\
\end{array}$ & $\begin{array}{c}\mathrm{C}_{\mathrm{sw}} \\
(\mathrm{MPa})\end{array}$ & Ponto & $\begin{array}{c}\begin{array}{c}V_{\text {Us }} \\
(\mathrm{m} / \mathrm{s})\end{array} \\
\end{array}$ & $\begin{array}{c}\mathrm{C}_{\text {Us }} \\
(\mathrm{MPa})\end{array}$ & $\begin{array}{c}V_{\mathrm{sw}} \\
(\mathrm{m} / \mathrm{s}) \\
\end{array}$ & $\begin{array}{c}\mathrm{C}_{\mathrm{sw}} \\
(\mathrm{MPa})\end{array}$ \\
\hline$\overline{\overline{1} 1}$ & 2474 & 3569 & 2256 & 2968 & $\overline{\overline{1} 1}$ & 2496 & 3520 & 2235 & 2822 \\
\hline 2 & 2469 & 3553 & 2240 & 2925 & 2 & 2514 & 3572 & 2241 & 2836 \\
\hline 3 & 2469 & 3555 & 2224 & 2884 & 3 & 2541 & 3649 & 2268 & 2906 \\
\hline 4 & 2467 & 3549 & 2223 & 2881 & 4 & 2535 & 3631 & 2296 & 2978 \\
\hline 5 & 2461 & 3530 & 2244 & 2936 & 5 & 2527 & 3608 & 2288 & 2959 \\
\hline 6 & 2488 & 3610 & 2282 & 3037 & 6 & 2530 & 3615 & 2300 & 2989 \\
\hline 7 & 2524 & 3713 & 2293 & 3065 & 7 & 2510 & 3560 & 2279 & 2936 \\
\hline 8 & 2653 & 4103 & 2299 & 3081 & 8 & 2482 & 3482 & 2213 & 2767 \\
\hline 9 & 2654 & 4105 & 2271 & 3006 & 9 & 2454 & 3404 & 2208 & 2755 \\
\hline 10 & 2528 & 3727 & 2246 & 2941 & 10 & 2448 & 3385 & 2219 & 2783 \\
\hline 11 & 2525 & 3718 & 2248 & 2947 & 11 & 2480 & 3476 & 2220 & 2785 \\
\hline 12 & 2512 & 3678 & 2240 & 2925 & 12 & 2480 & 3474 & 2208 & 2754 \\
\hline 13 & 2487 & 3606 & 2238 & 2921 & 13 & 2475 & 3462 & 2217 & 2778 \\
\hline 14 & 2461 & 3531 & 2229 & 2897 & 14 & 2489 & 3499 & 2222 & 2790 \\
\hline 15 & 2453 & 3507 & 2244 & 2936 & 15 & 2468 & 3442 & 2201 & 2737 \\
\hline 16 & 2453 & 3509 & 2236 & 2914 & 16 & 2449 & 3387 & 2210 & 2759 \\
\hline 17 & 2471 & 3559 & 2195 & 2808 & 17 & 2435 & 3350 & 2209 & 2757 \\
\hline 18 & 2489 & 3610 & 2200 & 2822 & 18 & 2471 & 3450 & 2221 & 2787 \\
\hline 19 & 2479 & 3584 & 2220 & 2874 & 19 & 2503 & 3541 & 2217 & 2778 \\
\hline 20 & 2495 & 3630 & 2230 & 2899 & 20 & 2467 & 3438 & 2227 & 2802 \\
\hline 21 & 2490 & 3616 & 2241 & 2928 & 21 & 2449 & 3389 & 2245 & 2849 \\
\hline 22 & 2466 & 3545 & 2248 & 2945 & 22 & 2476 & 3463 & 2213 & 2767 \\
\hline 23 & 2488 & 3608 & 2239 & 2923 & 23 & 2514 & 3571 & 2228 & 2804 \\
\hline 24 & 2525 & 3717 & 2242 & 2930 & 24 & 2497 & 3523 & 2250 & 2862 \\
\hline 25 & 2514 & 3685 & 2236 & 2914 & 25 & 2443 & 3371 & 2234 & 2820 \\
\hline 26 & 2501 & 3646 & 2218 & 2868 & 26 & 2443 & 3371 & 2248 & 2856 \\
\hline 27 & 2507 & 3665 & 2231 & 2903 & 27 & 2459 & 3417 & 2248 & 2854 \\
\hline 28 & 2509 & 3669 & 2238 & 2919 & 28 & 2450 & 3392 & 2227 & 2802 \\
\hline 29 & 2501 & 3647 & 2226 & 2890 & 29 & 2460 & 3418 & 2238 & 2831 \\
\hline 30 & 2485 & 3599 & 2235 & 2912 & 30 & 2484 & 3487 & 2253 & 2869 \\
\hline 31 & 2494 & 3627 & 2233 & 2906 & 31 & 2485 & 3490 & 2241 & 2838 \\
\hline 32 & 2494 & 3627 & 2227 & 2892 & 32 & 2479 & 3473 & 2227 & 2802 \\
\hline 33 & 2489 & 3612 & 2234 & 2910 & 33 & 2472 & 3452 & 2229 & 2808 \\
\hline 34 & 2521 & 3706 & 2243 & 2932 & 34 & 2435 & 3351 & 2243 & 2842 \\
\hline 35 & 2545 & 3775 & 2264 & 2989 & 35 & 2465 & 3434 & 2242 & 2840 \\
\hline 36 & 2527 & 3723 & 2265 & 2991 & 36 & 2493 & 3510 & 2222 & 2788 \\
\hline 37 & 2521 & 3707 & 2255 & 2964 & 37 & 2458 & 3414 & 2241 & 2838 \\
\hline 38 & 2525 & 3716 & 2236 & 2916 & 38 & 2467 & 3440 & 2220 & 2785 \\
\hline 39 & 2522 & 3708 & 2219 & 2870 & 39 & 2493 & 3512 & 2213 & 2766 \\
\hline 40 & 2521 & 3707 & 2221 & 2875 & 40 & 2502 & 3536 & 2243 & 2842 \\
\hline 41 & 2475 & 3570 & 2206 & 2838 & 41 & 2476 & 3463 & 2211 & 2762 \\
\hline 42 & 2438 & 3466 & 2195 & 2808 & 42 & 2459 & 3416 & 2197 & 2728 \\
\hline 43 & 2451 & 3502 & 2193 & 2805 & 43 & 2462 & 3425 & 2215 & 2771 \\
\hline 44 & 2452 & 3504 & 2201 & 2826 & 44 & 2466 & 3437 & 2221 & 2787 \\
\hline 45 & 2449 & 3497 & 2199 & 2820 & 45 & 2475 & 3461 & 2227 & 2802 \\
\hline 46 & 2451 & 3502 & 2182 & 2775 & 46 & 2495 & 3516 & 2233 & 2818 \\
\hline 47 & 2430 & 3443 & 2198 & 2817 & 47 & 2494 & 3513 & 2219 & 2781 \\
\hline 48 & 2420 & 3415 & 2195 & 2808 & 48 & 2470 & 3447 & 2209 & 2757 \\
\hline
\end{tabular}


Tabela C33 - Valores de V e C para os painéis 15 e 16, através dos métodos de ultrasom e stress wave, na direção transversal de propagação

\begin{tabular}{|c|c|c|c|c|c|c|c|c|c|}
\hline Ponto & $\begin{array}{c}\begin{array}{c}V_{\text {Us }} \\
(\mathrm{m} / \mathrm{s})\end{array} \\
\end{array}$ & $\begin{array}{c}\mathrm{C}_{\text {Us }} \\
(\mathrm{MPa})\end{array}$ & $\begin{array}{c}V_{\mathrm{SW}} \\
(\mathrm{m} / \mathrm{s}) \\
\end{array}$ & $\begin{array}{c}\mathrm{C}_{\mathrm{sw}} \\
(\mathrm{MPa})\end{array}$ & Ponto & $\begin{array}{c}\begin{array}{c}V_{\text {Us }} \\
(\mathrm{m} / \mathrm{s})\end{array} \\
\end{array}$ & $\begin{array}{c}\mathrm{C}_{\text {Us }} \\
(\mathrm{MPa})\end{array}$ & $\begin{array}{c}V_{\mathrm{sw}} \\
(\mathrm{m} / \mathrm{s}) \\
\end{array}$ & $\begin{array}{c}C_{\text {sw }} \\
(\mathrm{MPa}) \\
\end{array}$ \\
\hline$\overline{\overline{1} 1}$ & 2445 & 3552 & 2206 & 2890 & $\overline{\overline{1} 1}$ & 2461 & 3386 & 2239 & 2803 \\
\hline 2 & 2443 & 3546 & 2214 & 2911 & 2 & 2442 & 3335 & 2224 & 2766 \\
\hline 3 & 2449 & 3561 & 2217 & 2920 & 3 & 2459 & 3381 & 2229 & 2776 \\
\hline 4 & 2476 & 3642 & 2226 & 2944 & 4 & 2479 & 3435 & 2226 & 2769 \\
\hline 5 & 2506 & 3729 & 2264 & 3045 & 5 & 2437 & 3319 & 2190 & 2681 \\
\hline 6 & 2505 & 3728 & 2278 & 3082 & 6 & 2436 & 3318 & 2189 & 2679 \\
\hline 7 & 2469 & 3621 & 2215 & 2913 & 7 & 2476 & 3427 & 2204 & 2714 \\
\hline 8 & 2459 & 3591 & 2191 & 2852 & 8 & 2481 & 3441 & 2205 & 2718 \\
\hline 9 & 2483 & 3662 & 2201 & 2879 & 9 & 2481 & 3442 & 2219 & 2754 \\
\hline 10 & 2457 & 3586 & 2195 & 2861 & 10 & 2460 & 3382 & 2187 & 2673 \\
\hline 11 & 2468 & 3618 & 2216 & 2917 & 11 & 2415 & 3261 & 2164 & 2617 \\
\hline 12 & 2505 & 3729 & 2237 & 2972 & 12 & 2413 & 3255 & 2189 & 2679 \\
\hline 13 & 2495 & 3697 & 2236 & 2969 & 13 & 2451 & 3358 & 2218 & 2750 \\
\hline 14 & 2474 & 3637 & 2209 & 2899 & 14 & 2485 & 3453 & 2250 & 2831 \\
\hline 15 & 2482 & 3661 & 2159 & 2769 & 15 & 2486 & 3455 & 2253 & 2837 \\
\hline 16 & 2474 & 3635 & 2147 & 2737 & 16 & 2488 & 3460 & 2222 & 2760 \\
\hline 17 & 2451 & 3567 & 2206 & 2891 & 17 & 2505 & 3508 & 2237 & 2797 \\
\hline 18 & 2486 & 3673 & 2245 & 2995 & 18 & 2531 & 3581 & 2246 & 2820 \\
\hline 19 & 2510 & 3743 & 2248 & 3003 & 19 & 2521 & 3554 & 2236 & 2794 \\
\hline 20 & 2503 & 3722 & 2253 & 3014 & 20 & 2478 & 3433 & 2241 & 2808 \\
\hline 21 & 2460 & 3594 & 2243 & 2987 & 21 & 2453 & 3364 & 2201 & 2708 \\
\hline 22 & 2447 & 3557 & 2223 & 2935 & 22 & 2445 & 3341 & 2203 & 2713 \\
\hline 23 & 2476 & 3641 & 2199 & 2872 & 23 & 2450 & 3355 & 2244 & 2815 \\
\hline 24 & 2515 & 3756 & 2197 & 2866 & 24 & 2494 & 3476 & 2263 & 2864 \\
\hline 25 & 2532 & 3809 & 2208 & 2895 & 25 & 2520 & 3550 & 2248 & 2826 \\
\hline 26 & 2506 & 3730 & 2202 & 2881 & 26 & 2511 & 3525 & 2248 & 2824 \\
\hline 27 & 2523 & 3782 & 2208 & 2895 & 27 & 2519 & 3547 & 2266 & 2869 \\
\hline 28 & 2548 & 3857 & 2233 & 2961 & 28 & 2528 & 3572 & 2264 & 2866 \\
\hline 29 & 2513 & 3751 & 2263 & 3041 & 29 & 2540 & 3607 & 2252 & 2835 \\
\hline 30 & 2472 & 3629 & 2236 & 2969 & 30 & 2520 & 3551 & 2234 & 2790 \\
\hline 31 & 2470 & 3625 & 2196 & 2865 & 31 & 2495 & 3480 & 2238 & 2799 \\
\hline 32 & 2477 & 3644 & 2182 & 2828 & 32 & 2506 & 3512 & 2230 & 2780 \\
\hline 33 & 2460 & 3595 & 2166 & 2788 & 33 & 2534 & 3589 & 2218 & 2750 \\
\hline 34 & 2419 & 3476 & 2191 & 2850 & 34 & 2506 & 3512 & 2230 & 2780 \\
\hline 35 & 2419 & 3475 & 2219 & 2926 & 35 & 2462 & 3388 & 2236 & 2794 \\
\hline 36 & 2444 & 3547 & 2225 & 2941 & 36 & 2446 & 3343 & 2220 & 2755 \\
\hline 37 & 2471 & 3626 & 2238 & 2976 & 37 & 2435 & 3313 & 2209 & 2728 \\
\hline 38 & 2516 & 3760 & 2254 & 3018 & 38 & 2469 & 3407 & 2213 & 2738 \\
\hline 39 & 2528 & 3798 & 2297 & 3135 & 39 & 2489 & 3463 & 2226 & 2771 \\
\hline 40 & 2482 & 3660 & 2302 & 3149 & 40 & 2459 & 3381 & 2215 & 2743 \\
\hline 41 & 2504 & 3725 & 2266 & 3049 & 41 & 2457 & 3374 & 2182 & 2663 \\
\hline 42 & 2542 & 3838 & 2243 & 2989 & 42 & 2449 & 3352 & 2182 & 2663 \\
\hline 43 & 2531 & 3805 & 2248 & 3001 & 43 & 2441 & 3331 & 2192 & 2686 \\
\hline 44 & 2546 & 3851 & 2270 & 3061 & 44 & 2435 & 3315 & 2199 & 2703 \\
\hline 45 & 2531 & 3805 & 2264 & 3045 & 45 & 2403 & 3229 & 2219 & 2752 \\
\hline 46 & 2486 & 3672 & 2264 & 3045 & 46 & 2407 & 3237 & 2218 & 2750 \\
\hline 47 & 2477 & 3645 & 2282 & 3094 & 47 & 2424 & 3285 & 2216 & 2745 \\
\hline 48 & 2470 & 3624 & 2281 & 3090 & 48 & 2451 & 3358 & 2214 & 2740 \\
\hline
\end{tabular}


Tabela C34 - Valores de V e C para os painéis 17 e 18, através dos métodos de ultrasom e stress wave, na direção transversal de propagação

\begin{tabular}{|c|c|c|c|c|c|c|c|c|c|}
\hline Ponto & $\begin{array}{c}\begin{array}{c}V_{\text {Us }} \\
(\mathrm{m} / \mathrm{s})\end{array} \\
\end{array}$ & $\begin{array}{c}\mathrm{C}_{\mathrm{US}} \\
(\mathrm{MPa})\end{array}$ & $\begin{array}{c}V_{\mathrm{SW}} \\
(\mathrm{m} / \mathrm{s}) \\
\end{array}$ & $\begin{array}{c}C_{\text {sw }} \\
(\mathrm{MPa})\end{array}$ & Ponto & $\begin{array}{c}V_{\text {Us }} \\
(\mathrm{m} / \mathrm{s}) \\
\end{array}$ & $\begin{array}{c}\mathrm{C}_{\text {Us }} \\
(\mathrm{MPa})\end{array}$ & $\begin{array}{c}V_{\mathrm{Sw}} \\
(\mathrm{m} / \mathrm{s}) \\
\end{array}$ & $\begin{array}{c}\mathrm{C}_{\mathrm{sw}} \\
(\mathrm{MPa})\end{array}$ \\
\hline$\overline{\overline{1}}$ & 2186 & 2781 & 2017 & 2368 & $\overline{\overline{1}}$ & 2462 & 3455 & 2252 & 2891 \\
\hline 2 & 2195 & 2805 & 2019 & 2373 & 2 & 2471 & 3480 & 2231 & 2836 \\
\hline 3 & 2216 & 2858 & 2021 & 2376 & 3 & 2493 & 3544 & 2217 & 2801 \\
\hline 4 & 2228 & 2889 & 2042 & 2427 & 4 & 2506 & 3580 & 2225 & 2822 \\
\hline 5 & 2246 & 2936 & 2080 & 2518 & 5 & 2483 & 3514 & 2239 & 2858 \\
\hline 6 & 2243 & 2929 & 2098 & 2563 & 6 & 2459 & 3446 & 2255 & 2898 \\
\hline 7 & 2239 & 2916 & 2073 & 2500 & 7 & 2465 & 3465 & 2256 & 2902 \\
\hline 8 & 2260 & 2972 & 2056 & 2460 & 8 & 2457 & 3442 & 2236 & 2850 \\
\hline 9 & 2261 & 2974 & 2035 & 2410 & 9 & 2405 & 3297 & 2219 & 2808 \\
\hline 10 & 2261 & 2974 & 2023 & 2383 & 10 & 2396 & 3273 & 2244 & 2870 \\
\hline 11 & 2261 & 2975 & 2050 & 2447 & 11 & 2454 & 3432 & 2255 & 2900 \\
\hline 12 & 2241 & 2922 & 2055 & 2458 & 12 & 2464 & 3461 & 2250 & 2887 \\
\hline 13 & 2234 & 2905 & 2045 & 2434 & 13 & 2476 & 3494 & 2258 & 2905 \\
\hline 14 & 2211 & 2846 & 2034 & 2409 & 14 & 2521 & 3622 & 2255 & 2898 \\
\hline 15 & 2232 & 2900 & 2044 & 2433 & 15 & 2521 & 3622 & 2258 & 2905 \\
\hline 16 & 2264 & 2982 & 2073 & 2502 & 16 & 2501 & 3564 & 2255 & 2898 \\
\hline 17 & 2256 & 2962 & 2085 & 2530 & 17 & 2493 & 3543 & 2237 & 2852 \\
\hline 18 & 2247 & 2938 & 2090 & 2542 & 18 & 2513 & 3600 & 2219 & 2806 \\
\hline 19 & 2217 & 2861 & 2085 & 2530 & 19 & 2513 & 3600 & 2217 & 2802 \\
\hline 20 & 2226 & 2885 & 2083 & 2525 & 20 & 2486 & 3524 & 2224 & 2818 \\
\hline 21 & 2226 & 2885 & 2085 & 2531 & 21 & 2477 & 3496 & 2217 & 2802 \\
\hline 22 & 2224 & 2880 & 2062 & 2475 & 22 & 2483 & 3515 & 2197 & 2751 \\
\hline 23 & 2226 & 2884 & 2023 & 2382 & 23 & 2475 & 3491 & 2194 & 2744 \\
\hline 24 & 2212 & 2848 & 1999 & 2325 & 24 & 2457 & 3441 & 2205 & 2771 \\
\hline 25 & 2205 & 2830 & 2006 & 2343 & 25 & 2472 & 3482 & 2217 & 2802 \\
\hline 26 & 2205 & 2830 & 2003 & 2336 & 26 & 2488 & 3528 & 2250 & 2885 \\
\hline 27 & 2198 & 2811 & 2007 & 2345 & 27 & 2484 & 3518 & 2238 & 2856 \\
\hline 28 & 2203 & 2824 & 2052 & 2450 & 28 & 2513 & 3601 & 2229 & 2831 \\
\hline 29 & 2231 & 2898 & 2092 & 2548 & 29 & 2540 & 3678 & 2254 & 2896 \\
\hline 30 & 2247 & 2939 & 2066 & 2484 & 30 & 2524 & 3630 & 2245 & 2874 \\
\hline 31 & 2245 & 2933 & 2035 & 2410 & 31 & 2514 & 3603 & 2241 & 2861 \\
\hline 32 & 2233 & 2901 & 2026 & 2388 & 32 & 2493 & 3543 & 2236 & 2850 \\
\hline 33 & 2227 & 2886 & 2009 & 2348 & 33 & 2472 & 3484 & 2217 & 2802 \\
\hline 34 & 2216 & 2857 & 2015 & 2363 & 34 & 2464 & 3461 & 2211 & 2787 \\
\hline 35 & 2213 & 2851 & 2009 & 2348 & 35 & 2431 & 3370 & 2210 & 2785 \\
\hline 36 & 2202 & 2821 & 2010 & 2351 & 36 & 2399 & 3280 & 2178 & 2705 \\
\hline 37 & 2196 & 2808 & 2031 & 2401 & 37 & 2392 & 3262 & 2166 & 2674 \\
\hline 38 & 2231 & 2897 & 2032 & 2402 & 38 & 2416 & 3328 & 2180 & 2710 \\
\hline 39 & 2233 & 2902 & 2061 & 2472 & 39 & 2477 & 3497 & 2194 & 2744 \\
\hline 40 & 2238 & 2916 & 2094 & 2552 & 40 & 2513 & 3599 & 2213 & 2790 \\
\hline 41 & 2272 & 3003 & 2097 & 2558 & 41 & 2518 & 3614 & 2216 & 2799 \\
\hline 42 & 2301 & 3082 & 2077 & 2510 & 42 & 2502 & 3568 & 2200 & 2759 \\
\hline 43 & 2315 & 3120 & 2075 & 2506 & 43 & 2465 & 3464 & 2217 & 2802 \\
\hline 44 & 2274 & 3010 & 2076 & 2509 & 44 & 2457 & 3442 & 2260 & 2911 \\
\hline 45 & 2225 & 2882 & 2052 & 2450 & 45 & 2481 & 3508 & 2255 & 2900 \\
\hline 46 & 2218 & 2864 & 2022 & 2379 & 46 & 2505 & 3576 & 2236 & 2849 \\
\hline 47 & 2220 & 2867 & 1994 & 2315 & 47 & 2496 & 3550 & 2229 & 2833 \\
\hline 48 & 2185 & 2778 & 2002 & 2333 & 48 & 2503 & 3571 & 2219 & 2808 \\
\hline
\end{tabular}


Tabela C35 - Valores de V e C para os painéis 19 e 110, através dos métodos de ultrasom e stress wave, na direção transversal de propagação

\begin{tabular}{|c|c|c|c|c|c|c|c|c|c|}
\hline Ponto & $\begin{array}{c}\begin{array}{c}V_{\text {Us }} \\
(\mathrm{m} / \mathrm{s})\end{array} \\
\end{array}$ & $\begin{array}{c}\mathrm{C}_{\text {Us }} \\
(\mathrm{MPa})\end{array}$ & $\begin{array}{c}V_{\mathrm{SW}} \\
(\mathrm{m} / \mathrm{s}) \\
\end{array}$ & $\begin{array}{c}\mathrm{C}_{\mathrm{sw}} \\
(\mathrm{MPa})\end{array}$ & Ponto & $\begin{array}{c}\begin{array}{c}V_{\text {Us }} \\
(\mathrm{m} / \mathrm{s})\end{array} \\
\end{array}$ & $\begin{array}{c}\mathrm{C}_{\text {Us }} \\
(\mathrm{MPa})\end{array}$ & $\begin{array}{c}V_{\mathrm{sw}} \\
(\mathrm{m} / \mathrm{s}) \\
\end{array}$ & $\begin{array}{c}\mathrm{C}_{\mathrm{sw}} \\
(\mathrm{MPa})\end{array}$ \\
\hline$\overline{\overline{1} 1}$ & 2440 & 3352 & 2201 & 2729 & $\overline{\overline{1} 1}$ & 2475 & 3638 & 2226 & 2944 \\
\hline 2 & 2431 & 3329 & 2190 & 2700 & 2 & 2490 & 3684 & 2248 & 3003 \\
\hline 3 & 2446 & 3369 & 2209 & 2747 & 3 & 2499 & 3710 & 2296 & 3131 \\
\hline 4 & 2466 & 3423 & 2249 & 2848 & 4 & 2501 & 3715 & 2300 & 3143 \\
\hline 5 & 2479 & 3460 & 2243 & 2832 & 5 & 2531 & 3805 & 2318 & 3192 \\
\hline 6 & 2532 & 3611 & 2225 & 2787 & 6 & 2504 & 3725 & 2331 & 3228 \\
\hline 7 & 2532 & 3610 & 2225 & 2787 & 7 & 2483 & 3664 & 2309 & 3167 \\
\hline 8 & 2476 & 3451 & 2228 & 2794 & 8 & 2483 & 3662 & 2313 & 3178 \\
\hline 9 & 2457 & 3399 & 2224 & 2785 & 9 & 2457 & 3586 & 2296 & 3133 \\
\hline 10 & 2449 & 3377 & 2211 & 2753 & 10 & 2476 & 3641 & 2254 & 3018 \\
\hline 11 & 2423 & 3305 & 2204 & 2734 & 11 & 2461 & 3597 & 2204 & 2884 \\
\hline 12 & 2408 & 3266 & 2182 & 2680 & 12 & 2418 & 3474 & 2217 & 2920 \\
\hline 13 & 2424 & 3307 & 2155 & 2615 & 13 & 2457 & 3587 & 2242 & 2986 \\
\hline 14 & 2438 & 3347 & 2170 & 2652 & 14 & 2485 & 3670 & 2244 & 2991 \\
\hline 15 & 2440 & 3351 & 2212 & 2754 & 15 & 2463 & 3602 & 2263 & 3043 \\
\hline 16 & 2449 & 3377 & 2219 & 2772 & 16 & 2453 & 3576 & 2260 & 3033 \\
\hline 17 & 2460 & 3408 & 2208 & 2746 & 17 & 2442 & 3543 & 2278 & 3082 \\
\hline 18 & 2471 & 3437 & 2229 & 2798 & 18 & 2451 & 3568 & 2235 & 2967 \\
\hline 19 & 2501 & 3522 & 2219 & 2773 & 19 & 2462 & 3600 & 2203 & 2882 \\
\hline 20 & 2479 & 3460 & 2208 & 2746 & 20 & 2479 & 3650 & 2233 & 2963 \\
\hline 21 & 2483 & 3472 & 2217 & 2768 & 21 & 2514 & 3755 & 2241 & 2982 \\
\hline 22 & 2514 & 3559 & 2234 & 2810 & 22 & 2539 & 3829 & 2305 & 3157 \\
\hline 23 & 2510 & 3546 & 2286 & 2942 & 23 & 2540 & 3831 & 2310 & 3170 \\
\hline 24 & 2528 & 3597 & 2253 & 2859 & 24 & 2496 & 3700 & 2267 & 3053 \\
\hline 25 & 2532 & 3611 & 2222 & 2779 & 25 & 2493 & 3691 & 2248 & 3001 \\
\hline 26 & 2539 & 3630 & 2231 & 2803 & 26 & 2518 & 3766 & 2227 & 2946 \\
\hline 27 & 2517 & 3568 & 2229 & 2796 & 27 & 2450 & 3565 & 2224 & 2939 \\
\hline 28 & 2507 & 3539 & 2237 & 2817 & 28 & 2410 & 3450 & 2206 & 2890 \\
\hline 29 & 2502 & 3524 & 2192 & 2705 & 29 & 2410 & 3451 & 2183 & 2831 \\
\hline 30 & 2479 & 3459 & 2208 & 2746 & 30 & 2428 & 3501 & 2196 & 2865 \\
\hline 31 & 2436 & 3341 & 2258 & 2871 & 31 & 2470 & 3624 & 2213 & 2910 \\
\hline 32 & 2375 & 3176 & 2236 & 2814 & 32 & 2474 & 3637 & 2212 & 2906 \\
\hline 33 & 2413 & 3279 & 2221 & 2777 & 33 & 2481 & 3657 & 2183 & 2831 \\
\hline 34 & 2416 & 3286 & 2219 & 2773 & 34 & 2500 & 3713 & 2180 & 2822 \\
\hline 35 & 2336 & 3073 & 2187 & 2693 & 35 & 2500 & 3713 & 2219 & 2924 \\
\hline 36 & 2352 & 3115 & 2168 & 2647 & 36 & 2477 & 3643 & 2238 & 2976 \\
\hline 37 & 2417 & 3288 & 2180 & 2675 & 37 & 2460 & 3594 & 2244 & 2991 \\
\hline 38 & 2433 & 3334 & 2202 & 2730 & 38 & 2478 & 3646 & 2185 & 2836 \\
\hline 39 & 2428 & 3319 & 2215 & 2761 & 39 & 2470 & 3623 & 2169 & 2795 \\
\hline 40 & 2409 & 3268 & 2195 & 2712 & 40 & 2458 & 3588 & 2195 & 2863 \\
\hline 41 & 2429 & 3322 & 2179 & 2673 & 41 & 2458 & 3589 & 2202 & 2881 \\
\hline 42 & 2453 & 3386 & 2191 & 2703 & 42 & 2453 & 3574 & 2207 & 2893 \\
\hline 43 & 2449 & 3377 & 2212 & 2754 & 43 & 2453 & 3576 & 2197 & 2868 \\
\hline 44 & 2451 & 3383 & 2222 & 2780 & 44 & 2442 & 3542 & 2194 & 2859 \\
\hline 45 & 2476 & 3452 & 2243 & 2833 & 45 & 2413 & 3459 & 2181 & 2826 \\
\hline 46 & 2503 & 3527 & 2267 & 2894 & 46 & 2403 & 3430 & 2189 & 2847 \\
\hline 47 & 2491 & 3492 & 2253 & 2857 & 47 & 2419 & 3477 & 2209 & 2899 \\
\hline 48 & 2458 & 3402 & 2191 & 2703 & 48 & 2425 & 3492 & 2224 & 2937 \\
\hline
\end{tabular}


Tabela C36 - Valores de V e C para os painéis 21 e 22, através dos métodos de ultrasom e stress wave, na direção transversal de propagação

\begin{tabular}{|c|c|c|c|c|c|c|c|c|c|}
\hline Ponto & $\begin{array}{c}\begin{array}{c}V_{\text {Us }} \\
(\mathrm{m} / \mathrm{s})\end{array} \\
\end{array}$ & $\begin{array}{c}\mathrm{C}_{\text {Us }} \\
(\mathrm{MPa})\end{array}$ & $\begin{array}{c}V_{\mathrm{SW}} \\
(\mathrm{m} / \mathrm{s}) \\
\end{array}$ & $\begin{array}{c}\mathrm{C}_{\mathrm{sw}} \\
(\mathrm{MPa})\end{array}$ & Ponto & $\begin{array}{c}\begin{array}{c}V_{\text {Us }} \\
(\mathrm{m} / \mathrm{s})\end{array} \\
\end{array}$ & $\begin{array}{c}\mathrm{C}_{\text {Us }} \\
(\mathrm{MPa})\end{array}$ & $\begin{array}{c}V_{\mathrm{sw}} \\
(\mathrm{m} / \mathrm{s}) \\
\end{array}$ & $\begin{array}{c}C_{\text {sw }} \\
(\mathrm{MPa}) \\
\end{array}$ \\
\hline$\overline{\overline{1} 1}$ & 2552 & 3874 & 2314 & 3171 & $\overline{\overline{1} 1}$ & 2514 & 3773 & 2182 & 2844 \\
\hline 2 & 2524 & 3789 & 2269 & 3046 & 2 & 2532 & 3826 & 2205 & 2902 \\
\hline 3 & 2494 & 3702 & 2219 & 2916 & 3 & 2530 & 3820 & 2237 & 2987 \\
\hline 4 & 2460 & 3602 & 2210 & 2891 & 4 & 2512 & 3767 & 2213 & 2924 \\
\hline 5 & 2434 & 3526 & 2180 & 2815 & 5 & 2483 & 3681 & 2126 & 2699 \\
\hline 6 & 2430 & 3513 & 2164 & 2773 & 6 & 2461 & 3617 & 2085 & 2596 \\
\hline 7 & 2440 & 3544 & 2175 & 2801 & 7 & 2466 & 3630 & 2133 & 2717 \\
\hline 8 & 2488 & 3684 & 2185 & 2825 & 8 & 2475 & 3656 & 2151 & 2761 \\
\hline 9 & 2510 & 3749 & 2196 & 2855 & 9 & 2505 & 3747 & 2107 & 2651 \\
\hline 10 & 2519 & 3776 & 2165 & 2775 & 10 & 2551 & 3885 & 2156 & 2775 \\
\hline 11 & 2538 & 3832 & 2167 & 2780 & 11 & 2565 & 3927 & 2224 & 2954 \\
\hline 12 & 2506 & 3738 & 2203 & 2873 & 12 & 2559 & 3910 & 1254 & 939 \\
\hline 13 & 2484 & 3673 & 2157 & 2755 & 13 & 2588 & 3999 & 1254 & 939 \\
\hline 14 & 2488 & 3682 & 2161 & 2765 & 14 & 2589 & 4000 & 2216 & 2932 \\
\hline 15 & 2468 & 3624 & 2184 & 2823 & 15 & 2558 & 3907 & 2210 & 2917 \\
\hline 16 & 2464 & 3611 & 2187 & 2832 & 16 & 2517 & 3781 & 2157 & 2777 \\
\hline 17 & 2457 & 3593 & 2206 & 2882 & 17 & 2483 & 3681 & 2154 & 2770 \\
\hline 18 & 2482 & 3666 & 2222 & 2922 & 18 & 2485 & 3688 & 2209 & 2913 \\
\hline 19 & 2527 & 3799 & 2273 & 3058 & 19 & 2519 & 3788 & 2210 & 2917 \\
\hline 20 & 2521 & 3781 & 2242 & 2976 & 20 & 2567 & 3934 & 2208 & 2911 \\
\hline 21 & 2519 & 3774 & 2204 & 2875 & 21 & 2569 & 3941 & 2189 & 2861 \\
\hline 22 & 2531 & 3812 & 2238 & 2966 & 22 & 2578 & 3969 & 2223 & 2950 \\
\hline 23 & 2531 & 3813 & 2232 & 2949 & 23 & 2577 & 3963 & 2262 & 3055 \\
\hline 24 & 2499 & 3716 & 2196 & 2855 & 24 & 2540 & 3852 & 2238 & 2991 \\
\hline 25 & 2457 & 3593 & 2201 & 2869 & 25 & 2524 & 3803 & 2168 & 2807 \\
\hline 26 & 2453 & 3580 & 2199 & 2862 & 26 & 2512 & 3766 & 2161 & 2787 \\
\hline 27 & 2460 & 3600 & 2189 & 2837 & 27 & 2509 & 3759 & 2168 & 2805 \\
\hline 28 & 2477 & 3650 & 2210 & 2891 & 28 & 2499 & 3727 & 1095 & 716 \\
\hline 29 & 2511 & 3751 & 2249 & 2994 & 29 & 2510 & 3762 & 755 & 340 \\
\hline 30 & 2529 & 3806 & 2274 & 3062 & 30 & 2558 & 3905 & 1149 & 788 \\
\hline 31 & 2522 & 3784 & 2252 & 3002 & 31 & 2574 & 3957 & 2227 & 2961 \\
\hline 32 & 2503 & 3727 & 2220 & 2918 & 32 & 2584 & 3988 & 2224 & 2952 \\
\hline 33 & 2502 & 3724 & 2208 & 2887 & 33 & 2603 & 4046 & 2231 & 2970 \\
\hline 34 & 2476 & 3648 & 2209 & 2889 & 34 & 2574 & 3957 & 2217 & 2933 \\
\hline 35 & 2434 & 3524 & 2222 & 2922 & 35 & 2492 & 3708 & 2208 & 2911 \\
\hline 36 & 2426 & 3501 & 2245 & 2983 & 36 & 2455 & 3597 & 1557 & 1448 \\
\hline 37 & 2451 & 3574 & 2189 & 2836 & 37 & 2455 & 3597 & 1526 & 1390 \\
\hline 38 & 2501 & 3721 & 2155 & 2750 & 38 & 2449 & 3581 & 2112 & 2663 \\
\hline 39 & 2537 & 3829 & 2212 & 2896 & 39 & 2466 & 3632 & 2120 & 2683 \\
\hline 40 & 2567 & 3921 & 2231 & 2947 & 40 & 2484 & 3683 & 2098 & 2629 \\
\hline 41 & 2607 & 4044 & 2222 & 2922 & 41 & 2466 & 3631 & 2096 & 2623 \\
\hline 42 & 2598 & 4017 & 2239 & 2968 & 42 & 2494 & 3712 & 2155 & 2773 \\
\hline 43 & 2558 & 3894 & 2252 & 3002 & 43 & 2527 & 3814 & 2205 & 2902 \\
\hline 44 & 2512 & 3756 & 2241 & 2974 & 44 & 2507 & 3752 & 2203 & 2897 \\
\hline 45 & 2480 & 3659 & 2275 & 3064 & 45 & 2485 & 3687 & 2219 & 2939 \\
\hline 46 & 2462 & 3608 & 2239 & 2968 & 46 & 2459 & 3611 & 2199 & 2886 \\
\hline 47 & 2451 & 3574 & 2212 & 2896 & 47 & 2434 & 3536 & 2144 & 2743 \\
\hline 48 & 2447 & 3562 & 2210 & 2891 & 48 & 2417 & 3488 & 2134 & 2718 \\
\hline
\end{tabular}


Tabela C37 - Valores de V e C para os painéis 23 e 24, através dos métodos de ultrasom e stress wave, na direção transversal de propagação

\begin{tabular}{|c|c|c|c|c|c|c|c|c|c|}
\hline Ponto & $\begin{array}{c}\begin{array}{c}V_{\text {Us }} \\
(\mathrm{m} / \mathrm{s})\end{array} \\
\end{array}$ & $\begin{array}{c}\mathrm{C}_{\text {Us }} \\
(\mathrm{MPa})\end{array}$ & $\begin{array}{c}V_{\mathrm{SW}} \\
(\mathrm{m} / \mathrm{s}) \\
\end{array}$ & $\begin{array}{c}\mathrm{C}_{\mathrm{sw}} \\
(\mathrm{MPa})\end{array}$ & Ponto & $\begin{array}{c}\begin{array}{c}V_{\text {Us }} \\
(\mathrm{m} / \mathrm{s})\end{array} \\
\end{array}$ & $\begin{array}{c}\mathrm{C}_{\text {Us }} \\
(\mathrm{MPa})\end{array}$ & $\begin{array}{c}V_{\mathrm{sw}} \\
(\mathrm{m} / \mathrm{s}) \\
\end{array}$ & $\begin{array}{c}\mathrm{C}_{\mathrm{sw}} \\
(\mathrm{MPa})\end{array}$ \\
\hline$\overline{\overline{1} 1}$ & 2546 & 3910 & 2278 & 3129 & $\overline{\overline{1} 1}$ & 2475 & 3864 & 2222 & 3116 \\
\hline 2 & 2527 & 3852 & 2253 & 3060 & 2 & 2465 & 3835 & 2227 & 3130 \\
\hline 3 & 2516 & 3817 & 2240 & 3025 & 3 & 2457 & 3810 & 2247 & 3186 \\
\hline 4 & 2550 & 3922 & 2224 & 2982 & 4 & 2477 & 3870 & 2258 & 3216 \\
\hline 5 & 2574 & 3995 & 2166 & 2830 & 5 & 2514 & 3988 & 2249 & 3192 \\
\hline 6 & 2542 & 3895 & 2188 & 2886 & 6 & 2551 & 4105 & 2238 & 3162 \\
\hline 7 & 2501 & 3771 & 2221 & 2974 & 7 & 2577 & 4189 & 2229 & 3136 \\
\hline 8 & 2457 & 3639 & 2204 & 2928 & 8 & 2565 & 4151 & 2229 & 3136 \\
\hline 9 & 2449 & 3617 & 2192 & 2897 & 9 & 2521 & 4010 & 2227 & 3130 \\
\hline 10 & 2489 & 3737 & 2190 & 2892 & 10 & 2515 & 3990 & 2236 & 3154 \\
\hline 11 & 2511 & 3801 & 2197 & 2910 & 11 & 2501 & 3947 & 2230 & 3138 \\
\hline 12 & 2524 & 3840 & 2210 & 2946 & 12 & 2455 & 3804 & 2201 & 3056 \\
\hline 13 & 2542 & 3897 & 2226 & 2987 & 13 & 2457 & 3811 & 2177 & 2991 \\
\hline 14 & 2561 & 3955 & 2263 & 3087 & 14 & 2487 & 3902 & 2192 & 3032 \\
\hline 15 & 2574 & 3996 & 2270 & 3107 & 15 & 2532 & 4046 & 2241 & 3170 \\
\hline 16 & 2572 & 3990 & 2258 & 3075 & 16 & 2566 & 4154 & 2243 & 3174 \\
\hline 17 & 2546 & 3908 & 2285 & 3147 & 17 & 2572 & 4176 & 2226 & 3128 \\
\hline 18 & 2512 & 3806 & 2253 & 3060 & 18 & 2565 & 4150 & 2246 & 3184 \\
\hline 19 & 2469 & 3676 & 2206 & 2935 & 19 & 2548 & 4098 & 2200 & 3054 \\
\hline 20 & 2459 & 3647 & 2205 & 2932 & 20 & 2526 & 4026 & 2132 & 2868 \\
\hline 21 & 2494 & 3751 & 2208 & 2941 & 21 & 2484 & 3893 & 2173 & 2980 \\
\hline 22 & 2509 & 3797 & 2226 & 2989 & 22 & 2460 & 3819 & 2218 & 3104 \\
\hline 23 & 2529 & 3858 & 2263 & 3089 & 23 & 2477 & 3870 & 2215 & 3095 \\
\hline 24 & 2557 & 3941 & 2236 & 3014 & 24 & 2505 & 3961 & 2215 & 3097 \\
\hline 25 & 2567 & 3973 & 2244 & 3037 & 25 & 2531 & 4041 & 2223 & 3118 \\
\hline 26 & 2577 & 4004 & 2249 & 3050 & 26 & 2549 & 4100 & 2260 & 3222 \\
\hline 27 & 2574 & 3994 & 2309 & 3215 & 27 & 2568 & 4161 & 2265 & 3237 \\
\hline 28 & 2557 & 3942 & 2325 & 3260 & 28 & 2594 & 4246 & 2253 & 3204 \\
\hline 29 & 2514 & 3812 & 2221 & 2974 & 29 & 2565 & 4152 & 2239 & 3164 \\
\hline 30 & 2474 & 3692 & 2166 & 2830 & 30 & 2521 & 4010 & 2159 & 2940 \\
\hline 31 & 2475 & 3693 & 2164 & 2825 & 31 & 2488 & 3906 & 2168 & 2967 \\
\hline 32 & 2506 & 3786 & 2212 & 2950 & 32 & 2453 & 3797 & 2220 & 3110 \\
\hline 33 & 2548 & 3915 & 2233 & 3006 & 33 & 2444 & 3769 & 2213 & 3091 \\
\hline 34 & 2592 & 4053 & 2238 & 3019 & 34 & 2476 & 3868 & 2218 & 3104 \\
\hline 35 & 2632 & 4179 & 2241 & 3027 & 35 & 2536 & 4058 & 2214 & 3093 \\
\hline 36 & 2626 & 4157 & 2256 & 3070 & 36 & 2574 & 4179 & 2217 & 3100 \\
\hline 37 & 2587 & 4036 & 2253 & 3060 & 37 & 2567 & 4157 & 2230 & 3138 \\
\hline 38 & 2540 & 3891 & 2178 & 2862 & 38 & 2557 & 4124 & 2268 & 3245 \\
\hline 39 & 2510 & 3798 & 2168 & 2834 & 39 & 2527 & 4030 & 2288 & 3304 \\
\hline 40 & 2499 & 3766 & 2217 & 2965 & 40 & 2504 & 3955 & 2187 & 3019 \\
\hline 41 & 2504 & 3780 & 2215 & 2957 & 41 & 2489 & 3908 & 2151 & 2920 \\
\hline 42 & 2521 & 3834 & 2209 & 2943 & 42 & 2451 & 3792 & 2209 & 3079 \\
\hline 43 & 2544 & 3903 & 2224 & 2983 & 43 & 2434 & 3739 & 2206 & 3072 \\
\hline 44 & 2556 & 3940 & 2279 & 3131 & 44 & 2436 & 3744 & 2180 & 2998 \\
\hline 45 & 2565 & 3967 & 2256 & 3070 & 45 & 2461 & 3823 & 2191 & 3028 \\
\hline 46 & 2591 & 4047 & 2218 & 2967 & 46 & 2486 & 3900 & 2241 & 3168 \\
\hline 47 & 2577 & 4003 & 2241 & 3029 & 47 & 2501 & 3945 & 2249 & 3192 \\
\hline 48 & 2531 & 3864 & 2256 & 3070 & 48 & 2519 & 4003 & 2250 & 3194 \\
\hline
\end{tabular}


Tabela C38 - Valores de V e C para os painéis 25 e 26, através dos métodos de ultrasom e stress wave, na direção transversal de propagação

\begin{tabular}{|c|c|c|c|c|c|c|c|c|c|}
\hline Ponto & $\begin{array}{c}\begin{array}{c}V_{\text {Us }} \\
(\mathrm{m} / \mathrm{s})\end{array} \\
\end{array}$ & $\begin{array}{c}\mathrm{C}_{\text {Us }} \\
(\mathrm{MPa})\end{array}$ & $\begin{array}{c}V_{\mathrm{SW}} \\
(\mathrm{m} / \mathrm{s}) \\
\end{array}$ & $\begin{array}{c}\mathrm{C}_{\mathrm{sw}} \\
(\mathrm{MPa})\end{array}$ & Ponto & $\begin{array}{c}\begin{array}{c}V_{\text {Us }} \\
(\mathrm{m} / \mathrm{s})\end{array} \\
\end{array}$ & $\begin{array}{c}\mathrm{C}_{\text {Us }} \\
(\mathrm{MPa})\end{array}$ & $\begin{array}{c}V_{\mathrm{sw}} \\
(\mathrm{m} / \mathrm{s}) \\
\end{array}$ & $\begin{array}{c}\mathrm{C}_{\mathrm{sw}} \\
(\mathrm{MPa})\end{array}$ \\
\hline$\overline{\overline{1} 1}$ & 2479 & 3632 & 2248 & 2986 & $\overline{\overline{1} 1}$ & 2542 & 3832 & 2305 & 3150 \\
\hline 2 & 2471 & 3607 & 2248 & 2986 & 2 & 2546 & 3845 & 2302 & 3144 \\
\hline 3 & 2453 & 3557 & 2228 & 2933 & 3 & 2533 & 3804 & 2268 & 3050 \\
\hline 4 & 2444 & 3531 & 2176 & 2800 & 4 & 2478 & 3640 & 2217 & 2916 \\
\hline 5 & 2418 & 3457 & 2176 & 2798 & 5 & 2452 & 3565 & 2155 & 2755 \\
\hline 6 & 2409 & 3429 & 2213 & 2895 & 6 & 2466 & 3607 & 2134 & 2702 \\
\hline 7 & 2469 & 3602 & 2172 & 2788 & 7 & 2473 & 3626 & 2216 & 2912 \\
\hline 8 & 2512 & 3729 & 2171 & 2786 & 8 & 2477 & 3640 & 2255 & 3015 \\
\hline 9 & 2527 & 3775 & 2224 & 2924 & 9 & 2494 & 3688 & 2228 & 2943 \\
\hline 10 & 2530 & 3783 & 2218 & 2908 & 10 & 2544 & 3838 & 2257 & 3021 \\
\hline 11 & 2503 & 3704 & 2229 & 2935 & 11 & 2565 & 3903 & 2185 & 2830 \\
\hline 12 & 2484 & 3646 & 2231 & 2941 & 12 & 2532 & 3801 & 2191 & 2847 \\
\hline 13 & 2443 & 3526 & 2209 & 2884 & 13 & 2514 & 3748 & 2291 & 3113 \\
\hline 14 & 2426 & 3479 & 2207 & 2879 & 14 & 2515 & 3751 & 2236 & 2964 \\
\hline 15 & 2449 & 3545 & 2191 & 2838 & 15 & 2515 & 3751 & 2210 & 2897 \\
\hline 16 & 2483 & 3643 & 2218 & 2908 & 16 & 2496 & 3695 & 2210 & 2897 \\
\hline 17 & 2519 & 3750 & 2250 & 2993 & 17 & 2469 & 3615 & 2195 & 2858 \\
\hline 18 & 2556 & 3860 & 2260 & 3018 & 18 & 2469 & 3615 & 2243 & 2984 \\
\hline 19 & 2600 & 3996 & 2327 & 3201 & 19 & 2519 & 3763 & 2296 & 3125 \\
\hline 20 & 2594 & 3976 & 2332 & 3214 & 20 & 2565 & 3902 & 2315 & 3179 \\
\hline 21 & 2548 & 3835 & 2301 & 3129 & 21 & 2584 & 3958 & 2311 & 3166 \\
\hline 22 & 2533 & 3793 & 2264 & 3030 & 22 & 2581 & 3949 & 2315 & 3179 \\
\hline 23 & 2510 & 3722 & 2229 & 2937 & 23 & 2566 & 3905 & 2324 & 3202 \\
\hline 24 & 2485 & 3650 & 2220 & 2913 & 24 & 2569 & 3914 & 2291 & 3113 \\
\hline 25 & 2485 & 3650 & 2215 & 2900 & 25 & 2550 & 3857 & 2229 & 2947 \\
\hline 26 & 2485 & 3650 & 2233 & 2946 & 26 & 2501 & 3710 & 2200 & 2870 \\
\hline 27 & 2512 & 3730 & 2239 & 2963 & 27 & 2482 & 3652 & 2205 & 2883 \\
\hline 28 & 2556 & 3862 & 2265 & 3032 & 28 & 2500 & 3706 & 2204 & 2881 \\
\hline 29 & 2580 & 3934 & 2283 & 3081 & 29 & 2527 & 3786 & 2238 & 2969 \\
\hline 30 & 2562 & 3880 & 2276 & 3061 & 30 & 2544 & 3839 & 2254 & 3013 \\
\hline 31 & 2575 & 3920 & 2274 & 3057 & 31 & 2561 & 3891 & 2236 & 2966 \\
\hline 32 & 2569 & 3901 & 2263 & 3028 & 32 & 2575 & 3933 & 2245 & 2990 \\
\hline 33 & 2518 & 3747 & 2246 & 2982 & 33 & 2551 & 3860 & 2293 & 3119 \\
\hline 34 & 2500 & 3693 & 2245 & 2980 & 34 & 2540 & 3826 & 2285 & 3095 \\
\hline 35 & 2504 & 3706 & 2246 & 2982 & 35 & 2531 & 3800 & 2241 & 2979 \\
\hline 36 & 2503 & 3704 & 2233 & 2948 & 36 & 2512 & 3741 & 2237 & 2967 \\
\hline 37 & 2502 & 3700 & 2222 & 2917 & 37 & 2500 & 3707 & 2233 & 2958 \\
\hline 38 & 2521 & 3757 & 2215 & 2898 & 38 & 2499 & 3702 & 2203 & 2878 \\
\hline 39 & 2540 & 3812 & 2254 & 3003 & 39 & 2510 & 3736 & 2144 & 2725 \\
\hline 40 & 2582 & 3941 & 2316 & 3170 & 40 & 2542 & 3833 & 2168 & 2788 \\
\hline 41 & 2620 & 4058 & 2287 & 3091 & 41 & 2560 & 3887 & 2226 & 2939 \\
\hline 42 & 2566 & 3891 & 2233 & 2948 & 42 & 2550 & 3856 & 2182 & 2823 \\
\hline 43 & 2503 & 3703 & 2210 & 2888 & 43 & 2537 & 3818 & 2183 & 2826 \\
\hline 44 & 2448 & 3543 & 2190 & 2834 & 44 & 2511 & 3738 & 2236 & 2964 \\
\hline 45 & 2430 & 3491 & 2186 & 2824 & 45 & 2495 & 3690 & 2197 & 2862 \\
\hline 46 & 2447 & 3539 & 2165 & 2771 & 46 & 2477 & 3639 & 2182 & 2825 \\
\hline 47 & 2438 & 3512 & 2200 & 2861 & 47 & 2470 & 3617 & 2208 & 2892 \\
\hline 48 & 2472 & 3611 & 2265 & 3032 & 48 & 2442 & 3535 & 2214 & 2906 \\
\hline
\end{tabular}


Tabela C39 - Valores de V e C para os painéis 27 e 28, através dos métodos de ultrasom e stress wave, na direção transversal de propagação

\begin{tabular}{|c|c|c|c|c|c|c|c|c|c|}
\hline Ponto & $\begin{array}{c}\begin{array}{c}V_{\text {Us }} \\
(\mathrm{m} / \mathrm{s})\end{array} \\
\end{array}$ & $\begin{array}{c}\mathrm{C}_{\text {Us }} \\
(\mathrm{MPa})\end{array}$ & $\begin{array}{c}V_{\mathrm{SW}} \\
(\mathrm{m} / \mathrm{s}) \\
\end{array}$ & $\begin{array}{c}\mathrm{C}_{\mathrm{sw}} \\
(\mathrm{MPa})\end{array}$ & Ponto & $\begin{array}{c}\begin{array}{c}V_{\text {Us }} \\
(\mathrm{m} / \mathrm{s})\end{array} \\
\end{array}$ & $\begin{array}{c}\mathrm{C}_{\text {Us }} \\
(\mathrm{MPa})\end{array}$ & $\begin{array}{c}V_{\mathrm{sw}} \\
(\mathrm{m} / \mathrm{s}) \\
\end{array}$ & $\begin{array}{c}\mathrm{C}_{\mathrm{sw}} \\
(\mathrm{MPa})\end{array}$ \\
\hline$\overline{\overline{1} 1}$ & 2550 & 3876 & 2278 & 3093 & $\overline{\overline{1} 1}$ & 2459 & 3355 & 2252 & 2814 \\
\hline 2 & 2527 & 3807 & 2260 & 3044 & 2 & 2484 & 3424 & 2253 & 2818 \\
\hline 3 & 2528 & 3808 & 2264 & 3055 & 3 & 2530 & 3552 & 2223 & 2742 \\
\hline 4 & 2569 & 3933 & 2209 & 2908 & 4 & 2558 & 3631 & 2201 & 2690 \\
\hline 5 & 2558 & 3899 & 2132 & 2709 & 5 & 2584 & 3706 & 2185 & 2649 \\
\hline 6 & 2521 & 3789 & 2106 & 2643 & 6 & 2603 & 3760 & 2201 & 2688 \\
\hline 7 & 2503 & 3735 & 2164 & 2792 & 7 & 2600 & 3753 & 2208 & 2705 \\
\hline 8 & 2485 & 3681 & 2234 & 2975 & 8 & 2574 & 3677 & 2204 & 2697 \\
\hline 9 & 2470 & 3636 & 2217 & 2928 & 9 & 2521 & 3529 & 2206 & 2700 \\
\hline 10 & 2457 & 3598 & 2213 & 2919 & 10 & 2486 & 3430 & 2161 & 2591 \\
\hline 11 & 2498 & 3720 & 2224 & 2949 & 11 & 2453 & 3339 & 2199 & 2683 \\
\hline 12 & 2547 & 3865 & 2235 & 2977 & 12 & 2433 & 3286 & 2261 & 2838 \\
\hline 13 & 2531 & 3818 & 2197 & 2878 & 13 & 2459 & 3357 & 2247 & 2802 \\
\hline 14 & 2540 & 3846 & 2239 & 2988 & 14 & 2522 & 3530 & 2248 & 2806 \\
\hline 15 & 2568 & 3930 & 2283 & 3107 & 15 & 2574 & 3677 & 2263 & 2842 \\
\hline 16 & 2524 & 3795 & 2233 & 2973 & 16 & 2594 & 3736 & 2302 & 2942 \\
\hline 17 & 2515 & 3770 & 2216 & 2927 & 17 & 2586 & 3710 & 2326 & 3002 \\
\hline 18 & 2530 & 3815 & 2217 & 2928 & 18 & 2546 & 3597 & 2282 & 2891 \\
\hline 19 & 2503 & 3733 & 2224 & 2947 & 19 & 2526 & 3542 & 2257 & 2827 \\
\hline 20 & 2512 & 3762 & 2243 & 2999 & 20 & 2508 & 3492 & 2238 & 2781 \\
\hline 21 & 2539 & 3843 & 2255 & 3032 & 21 & 2486 & 3429 & 2217 & 2729 \\
\hline 22 & 2560 & 3906 & 2248 & 3013 & 22 & 2486 & 3429 & 2224 & 2744 \\
\hline 23 & 2587 & 3988 & 2268 & 3065 & 23 & 2510 & 3497 & 2189 & 2658 \\
\hline 24 & 2576 & 3956 & 2288 & 3121 & 24 & 2520 & 3525 & 2191 & 2663 \\
\hline 25 & 2557 & 3896 & 2281 & 3101 & 25 & 2495 & 3456 & 2250 & 2811 \\
\hline 26 & 2536 & 3834 & 2238 & 2986 & 26 & 2522 & 3529 & 2243 & 2793 \\
\hline 27 & 2474 & 3648 & 2206 & 2899 & 27 & 2538 & 3576 & 2245 & 2798 \\
\hline 28 & 2433 & 3529 & 2199 & 2883 & 28 & 2501 & 3472 & 2234 & 2770 \\
\hline 29 & 2425 & 3504 & 2178 & 2827 & 29 & 2492 & 3445 & 2216 & 2725 \\
\hline 30 & 2407 & 3452 & 2187 & 2851 & 30 & 2466 & 3375 & 2176 & 2629 \\
\hline 31 & 2439 & 3545 & 2169 & 2804 & 31 & 2430 & 3277 & 2151 & 2567 \\
\hline 32 & 2500 & 3725 & 2195 & 2872 & 32 & 2439 & 3302 & 2111 & 2473 \\
\hline 33 & 2521 & 3789 & 2273 & 3079 & 33 & 2460 & 3358 & 2131 & 2521 \\
\hline 34 & 2557 & 3897 & 2273 & 3079 & 34 & 2492 & 3446 & 2232 & 2765 \\
\hline 35 & 2586 & 3984 & 2256 & 3034 & 35 & 2537 & 3571 & 2252 & 2814 \\
\hline 36 & 2576 & 3955 & 2225 & 2951 & 36 & 2556 & 3626 & 2242 & 2790 \\
\hline 37 & 2549 & 3871 & 2189 & 2855 & 37 & 2547 & 3601 & 2250 & 2811 \\
\hline 38 & 2524 & 3796 & 2149 & 2752 & 38 & 2528 & 3546 & 2246 & 2800 \\
\hline 39 & 2494 & 3708 & 2118 & 2673 & 39 & 2500 & 3469 & 2238 & 2779 \\
\hline 40 & 2447 & 3569 & 2136 & 2720 & 40 & 2467 & 3377 & 2241 & 2788 \\
\hline 41 & 2441 & 3551 & 2229 & 2960 & 41 & 2440 & 3303 & 2222 & 2741 \\
\hline 42 & 2505 & 3740 & 2280 & 3099 & 42 & 2425 & 3265 & 2153 & 2572 \\
\hline 43 & 2559 & 3904 & 2295 & 3139 & 43 & 2435 & 3291 & 2090 & 2425 \\
\hline 44 & 2579 & 3963 & 2206 & 2901 & 44 & 2457 & 3350 & 2159 & 2586 \\
\hline 45 & 2560 & 3906 & 2111 & 2656 & 45 & 2498 & 3463 & 2232 & 2765 \\
\hline 46 & 2532 & 3822 & 2159 & 2779 & 46 & 2509 & 3493 & 2220 & 2736 \\
\hline 47 & 2524 & 3796 & 2230 & 2964 & 47 & 2508 & 3490 & 2245 & 2797 \\
\hline 48 & 2511 & 3756 & 2255 & 3032 & 48 & 2499 & 3465 & 2258 & 2831 \\
\hline
\end{tabular}


Tabela C40 - Valores de V e C para os painéis 29 e 210, através dos métodos de ultrasom e stress wave, na direção transversal de propagação

\begin{tabular}{|c|c|c|c|c|c|c|c|c|c|}
\hline Ponto & $\begin{array}{c}\begin{array}{c}V_{\text {Us }} \\
(\mathrm{m} / \mathrm{s})\end{array} \\
\end{array}$ & $\begin{array}{c}\mathrm{C}_{\text {Us }} \\
(\mathrm{MPa})\end{array}$ & $\begin{array}{c}V_{\mathrm{SW}} \\
(\mathrm{m} / \mathrm{s}) \\
\end{array}$ & $\begin{array}{c}\mathrm{C}_{\mathrm{sw}} \\
(\mathrm{MPa})\end{array}$ & Ponto & $\begin{array}{c}\begin{array}{c}V_{\text {Us }} \\
(\mathrm{m} / \mathrm{s})\end{array} \\
\end{array}$ & $\begin{array}{c}\mathrm{C}_{\text {Us }} \\
(\mathrm{MPa})\end{array}$ & $\begin{array}{c}V_{\mathrm{sw}} \\
(\mathrm{m} / \mathrm{s}) \\
\end{array}$ & $\begin{array}{c}\mathrm{C}_{\mathrm{sw}} \\
(\mathrm{MPa})\end{array}$ \\
\hline$\overline{\overline{1} 1}$ & 2411 & 3226 & 2222 & 2741 & $\overline{\overline{1} 1}$ & 2463 & 3554 & 2287 & 3065 \\
\hline 2 & 2419 & 3247 & 2215 & 2722 & 2 & 2468 & 3570 & 2279 & 3045 \\
\hline 3 & 2427 & 3269 & 2204 & 2697 & 3 & 2483 & 3613 & 2289 & 3070 \\
\hline 4 & 2461 & 3360 & 2194 & 2672 & 4 & 2482 & 3611 & 2276 & 3035 \\
\hline 5 & 2494 & 3452 & 2139 & 2539 & 5 & 2467 & 3568 & 2232 & 2919 \\
\hline 6 & 2519 & 3523 & 2203 & 2693 & 6 & 2467 & 3565 & 2222 & 2894 \\
\hline 7 & 2547 & 3600 & 2268 & 2854 & 7 & 2473 & 3584 & 2224 & 2899 \\
\hline 8 & 2545 & 3594 & 2259 & 2832 & 8 & 2486 & 3622 & 2238 & 2934 \\
\hline 9 & 2547 & 3601 & 2311 & 2965 & 9 & 2513 & 3700 & 2251 & 2970 \\
\hline 10 & 2510 & 3497 & 2264 & 2845 & 10 & 2539 & 3779 & 2233 & 2921 \\
\hline 11 & 2463 & 3367 & 2241 & 2788 & 11 & 2532 & 3757 & 2258 & 2987 \\
\hline 12 & 2482 & 3420 & 2248 & 2806 & 12 & 2476 & 3594 & 2261 & 2994 \\
\hline 13 & 2494 & 3453 & 2212 & 2715 & 13 & 2468 & 3569 & 2221 & 2890 \\
\hline 14 & 2459 & 3357 & 2140 & 2542 & 14 & 2485 & 3619 & 2231 & 2918 \\
\hline 15 & 2457 & 3350 & 2092 & 2428 & 15 & 2465 & 3562 & 2242 & 2945 \\
\hline 16 & 2485 & 3428 & 2180 & 2639 & 16 & 2417 & 3422 & 2238 & 2936 \\
\hline 17 & 2521 & 3528 & 2273 & 2867 & 17 & 2402 & 3381 & 2208 & 2858 \\
\hline 18 & 2555 & 3624 & 2241 & 2786 & 18 & 2432 & 3465 & 2200 & 2837 \\
\hline 19 & 2539 & 3579 & 2221 & 2737 & 19 & 2466 & 3563 & 2237 & 2932 \\
\hline 20 & 2515 & 3511 & 2270 & 2860 & 20 & 2505 & 3678 & 2226 & 2903 \\
\hline 21 & 2504 & 3479 & 2291 & 2912 & 21 & 2538 & 3776 & 2211 & 2865 \\
\hline 22 & 2474 & 3398 & 2258 & 2829 & 22 & 2538 & 3776 & 2222 & 2892 \\
\hline 23 & 2467 & 3379 & 2231 & 2762 & 23 & 2513 & 3701 & 2224 & 2899 \\
\hline 24 & 2475 & 3399 & 2243 & 2791 & 24 & 2495 & 3648 & 2238 & 2936 \\
\hline 25 & 2493 & 3449 & 2268 & 2854 & 25 & 2485 & 3620 & 2258 & 2987 \\
\hline 26 & 2540 & 3582 & 2248 & 2806 & 26 & 2483 & 3613 & 2262 & 2998 \\
\hline 27 & 2549 & 3607 & 2224 & 2746 & 27 & 2465 & 3560 & 2236 & 2931 \\
\hline 28 & 2530 & 3553 & 2269 & 2856 & 28 & 2493 & 3642 & 2234 & 2925 \\
\hline 29 & 2539 & 3578 & 2306 & 2952 & 29 & 2524 & 3733 & 2239 & 2938 \\
\hline 30 & 2542 & 3585 & 2262 & 2840 & 30 & 2521 & 3726 & 2231 & 2918 \\
\hline 31 & 2514 & 3509 & 2222 & 2739 & 31 & 2521 & 3726 & 2243 & 2949 \\
\hline 32 & 2485 & 3429 & 2224 & 2744 & 32 & 2504 & 3673 & 2258 & 2987 \\
\hline 33 & 2459 & 3357 & 2213 & 2717 & 33 & 2510 & 3691 & 2238 & 2934 \\
\hline 34 & 2434 & 3287 & 2204 & 2697 & 34 & 2535 & 3766 & 2229 & 2910 \\
\hline 35 & 2433 & 3286 & 2153 & 2573 & 35 & 2510 & 3692 & 2248 & 2962 \\
\hline 36 & 2457 & 3350 & 2141 & 2544 & 36 & 2467 & 3566 & 2252 & 2972 \\
\hline 37 & 2493 & 3448 & 2222 & 2739 & 37 & 2412 & 3409 & 2240 & 2940 \\
\hline 38 & 2531 & 3554 & 2193 & 2668 & 38 & 2403 & 3383 & 2235 & 2927 \\
\hline 39 & 2519 & 3523 & 2173 & 2621 & 39 & 2480 & 3605 & 2258 & 2987 \\
\hline 40 & 2513 & 3505 & 2231 & 2763 & 40 & 2517 & 3713 & 2265 & 3006 \\
\hline 41 & 2494 & 3453 & 2199 & 2685 & 41 & 2528 & 3745 & 2251 & 2970 \\
\hline 42 & 2448 & 3326 & 2150 & 2566 & 42 & 2528 & 3745 & 2237 & 2932 \\
\hline 43 & 2425 & 3264 & 2157 & 2581 & 43 & 2508 & 3687 & 2213 & 2870 \\
\hline 44 & 2419 & 3247 & 2176 & 2627 & 44 & 2476 & 3592 & 2203 & 2844 \\
\hline 45 & 2399 & 3193 & 2180 & 2637 & 45 & 2423 & 3441 & 2163 & 2742 \\
\hline 46 & 2413 & 3232 & 2185 & 2650 & 46 & 2396 & 3365 & 2102 & 2590 \\
\hline 47 & 2474 & 3397 & 2245 & 2798 & 47 & 2404 & 3388 & 2121 & 2636 \\
\hline 48 & 2485 & 3429 & 2288 & 2906 & 48 & 2421 & 3434 & 2177 & 2778 \\
\hline
\end{tabular}


Apênatice (2) 
No Apêndice D estão contidos os gráficos de correlações entre os valores dos parâmetros não-destrutivos ( $\mathrm{V}, \mathrm{C}$ e Atn) e os obtidos nos ensaios mecânicos destrutivos $\left(E_{m / /}, E_{m \perp}, f_{m / /}, f_{m \perp}\right.$ e $\left.A l\right)$ e nos ensaios físicos $\left(D, G_{t}\right.$ e $\left.A_{m}\right)$, referentes a todos os corpos-de-prova ensaiados nos ensaios principais (primeira parte), para os painéis de espessura 15(1) e 25mm, através de medições por ultra-som.

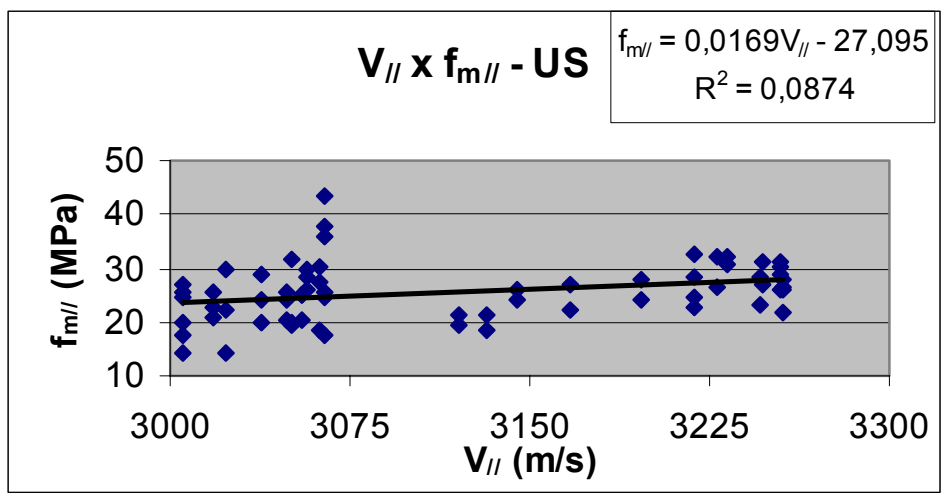

Figura D1 - $V_{/ /} \times f_{m / /}$ através do método de ultra-som.

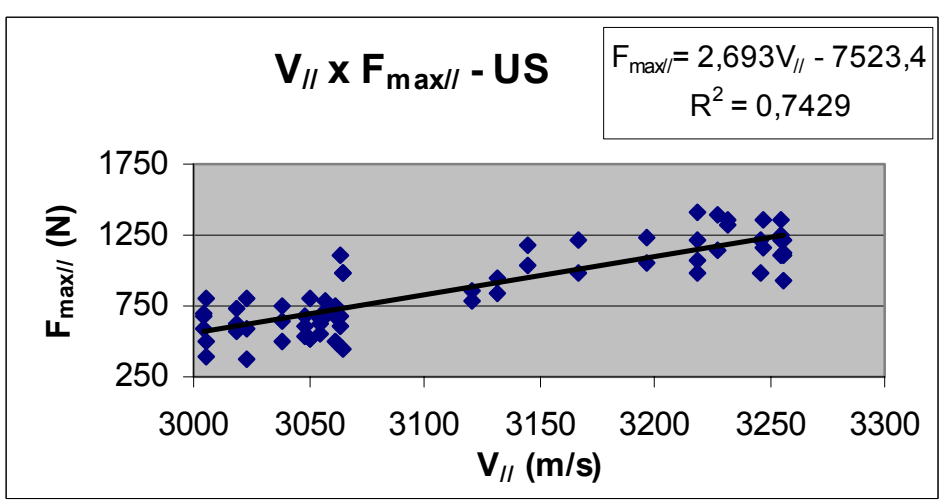

Figura $\mathrm{D} 2-\mathrm{V}_{/ /} \times \mathrm{F}_{\mathrm{max} / /}$ através do método de ultra-som.

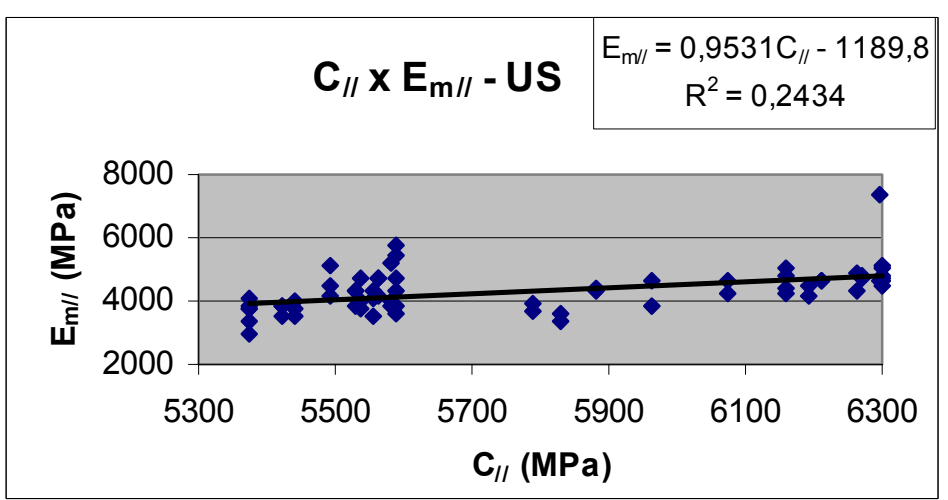

Figura D3 $-C_{/ /} \times E_{m / /}$ através do método de ultra-som. 


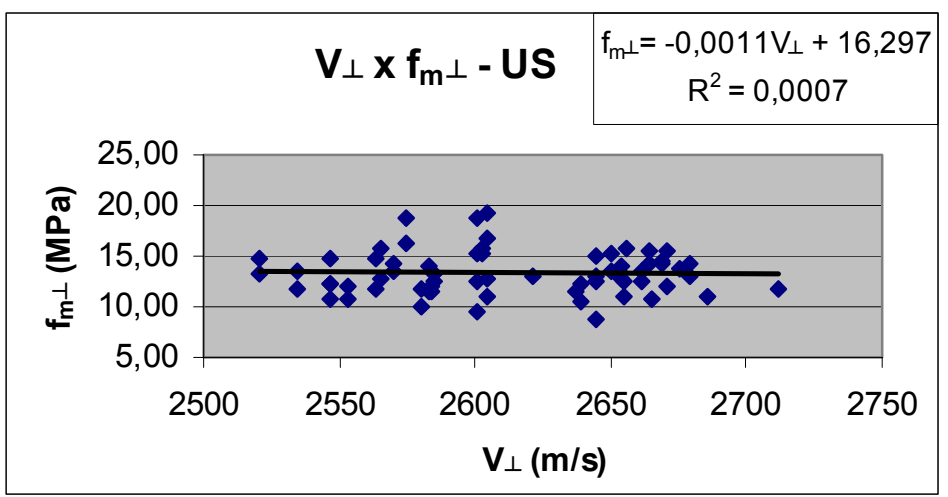

Figura $\mathrm{D} 4-\mathrm{V}_{\perp} \times \mathrm{f}_{\mathrm{m} \perp}$ através do método de ultra-som.

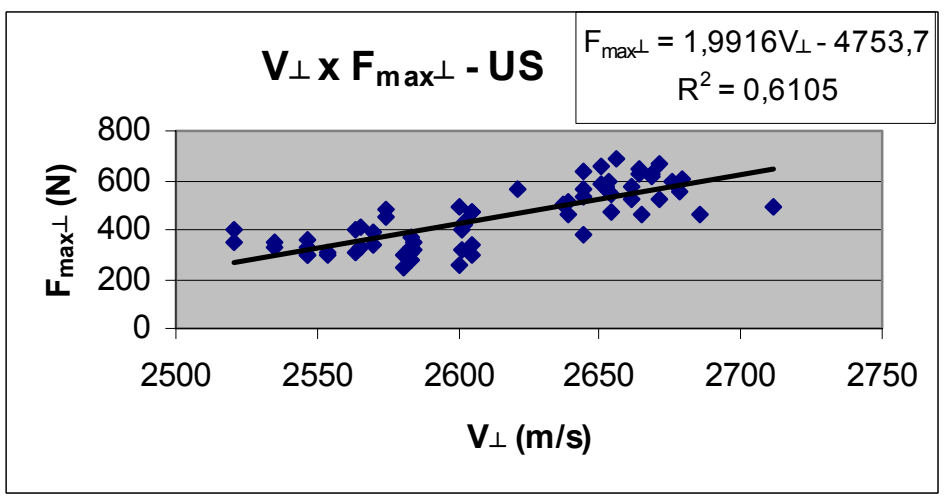

Figura D5 - $V_{\perp} \times F_{\max } \perp$ através do método de ultra-som.

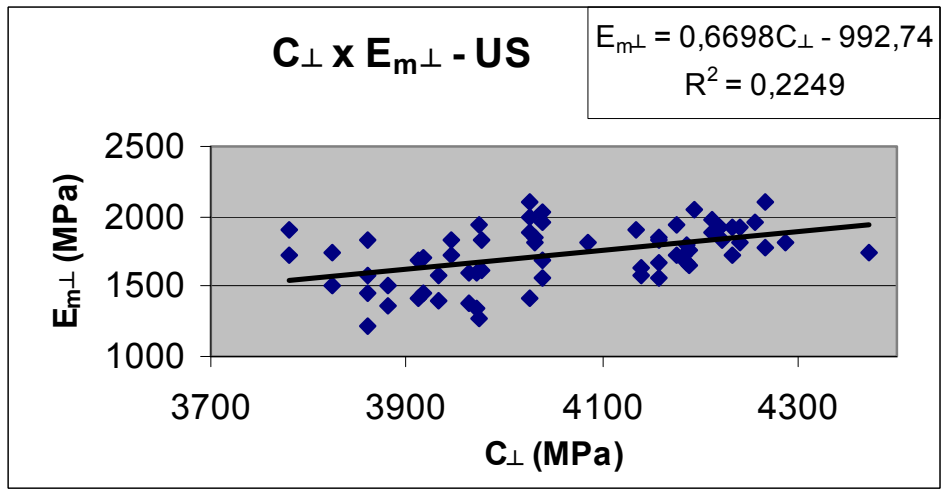

Figura $D 6-C_{\perp} \times E_{m} \perp$ através do método de ultra-som. 


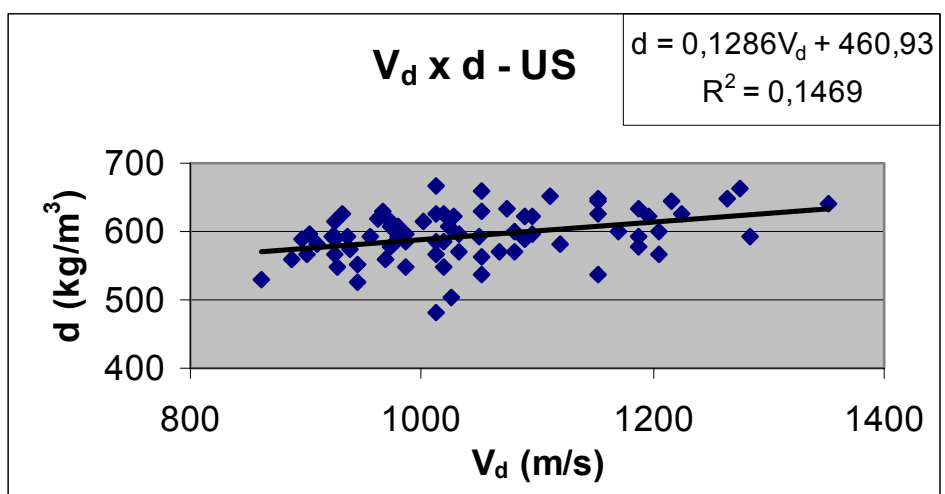

Figura D7 - $V_{d} x d$ através do método de ultra-som.

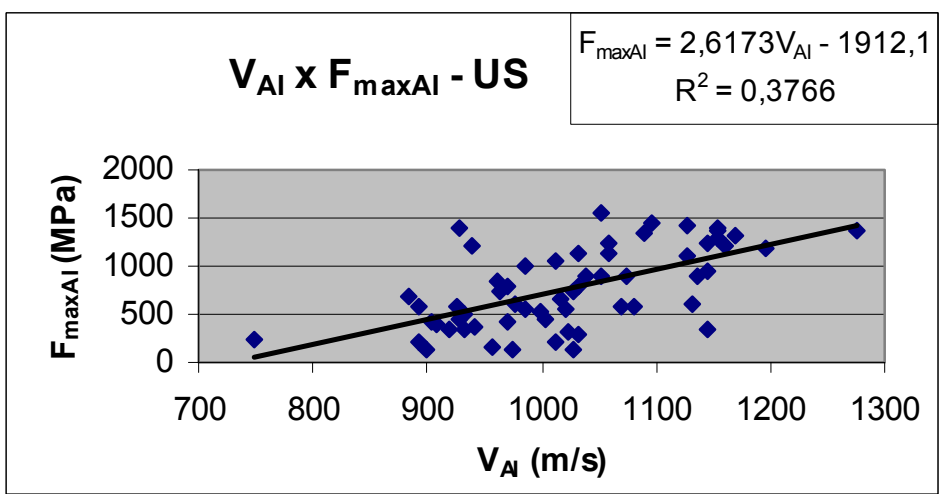

Figura $D 8-V_{A l} \times F_{\operatorname{maxAl}}$ através do método de ultra-som.

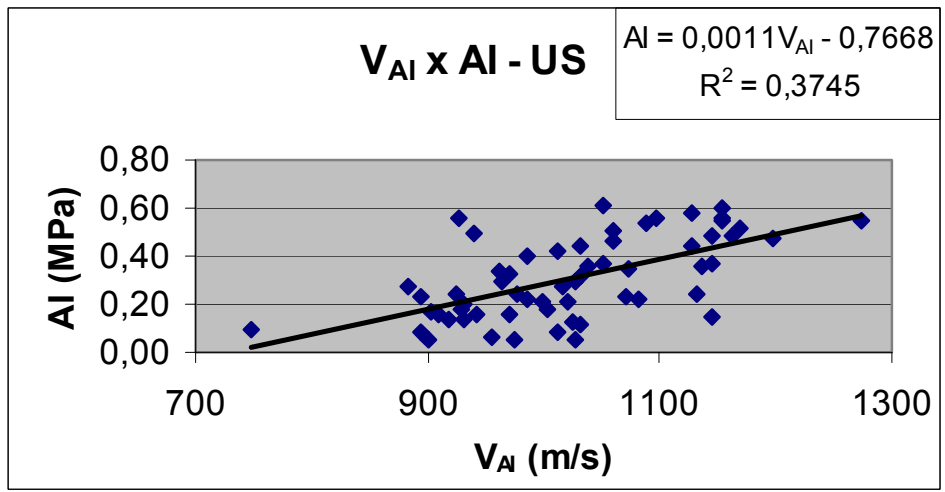

Figura D9 - $\mathrm{V}_{\mathrm{Al}} \times \mathrm{Al}$ através do método de ultra-som. 


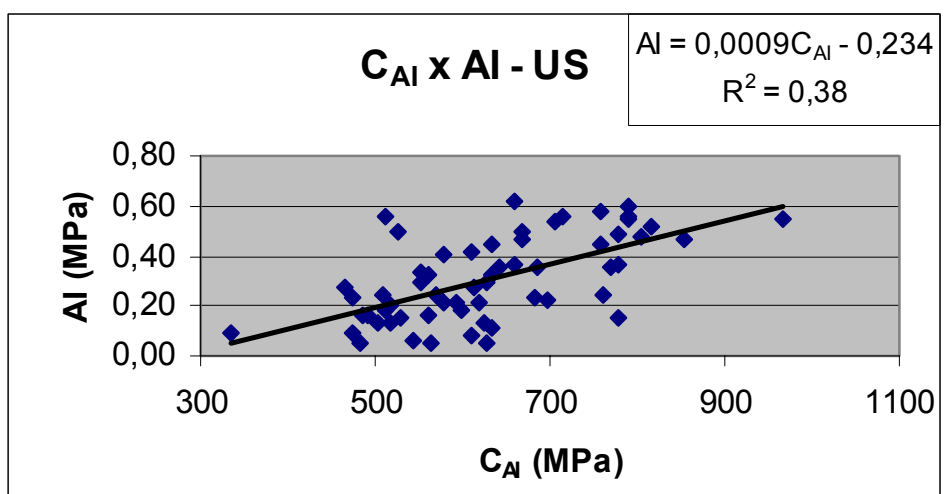

Figura $\mathrm{D} 10-\mathrm{C}_{\mathrm{Al}} \times \mathrm{Al}$ através do método de ultra-som.

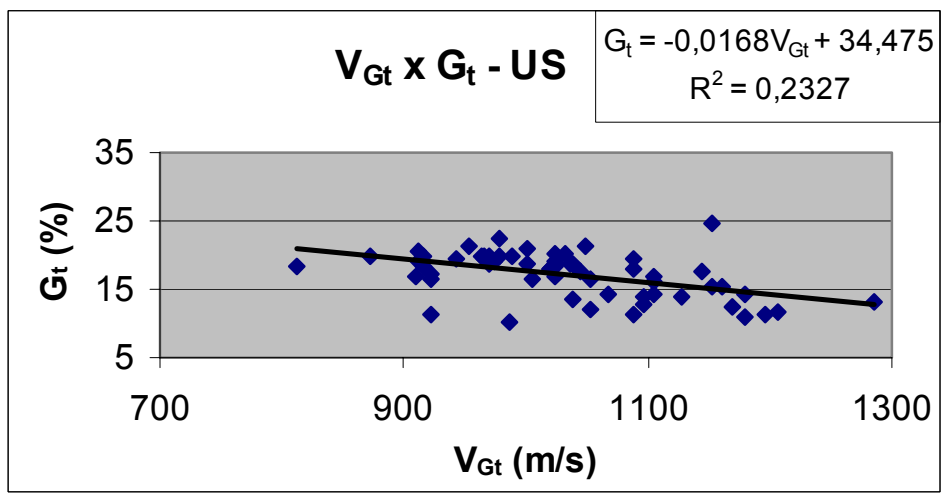

Figura $\mathrm{D} 11-\mathrm{V}_{\mathrm{Gt}} \times \mathrm{G}_{\mathrm{t}}$ através do método de ultra-som.

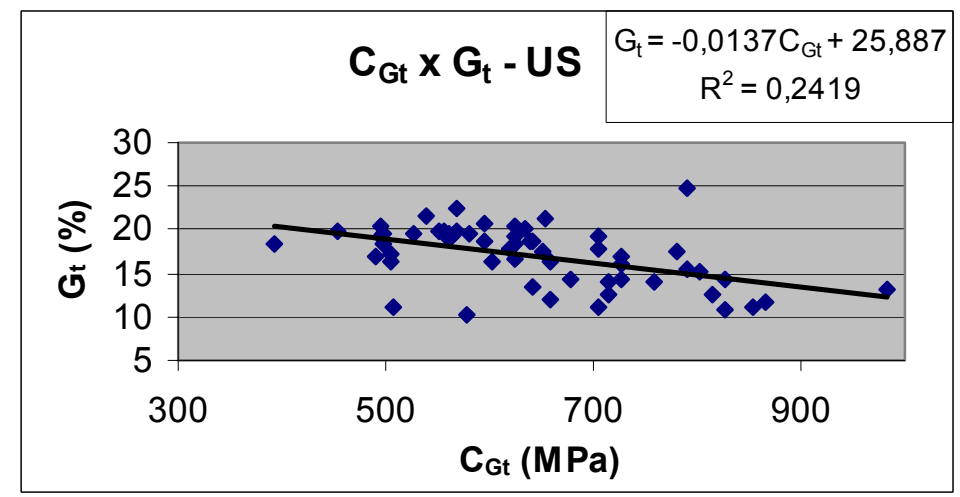

Figura D12 $-\mathrm{C}_{\mathrm{Gt}} \times \mathrm{G}_{\mathrm{t}}$ através do método de ultra-som. 


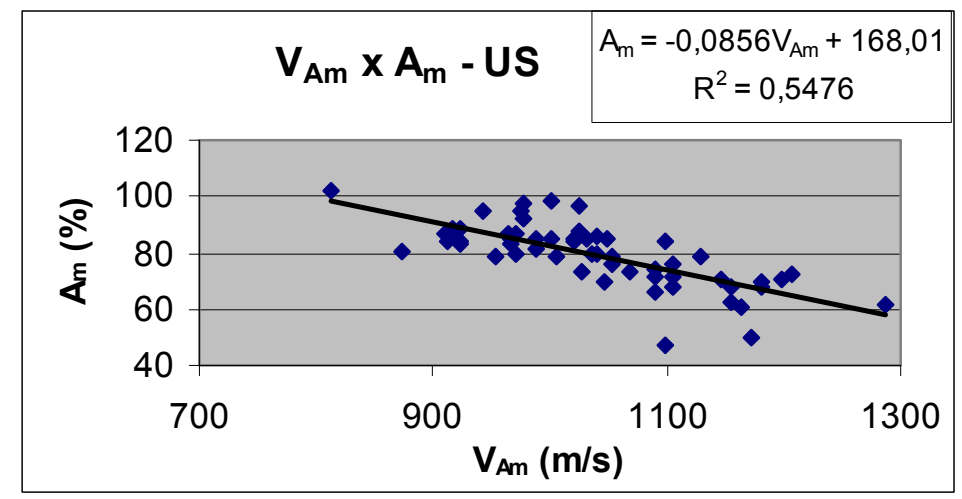

Figura D13 $-V_{A m} \times A_{m}$ através do método de ultra-som.

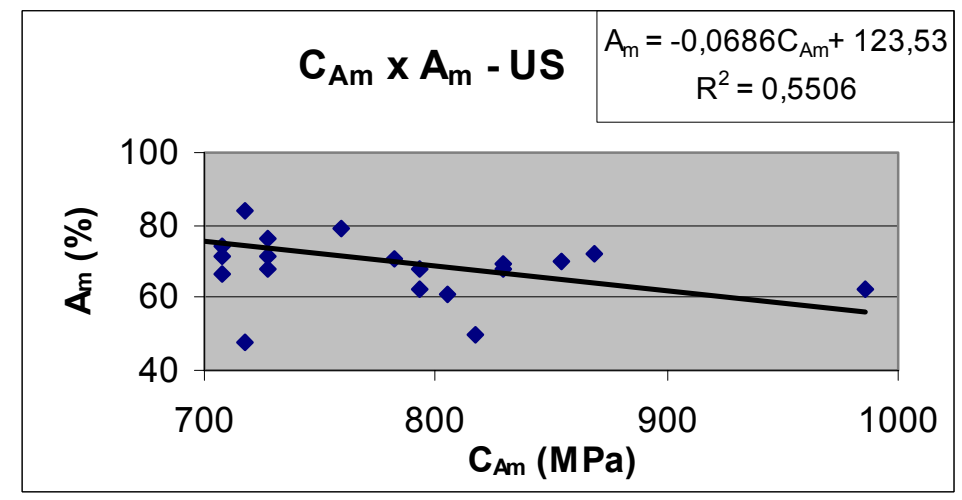

Figura D14 $-C_{A m} \times A_{m}$ através do método de ultra-som. 
Apênatice \& 
No Apêndice E estão contidos os gráficos de correlações entre os valores dos parâmetros não-destrutivos ( $\mathrm{V}$ e $\mathrm{C}$ ) e os obtidos nos ensaios mecânicos destrutivos $\left(E_{m / /}, E_{m \perp}, f_{m / /}\right.$ e $\left.f_{m \perp}\right)$, referentes a todos os corpos-de-prova ensaiados nos ensaios principais (primeira parte), para os painéis de espessuras 15(1), 15(2) e 25mm, através de medições por stress wave.

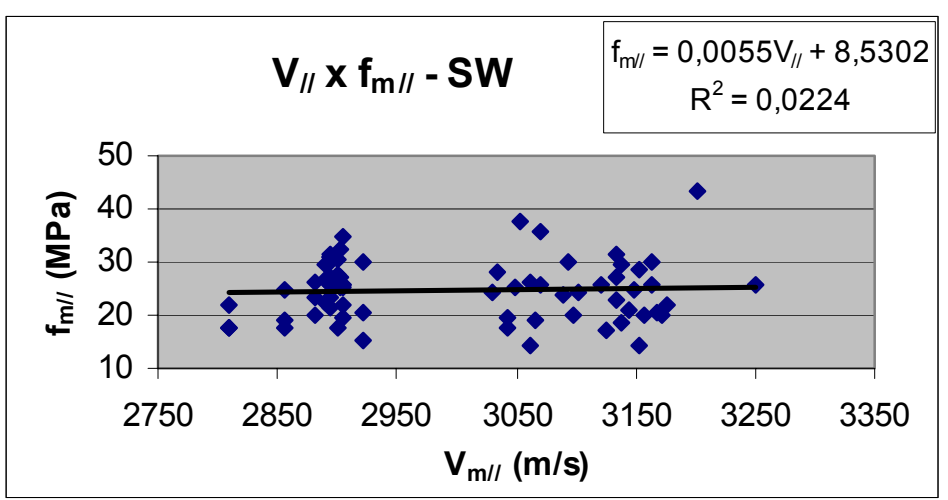

Figura $\mathrm{E} 1-\mathrm{V}_{/ /} \times \mathrm{f}_{\mathrm{m} / /}$ através do método de stress wave - painéis 15(1) e 15(2)mm.

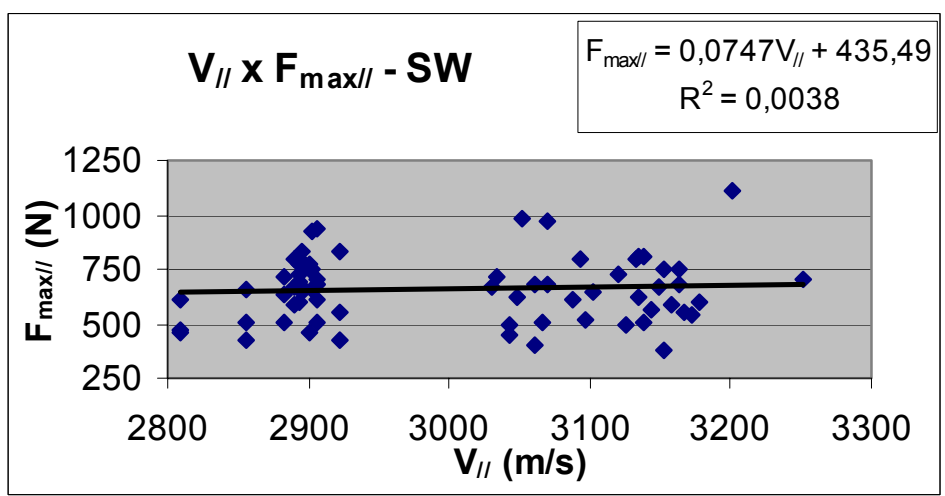

Figura E2 - $V_{/ /} \times F_{\max / /}$ através do método de stress wave - painéis 15(1) e 15(2)mm.

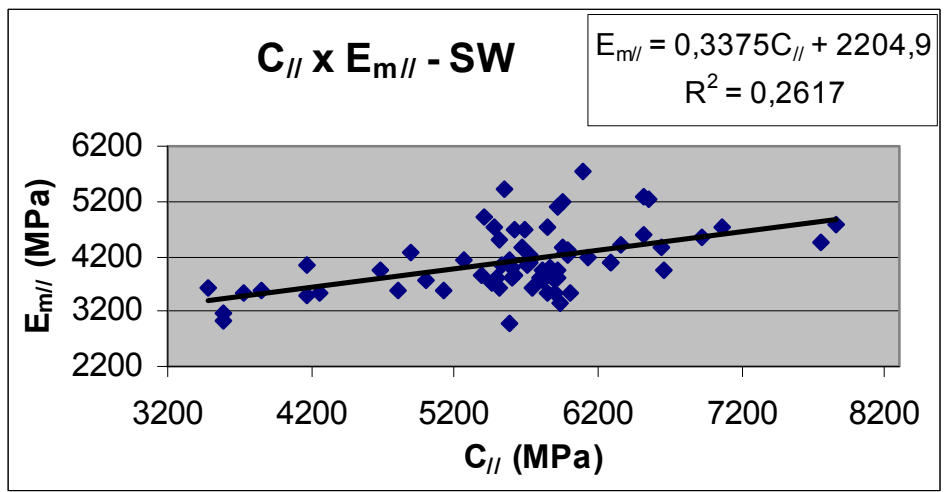

Figura $E 3-C_{/ /} \times E_{m / /}$ através do método de stress wave - painéis 15(1) e 15(2)mm. 


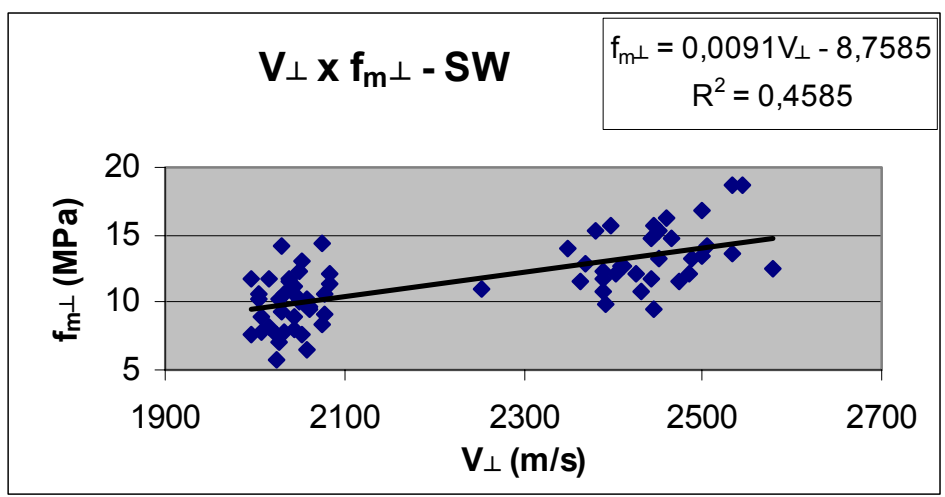

Figura $E 4-V_{\perp} \times f_{m} \perp$ através do método de stress wave - painéis 15(1) e 15(2)mm.

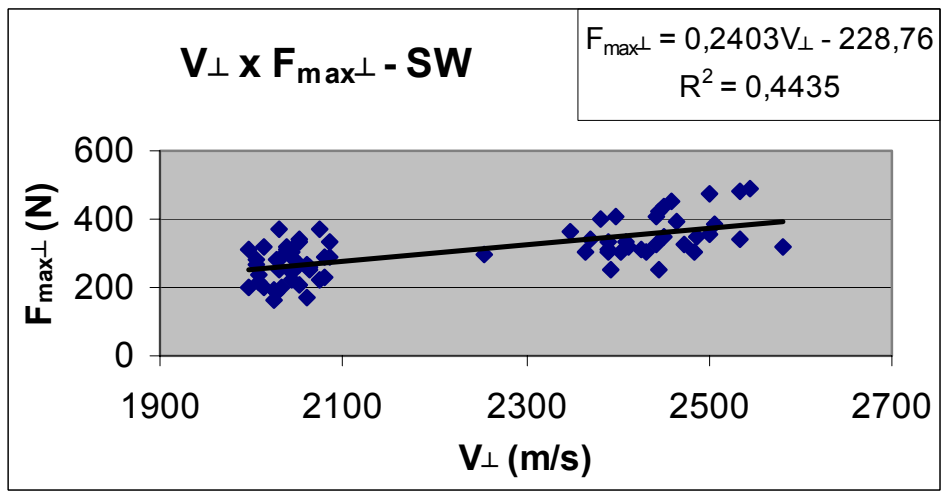

Figura $E 5-V_{\perp} \times F_{\max } \perp$ através do método de stress wave - painéis 15(1) e 15(2)mm.

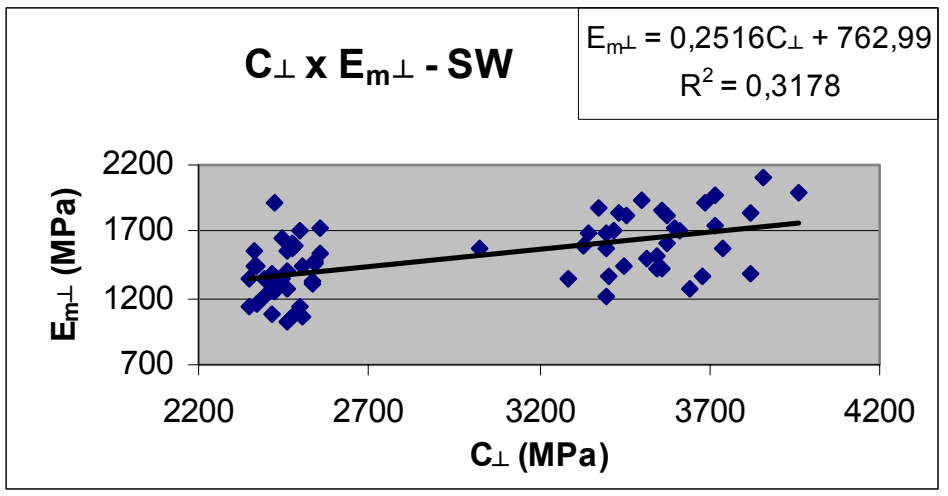

Figura $E 6-C_{\perp} x E_{m \perp}$ através do método de stress wave - painéis 15(1) e 15(2)mm. 


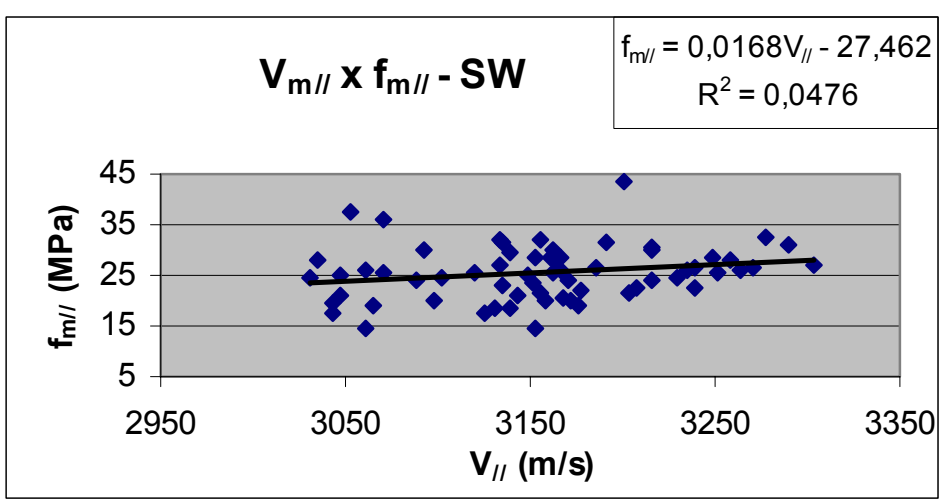

Figura E7 - $V_{/ /} \times f_{m / /}$ através do método de stress wave - painéis 15(1) e $25 \mathrm{~mm}$.

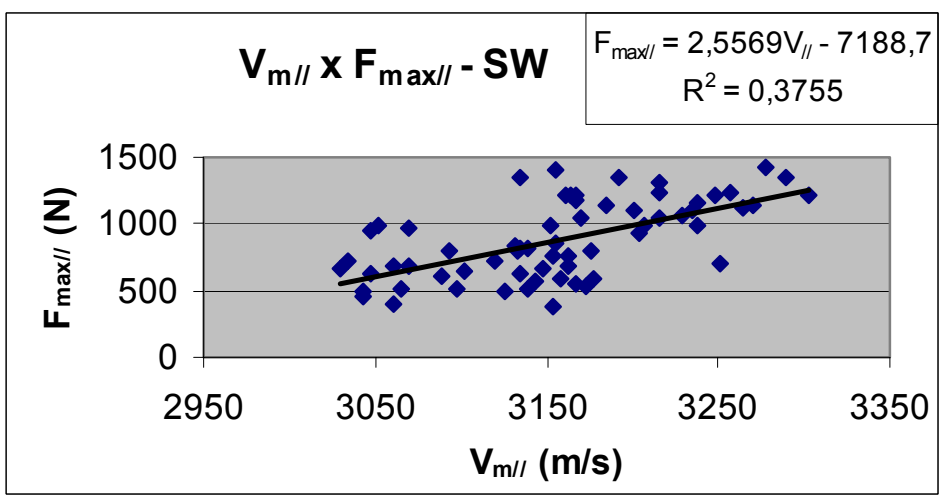

Figura E8 - $V_{/ /} \times F_{\max / /}$ através do método de stress wave - painéis 15(1) e $25 \mathrm{~mm}$.

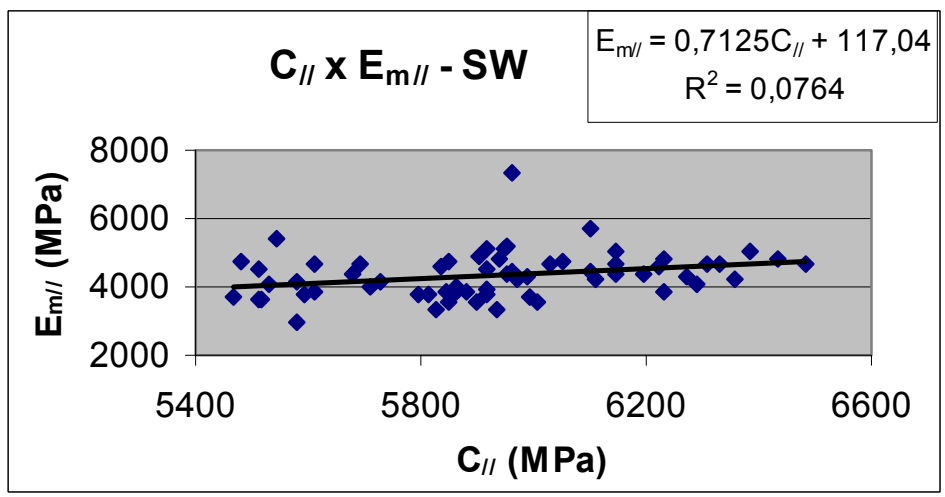

Figura $E 9-C_{/ /} \times E_{m / /}$ através do método de stress wave - painéis 15(1) e 25mm. 


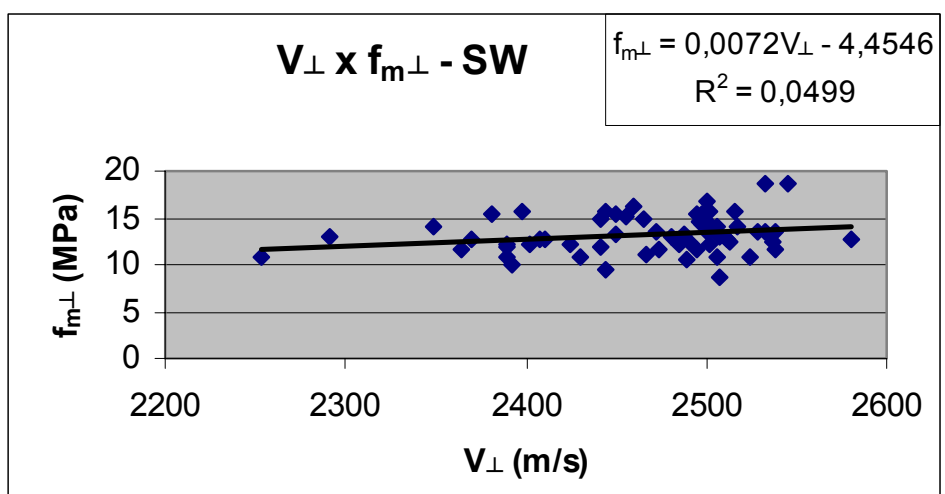

Figura $\mathrm{E} 10-\mathrm{V}_{\perp} \times \mathrm{f}_{\mathrm{m} \perp}$ através do método de stress wave - painéis $15(1)$ e $25 \mathrm{~mm}$.

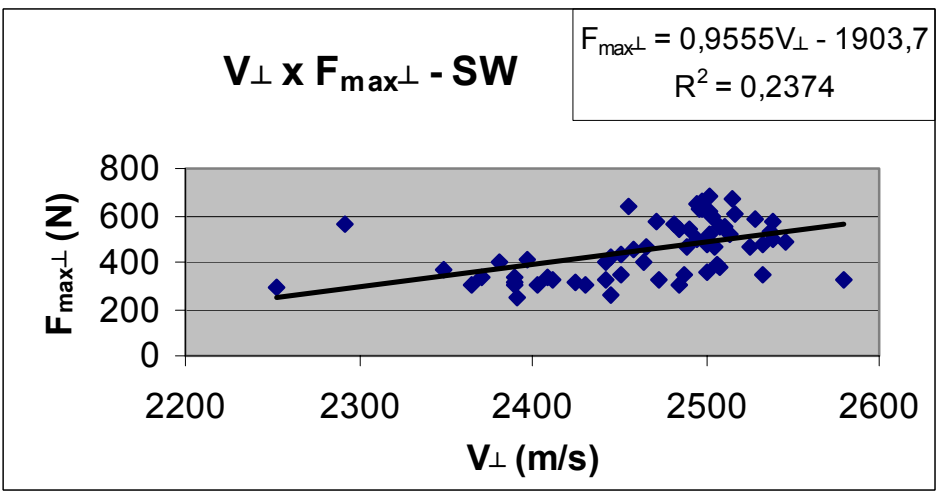

Figura $\mathrm{E} 11-V_{\perp} \times F_{\max } \perp$ através do método de stress wave - painéis 15(1) e 25mm.

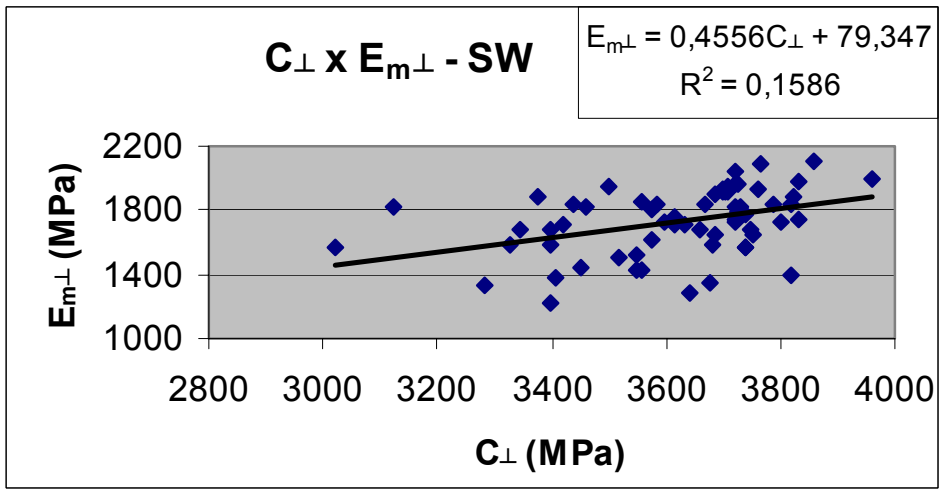

Figura $E 12-C_{\perp} x E_{m \perp}$ através do método de stress wave - painéis 15(1) e 25mm. 


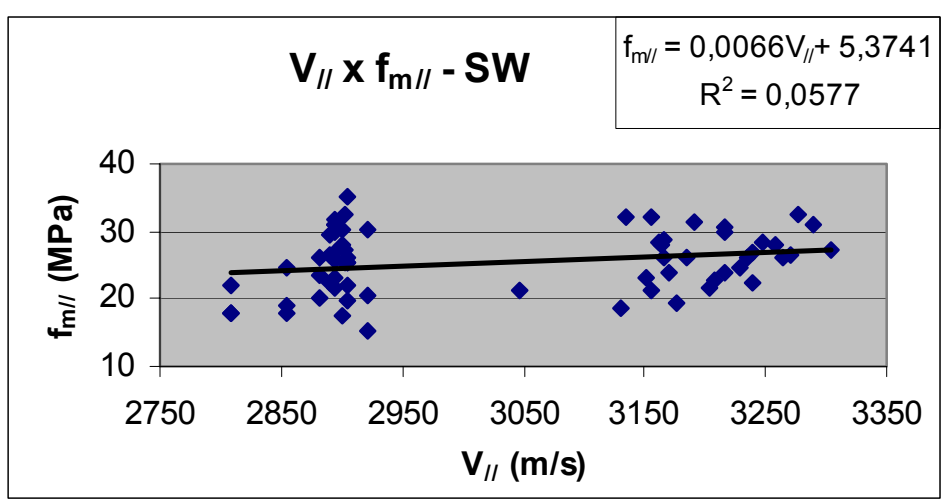

Figura $\mathrm{E} 13-\mathrm{V}_{/ /} \times \mathrm{f}_{\mathrm{m} / /}$ através do método de stress wave - painéis $15(2)$ e $25 \mathrm{~mm}$.

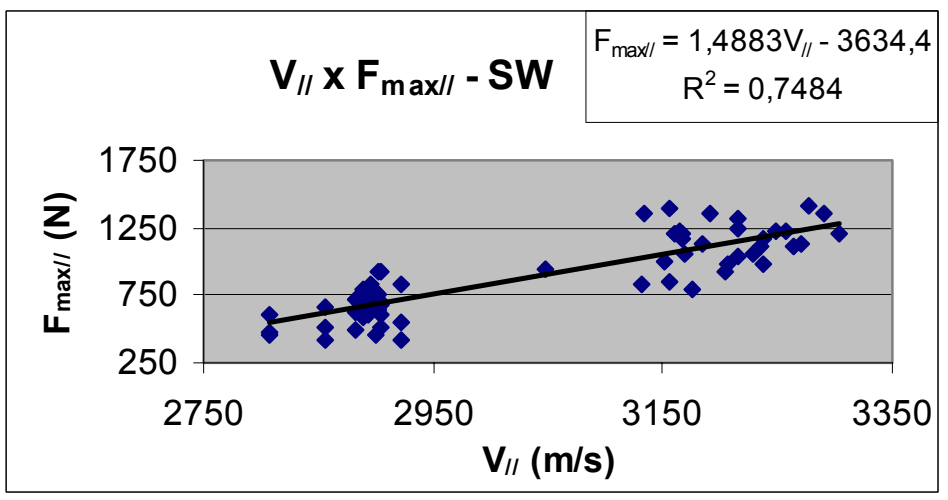

Figura $\mathrm{E} 14-\mathrm{V}_{/ /} \times \mathrm{F}_{\mathrm{max} / /}$ através do método de stress wave - painéis $15(2)$ e $25 \mathrm{~mm}$.

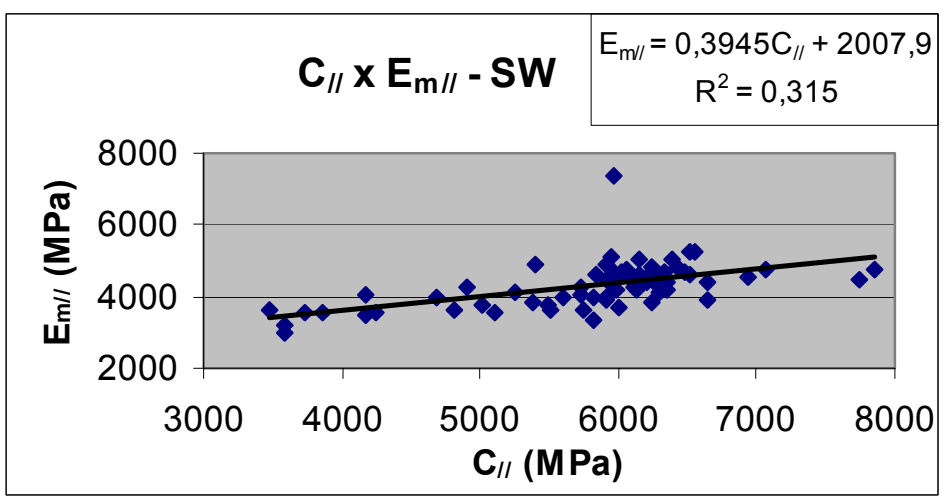

Figura $E 15-C_{/ /} \times E_{m / /}$ através do método de stress wave - painéis $15(2)$ e $25 \mathrm{~mm}$. 


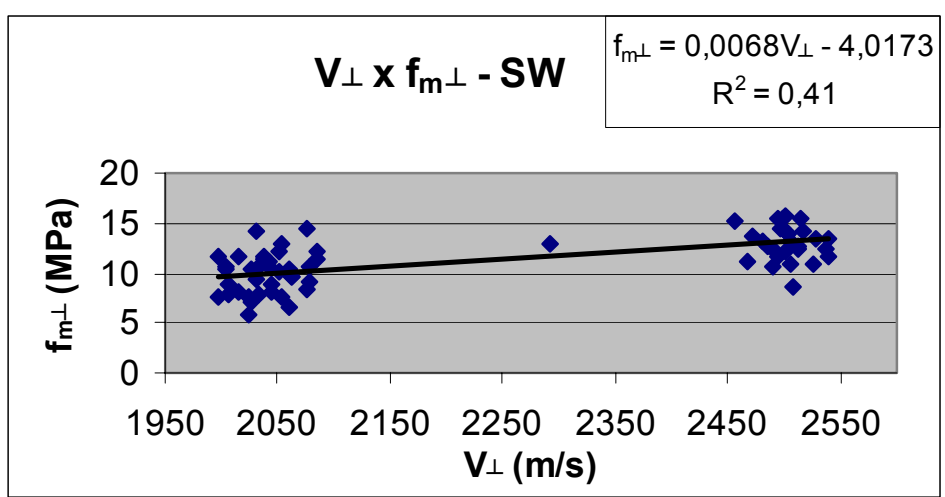

Figura $\mathrm{E} 16-\mathrm{V}_{\perp} \mathrm{x} \mathrm{f}_{\mathrm{m} \perp}$ através do método de stress wave - painéis $15(2)$ e $25 \mathrm{~mm}$.

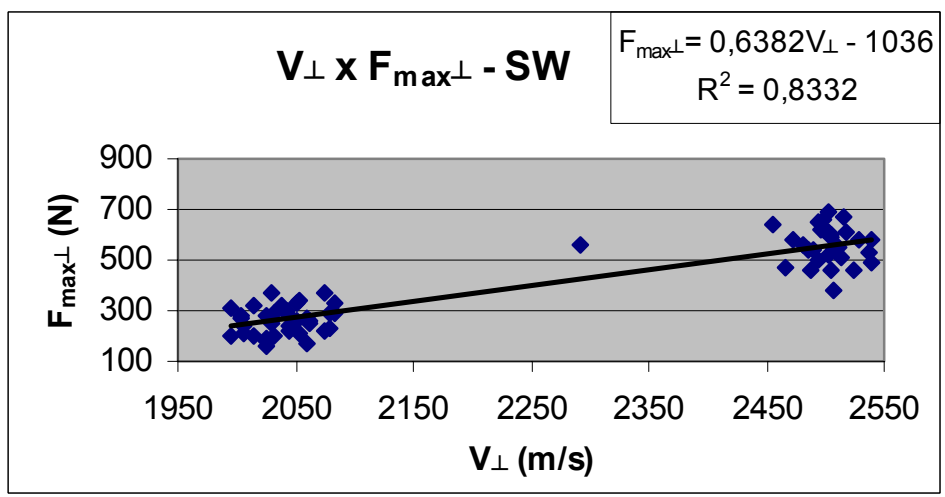

Figura $\mathrm{E} 17-\mathrm{V}_{\perp} \times \mathrm{F}_{\max } \perp$ através do método de stress wave - painéis $15(2)$ e $25 \mathrm{~mm}$.

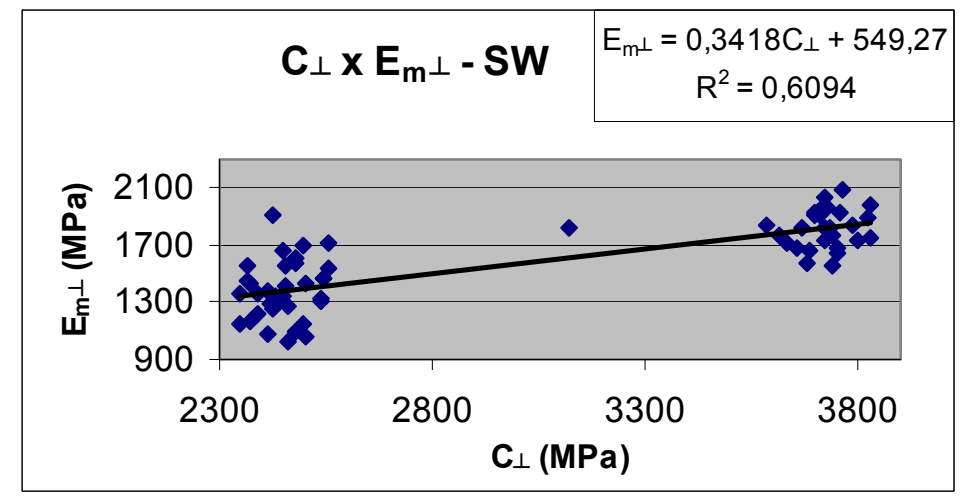

Figura $E 18-C_{\perp} x E_{m}$ através do método de stress wave - painéis 15(2) e $25 \mathrm{~mm}$. 
Apêndice of 
No Apêndice F estão contidos os gráficos de correlações entre os valores dos parâmetros não-destrutivos ( $\mathrm{V}, \mathrm{C}$ e Atn) e os obtidos nos ensaios mecânicos destrutivos $\left(E_{m / /}, E_{m \perp}, f_{m / /}\right.$ e $\left.f_{m \perp}\right)$, referentes a todos os corpos-de-prova ensaiados nos ensaios principais (segunda parte), para os grupos 1 e 2, através de medições por ultra-som.

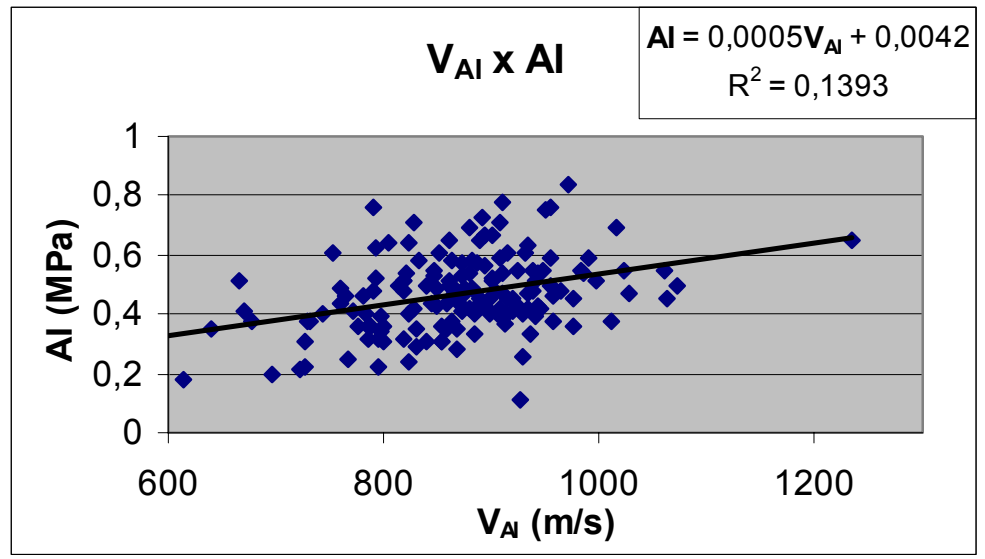

Figura $\mathrm{F} 1-\mathrm{V}_{\mathrm{Al}} \times \mathrm{Al}$ através do método de ultra-som.

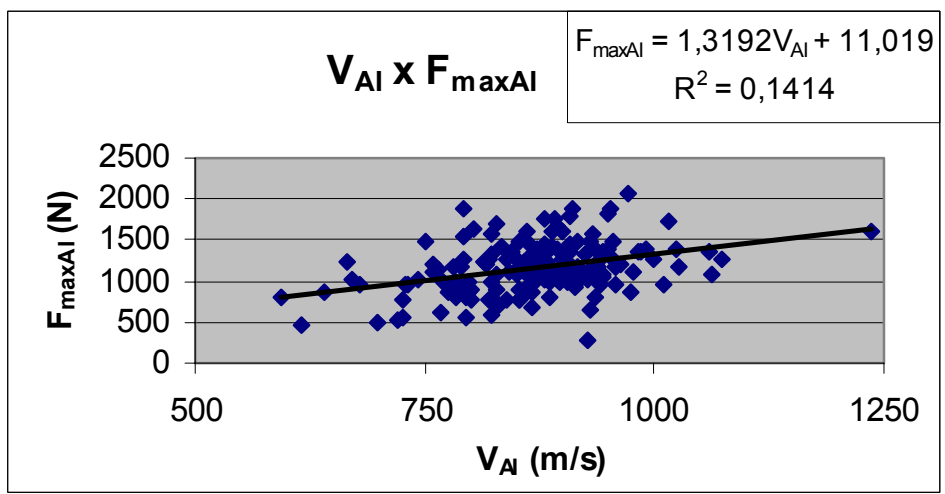

Figura $\mathrm{F} 2-\mathrm{V}_{\mathrm{Al}} \times \mathrm{F}_{\mathrm{maxAl}}$ através do método de ultra-som.

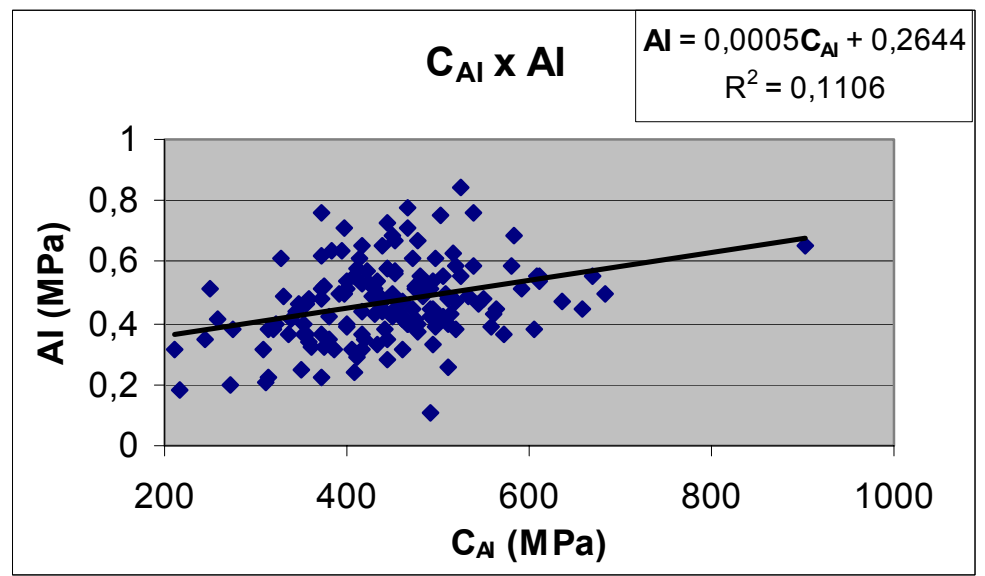

Figura $\mathrm{F} 3-\mathrm{C}_{\mathrm{Al}} \times \mathrm{Al}$ através do método de ultra-som. 


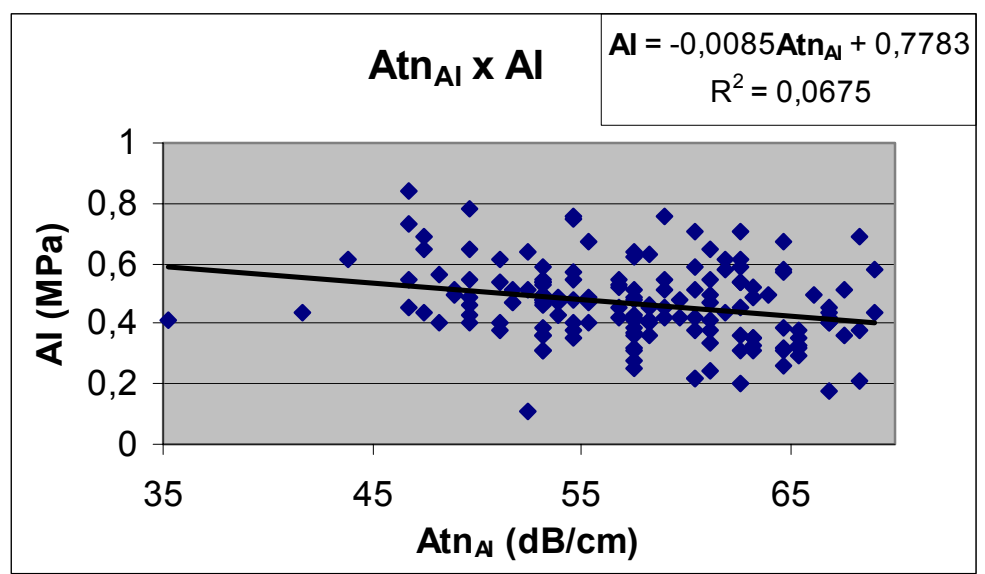

Figura F4 - Atn $\mathrm{Al}_{\mathrm{X}} \times \mathrm{Al}$ através do método de ultra-som.

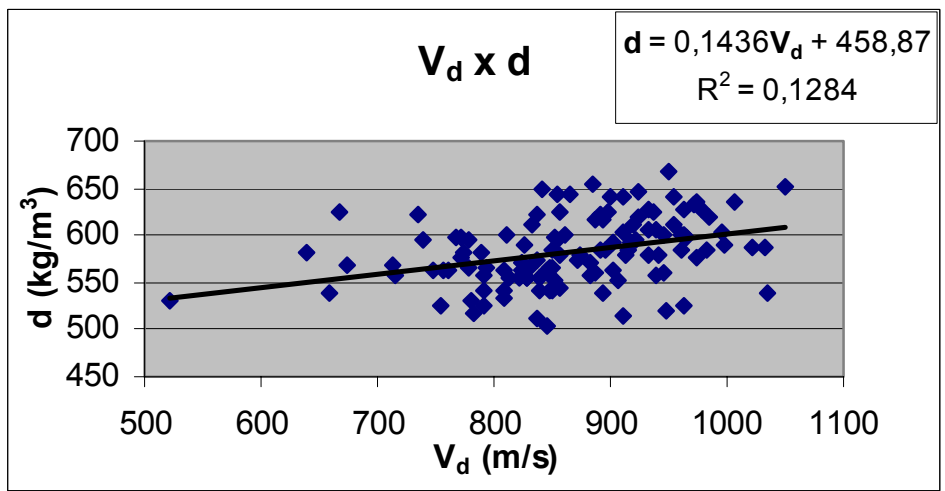

Figura $\mathrm{F} 5-\mathrm{V}_{\mathrm{d}} \mathrm{x} d$ através do método de ultra-som.

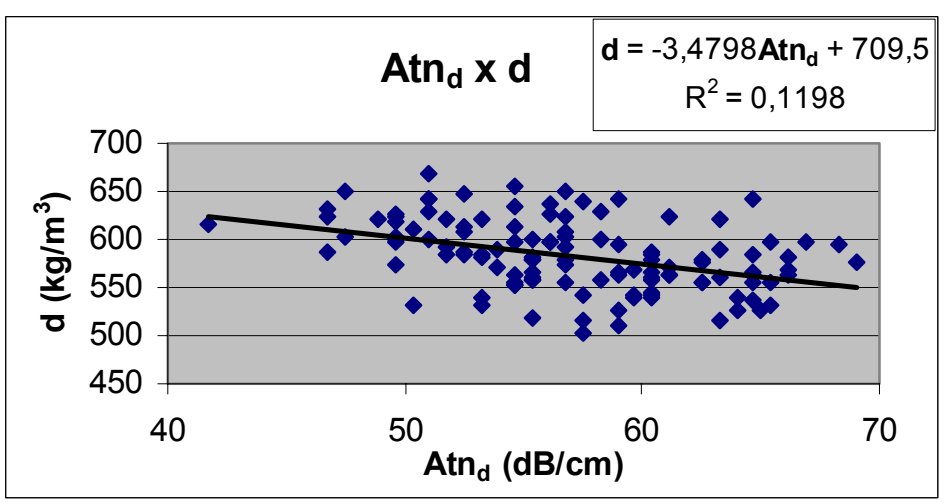

Figura F6 - Atn ${ }_{d} x$ d através do método de ultra-som. 


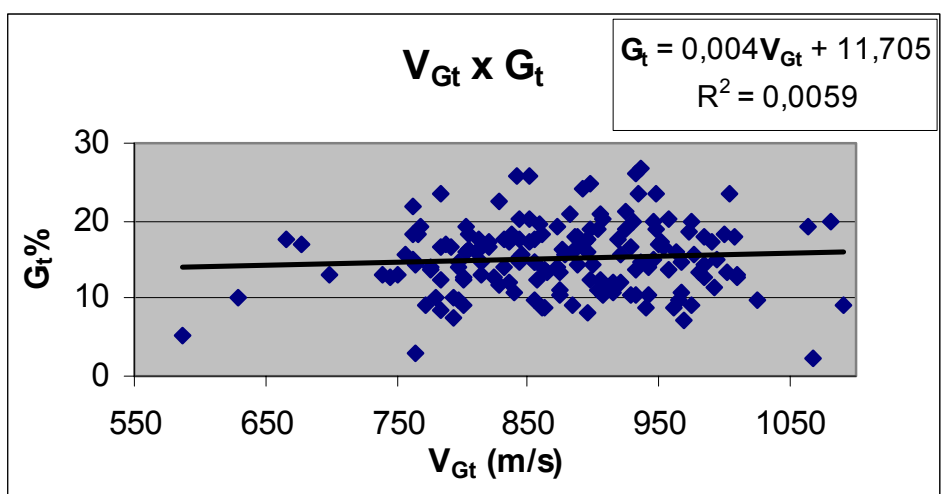

Figura $F 7-V_{G t} \times G_{t}$ através do método de ultra-som.

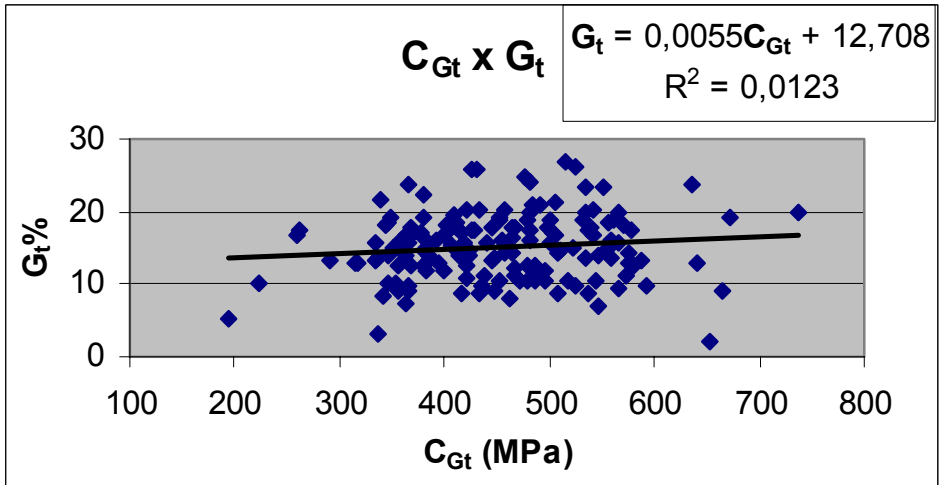

Figura $\mathrm{F} 8-\mathrm{C}_{\mathrm{Gt}} \times \mathrm{G}_{\mathrm{t}}$ através do método de ultra-som.

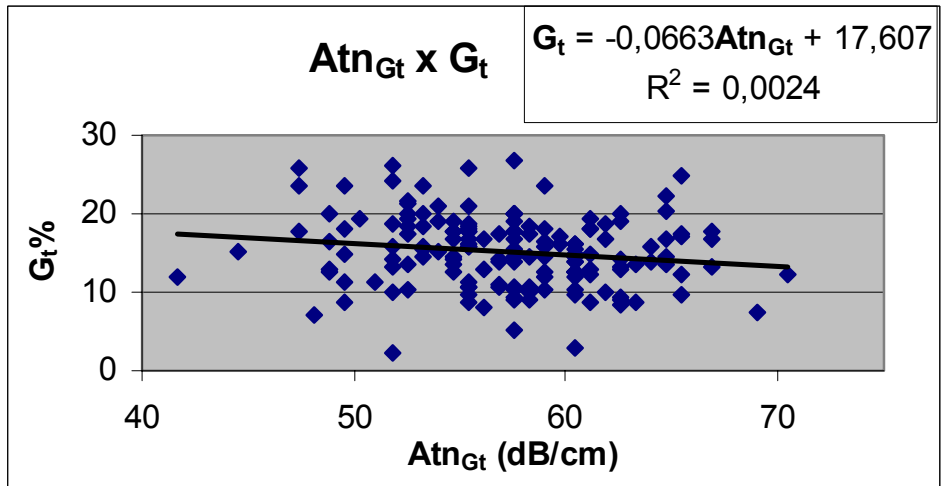

Figura F9 $-A_{t n} \operatorname{Gt} \times G_{t}$ através do método de ultra-som. 


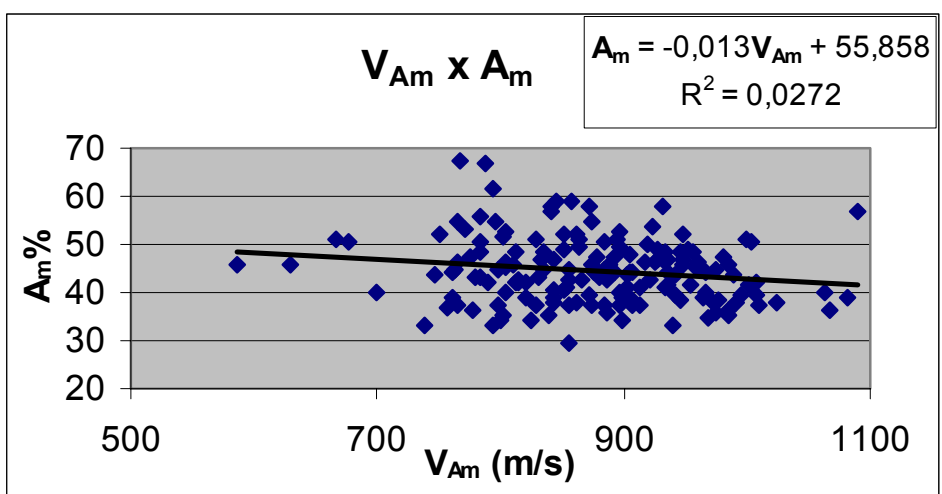

Figura $F 10-V_{A m} \times A_{m}$ através do método de ultra-som.

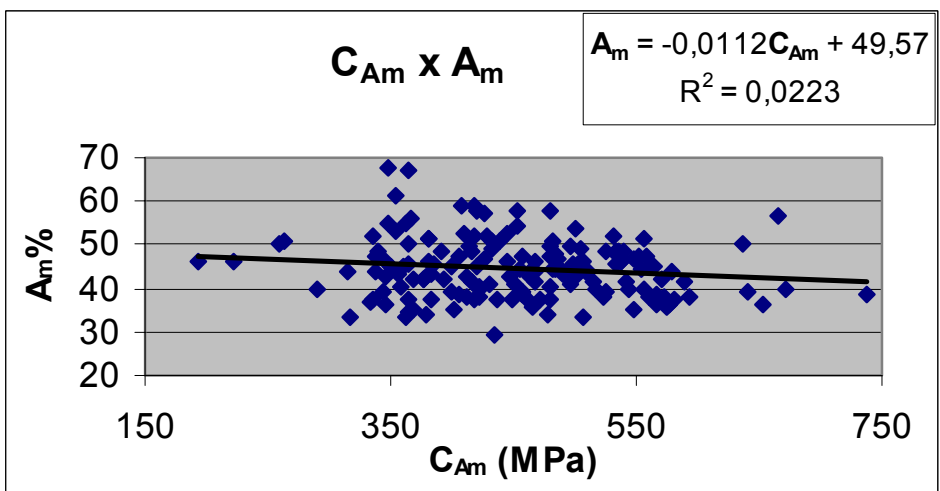

Figura $F 11-C_{A m} \times A_{m}$ através do método de ultra-som.

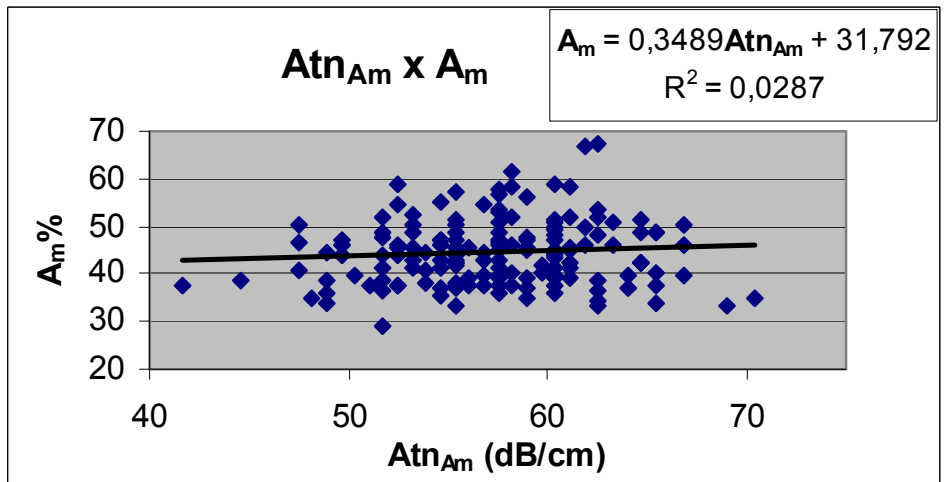

Figura $\mathrm{F} 12-\mathrm{Atn}_{\mathrm{Am}} \times A_{m}$, através do método de ultra-som. 


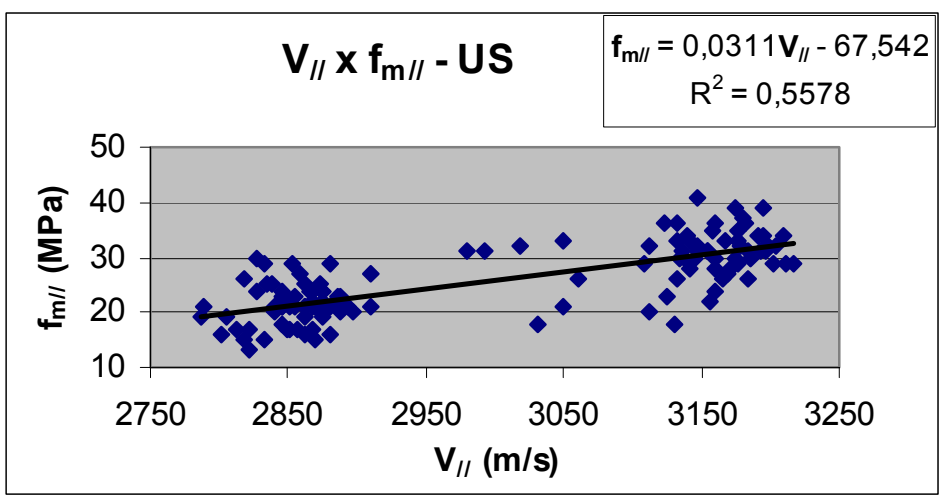

Figura $F 13-V_{/ /} \times f_{m / /}$ através do método de ultra-som.

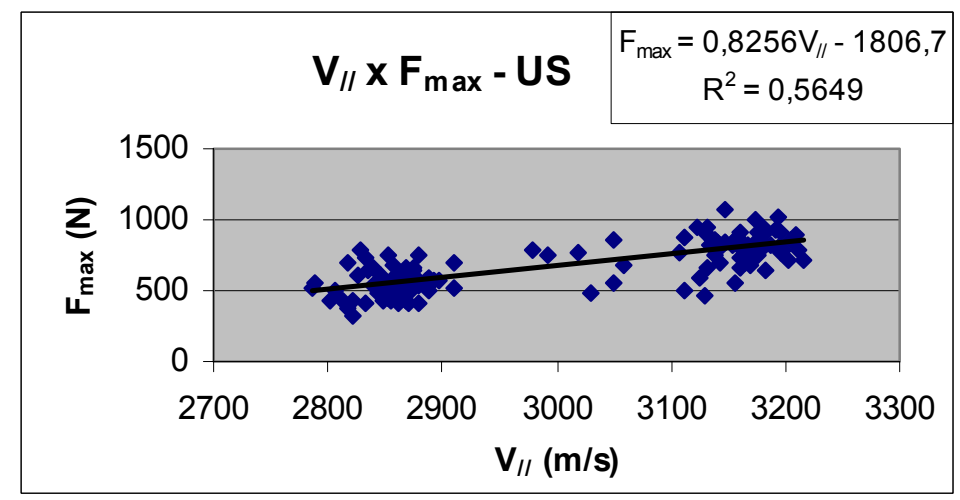

Figura $\mathrm{F} 14-V_{/ /} \times F_{\max }$ através do método de ultra-som.

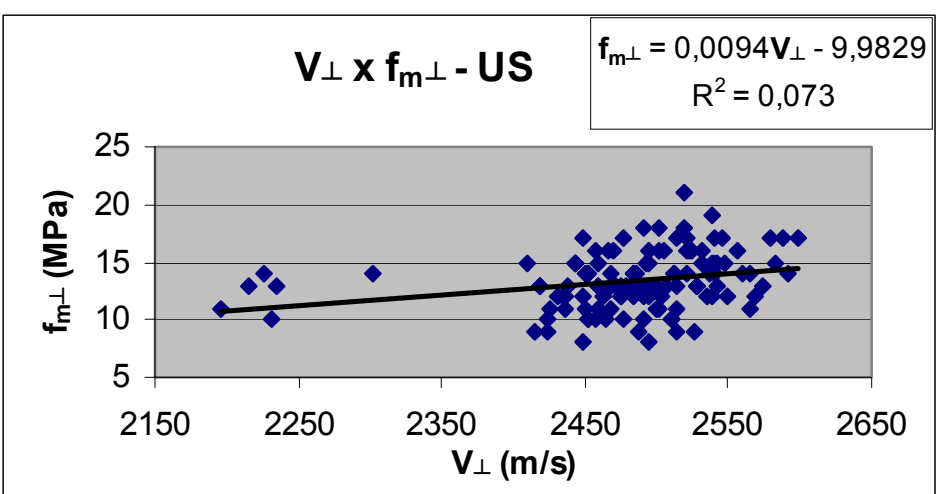

Figura $\mathrm{F} 15-\mathrm{V}_{\perp} \times \mathrm{f}_{\mathrm{m} \perp}$ através do método de ultra-som. 


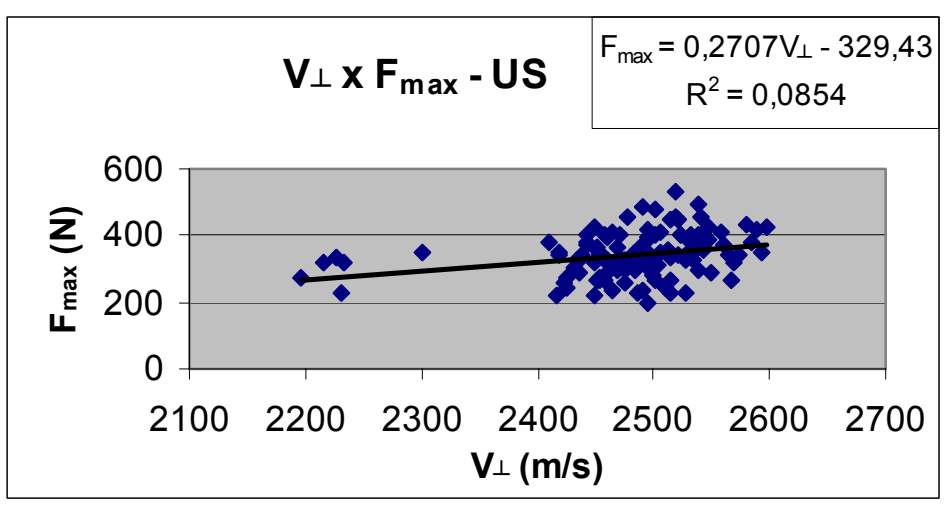

Figura $F 16-V_{\perp} \times F_{\max \perp}$ através do método de ultra-som.

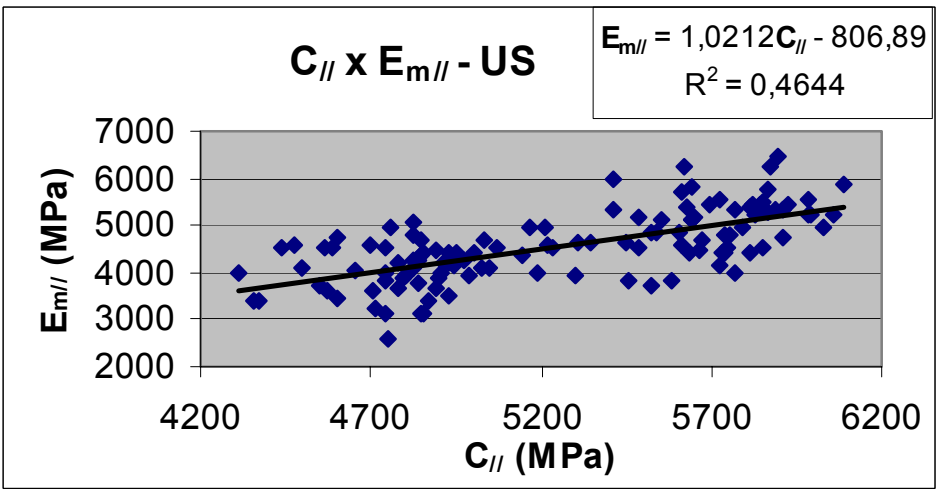

Figura $\mathrm{F} 17-\mathrm{C}_{/ /} \times \mathrm{E}_{\mathrm{m} / /}$ através do método de ultra-som.

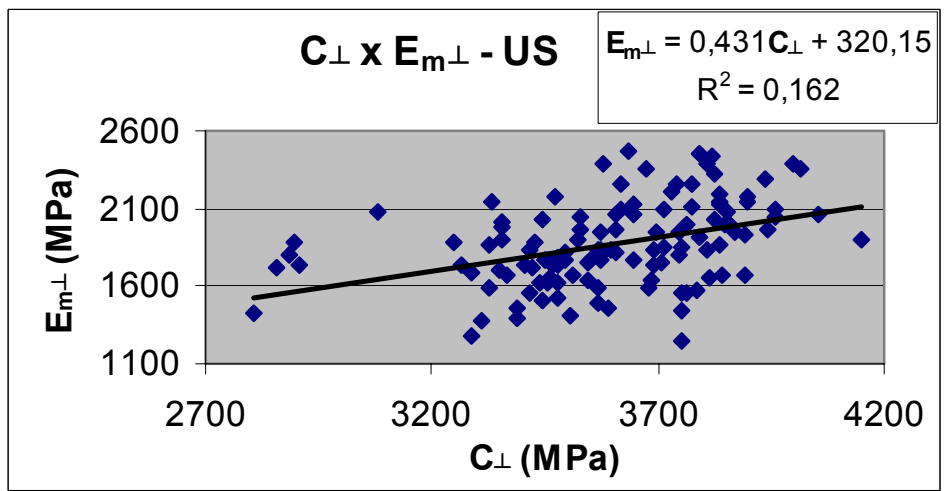

Figura $\mathrm{F} 18-\mathrm{C}_{\perp} \times \mathrm{E}_{\mathrm{m} \perp}$ através do método de ultra-som. 
Apênatice G 
No Apêndice G estão contidos os gráficos de correlações entre os valores dos parâmetros não-destrutivos ( $\mathrm{V}$ e $\mathrm{C}$ ) e os obtidos nos ensaios mecânicos destrutivos $\left(E_{m / /}, E_{m \perp}, f_{m / /}\right.$ e $\left.f_{m \perp}\right)$, referentes a todos os corpos-de-prova ensaiados nos ensaios principais (segunda parte), para os grupos 1 e 2, através de medições por stress wave.

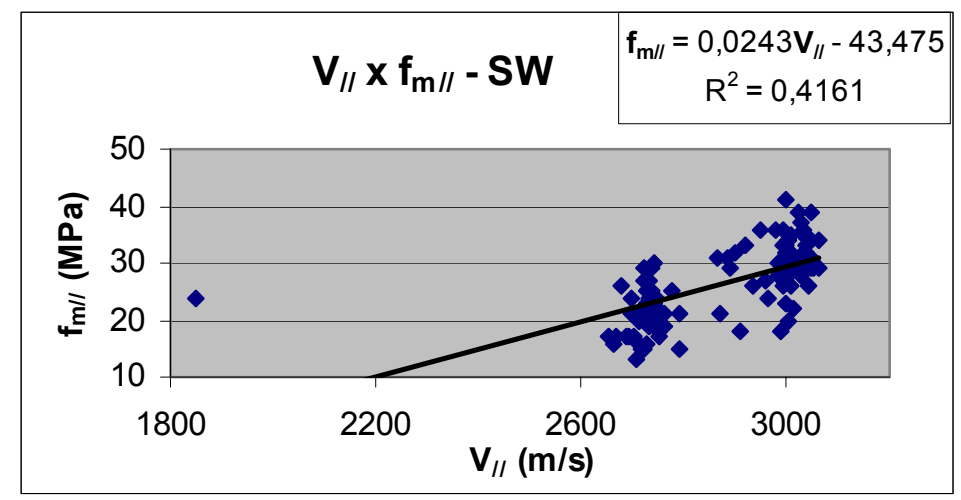

Figura $\mathrm{G} 1-\mathrm{V}_{/ /} \times \mathrm{f}_{\mathrm{m} / /}$ através do método de stress wave - todos os valores.

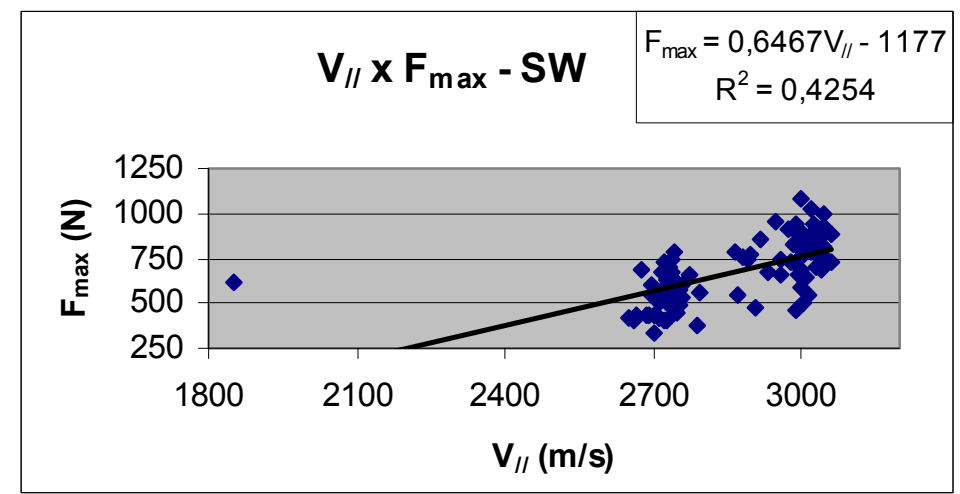

Figura $\mathrm{G} 2-\mathrm{V}_{/ /} \times \mathrm{F}_{\max }$ através do método de stress wave - todos os valores.

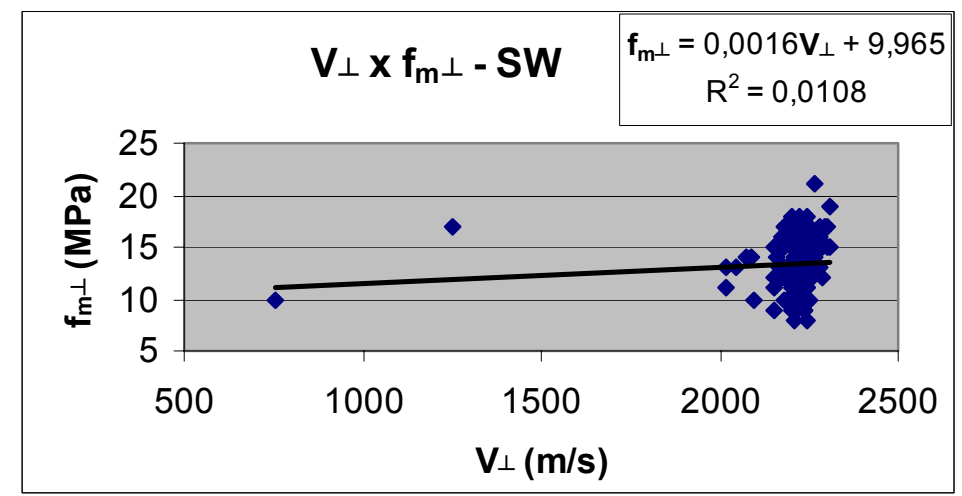

Figura $\mathrm{G} 3-\mathrm{V}_{\perp} \times \mathrm{f}_{\mathrm{m} \perp}$ através do método de stress wave - todos os valores. 


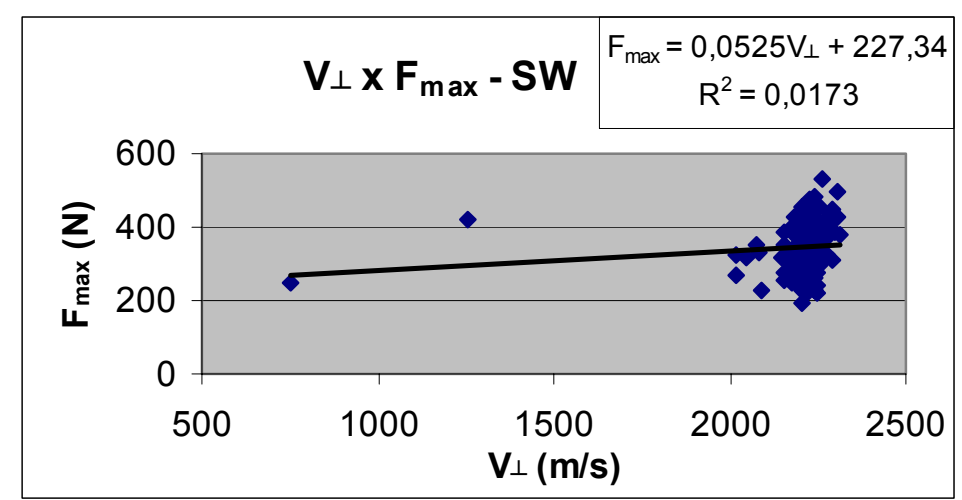

Figura $\mathrm{G} 4-\mathrm{V}_{\perp} \times \mathrm{F}_{\max \perp}$ através do método de stress wave - todos os valores.

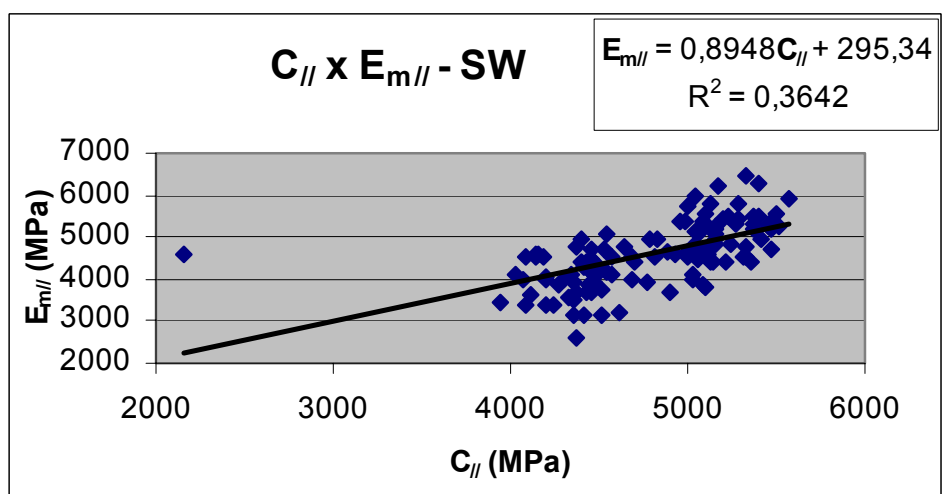

Figura $\mathrm{G} 5-\mathrm{C}_{/ /} \times \mathrm{E}_{\mathrm{m} / /}$ através do método de stress wave - todos os valores.

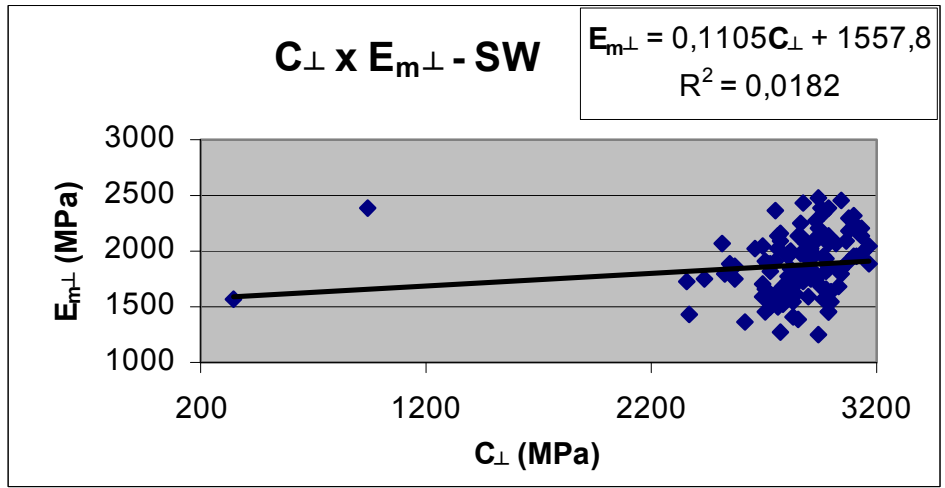

Figura $\mathrm{G} 6-\mathrm{C}_{\perp} \times \mathrm{E}_{\mathrm{m} \perp}$ através do método de stress wave - todos os valores.

Nas Figuras G7, G8, G9, G10, G11 e G12 estão contidos os gráficos de correlações entre os valores dos parâmetros não-destrutivos ( $\mathrm{V}$ e C ) e os obtidos nos ensaios mecânicos destrutivos $\left(E_{m / /}, E_{m \perp}, f_{m / /}\right.$ e $\left.f_{m \perp}\right)$, referentes a todos os corpos-de-prova ensaiados nos 
ensaios principais (segunda parte), para os grupos 1 e 2, através de medições por stress wave, excluindo-se os valores de velocidades e de constantes dinâmicas relacionados às leituras discrepantes de tempo no painel 24, na direção longitudinal (ponto de leitura 12॥) e

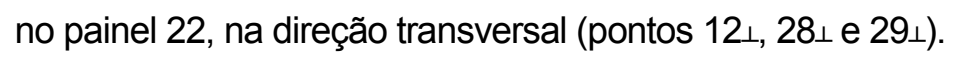

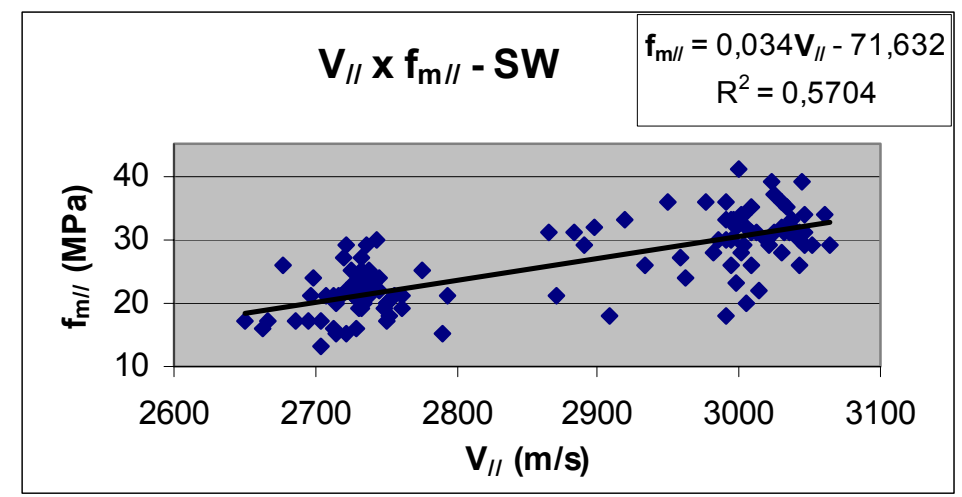

Figura $G 7-V_{/ /} \times f_{m / /}$ através do método de stress wave.

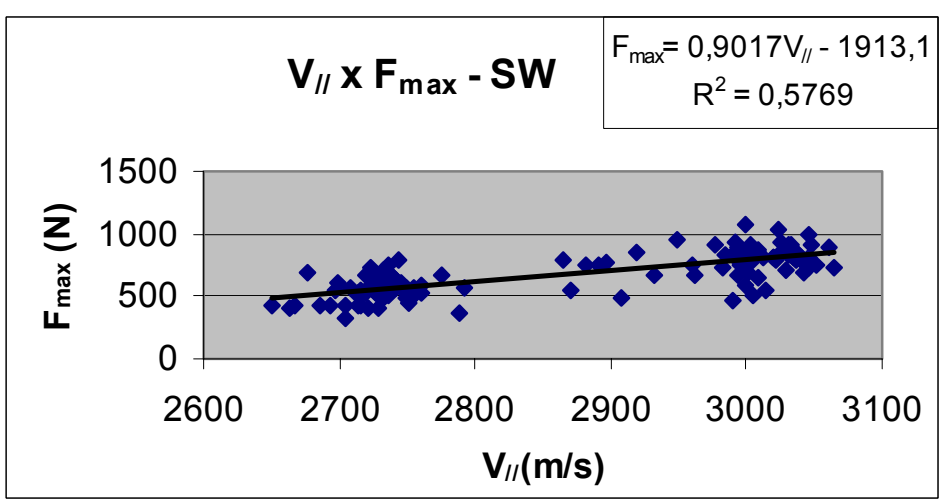

Figura $G 8-V_{/ /} \times F_{\max }$ através do método de stress wave.

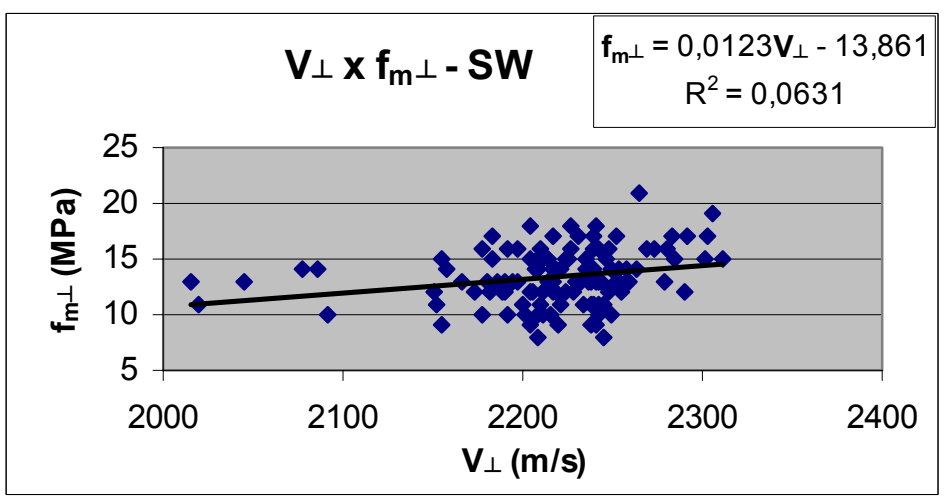

Figura $\mathrm{G} 9-\mathrm{V}_{\perp} \times \mathrm{f}_{\mathrm{m} \perp}$ através do método de stress wave. 


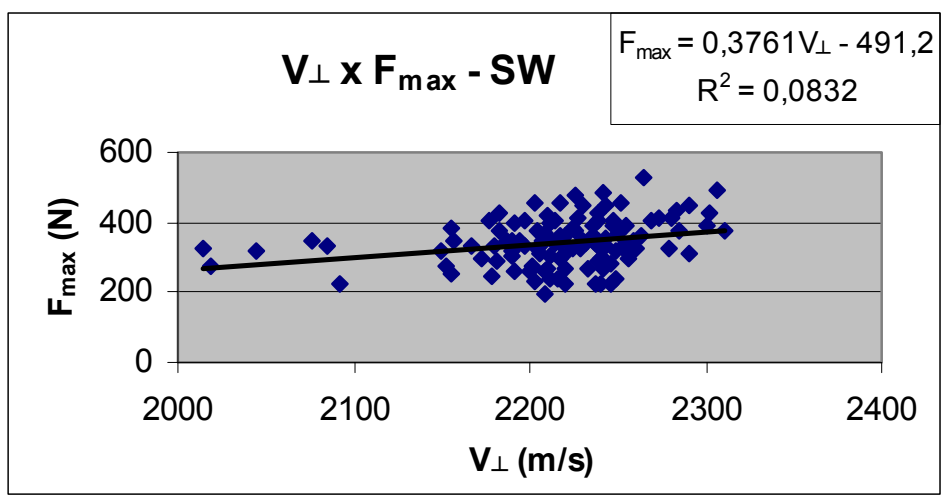

Figura $\mathrm{G} 10-\mathrm{V}_{\perp} \times \mathrm{F}_{\max }$ através do método de stress wave.

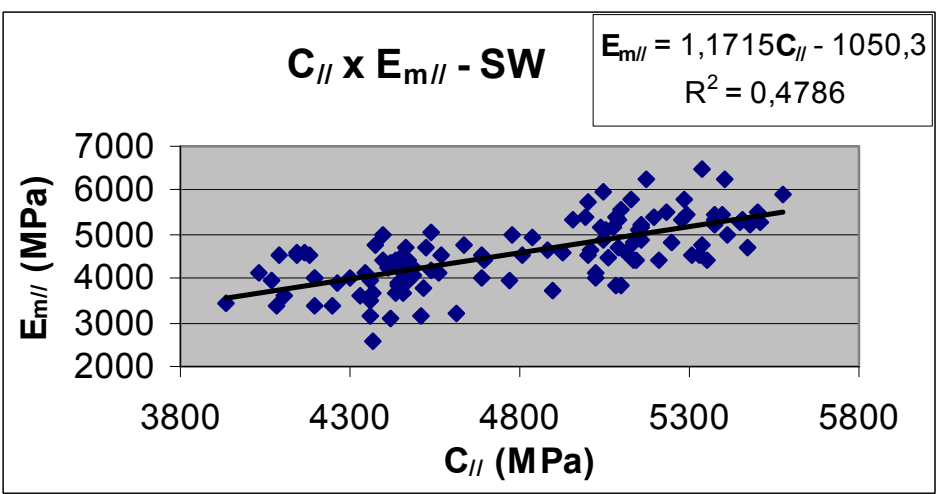

Figura $\mathrm{G} 11-\mathrm{C}_{/ /} \times \mathrm{E}_{\mathrm{m} / /}$ através do método de stress wave.

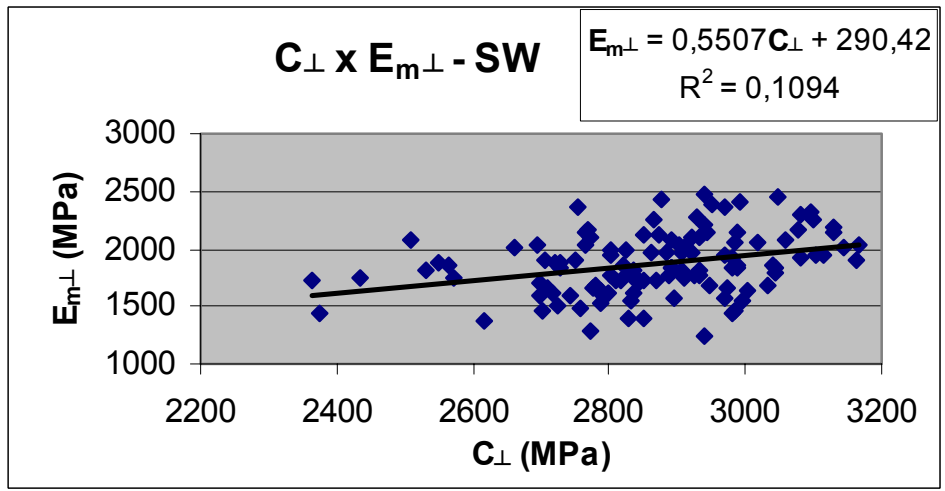

Figura $\mathrm{G} 12-\mathrm{C}_{\perp} \times \mathrm{E}_{\mathrm{m} \perp}$ através do método de stress wave. 
Apéndice ote 
No Apêndice H estão contidos os gráficos de correlações entre os valores médios dos parâmetros não-destrutivos ( $\mathrm{V}, \mathrm{C}$ e Atn) e os obtidos nos ensaios mecânicos destrutivos $\left(E_{m / /}, E_{m \perp}, f_{m / /}, f_{m \perp}\right.$ e $\left.A l\right)$ e nos ensaios físicos (d, $G_{t}$ e $\left.A_{m}\right)$, referentes aos ensaios principais (segunda parte), para os grupos 1 e 2 , através de medições por ultra-som.

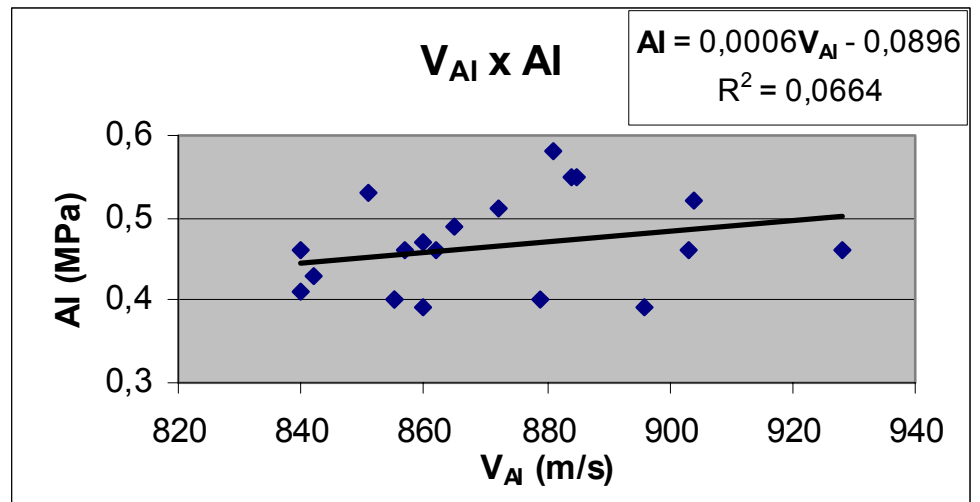

Figura $\mathrm{H} 1-\mathrm{V}_{\mathrm{Al}} \times \mathrm{Al}$ através do método de ultra-som.

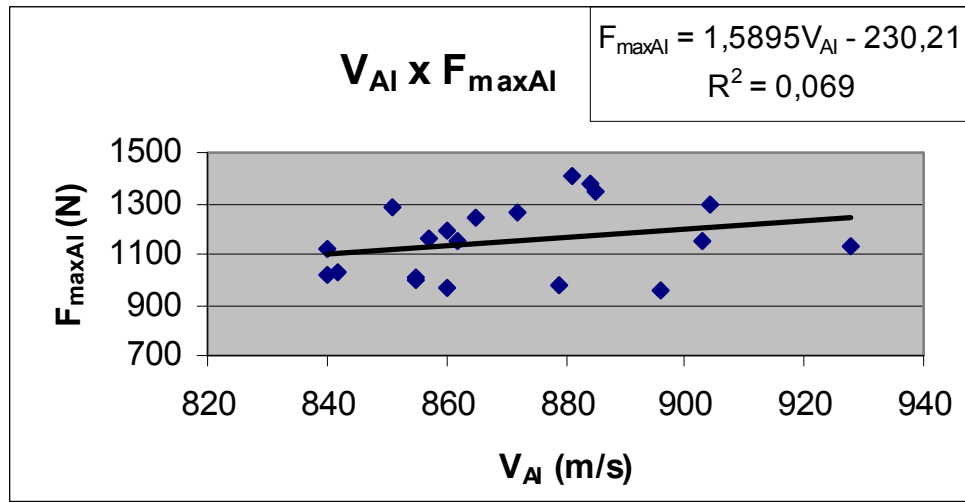

Figura $\mathrm{H} 2-\mathrm{V}_{\mathrm{Al}} \times \mathrm{F}_{\text {maxAl }}$ através do método de ultra-som.

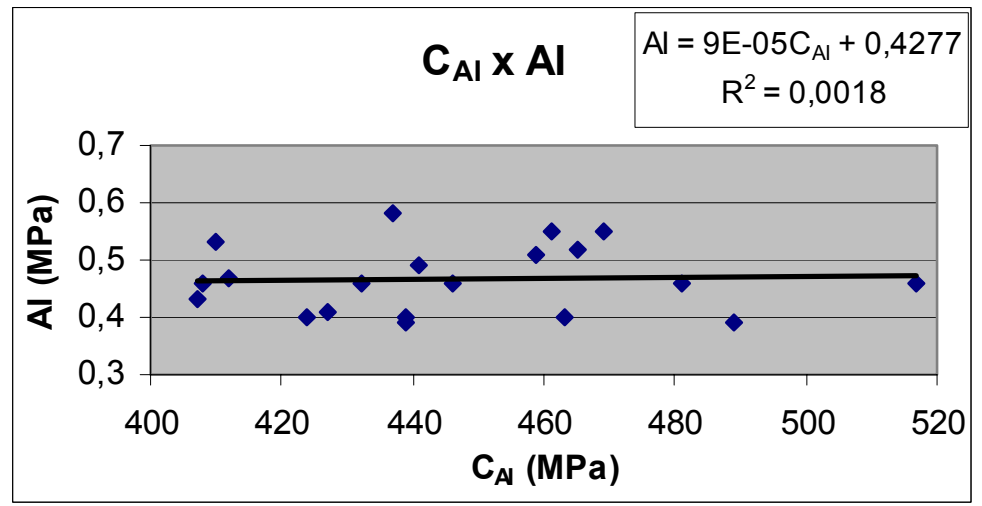

Figura $\mathrm{H} 3-\mathrm{C}_{\mathrm{Al}} \times \mathrm{Al}$ através do método de ultra-som. 


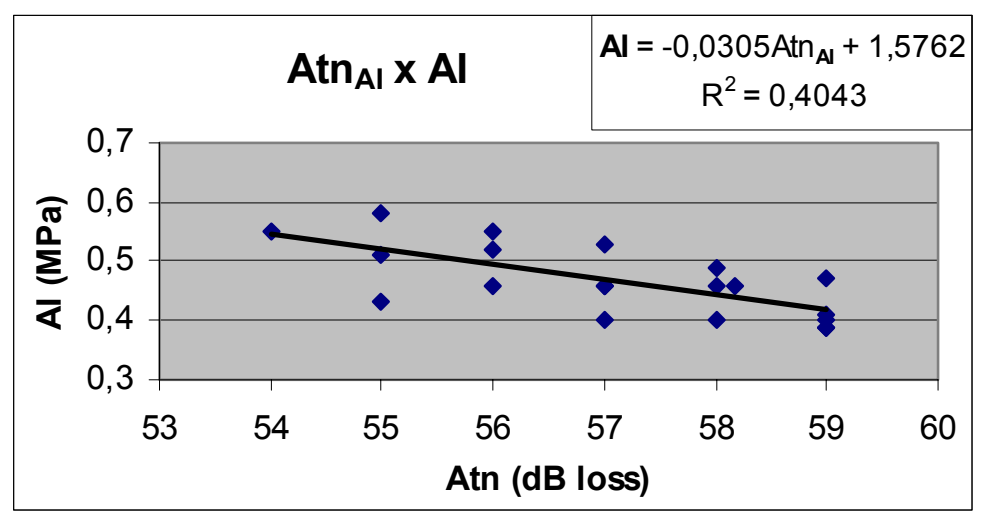

Figura $\mathrm{H} 4-\mathrm{Atn}_{\mathrm{Al}} \times \mathrm{Al}$ através do método de ultra-som.

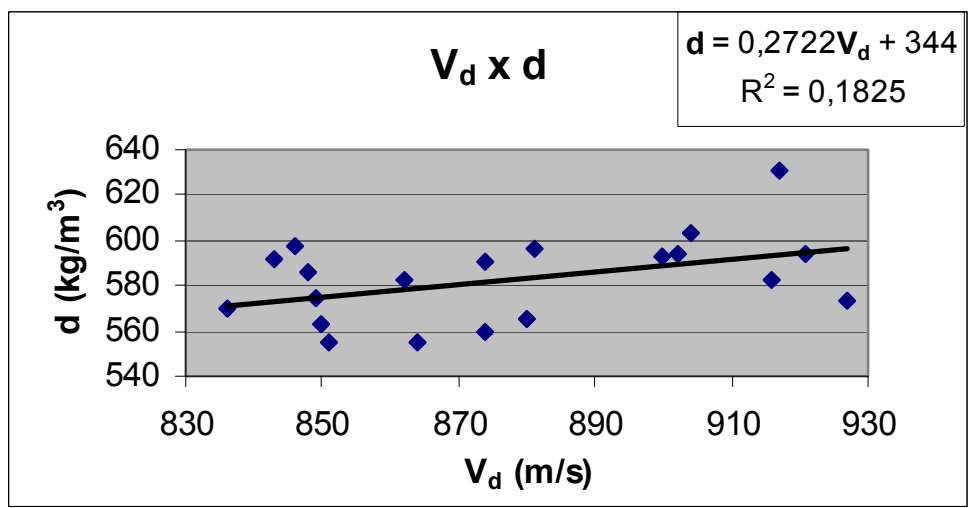

Figura $\mathrm{H} 5-\mathrm{V}_{\mathrm{d}} \mathrm{x} d$ através do método de ultra-som.

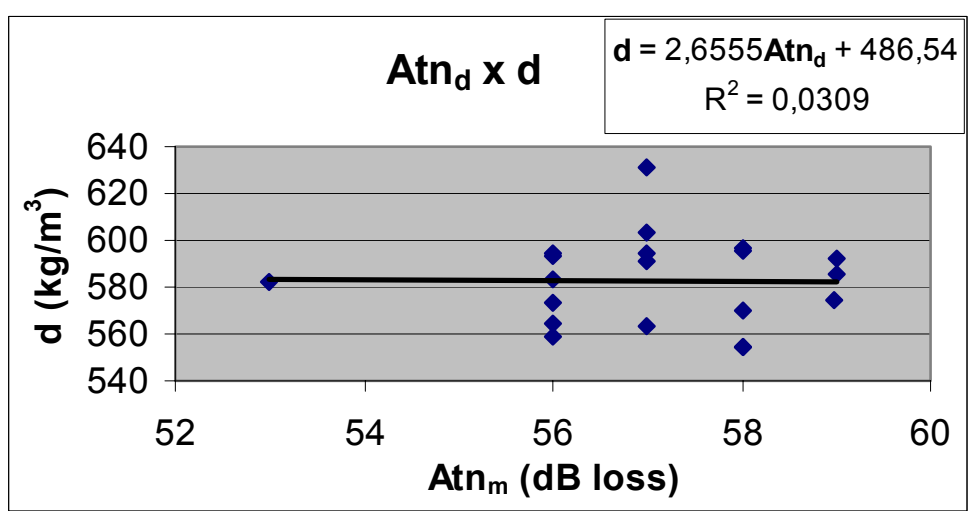

Figura H6 - Atn $\mathrm{d} x \mathrm{~d}$ através do método de ultra-som. 


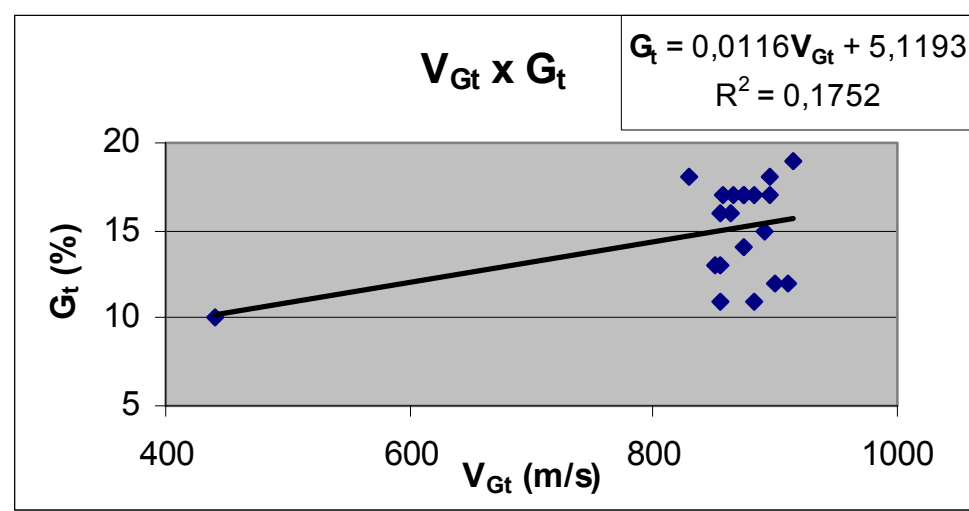

Figura $\mathrm{H} 7-\mathrm{V}_{\mathrm{Gt}} \times \mathrm{G}_{\mathrm{t}}$ através do método de ultra-som.

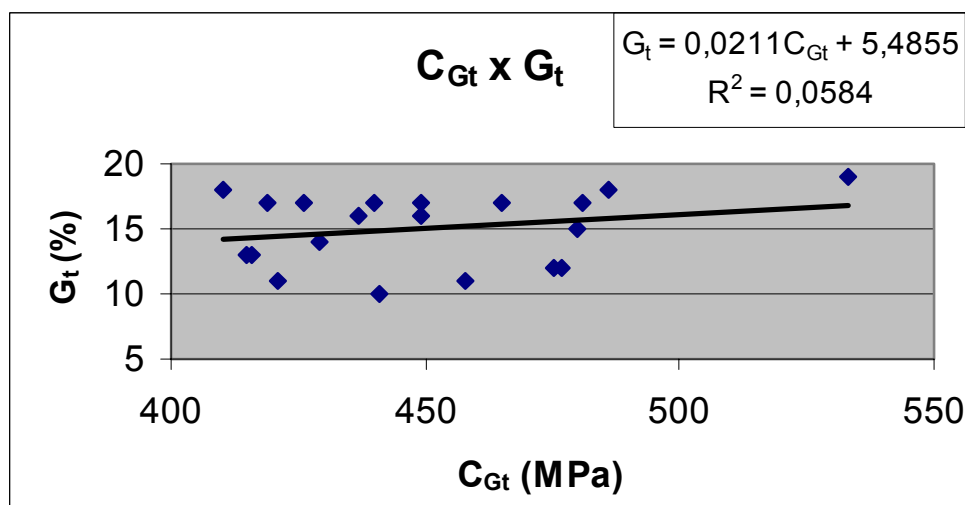

Figura $\mathrm{H} 8-\mathrm{C}_{\mathrm{Gt}} \times \mathrm{G}_{\mathrm{t}}$ através do método de ultra-som.

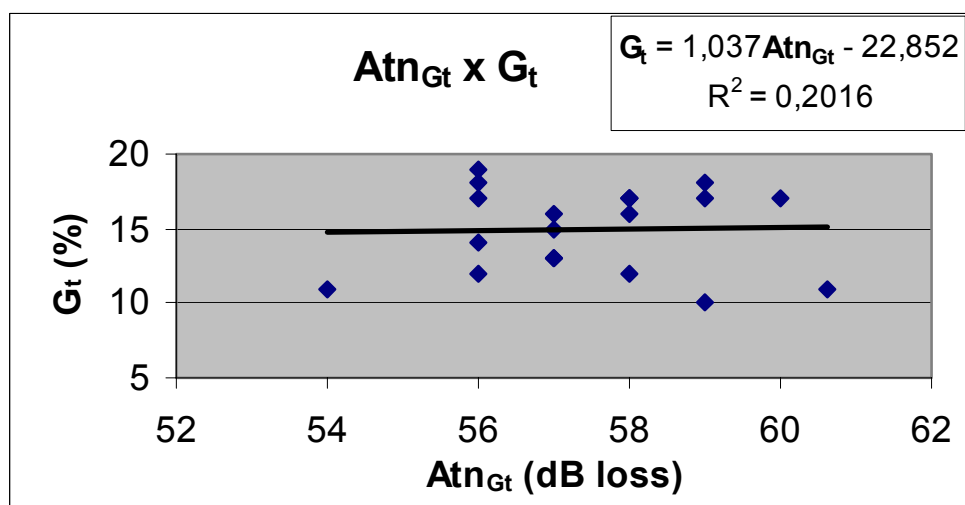

Figura $\mathrm{H} 9-\operatorname{Atn}_{\mathrm{Gt}} \times \mathrm{G}_{\mathrm{t}}$ através do método de ultra-som. 


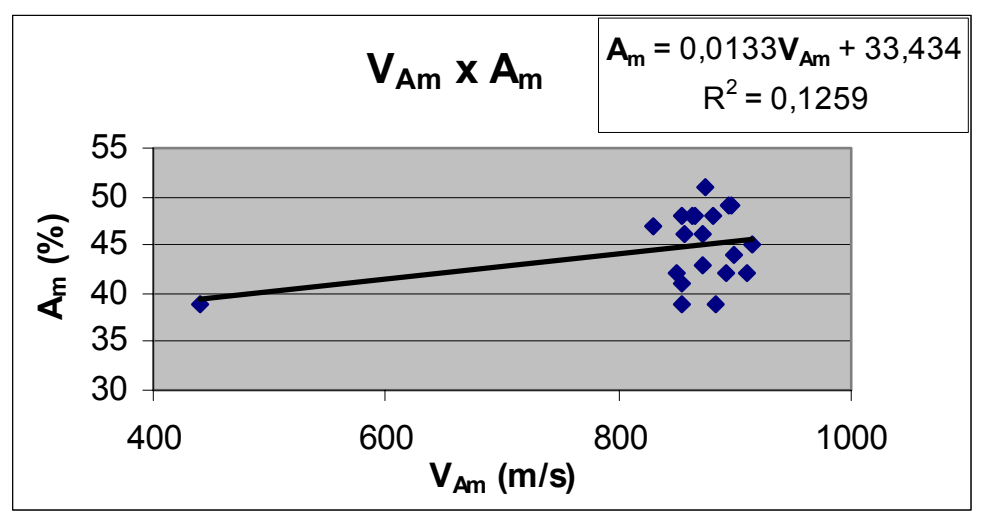

Figura $\mathrm{H} 10-V_{A m} \times A_{m}$ através do método de ultra-som.

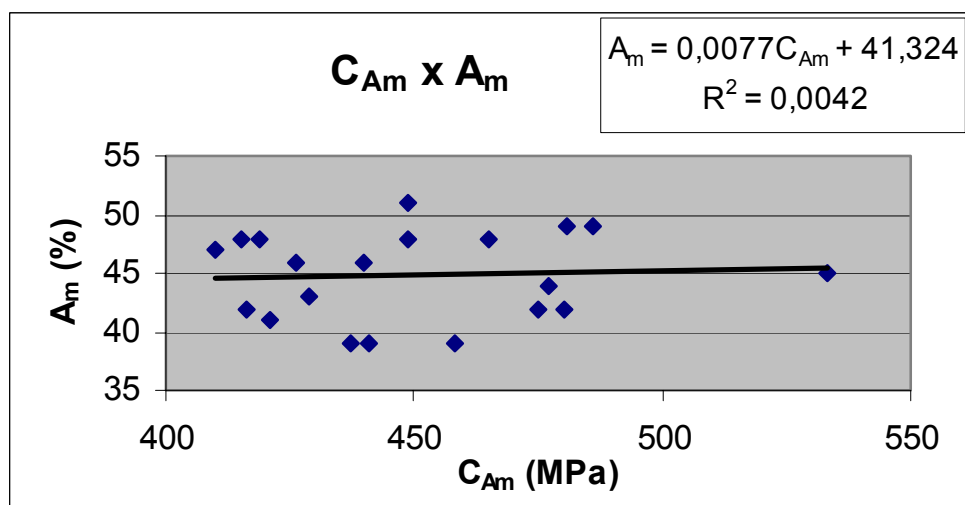

Figura $\mathrm{H} 11-\mathrm{C}_{\mathrm{Am}} \times \mathrm{A}_{m}$ através do método de ultra-som.

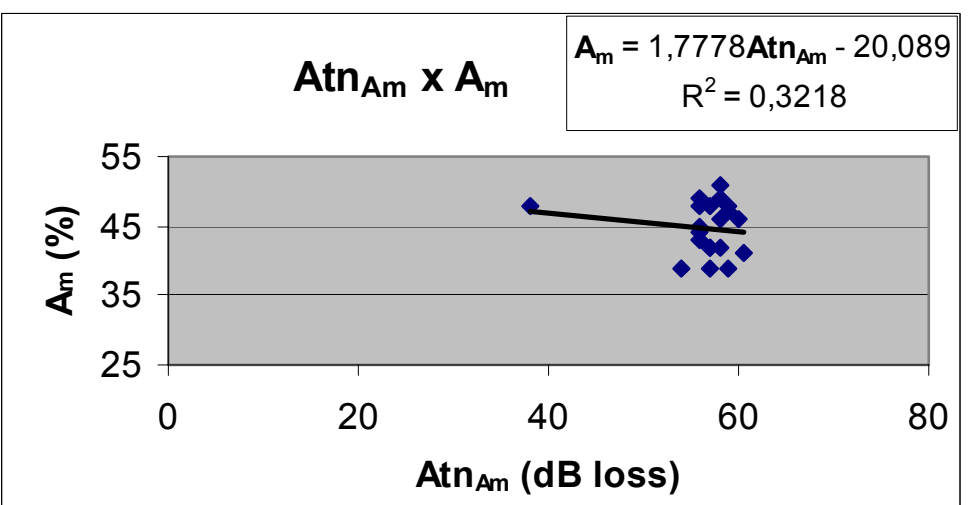

Figura $\mathrm{H} 12-\operatorname{Atn}_{\mathrm{Am}} \times A_{m}$, através do método de ultra-som. 


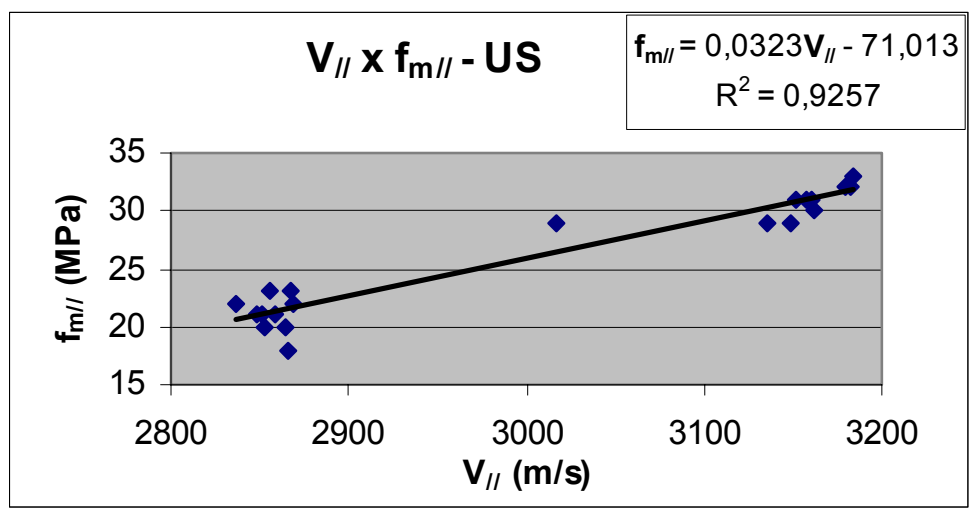

Figura $\mathrm{H} 13-\mathrm{V}_{/ /} \times \mathrm{f}_{\mathrm{m} / /}$ através do método de ultra-som.

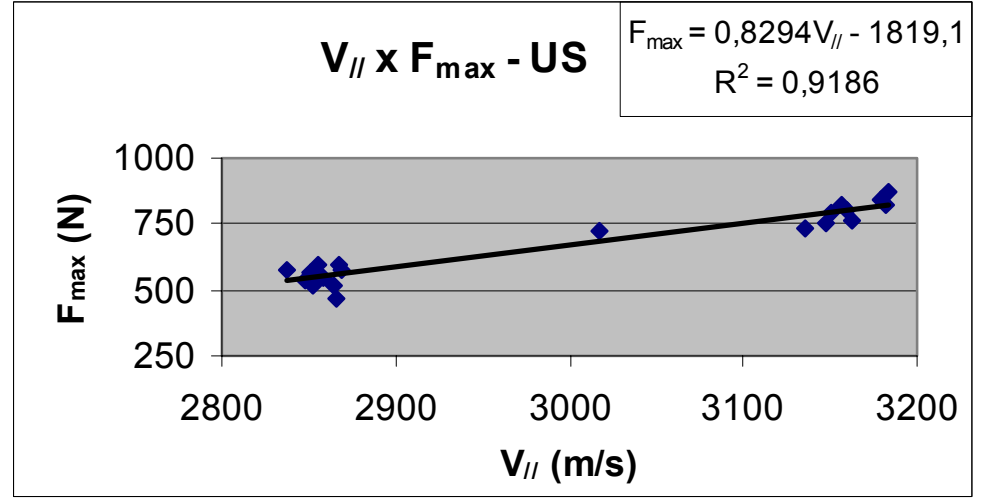

Figura $\mathrm{H} 14-\mathrm{V}_{/ /} \times \mathrm{F}_{\max }$ através do método de ultra-som.

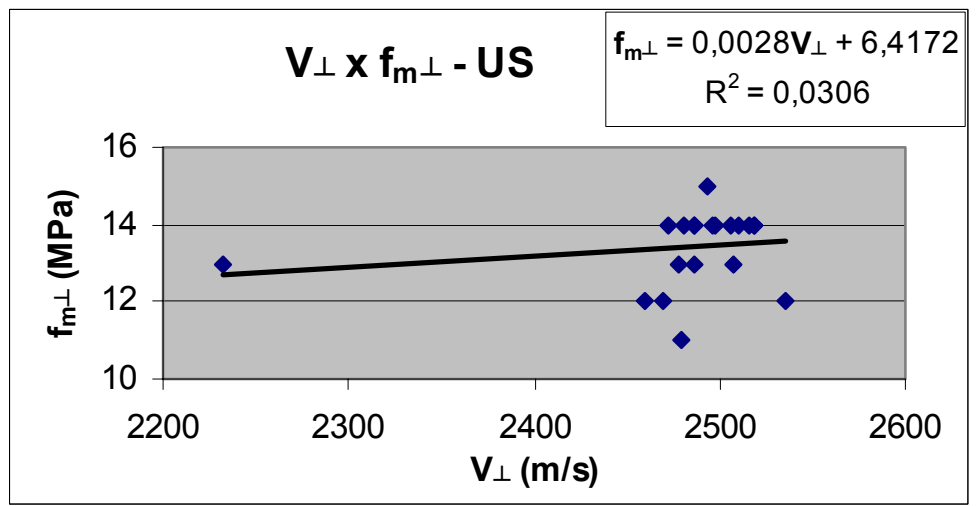

Figura $\mathrm{H} 15-\mathrm{V}_{\perp} \times \mathrm{f}_{\mathrm{m} \perp}$ através do método de ultra-som. 


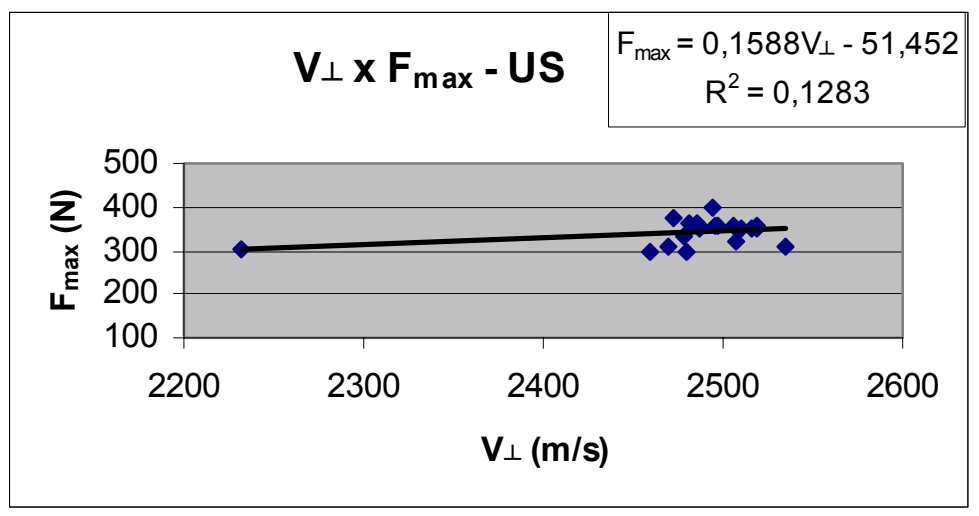

Figura $\mathrm{H} 16-\mathrm{V}_{\perp} \times \mathrm{F}_{\max \perp}$ através do método de ultra-som.

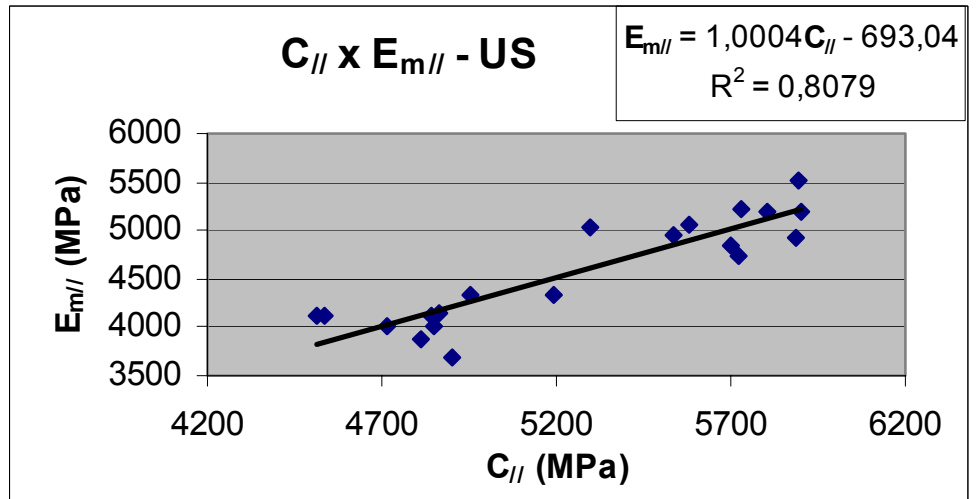

Figura $\mathrm{H} 17-\mathrm{C}_{/ /} \times \mathrm{E}_{\mathrm{m} / /}$ através do método de ultra-som.

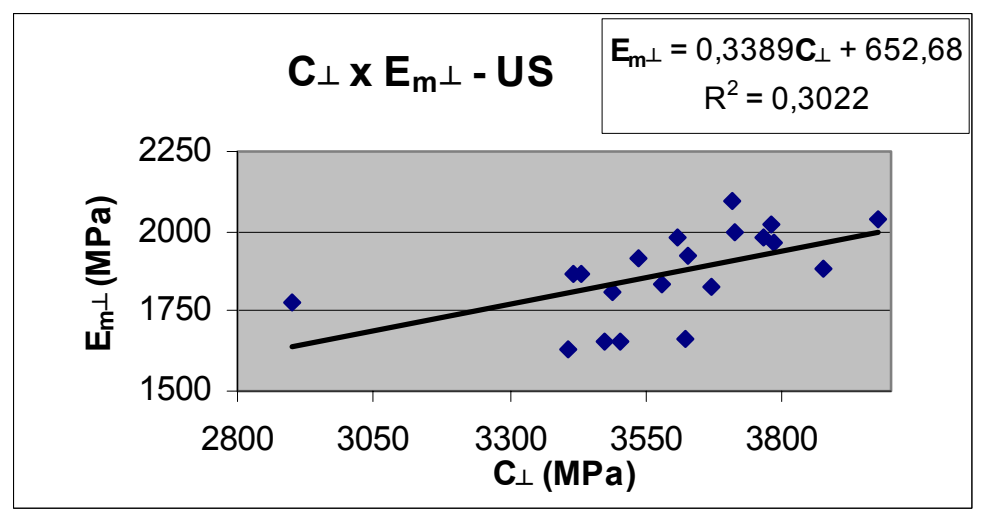

Figura $\mathrm{H} 18-\mathrm{C}_{\perp} \times \mathrm{E}_{\mathrm{m} \perp}$ através do método de ultra-som. 
Apênatice @ 
No Apêndice I estão contidos os gráficos de correlações entre os valores médios dos parâmetros não-destrutivos $(\mathrm{V}$ e $\mathrm{C})$ e os obtidos nos ensaios mecânicos destrutivos $\left(E_{m / /}, E_{m \perp}, f_{m / /}\right.$ e $\left.f_{m \perp}\right)$, aos ensaios principais (segunda parte), para os grupos 1 e 2, através de medições por stress wave.

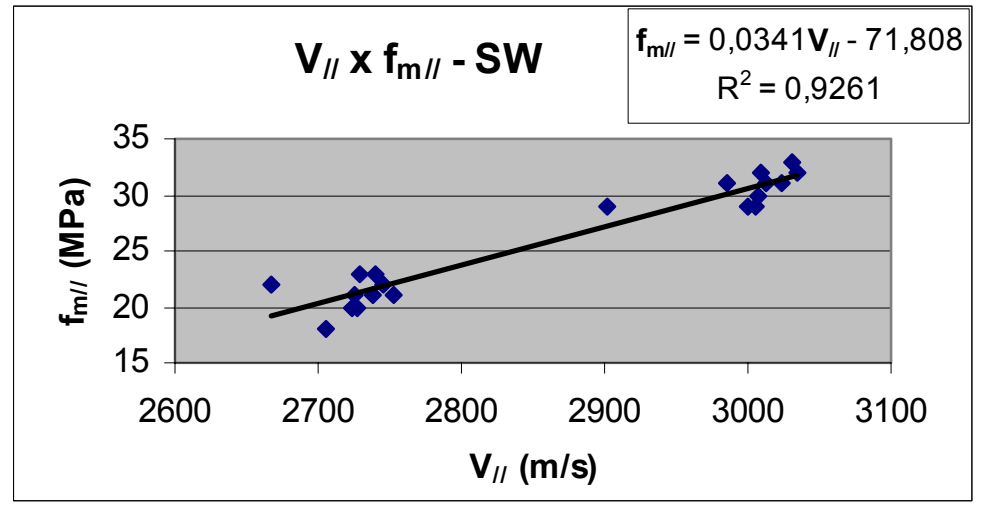

Figura I1 $-V_{/ /} \times f_{m / /}$ através do método de stress wave.

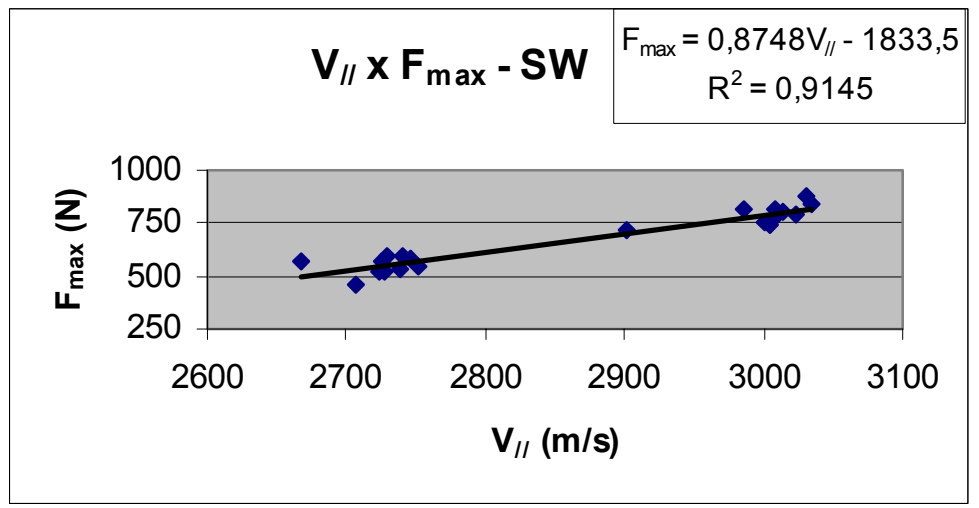

Figura $12-V_{/ /} \times F_{\max }$ através do método de stress wave.

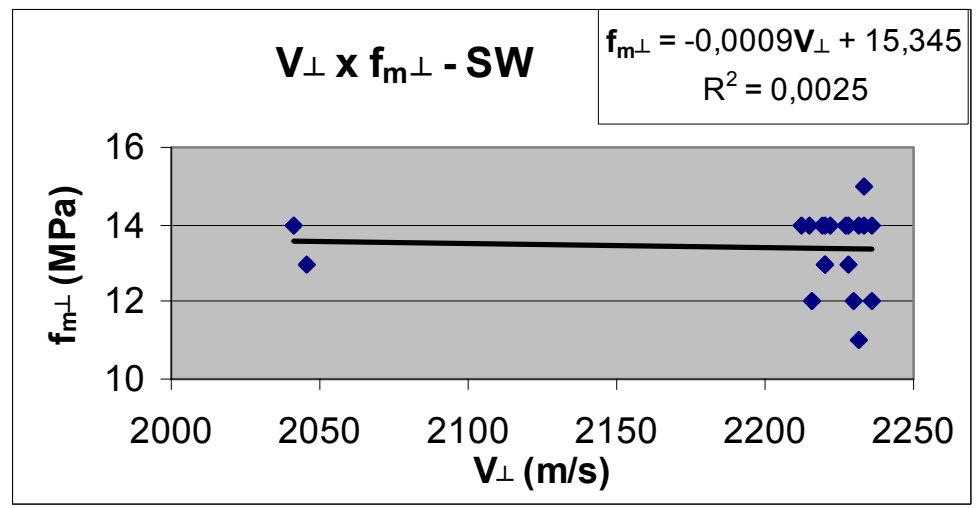

Figura I3 $-V_{\perp} \times f_{m \perp}$ através do método de stress wave. 


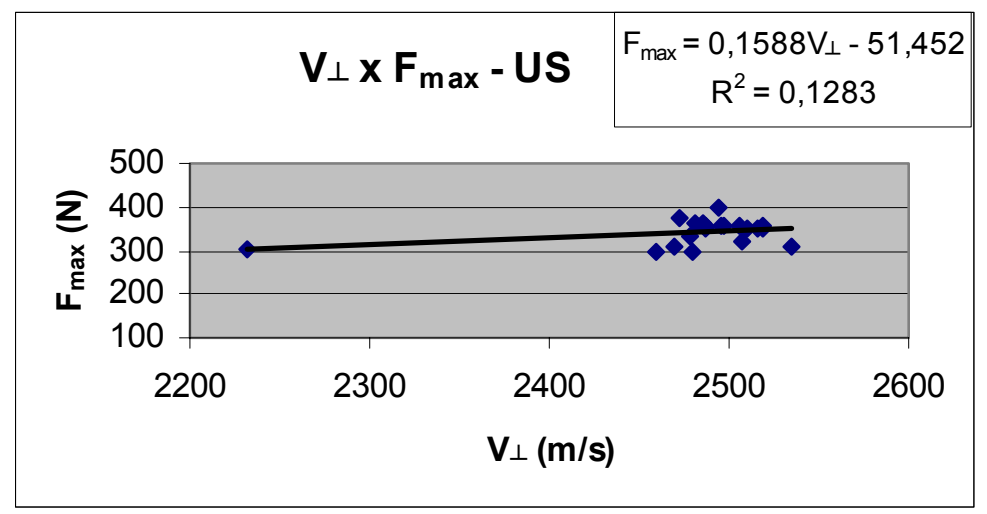

Figura $14-V_{\perp} \times F_{\max \perp}$ através do método de stress wave.

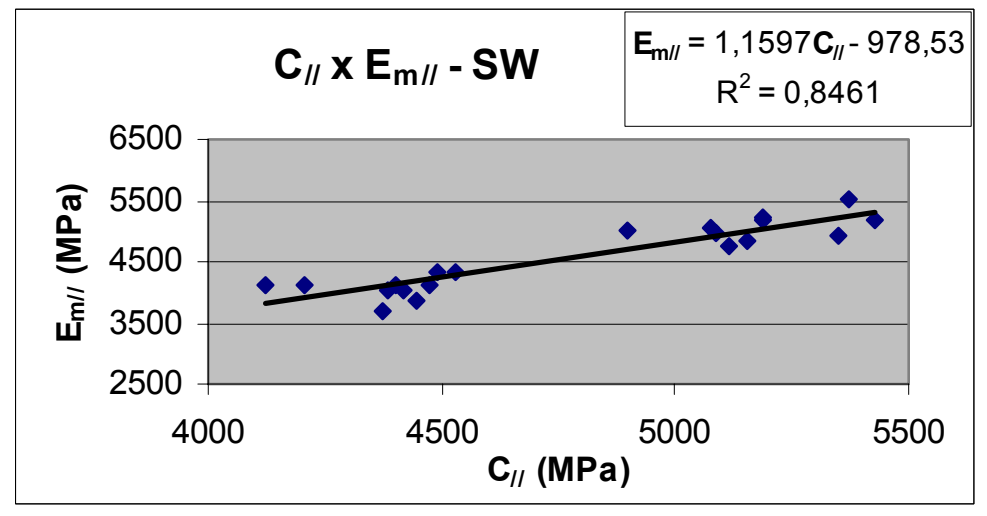

Figura $15-C_{/ /} \times E_{m / /}$ através do método de stress wave.

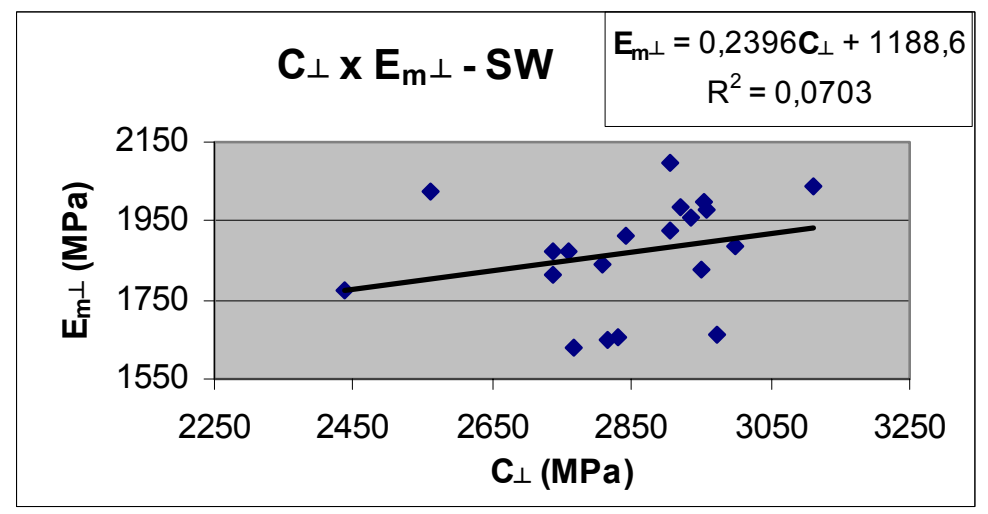

Figura $16-C_{\perp} \times E_{m \perp}$ através do método de stress wave. 
Apéndice 8 
No Apêndice $\mathrm{J}$ estão contidos os gráficos de correlações entre os valores de C e $\mathrm{V}$ obtidos nos ensaios dos métodos de ultra-som (US) e stress wave (SW) referentes a todos os corpos-de-prova ensaiados nos ensaios principais (segunda parte), nas direções longitudinal e transversal, para os grupos 1 e 2.

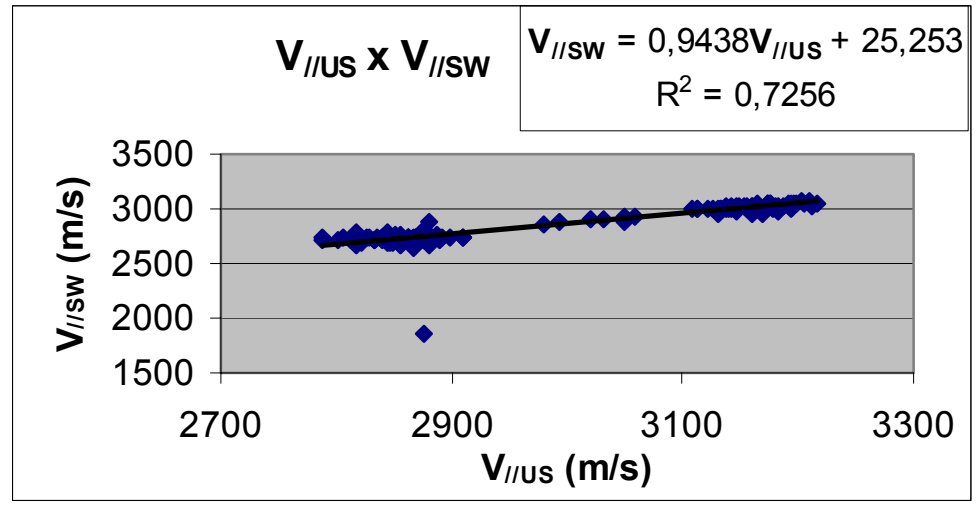

Figura $\mathrm{J} 1-\mathrm{V}_{\text {//US }} \mathrm{x} \mathrm{V}_{\text {//SW }}-$ Todos os valores.

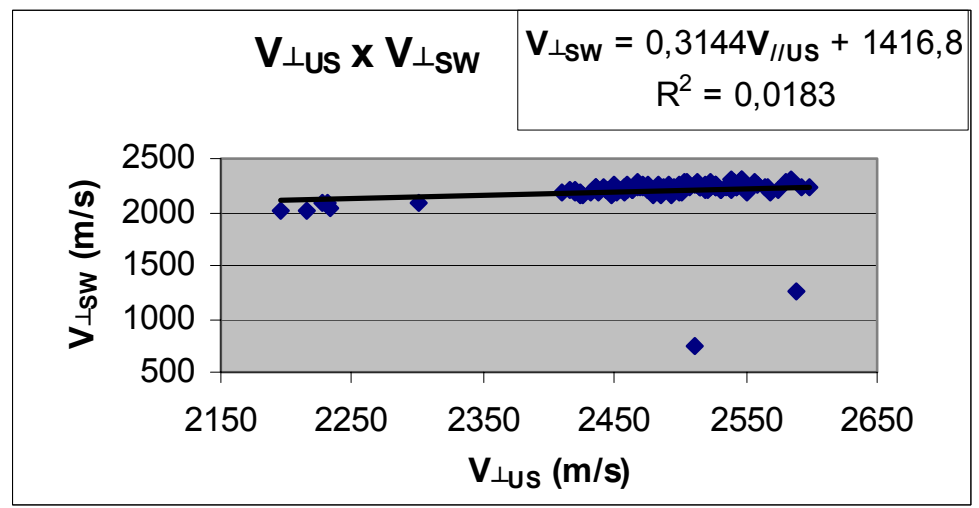

Figura $\mathrm{J} 2-\mathrm{V}_{\perp_{\text {US }}} \times \mathrm{V}_{\perp_{S W}}-$ Todos os valores.

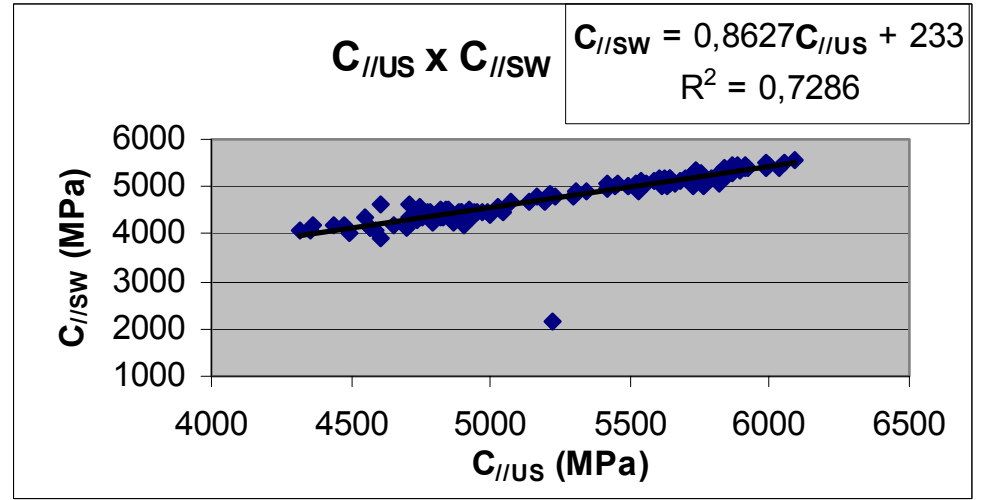

Figura J3 $-\mathrm{C}_{/ / \mathrm{US}} \times \mathrm{C}_{/ / \mathrm{SW}}-$ Todos os valores. 


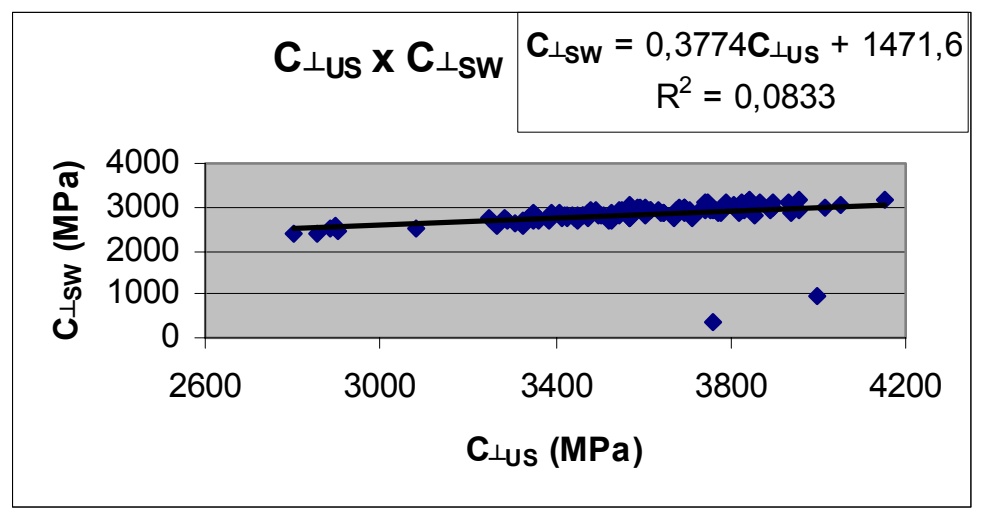

Figura J4 - $\mathrm{C}_{\perp \text { US }} \times \mathrm{C}_{\perp \text { SW }}-$ Todos os valores.

As Figuras J5, J6, J7 e J8 mostram os gráficos de correlações entre os valores de $\mathrm{C}$ e $\mathrm{V}$ obtidos nos ensaios dos métodos de ultra-som e stress wave retirando-se os corpos-de-prova ensaiados nos ensaios principais (segunda parte), nas direções longitudinal e transversal, para o grupo 2, que apresentaram valores discrepantes para o stress wave.

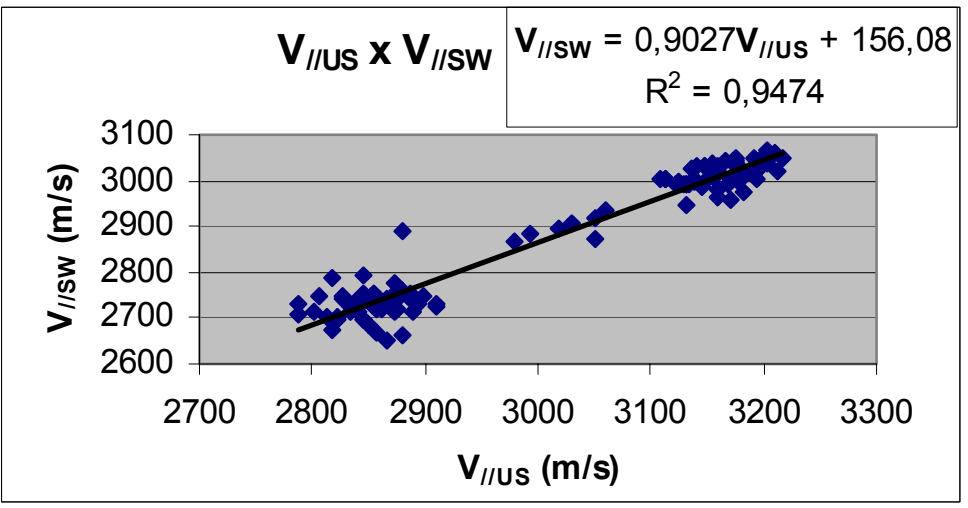

Figura J5 $-\mathrm{V}_{\text {//US }} \times \mathrm{V}_{/ / \mathrm{SW}}-$ Sem os valores discrepantes.

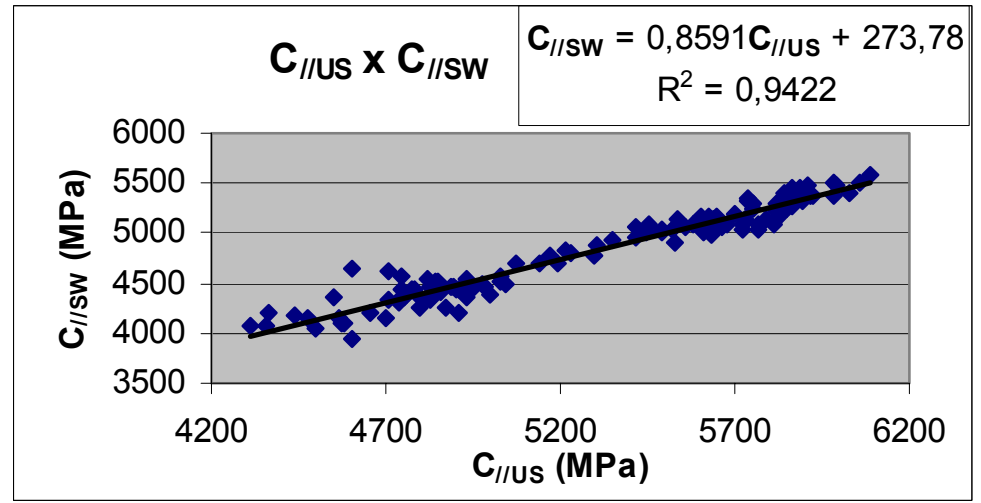

Figura $\mathrm{J} 6-\mathrm{C}_{/ / \mathrm{US}} \times \mathrm{C}_{/ / \mathrm{SW}}-$ Sem os valores discrepantes. 


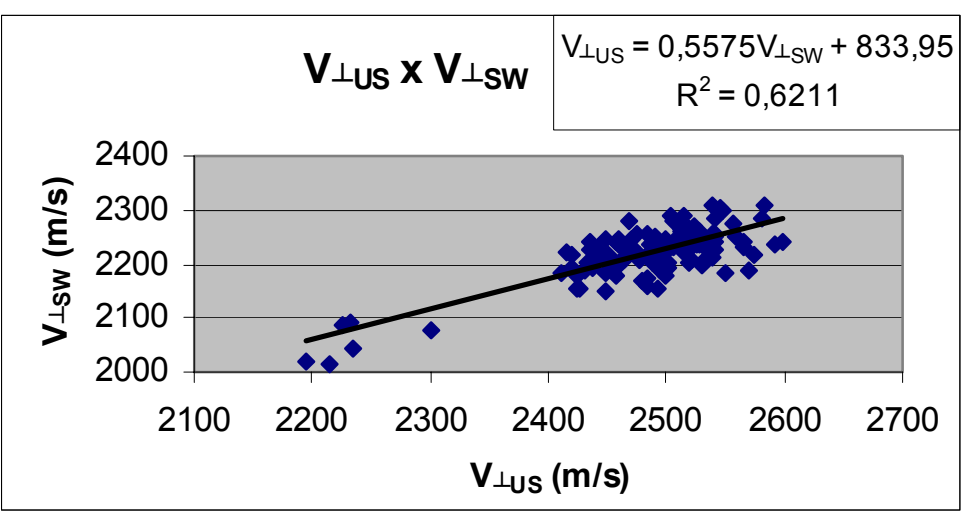

Figura $\mathrm{J} 7-\mathrm{V}_{\perp_{\mathrm{US}}} \times \mathrm{V}_{\perp_{S \mathrm{SW}}}-$ Sem os valores discrepantes.

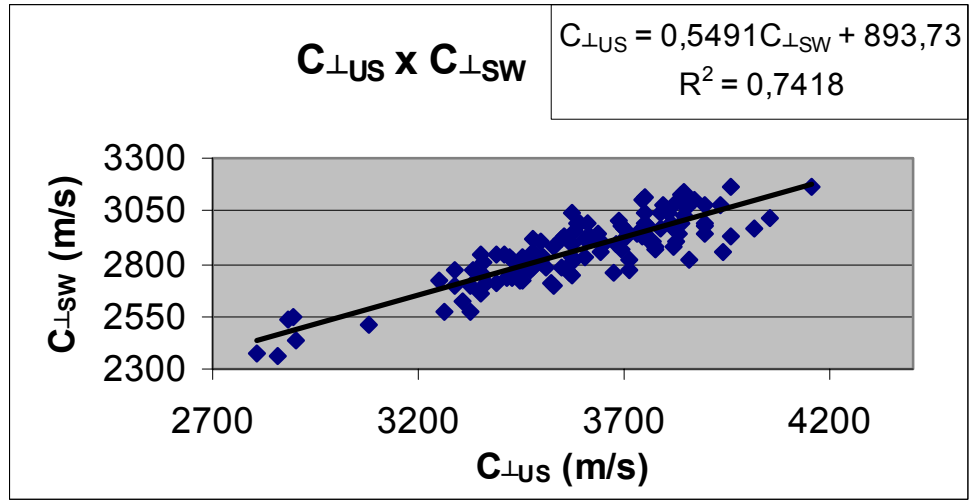

Figura J8 $-\mathrm{C}_{\perp_{\text {US }}} \times \mathrm{C}_{\perp_{\text {SW }}}-$ Sem os valores discrepantes. 
Apéndice $e^{2}$ 
No Apêndice L estão contidos os gráficos de correlações entre os valores médios de $\mathrm{C}$ e $\mathrm{V}$ obtidos nos ensaios dos métodos de ultra-som (US) e stress wave (SW) referentes a todos os corpos-de-prova ensaiados nos ensaios principais (segunda parte), nas direções longitudinal e transversal, para os grupos 1 e 2.

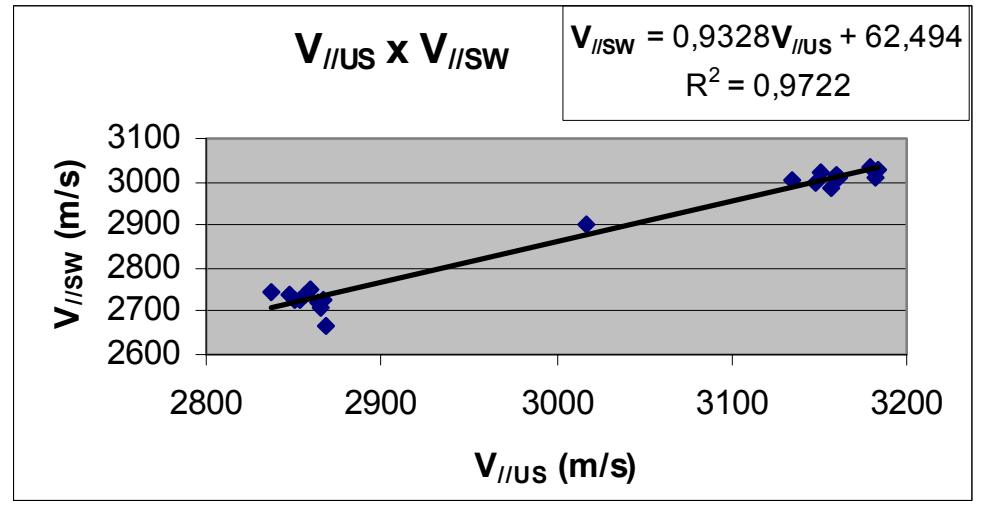

Figura $L 1-V_{/ / U S} \times V_{/ / S W}-$ Todos os valores.

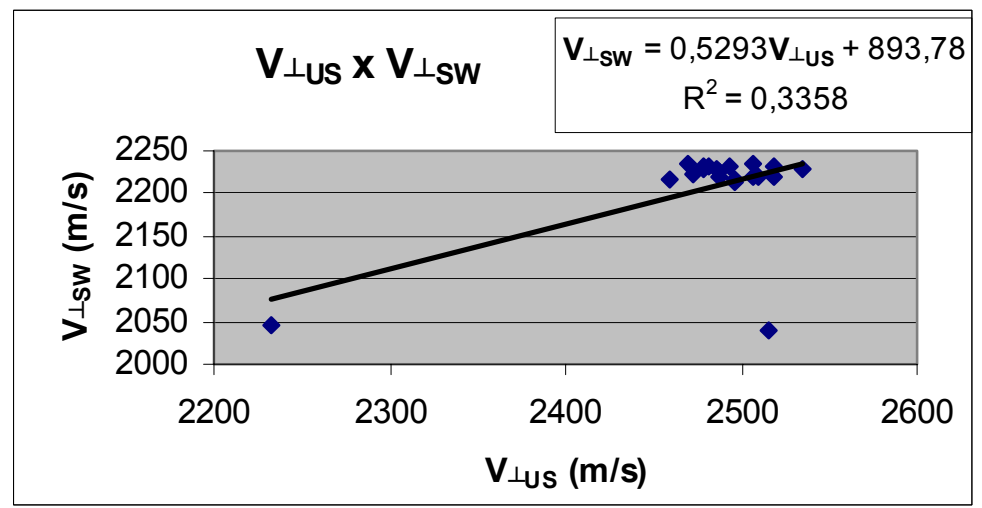

Figura $\mathrm{L} 2-\mathrm{V}_{\perp_{\mathrm{US}}} \mathrm{x} \mathrm{V}_{\perp_{S W}}-$ Todos os valores.

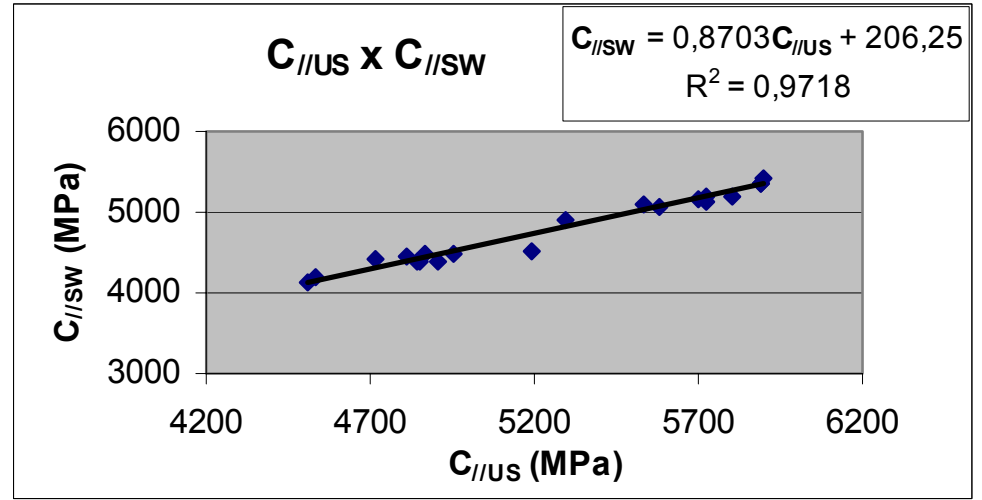

Figura L3 - $\mathrm{C}_{/ / \mathrm{US}} \times \mathrm{C}_{/ / \mathrm{SW}}-$ Todos os valores. 


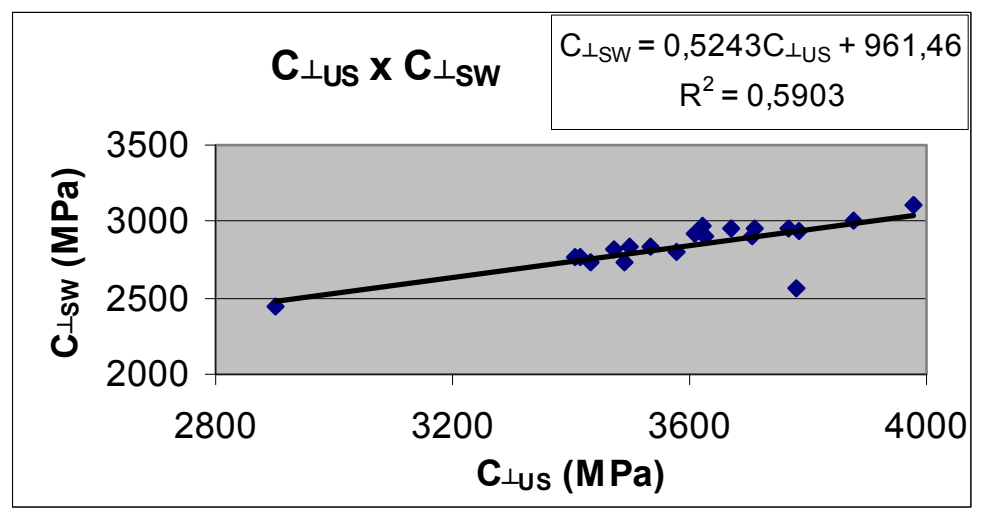

Figura $\mathrm{L} 4-\mathrm{C}_{\perp \text { US }} \times \mathrm{C}_{\perp \text { SW }}-$ Todos os valores.

As Figuras J5, J6, J7 e J8 mostram os gráficos de correlações entre os valores médios de $\mathrm{C}$ e $\mathrm{V}$ obtidos nos ensaios dos métodos de ultra-som e stress wave retirando-se os corpos-de-prova ensaiados nos ensaios principais (segunda parte), na direção transversal, para o grupo 2, que apresentaram valores discrepantes para o stress wave.

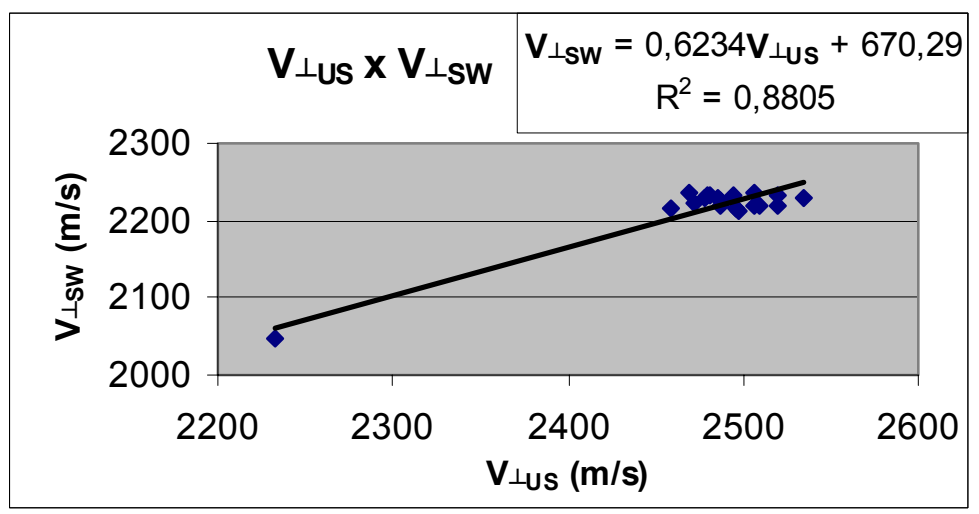

Figura $L 5-V_{\perp U S} \times V_{\perp S W}-S e m$ os valores discrepantes.

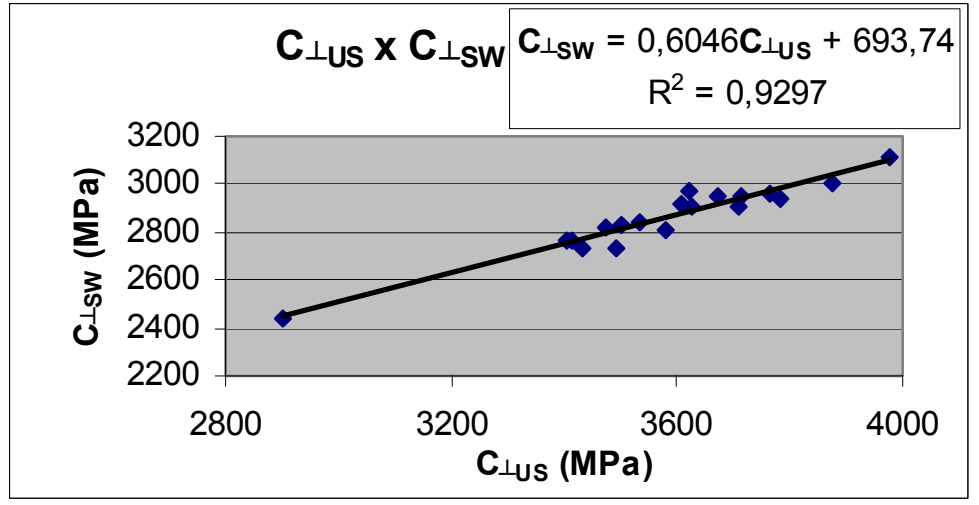

Figura $L 6-C_{\perp \text { US }} \times C_{\perp s W}-$ Sem os valores discrepantes. 